\author{
UNIVERSIDADE DE SÃO PAULO \\ ESCOLA DE ENGENHARIA DE SÃO CARLOS \\ PROGRAMA DE PÓS-GRADUAÇÃO EM ENGENHARIA DE PRODUÇÃo
}

GESTÃO ÁGIL DE REDES DE INOVAÇÃO AUTO-ORGANIZADAS

Cristiane Carneiro da Silva

Dissertação apresentada à Escola de Engenharia de São Carlos da Universidade de São Paulo, como parte dos requisitos para a obtenção do título de Mestre em Engenharia de Produção.

Área de Concentração: Processos e Gestão de Operações

Linha de Pesquisa: Redes Produtivas e Logística Integrada

Orientador: Prof. Associado Fábio Müller Guerrini

São Carlos - SP

2015 

CRISTIANE CARNEIRO DA SILVA

\section{GESTÃO ÁGIL DE REDES DE INOVAÇÃO AUTO-ORGANIZADAS}

Dissertação apresentada à Escola de Engenharia de São Carlos da Universidade de São Paulo, como parte dos requisitos para a obtenção do título de Mestre em Engenharia de Produção.

Área de Concentração: Processos e Gestão de Operações

Orientador: Prof. Associado Fábio Müller Guerrini

São Carlos - SP

2015 
AUTORIZO A REPRODUÇÃO TOTAL OU PARCIAL DESTE TRABALHO, POR QUALQUER MEIO CONVENCIONAL OU ELETRÔNICO, PARA FINS DE ESTUDO E PESQUISA, DESDE QUE CITADA A FONTE.

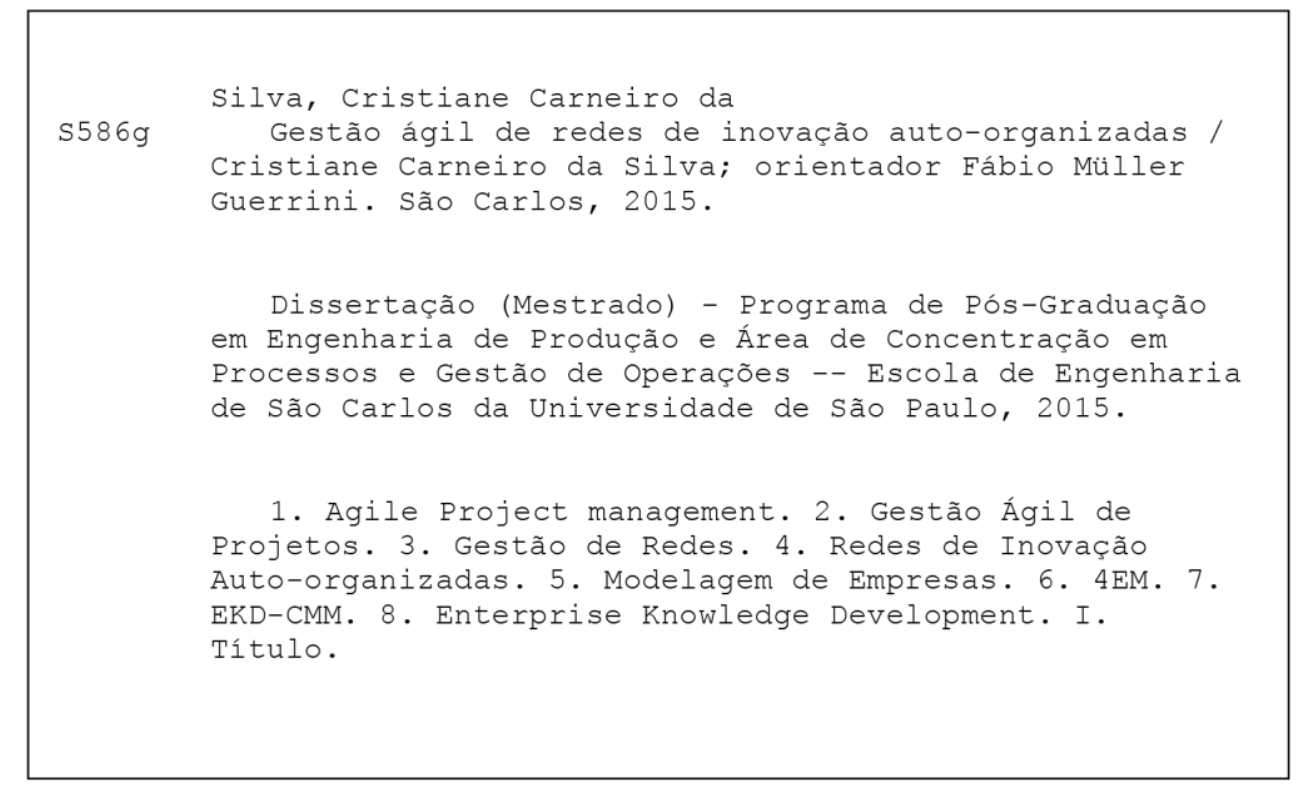




\section{FOLHA DE JULGAMENTO}

Craroikdala: Eocharela CRISTIANE CARNEIRO DA SILVA.

Tílule da dissertaçōo: "Gestōo ógil de reces do inovoça as aoganizcdas".

Cata da deteso: 11/12/2015

Comissāo Julgadora:

Resultado:

Prot, Associado Fóbio Müller Guewinl (Orlentador)

(Escolo de Engenhoria do São Caros/EESC)

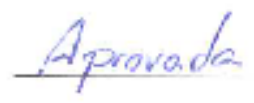

Frof. Dr. Edson Walmir Cazarini

[Escola de Engentharia de Sao Carlos/EESC]

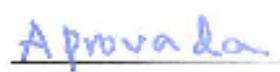

Proia. Dro. Camila de Araújo

IUniversidade Federal de Ubcrlanda/UFU,

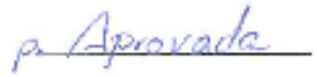

Coordonadora do Programa de Pús-Giacuaçao em Engenhaia de Produçäo:

Profo. Associada Daisy Aparecida do Nascimento Rebelatto

Fresidente da Comissōo de Fós-Graduaço:

Prof. Associado Paulo César Lima 5egantine 

DEDICATÓRIA

Aos meus pais, Luiz e Neuza, por terem me ensinado a ver a educação como o caminho para verdadeiras mudanças. 



\section{AGRADECIMENTOS}

A Deus por ter me concedido vida, sabedoria e força para compreender e alcançar meus objetivos ao longo dessa caminhada.

Aos meus pais, Neuza e Luiz, ao meu irmão Jefferson e ao meu companheiro Tales, pilares fundamentais na minha vida, por todo apoio, paciência e palavras de carinho nos momentos essenciais.

Ao pesquisador e estimado orientador, Fábio Müller Guerrini, por todo apoio, incentivo, paciência, colaboração e também, por ter me motivado com seu amor pela educação, sua sabedoria e ética.

Aos meus amigos, em especial Thiago, Lígia e Jhonatan, que de alguma forma participaram comigo dessa caminhada, pelo apoio e pelos necessários momentos de descontração.

Aos meus familiariares e demais conhecidos pelos importantes momentos de alegria, palavras de incentivo e votos de sucesso.

Ao Centro de Pesquisas, por ter permitido a realização da pesquisa de campo e à sua equipe, por toda dedicação em momentos de trabalho duro e por enfrentá-los com diversão.

À Universidade de São Paulo e ao Departamento de Engenharia de Produção, nas figuras de seus professores e funcionários, por terem me auxiliado em todos os momentos e pelo empenho em manter ambientes de qualidade para o ensino.

Aos professores da banca de qualificação e defesa, Edson Waldir Cazarini e Camila de Araújo, por terem aceito aos convites e pelas valiosas contibuições à pesquisa.

Aos colegas do grupo de pesquisa e de disciplinas, em especial Thales, Silvia e Marcos, pelo apoio e pelos momentos de aprendizado e diversão.

A todos os educadores que participaram da minha formação desde a infância, aqueles que verdadeiramente me fizeram compreender o sentido de aprender. 



\section{EPÍGRAFE}

"Há duas coisas na vida que se você guardar você perde. Conhecimento e afeto. Se você os guarda eles vão embora. A única maneira de ter conhecimento e afeto é reparti-los."

Mario Sergio Cortella 



\section{RESUMO}

SILVA, C. C. Gestão ágil de redes de inovação auto-organizadas. 2015. 294 p. Dissertação (Mestrado em Engenharia de Produção). Escola de Engenharia de São Carlos, Universidade de São Paulo, São Carlos. 2015.

A busca por vantagem competitiva é a realidade das empresas na atual economia global. A formação de redes de inovação representa uma forma colaborativa de desenvolver inovações e adquirir vantagem competitiva para atingir novos mercados. Nesses ambientes a gestão constitui-se em um desafio e diversas abordagens podem ser aplicadas na busca pelo sucesso. Esta pesquisa tem o objetivo de identificar e sistematizar como a abordagem de gestão ágil, fundamentada na flexibilidade e adaptabilidade, pode ser aplicada nesses ambientes. A metodologia de pesquisa compreende um estudo bibliográfico para embasamento teórico da temática proposta e uma pesquisa-ação para coletar dados em campo. A análise e discussão do cruzamento entre as evidências teóricas e os dados práticos visa propor uma modelagem de empresas para apoiar a aplicação da gestão ágil em ambientes de redes de inovação autoorganizadas. A modelagem desenvolvida foi guiada pela metodologia Enterprise Knowledge Development-Change Management Method (EKD-CMM) conforme a For Enterprise Modeling (4EM). O resultado da pesquisa identifica os benefícios e limitações observados na aplicação prática da mesma e contribui para ampliar a compreensão dos elementos envolvidos no processo de gestão de redes de inovação auto-organizadas, utilizando a abordagem ágil.

Palavras-chave: Agile Project management, Gestão ágil de projetos, Gestão de Redes, Redes de Inovação Auto-organizadas, modelagem de empresas, 4EM, EKD-CMM, Enterprise Knowledge Development. 



\begin{abstract}
SILVA, C. C. Agile management of self-organizing innovation networks. 2015. 294 p. Dissertation (Master's Degree in Industrial Engineering). Escola de Engenharia de São Carlos, Universidade de São Paulo, São Carlos. 2015.

The race for competitive advantage is the business reality in today's global economy. Innovation networks formation is a collaborative way to develop innovations and acquire competitive advantage to reach new markets. Management is a challenge in these environments and different approaches can be applied in the pursuit of success. This research aims to identify and systematize how agile management approach, based on flexibility and adaptability, can be applied in these environments. The research methodology comprises a bibliographical study to present the theoretical background in the field of interest and one action research to data collection. The analysis and discussion of the intersection between theoretical background and field practical data aims to propose an enterprise modeling to support the application of agile management in self-organized innovation network environments. The modeling development was guided by the Enterprise Knowledge Development-Change Management Method (EKDCMM) based on For Enterprise Modeling (4EM) methodology. The research result identifies the benefits and limitations observed in its pratical implementation and contributes to expand the understanding of the elements involved in the management process of self-organizing innovation networks using agile management approach.
\end{abstract}

Keywords: Agile Project management, Network management, Self-organizing Innovation Networks, Enterprise modeling, 4EM, EKD-CMM, Enterprise Knowledge Development. 



\section{LISTA DE QUADROS}

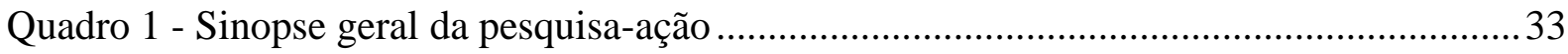

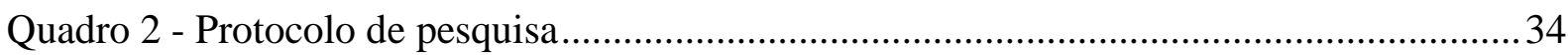

Quadro 3 - Instrumentos e fases da pesquisa-ação .............................................................. 35

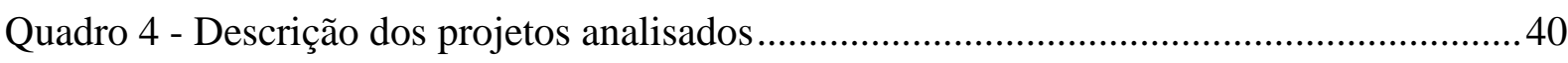

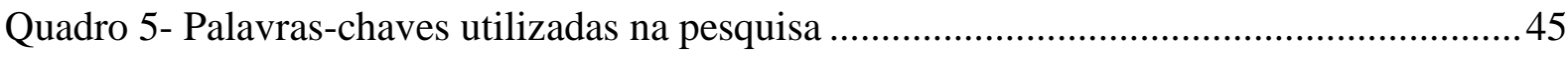

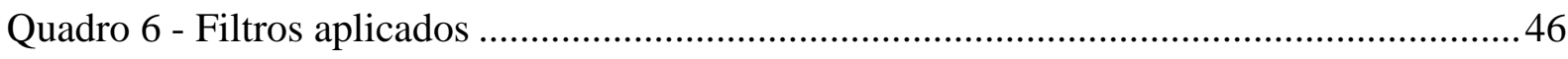

Quadro 7 - Principais assuntos relevantes para análise ..........................................................66

Quadro 8 - Problemas relacionados à características do ambiente.........................................96

Quadro 9 - Problemas relacionados à metodologia de gestão inadequada ..............................97

Quadro 10 - Oportunidades relacionadas à flexibilidade da organização ..............................98

Quadro 11 - Oportunidades relacionadas à flexibilidade da equipe .....................................99

Quadro 12 - Problemas relacionados à ferramentas inadequadas ....................................... 104 



\section{LISTA DE FIGURAS}

Figura 1: Metodologia 4EM.

Figura 2- Gestão ágil de redes de inovação auto-organizadas (áreas comuns/aplicabilidade). 72

Figura 3 - Modelo de objetivos - asis (Parte 1/2) ..................................................................... 79

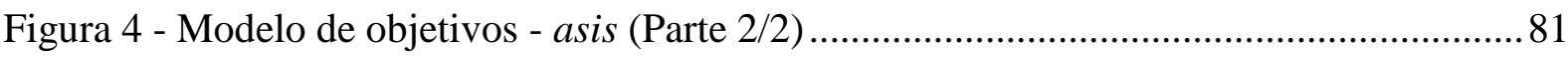

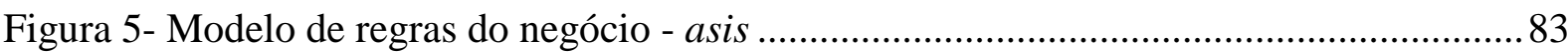

Figura 6 - Modelo de atores e recursos - asis (parte 1/2) .................................................... 85

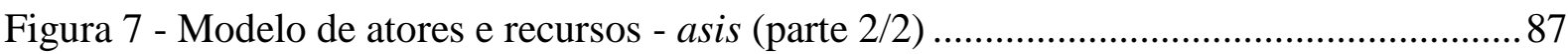

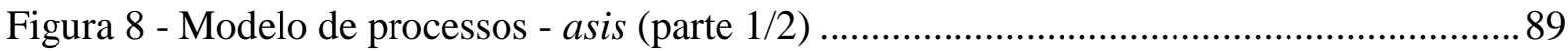

Figura 9 - Modelo de processos - asis (parte 2/2) …............................................................. 91

Figura 10 - Modelo de componentes e requisitos técnicos - asis $(2 / 3)$................................... 93

Figura 11 - Modelo de componentes e requisitos técnicos - asis (3/3) ..................................95

Figura 12 - Modelo de objetivos - tobe (Parte 1/2) ............................................................. 111

Figura 13 - Modelo de objetivos - tobe (Parte 2/2) ............................................................. 113

Figura 14- Modelo de regras do negócio - tobe (Parte 1/2) .................................................115

Figura 15 - Modelo de regras do negócio - tobe (Parte 2/2) .................................................. 118

Figura 16 - Modelo de atores e recursos - tobe (parte 1/3) …................................................ 120

Figura 17 - Modelo de atores e recursos - tobe (parte 2/3)................................................... 123

Figura 18 - Modelo de atores e recursos - tobe (parte 3/3) ................................................ 125

Figura 19 - Modelo de Processos - tobe (Parte 1/2) .............................................................. 128

Figura 20 - Modelo de Processos - tobe (Parte 2/2) .............................................................. 131

Figura 21 - Modelo de componentes e requisitos técnicos - tobe $(1 / 3)$................................. 133

Figura 22 - Modelo de componentes e requisitos técnicos - tobe (2/3)................................. 136

Figura 23 - Modelo de componentes e requisitos técnicos - tobe (3/3)................................ 139

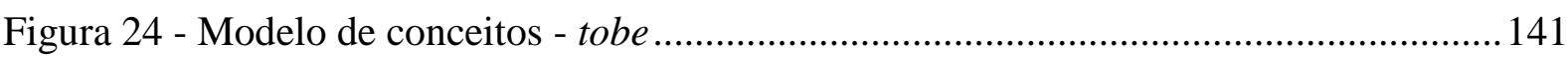

Figura 25 - Processos abrangidos no EKD-CMM........................................................... 155

Figura 26 - Modelo de processos: gerar demandas - asis (parte 1/2) ...................................238

Figura 27 - Modelo de processos: gerar demandas - asis (parte 2/2) ....................................240

Figura 28 - Modelo de processos: receber e tratar demandas - asis ......................................242

Figura 29 - Modelo de processos: acompanhar resultados e comunicar interessados - asis (parte $1 / 2)$

Figura 30 - Modelo de processos: acompanhar resultados e comunicar interessados - asis (parte $2 / 2)$ 
Figura 31 - Modelo de processos: entregar resultados e comunicar interessados - asis.........248

Figura 32 - Modelo de processos: transferência de conhecimento mensal - asis ..................250

Figura 33 - Modelo de processos: estimular inovação na rede - asis ...................................252

Figura 34 - Modelo de processos: disseminar melhores práticas no segmento - asis ...........254

Figura 35 - Modelo de processos: gestão de parcerias e RH - ais (parte 1/2) ........................256

Figura 36 - Modelo de processos: gestão de parcerias e RH - asis (parte 2/2)......................258

Figura 37 - Modelo de processos: acompanhamento e liberação de recursos - asis ..............260

Figura 38 - Modelo de processos: transição no modelo de gestão - tobe...............................263

Figura 39 - Modelo de processos: gerar demandas - tobe (parte 1/2) ..................................265

Figura 40 - Modelo de processos: gerar demandas - tobe (parte 2/2) ..................................267

Figura 41 - Modelo de processos: receber e tratar demandas - tobe (parte 1/2) ...................269

Figura 42 - Modelo de processos: receber e tratar demandas - tobe (parte 2/2) ...................271

Figura 43 - Modelo de processos: tratar demandas fixas - tobe .......................................274

Figura 44 - Modelo de processos: acompanhar resultados e comunicar interessados - tobe .276

Figura 45 - Modelo de processos: entregar resultados e comunicar interessados - tobe........278

Figura 46 - Modelo de processos: transferência de conhecimento mensal - tobe (parte 1/2) 280

Figura 47 - Modelo de processos: transferência de conhecimento mensal - tobe (parte 2/2) 282

Figura 48 - Modelo de processos: estimular inovação na rede - tobe ....................................284

Figura 49 - Modelo de processos: disseminar melhores práticas no segmento - tobe............286

Figura 50 - Modelo de processos: gestão de parcerias e RH - tobe (parte 1/2) ......................288

Figura 51 - Modelo de processos: gestão de parcerias e RH - tobe (parte 2/2) .....................290

Figura 52 - Modelo de processos: acompanhamento e liberação de recursos - tobe..............292

Figura 53 - Modelo de componentes e requisitos técnicos - asis (1/3).................................294 


\section{LISTA DE SIGLAS}

4EM For Enterprise Modeling

APM Agile Project Management

ARIS Architecture of Integrated Information Systems

BPMN Business Process Modeling Notation

CAD Computer aided design

CIMOSA Computer Integrated Manufacturing Open System Architecture

EKD Enterprise Knowledge Development

EKD-CMM Enterprise Knowledge Development-Change Management Method

EM Enterprise Modeling

ITIL Information Technology Infrastructure Library

OCD Órgão Certificador Designado

P\&D Pesquisa e Desenvolvimento

PDCA Plan-Do-Check-Act

PMBOK Project Management Body of Knowledge

PMI Project Management Institute

RFID Radio Frequency Identification

RH Recursos Humanos

UML Unified Modeling Language 



\section{SUMÁRIO}

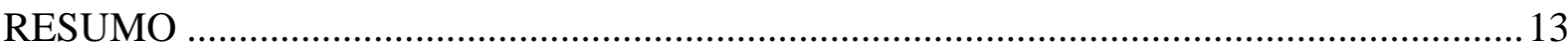

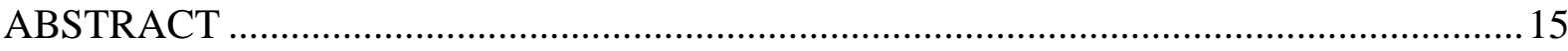

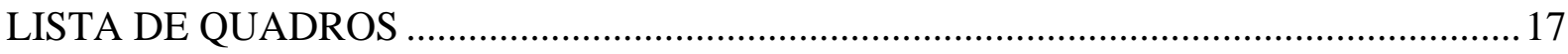

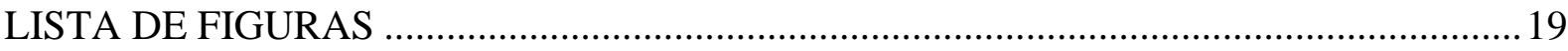

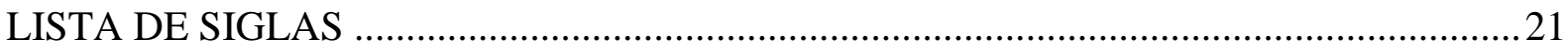

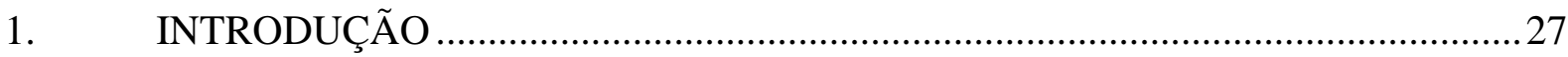

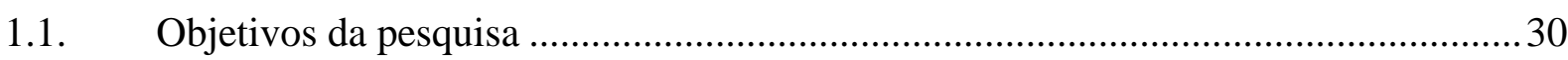

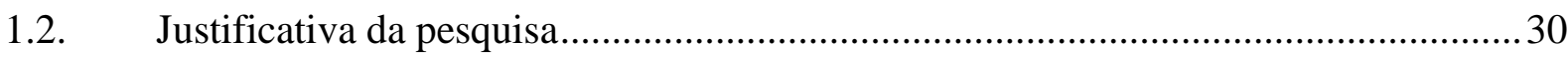

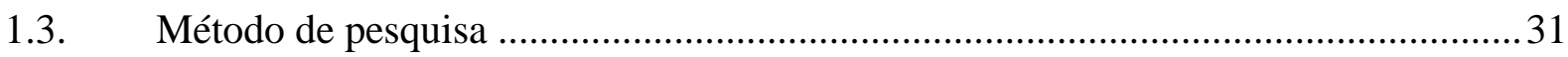

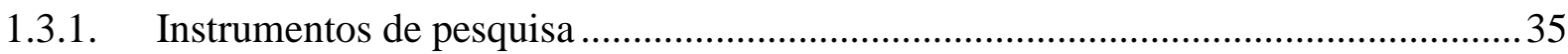

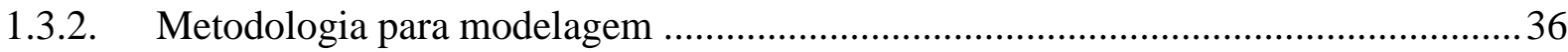

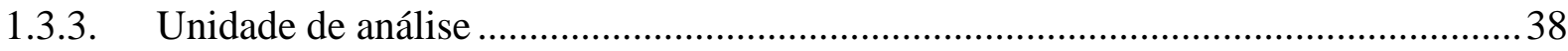

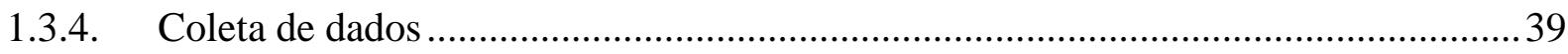

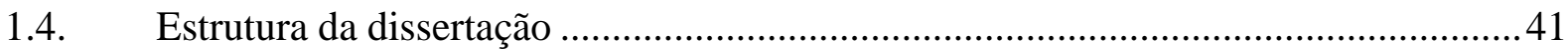

2. REVISÃO BIBLIOGRÁFICA SISTEMÁTICA: GESTÃO ÁGIL DE REDES DE

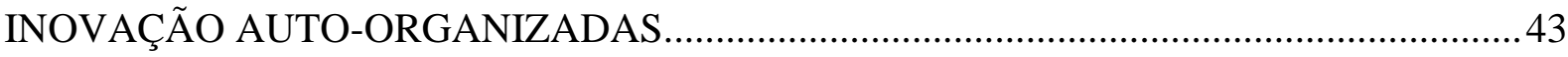

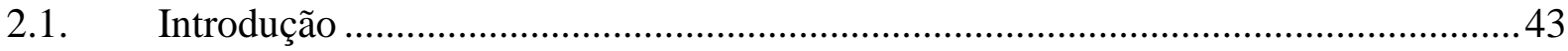

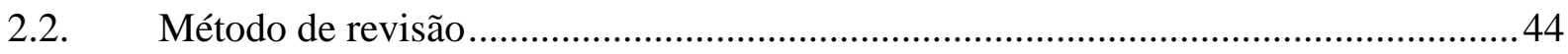

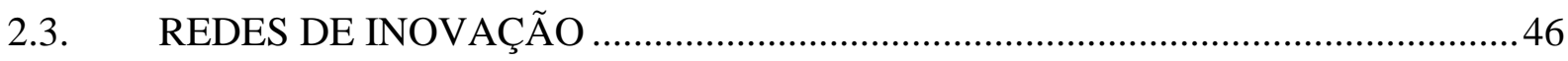

2.3.1. Vantagens, características e desafios que influenciam na gestão da rede..................48

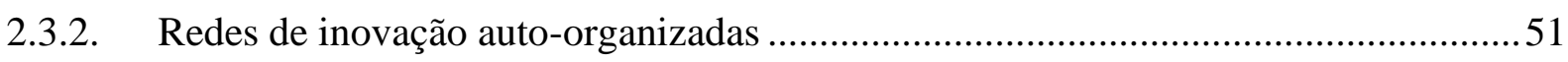

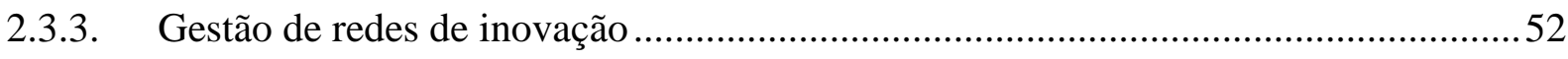

2.3.4. Influência do papel do coordenador na gestão da rede ...........................................53

2.3.5. Influência da comunicação, da confiança e da gestão do conhecimento na gestão da rede 54

2.3.6. Influência das ferramentas na gestão da rede ............................................................55

2.3.7. Cenário atual da gestão de redes de inovação........................................................55 


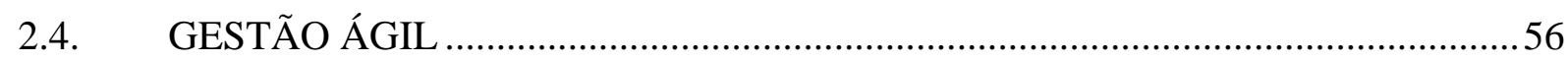

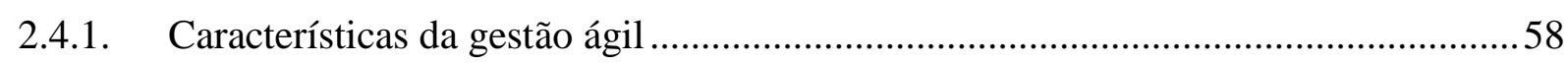

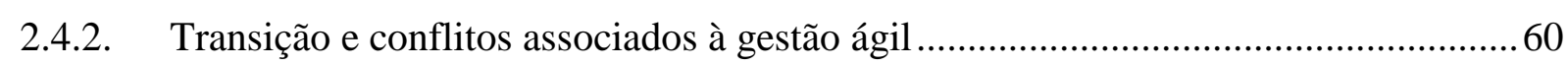

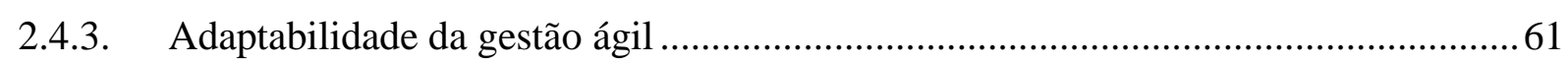

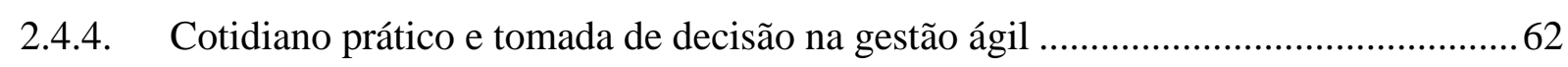

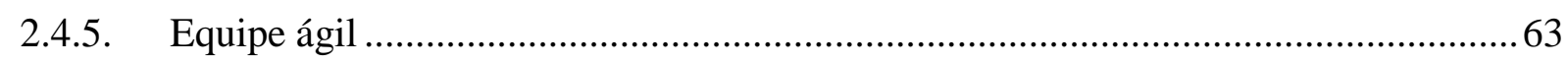

2.4.6. Cenário atual de aplicação da gestão ágil ................................................................64

2.5. ANÁlise DA GESTÃO ÁGIL DE REDES DE INOVAÇÃO AUTO-

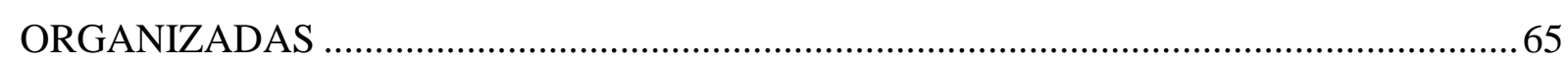

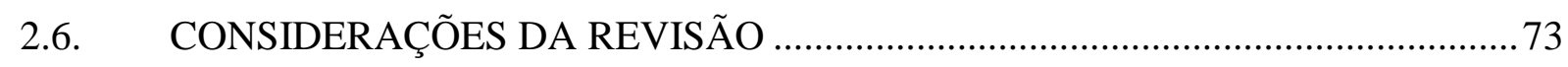

3. MODELO ATUAL E IDENTIFICAÇÃO DAS NECESSIDADES DE MUDANÇA 75

3.1. ANÁLISE DE DADOS E RESULTADOS DE UMA PESQUISA AÇÃO................75

3.1.1. Análise dos questionários .................................................................................76

3.1.2. Modelagem de empresas da pesquisa-ação $(A S-I S)$...................................................77

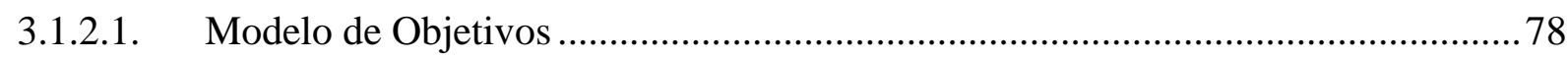

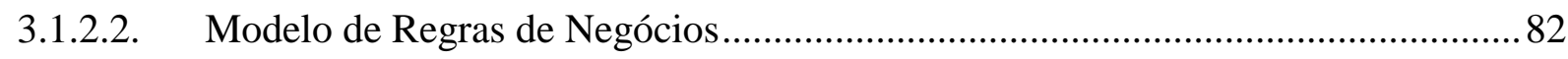

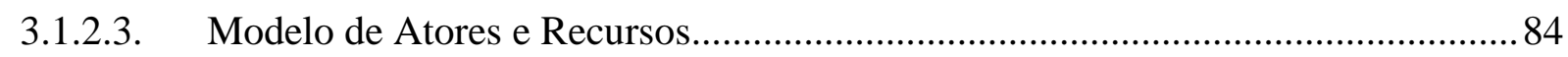

3.1.2.4. Modelo de Processos .................................................................................... 88

3.1.2.5. Modelo de Componentes e Requisitos Técnicos....................................................92

3.2. ANÁLISE DA NECESSIDADE DE MUDANÇA (NEED-FOR-CHANGE)............96

3.2.1. Necessidade de mudanças para o Modelo de Objetivos .............................................. 96

3.2.2. Necessidade de mudanças para o Modelo de Regras de Negócios............................100

3.2.3. Necessidade de mudanças para o Modelo de Atores e Recursos................................ 100

3.2.4. Necessidade de mudanças para o Modelo de Processos............................................. 101

3.2.5. Necessidade de mudanças para o Modelo de Componentes e Requisitos Técnicos 104

3.3. CONTRIBUIÇÕES DO NEED-FOR-CHANGE: REQUISITOS PARA APLICAÇÃO

DA GESTÃO ÁGIL EM REDES DE INOVAÇÃO AUTO-ORGANIZADAS .....................105 
4. MODELAGEM DE EMPRESAS PARA GESTÃO ÁGIL DE REDES DE

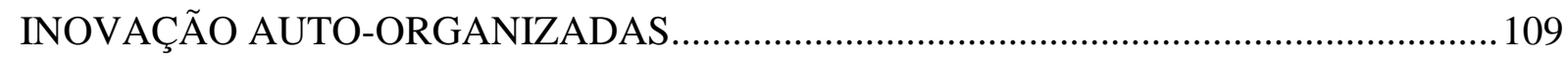

4.1. MODELAGEM DE EMPRESAS PROPOSTA A PARTIR DA PESQUISA-AÇÃO (TO-BE) 109

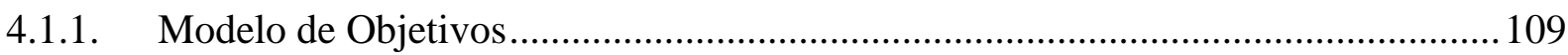

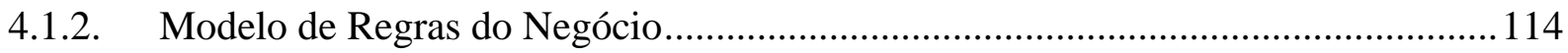

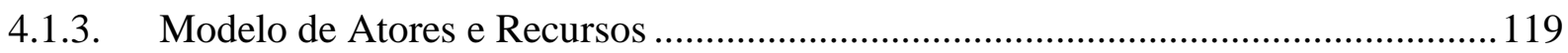

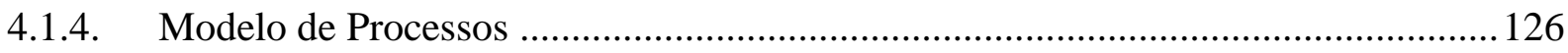

4.1.5. Modelo de Componentes e Requisitos Técnicos ............................................... 132

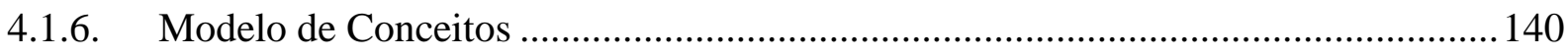

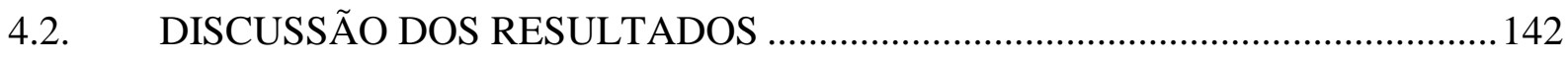

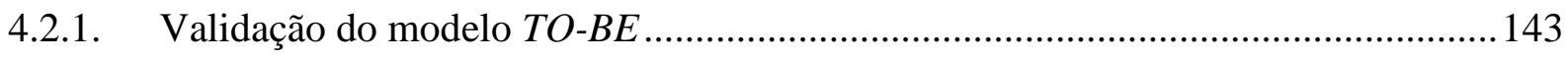

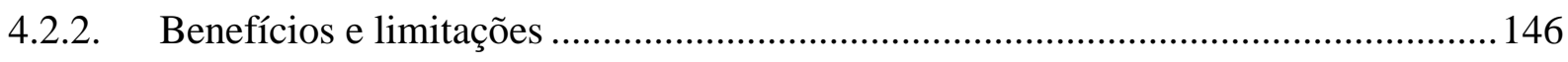

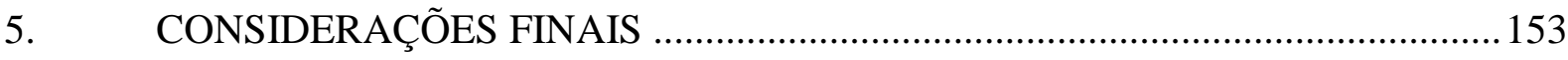

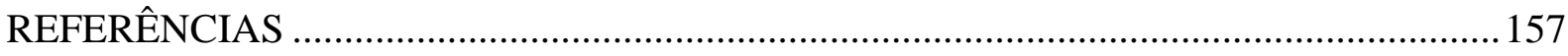

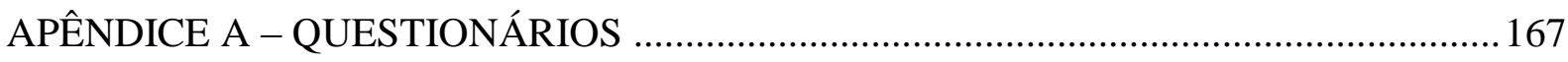

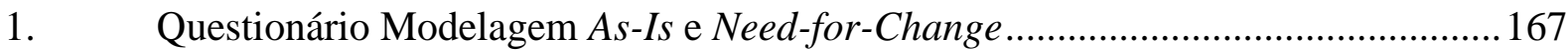

2. Questionário Modelagem To-Be (Parte 1/3) ........................................................ 190

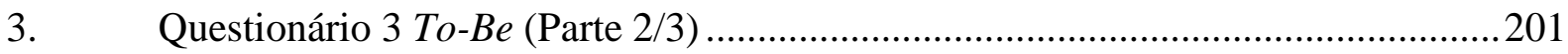

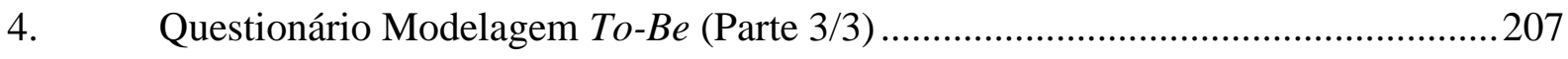

5. Questionário Validação da Modelagem de Empresas ...........................................214

APÊNDICE B - DETALHAMENTOS DE MODELOS EKD-CMM ................................237

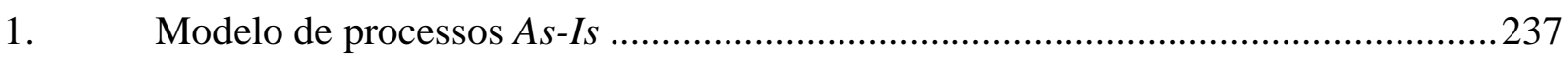

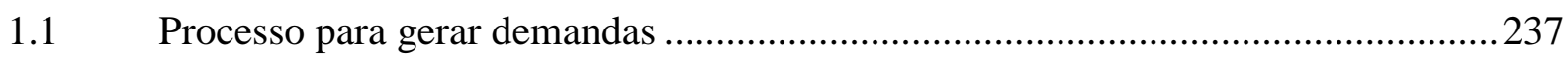

1.2 Processo para receber e tratar demandas ..................................................... 241

1.3 Processo para acompanhar resultados e comunicar interessados ..........................243

1.4 Processo para entregar resultados e comunicar interessados ................................247

1.5 Processo para transferência do conhecimento mensal ........................................249 
1.6 Processo para estimular inovação na rede ….......................................................251

1.7 Processo para disseminar melhores práticas no segmento ..................................253

1.8 Processo para gestão de parcerias e recursos humanos .......................................255

1.9 Processo de acompanhamento e liberação de recursos ...........................................259

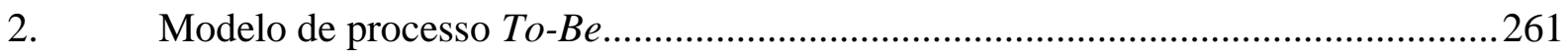

2.1 Processo para transição no modelo de gestão .....................................................261

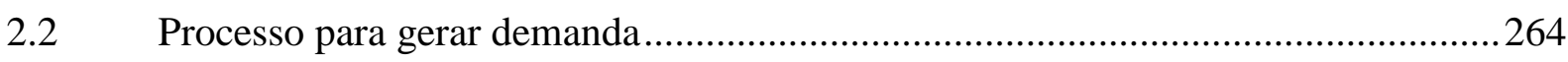

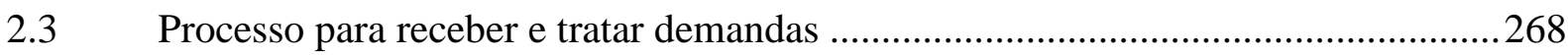

2.4 Processo para tratar demandas fixas (Gestão híbrida) .........................................22

2.5 Processo para acompanhar resultados e comunicar interessados ...........................2275

2.6 Processo para entregar resultados e comunicar interessados ...............................277

2.7 Processo para transferência do conhecimento .....................................................279

2.8 Processo para estimular inovação na rede .........................................................283

2.9 Processo para disseminar melhores práticas no segmento ....................................285

2.10 Processo para gestão de parcerias e recursos humanos .........................................287

2.11 Processo de acompanhamento e liberação de recursos ............................................291

3. Modelo de Componentes e Requisitos Técnicos (Parte 1/3) As-Is .........................293

APÊNDICE C - DETALHAMENTO DO PLANO DE AÇÃO ...........................................295

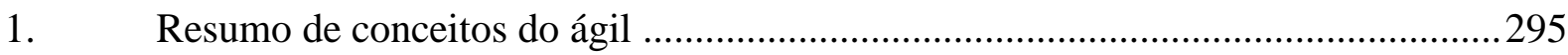

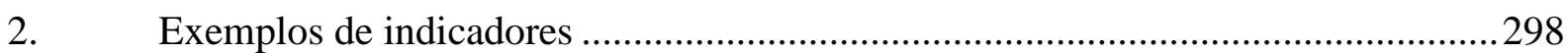




\section{INTRODUÇÃO}

A busca por melhoria de desempenho e competitividade, configura-se em um motivador para que as empresas invistam em novas formas de aumentar sua capacidade de inovar. Nesse contexto, os elos cooperativos entre empresas são considerados fatores de transferência de inovação (OCDE, 2005), por estimularem a formação de ambientes nos quais diferentes elementos atuam para gerar inovação, visando responder ativamente às oportunidades do mercado.

A inovação pode ocorrer em diversas esferas e entre as mais estudadas e almejadas estão a de produto e processo (BECHEIKH, LANDRY e AMARA, 2006), que apesar de passíveis de existir de modo isolado, são comumente vistas como interdependentes (MARTINEZ-ROS, 1999) e vinculadas à avanços tecnológicos, que influenciam inclusive os avanços econômicos (FAGERBERG, SRHOLEC e VERSPAGEN, 2010). Nesse cenário, o conhecimento é identificado como o principal agente condutor da inovação (OCDE, 2005), consistindo em um dos principais ativos de uma organização, no qual a vantagem competitiva é fundamentada (NONAKA, 1994).

Nas empresas criadoras de conhecimento a busca por inovação contínua é o cerne do negócio (NONAKA, 2000), visualizada como uma cadeia de valor envolvendo três fases: geração da ideia, conversão e difusão (HANSEN e BIRKINSHAW, 2007), em que a última consiste em um processo de disseminação em um sistema social (NOOTEBOOM, 1994). Sob esse olhar é válido considerar o proposto pelas abordagens evolucionistas (OCDE, 2005) que compreendem o desenvolvimento de conhecimento e tecnologia, bases da inovação, como o resultado da interação entre vários atores e fatores agindo como intermediários de conhecimento e tecnologia (NELSON e WINTER, 1982; LANDRY et al., 2013), sendo a difusão parcela importante da interação.

Atualmente, somente uma minoria de empresas inova isoladamente (RYCROFT e KASH, 2004), destacando-se a interação com outras organizações e empresas, através da formação de elos cooperativos, como uma forma de alcançar a inovação (CHESBROUGH e TEECE, 2002), em especial, nos ambientes de desenvolvimento de tecnologias complexas, difíceis de serem compreendidas completamente por uma única organização, como os setores de alta tecnologia, nos quais as alianças tornaram-se a chave das estratégias de inovação (NOOTEBOOM et al., 2007). 
Entre as principais razões para que empresas atuem colaborativamente, apesar dos riscos e incertezas, estão a exploração das principais competências dos envolvidos e a possibilidade de aumento da capacidade competitiva ao compartilhar ativos, almejando vencer desafios, bem como identificar oportunidades de negócios valiosas e obter flexibilidade para atender as demandas em ambientes dinâmico (CHOUDHARY et al., 2013).

Trabalhos recentes (CAMARINHA-MATOS et al., 2009; CAMARINHA-MATOS e BOUCHER, 2012) apontam a crescente importância da colaboração em um contexto amplo: projetos de engenharia, consultoria, sustentabilidade, saúde e biociência, alimentos e bebidas, construção, química, tecnologia de informação e comunicação, logística, aeronáutica, entre outros, com foco em inovação tecnológica, demonstrando as diferentes áreas nas quais as redes podem ser formadas.

Nesses ambientes, Kash e Rycroft (2003) apontam o surgimento de redes de inovação gerenciadas por processos auto-organizados que estão transformando-se no foco da gestão quando comparadas à empresa individual. Nas redes de inovação auto-organizadas, não é necessária a existência de uma figura central agindo como controlador, os envolvidos possuem responsabilidades, competências e restrições identificadas, mas não estão presos a hierarquias, interagindo fluente e informalmente para gerar novos conhecimentos, mantendo-se flexíveis a mudanças do ambiente. Por ser auto-organizada, permite a transparência e flexibilidade necessárias para que adaptações ocorram e novas estruturas ou processos surjam, solucionando problemas, aproveitando oportunidades, influenciando seus ambientes e o mercado (PRAHALAD e HAMEL, 1990; RYCROFT e KASH, 2004).

Muitos desafios influenciam a aquisição de sucesso em ambientes tão diversificados: a formação de parcerias adequadas (HANSEN e BIRKINSHAW, 2007; TIDD e BESSANT, 2009); a falta de preparo inicial dos atores para atuar nesse tipo de ambiente (DILK et al., 2008); o baixo nível de previsibilidade de resultados e elevado nível de incerteza (DHANARAJ e PARKHE, 2006); ausência de instrumentos adequados para planejar e coordenar (DILK et al., 2008) e; a compreensão sobre como a divisão de atividades e compartilhamento de recursos, relaciona-se com obtenção de capacidades e inovação (PERKS e MOXEY, 2011).

Nesse cenário, a gestão de conhecimento eficiente é um ponto central para que o compartilhamento dos ativos entre os interessados seja realizado adequadamente e os resultados da interação sejam bem-sucedidos aos olhos dos envolvidos (CHOUDHARY et al., 2013), tornando-se importante para a rede não só gerenciar o conhecimento, mas criar, reter, absorver e disseminar. Desse modo, conjuntamente com os relacionamentos e mecanismos de funcionamento da rede, a gestão do conhecimento torna-se crítica para decisões relacionadas à 
gerenciamento, envolvendo diversos fatores, como humanos, financeiros, tecnológicos, recursos, entre outros (OLLUS et al., 2011).

No ambiente de redes, pode-se considerar o ciclo de vida proposto por CamarinhaMatos e Afsarmanesh (1999), composto por quatro fases - criação/configuração, operação, evolução/reconfiguração e dissolução -, conjuntamente com os fatores de gerenciamento apontados por Ollus et al. (2011), como a estrutura na qual um projeto colaborativo é desenvolvido. Assim, o gerenciamento pode assumir a dimensão de gerenciamento da rede como um todo e/ou dos projetos colaborativos desenvolvidos na mesma.

O gerenciamento da rede relaciona-se a gestão de suas operações para atingir seus objetivos de forma coordenada (JANSSON et al., 2008); por sua vez, o gerenciamento de projetos é apresentado como uma disciplina para planejar, organizar e administrar recursos para alcançar uma conclusão bem-sucedida de metas e objetivos especificados (OLLUS et al., 2011). Deste modo, é esperado que o gerenciamento da rede envolva aspectos do gerenciamento de projetos, mas também questões relacionadas a confiança, transparência, comunicação, informalidade, ausência de uma figura central, uso de ferramentas, gestão de riscos, ação baseada em informações incompletas e gestão de capacidades e conhecimento adequados, pontos essenciais para que a rede atinja seus objetivos (JANSSON et al., 2008; NEGRETTO et al., 2008).

Embora existam muitas pesquisas no campo de gestão de projetos, não são muitas no campo de gestão de projetos colaborativos, em especial, focadas no apoio a tomada de decisão (OLLUS et al., 2011). O mesmo ocorre no campo de gestão da rede, no qual os desafios existentes são relacionados as suas características, ciclo de vida e a forma de distribuição das operações entre diferentes envolvidos, cada um com intenções, comportamentos e cultura próprios (JANSSON et al., 2008).

Diferentes abordagens, metodologias e ferramentas podem ser utilizadas no gerenciamento da rede e dos projetos colaborativos que nela nascem (CAMARINHA-MATOS e AFSARMANESH, 2008; AFSARMANESH et al., 2009), entre eles a abordagem ágil surge como uma possibilidade, fornecendo meios para lidar com os desafios desse ambiente dinâmico e turbulento (AMARAL et al., 2011), buscando o que Ollus et al. (2011) definem como gerenciamento focado na colaboração, envolvendo diversos atores em um esforço social, atrelado ao objetivo da rede. 


\subsection{Objetivos da pesquisa}

Com base no que foi abordado, o objetivo dessa pesquisa é compreender e sistematizar o gerenciamento de redes de inovação auto-organizadas com uso da abordagem ágil, por meio de uma modelagem de empresas, considerando um recorte "macro" - da rede como um todo e "micro" - dos projetos colaborativos desenvolvidos nesse ambiente. Esse objetivo é apoiado pelos seguintes objetivos secundários:

- Mediante pesquisa-ação em uma rede com as características apresentadas, identificar os requisitos para aplicação da gestão ágil em redes de inovação autoorganizadas, sistematizando-os através de modelagens da situação atual da gestão e das necessidades de mudança;

- Confrontando os resultados obtidos com os apontamentos da literaruta, também mediante pesquisa-ação, desenvolver um modelo do estado futuro da transição, em prol de sistematizar como pode ser realizada a gestão ágil da rede e de seus projetos e, compreender os benefícios e limitações da sua aplicação.

\subsection{Justificativa da pesquisa}

Considerando os desafios existentes, Negretto et al. (2008) apontam a coordenação adequada como chave para gerenciar a rede; corroborando com esse pensamento, para Ollus et al. (2011) a grande quantidade de conhecimento obtido na área de gestão de projetos, pode ser utilizada e atuar como ponto de partida para pesquisar o ambiente da gestão dos projetos colaborativos, considerando suas características e possibilidades de interpretação.

Para Boehm e Hogan (2012) o sucesso da rede depende do foco da gestão em todos os agentes envolvidos e ainda, da correta definição, alinhamento e monitoramento dos objetivos, responsabilidades e atividades. Para Loss e Crave (2011) é importante o surgimento de modelos ágeis que forneçam as características necessárias para o dinamismo desses ambientes, visando simplificar o processo de gerenciamento. A adaptabilidade da gestão ágil pode ser de grande valia nesses ambientes, por priorizar os impactos da comunicação, coordenação e controle na gestão e, por utilizar somente processos, ferramentas, procedimentos e documentação realmente necessários (FERNANDEZ e FERNANDEZ, 2008; MELO et al., 2013).

Nesse contexto, a abordagem ágil surge como uma possibilidade, frente aos modelos tradicionais de gerenciamento, fornecendo meios para lidar com os desafios desses ambientes, visando simplificar o processo de gerenciamento, tornando-o flexível e iterativo com o intuito de atingir as metas, minimizando esforços desnecessários, maximizando o desempenho de tempo, custo, qualidade e gerando inovação (AMARAL et al., 2011). 
No entanto, apesar da importância da gestão nesses ambientes, não são muitas as pesquisas nesse campo (OLLUS et al., 2011; LOWE et al., 2012), em especial, abordando a aplicação da gestão ágil em ambientes de redes de inovação auto-organizadas. Existe pouca discussão sobre como projetar e gerenciar operações na rede de inovação (DHANARAJ e PARKHE, 2006; SMART, BESSANT e GUPTA, 2007; MOLLER e SVAHN, 2009; LEVÉN, HOLMSTRÖM e MATHIASSEN, 2014), sendo que a maioria existente foca na gestão da inovação em uma única empresa e não visualiza a influência da gestão na rede como um todo (RAMPERSAD, QUESTER, TROSHANI, 2010; LEVÉN, HOLMSTRÖM e MATHIASSEN, 2014).

Assim, busca-se corroborar com literatura da área e auxiliar as empresas, ao fornecer material que permita analisar quais características deste ambiente estimulam a aplicação do ágil, como isso pode ser feito e quais os possíveis benefícios e limitações desta ação para os envolvidos.

\subsection{Método de pesquisa}

O levantamento e análise do estado da arte do tema gestão ágil de redes de inovação auto-organizadas é o ponto de partida da pesquisa e foi realizado conforme as diretrizes da revisão biliográfica sistemática, visando abranger o máximo possível de informações relacionadas ao objetivo da pesquisa.

Com relação a abordagem adotada é do tipo qualitativa, devido a característica descritiva assumida, a utilização de um ambiente real como fonte de dados, a necessidade de aprofundamento no ambiente estudado e também, a perspectiva interpretativa com a qual a pesquisa foi conduzida (MARTINS, 2012); com relação a natureza, a pesquisa é aplicada, devido ao objetivo de verificação em ambiente real e aplicação prática (TURRIONI e MELLO, 2012) e; com relação ao tipo é exploratória, com o objetivo de obter maior familiaridade, acerca de um problema não tão extensamente explorado pela literatura (GIL, 2010).

O método de pesquisa adotado para planejar, coletar e analisar os dados é a pesquisaação, devido as características práticas da pesquisa e particularidades da unidade de análise. Segundo Thiollent (2009) na área organizacional e tecnológica, este método é indicado por ser adaptável e auxiliar os envolvidos a lidar com a inserção de conhecimentos na prática, ao permitir a interação de pesquisadores e empresas, por meio da imersão do pesquisador na unidade de análise.

Dessa forma, é concebida e realizada de forma colaborativa por participantes representativos da situação pesquisada, visando ação e resolução de problemas (THIOLLENT, 
2011), bem como geração de elementos que corroborem com a mudança organizacional e que tenham utilidade para verificação e validação dos construtos da pesquisa.

Essa metodologia permite a existência de um relacionamento entre pesquisa, aprendizagem, ação e avaliação e é realizada com base em um roteiro flexível que contempla um conjunto de ações não ordenados no tempo, identificadas em quatro grandes fases que podem se repetir: exploratória; aprofundada, ação e de avaliação (THIOLLENT, 2009).

Essas fases abrangem o planejamento da pesquisa, com identificação do problema associado à gestão e construção de hipóteses; coleta de dados; análise e planejamento de ações; implementação das ações mapeadas; avaliação de resultados e geração de relatórios, com monitoramento presente em todas as ações (COUGHLAN e COUGHLAN, 2002).

O resultado das atividades realizadas nas fases da pesquisa-ação contempladas nesse trabalho será um conjunto de submodelos organizacionais inter-relacionados, desenvolvidos com a metodologia EKD-CMM (NURCAN e ROLLAND, 2003), constituindo três situações da unidade de análise: estado atual, necessidade de mudança e estado futuro.

O Quadro 1 (página 33) ilustra a sinopse geral da pesquisa-ação, considerando as fases abrangidas e o seu relacionamento com os modelos resultantes da pesquisa. 
Quadro 1 - Sinopse geral da pesquisa-ação

\begin{tabular}{|c|c|c|c|c|c|}
\hline \multicolumn{2}{|r|}{ Fases } & \multirow[b]{2}{*}{ Principais etapas } & \multirow[b]{2}{*}{ Ações envolvidas } & \multirow{2}{*}{\multicolumn{2}{|c|}{ Detalhamentos }} \\
\hline $\begin{array}{l}\text { EKD- } \\
\text { CMM }\end{array}$ & Pesquisa-ação & & & & \\
\hline \multirow{13}{*}{ 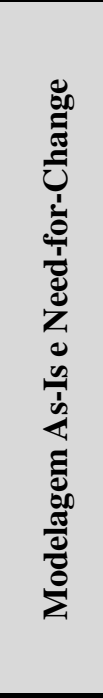 } & \multirow{9}{*}{$\begin{array}{l}\text { Exploratória } \\
\text { (planejamento) }\end{array}$} & \multirow{2}{*}{ Definir contexto e propósito } & Diagnosticar situação & \multirow{4}{*}{ Seminário inicial e entrevista } & \\
\hline & & & Definir tema e equipe & & \\
\hline & & \multirow{2}{*}{ Definir estrutura conceitual-teórica } & Entender objetivos e métodos da pesquisa & & \\
\hline & & & Definir projeto/problema prático & & \\
\hline & & \multirow{5}{*}{$\begin{array}{l}\text { Selecionar unidade de análise e } \\
\text { técnica de coleta de dados }\end{array}$} & Definir técnicas de coleta de dados & \multirow{5}{*}{$\begin{array}{l}\text { Entrevistas/Seminários (individuais } \\
\text { e coletivas) }\end{array}$} & Preparação de roteiro \\
\hline & & & \begin{tabular}{|l|} 
Preparar próxima fase \\
\end{tabular} & & Aplicação do roteiro \\
\hline & & & \multirow{3}{*}{ Elaborar protocolo } & & Análise e interpretação \\
\hline & & & & & Relatório de análise \\
\hline & & & & & Retorno aos participantes \\
\hline & \multirow{4}{*}{$\begin{array}{l}\text { Aprofundada } \\
\text { (Coletar dados) }\end{array}$} & \multirow{2}{*}{ Registrar dados } & \multirow{2}{*}{ Investigar aprofundadamente os problemas } & \multirow{4}{*}{ Entrevistas/Seminários } & $\begin{array}{l}\text { Elaboração das prioridades (principais } \\
\text { problemas) }\end{array}$ \\
\hline & & & & & $\begin{array}{l}\text { Definição de possíveis propostas para } \\
\text { ação }\end{array}$ \\
\hline & & \multirow[b]{2}{*}{ Analisar dados e planejar ações } & Comparar dados empíricos com teoria & & Acompanhamento das entrevistas \\
\hline & & & $\begin{array}{l}\text { Elaborar plano de ação (centralizar propostas/ } \\
\text { encaminhar/negociar) }\end{array}$ & & Interpretações dos dados \\
\hline \multirow{14}{*}{ 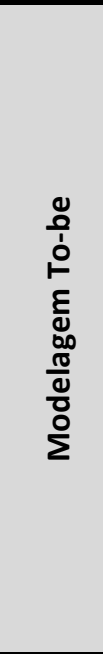 } & \multirow{2}{*}{$\begin{array}{c}\text { Ação } \\
\text { (Implementar } \\
\text { plano de ação) } \\
\end{array}$} & \multirow[b]{2}{*}{ Realizar ações piloto } & Apresentar propostas concretas & \multicolumn{2}{|c|}{ Seminários } \\
\hline & & & $\begin{array}{l}\begin{array}{l}\text { Iniciar difusão dos resultados (conscientizar } \\
\text { envolvidos) }\end{array} \\
\end{array}$ & \multicolumn{2}{|c|}{$\begin{array}{l}\text { Modo centralizado (no setor da pesquisa-ação) e/ou descentralizado (nos } \\
\text { demais setores e parceiros) }\end{array}$} \\
\hline & \multirow{12}{*}{$\begin{array}{l}\text { Avaliação } \\
\text { (Avaliar } \\
\text { resultados e } \\
\text { gerar relatório) }\end{array}$} & \multirow{12}{*}{$\begin{array}{l}\text { Controlar a efetividade das ações e } \\
\text { extrair conhecimento para } \\
\text { continuidade }\end{array}$} & \multirow{10}{*}{ Avaliar resultados constantemente } & \multirow{10}{*}{ Questionários } & Pontos estratégicos da pesquisa \\
\hline & & & & & Capacidade de mobilização \\
\hline & & & & & Capacidade de propostas \\
\hline & & & & & \begin{tabular}{|l|} 
Continuidade do projeto \\
\end{tabular} \\
\hline & & & & & Participação \\
\hline & & & & & Qualidade do trabalho em equipe \\
\hline & & & & & Efetividade dos treinamentos \\
\hline & & & & & Conhecimento e informação \\
\hline & & & & & Comunicação \\
\hline & & & & & Atividades de apoio \\
\hline & & & Prover estrutura para replicação & \multicolumn{2}{|l|}{ Modelagem de empresas } \\
\hline & & & Redigir relatório & \multicolumn{2}{|l|}{ Análise dos resultados } \\
\hline
\end{tabular}


A elaboração de um protocolo de pesquisa, ilustrado no Quadro 2 (página 34), é uma das ações contempladas no roteiro da pesquisa-ação, visando contribuir para a melhoria e aumento da confiabilidade da mesma.

Quadro 2 - Protocolo de pesquisa

\begin{tabular}{|c|c|c|}
\hline \multicolumn{3}{|c|}{ Protocolo da pesquisa-ação } \\
\hline \multirow{9}{*}{ 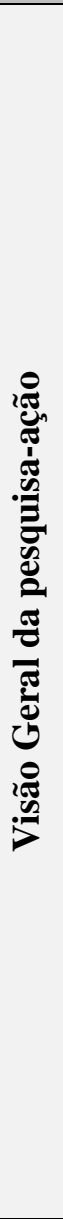 } & Tipo de pesquisa & Exploratória. \\
\hline & Objetivo da pesquisa & $\begin{array}{l}\text { Identificação dos requisitos para aplicação da } \\
\text { abordagem ágil em redes de inovação auto-organizadas, } \\
\text { seguido de desenvolvimento e aplicação de um modelo } \\
\text { para realizar gestão ágil em tais ambientes. }\end{array}$ \\
\hline & \multirow{3}{*}{ Questões de pesquisa } & $\begin{array}{l}1 \text { - Quais os elementos identificados na unidade de } \\
\text { análise apoiam a utilização da abordagem ágil? }\end{array}$ \\
\hline & & $\begin{array}{l}2 \text { - Quais os benefícios identificados com a aplicação do } \\
\text { modelo proposto? }\end{array}$ \\
\hline & & $\begin{array}{l}3 \text { - Quais as limitações identificadas com a aplicação do } \\
\text { modelo proposto? }\end{array}$ \\
\hline & $\begin{array}{l}\text { Problema prático a ser solucionado na } \\
\text { pesquisa de campo }\end{array}$ & $\begin{array}{l}\text { Melhoria da comunicação e ganho de velocidade na } \\
\text { geração e compartilhamento de relatórios e demais } \\
\text { artefatos entregáveis relacionados aos projetos da } \\
\text { unidade de análise. }\end{array}$ \\
\hline & Validade do constructo & $\begin{array}{l}\text { A combinação das fontes de evidência (revisão } \\
\text { bibliográfica, pesquisa-ação e modelagem) permite a } \\
\text { consolidação das perspectivas de avaliação do objeto de } \\
\text { estudo. }\end{array}$ \\
\hline & Validade externa & $\begin{array}{l}\text { Como a unidade de análise selecionada é ativa no } \\
\text { mercado e com características comuns em relaçãção à } \\
\text { gestão de redes, existe a possibilidade de } \\
\text { aproveitamento para replicação em ambientes } \\
\text { semelhantes. }\end{array}$ \\
\hline & Confiabilidade & $\begin{array}{l}\text { Utilização do protocolo e validação de ciclos já } \\
\text { realizados. }\end{array}$ \\
\hline \multirow{6}{*}{ 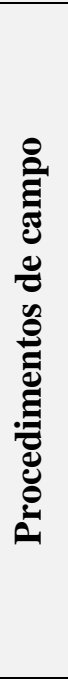 } & Unidade de análise & $\begin{array}{l}\text { Rede formada por distintos setores e unidades de um } \\
\text { centro de pesquisas, interagindo em relações de } \\
\text { parceria, envolvendo também clientes, bem como outras } \\
\text { empresas e instituições de pesquisa }\end{array}$ \\
\hline & Definição do grupo de pesquisa-ação & $\begin{array}{l}\text { Grupo formados por integrantes da empresa principal, } \\
\text { sendo sede e uma filial. }\end{array}$ \\
\hline & Agenda da coleta de dados & De Dezembro de 2014 a Agosto de 2015. \\
\hline & Local & São Carlos - SP e Campinas - SP. \\
\hline & $\begin{array}{l}\text { Ciclos de pesquisa-ação (melhoria e } \\
\text { aprendizagem) }\end{array}$ & $\begin{array}{l}\text { Ciclos iterativos definidos por subprojetos da unidade } \\
\text { de análise e envolvem os diferentes integrantes da rede }\end{array}$ \\
\hline & Fontes gerais de informação & $\begin{array}{l}\text { Reuniões, material de documentação dos subprojetos, e- } \\
\text { mails, atas, seminários da pesquisa-ação, anotações, } \\
\text { plano de ação da pesquisa-ação e áudios de } \\
\text { monitoramento e entrevistas. }\end{array}$ \\
\hline
\end{tabular}




\subsubsection{Instrumentos de pesquisa}

Três instrumentos de pesquisa principais foram considerados para realização do trabalho de campo: seminários, entrevistas e modelagem de empresas; combinados ou individualmente, em várias etapas das fases exploratória, aprofundamento, de ação e de avaliação da pesquisaação.

Os seminários foram utilizados como ferramenta de comunicação, análise, coleta de dados, monitoramento das ações e motivação do grupo, em situações nos quais a apresentação visual de conteúdo facilitava o entendimento e alinhamento dos envolvidos. As entrevistas (apoiadas por roteiro ou abertas) presenciais e através de formulários virtuais, foram essenciais para coleta de dados, tanto para entendimento da situação atual, quanto para monitoramento das ações em andamento e obtenção de opiniões de retorno.

Por fim, a modelagem foi utilizada como ferramenta para a sistematização e documentação, facilitando a visualização da situação e das necessidades de melhoria, servindo também para monitoramento, entendimento de procedimentos e ferramentas e ainda, como fonte de informação para tomada de decisão estratégica. O Quadro 3 (página 35) apresenta uma sumarização dos instrumentos utilizados para as fases da pesquisa-ação.

Quadro 3 - Instrumentos e fases da pesquisa-ação

\begin{tabular}{|c|c|}
\hline \multicolumn{2}{|c|}{ Fases de pesquisa-ação e instrumentos utilizados } \\
\hline Exploratória & Aprofundada \\
\hline Seminário de apresentação & Seminário com plano de ação com fases de atuação \\
\hline Entrevista com gestor & Entrevistas com envolvidos \\
\hline $\begin{array}{l}\text { Reunião com grupo de trabalho para definição do } \\
\text { problema prático }\end{array}$ & $\begin{array}{l}\text { Modelagem para entender situação e planejar } \\
\text { transição }\end{array}$ \\
\hline Seminário de definição do problema & Entrevistas de feedback do plano de ação \\
\hline $\begin{array}{l}\text { Reunião do grupo de trabalho para estruturar o plano } \\
\text { de ação e coletar de dados }\end{array}$ & Reuniões de alinhamento \\
\hline Ação & Avaliação \\
\hline Modelagem para implantação da gestão ágil & $\begin{array}{l}\text { Questionários e reuniões para coleta de feedback } \\
\text { das ações realizadas }\end{array}$ \\
\hline Seminários para apresentação e treinamento & Análise de resultados com reuniões \\
\hline $\begin{array}{l}\text { Acompanhamento diário da implantação com } \\
\text { entrevistas }\end{array}$ & Avaliação para nova fase \\
\hline Adaptações necessárias no modelo & \\
\hline
\end{tabular}




\subsubsection{Metodologia para modelagem}

Modelagem de Empresas (Enterprise Modeling - EM) é o processo de criação de um modelo de empresa integrado que captura os aspectos de uma empresa requeridos para o propósito da modelagem em questão. Uma empresa neste contexto pode ser uma companhia privada, governo, departamento, instituição acadêmica ou outro tipo de organização, ou da mesma parte. Um modelo de empresa consiste em um número de submodelos relacionados, cada um com foco em um aspecto em particular da empresa, i.e., processos, regras de negócio, conceitos/informação, visão/objetivos, e atores. Um modelo de empresa descreve o estado atual ou futuro de uma empresa e contém comumente compartilhamento de conhecimento e dos participantes envolvidos no processo de modelagem (BUBENKO, et al. 2001).

Ao analisar a aplicabilidade de uma abordagem de gestão, bem como planejar a transição para um novo modelo de gestão, é importante analisar a empresa sob diferentes perspectivas. A modelagem é um processo que facilita tal análise, pois visa descrever, modelar, desenhar e documentar um conjunto de fenômenos abstratos ou concretos de forma estruturada; consistindo em uma técnica chave para auxiliar na compreensão e racionalização da organização, assim como para facilitar a comunicação entre diversos interessados e a visualização das necessidades de melhorias (BUBENKO, PERSSON, STIRNA, 2001; PÁDUA, CAZARINI e INAMASU, 2004).

Diferentes metodologias podem ser utilizados para realizar a modelagem de empresas, como ARIS, CIMOSA, Canvas Business Model, Archimate, BPMN, UML e entre elas, o EKDCMM (Enterprise Knowledge Development-Change Management Method) que destaca-se por ser focado na gestão de mudanças e possibilitar a obtenção de respostas as principais questões do processo de modelagem ("por que", “o que”, “quem”, “qual”, “quando", “onde” e “como”), identificadas por Pádua (2012), de modo simples e objetivo.

Proposto por Nurcan e Rolland (2003) o EKD-CMM estabelece um framework com base na metodologia For Enterprise Modeling (4EM) conforme Sandkul, Stirna, Persson e Wibotzki (2014). O diferencial do EKD-CMM reside em abranger diferentes estágios da organização na modelagem: seu funcionamento atual (as-is); identificação das necessidades de mudança (need-for-change) e alternativas para realizá-la e; seu estado futuro (to-be). Esses estágios são documentados utilizando o conjunto de seis submodelos que analisam a empresa e seus requisitos sob uma série de perspectivas inter-relacionadas, conforme ilustrado na Figura 1 (página 37). 


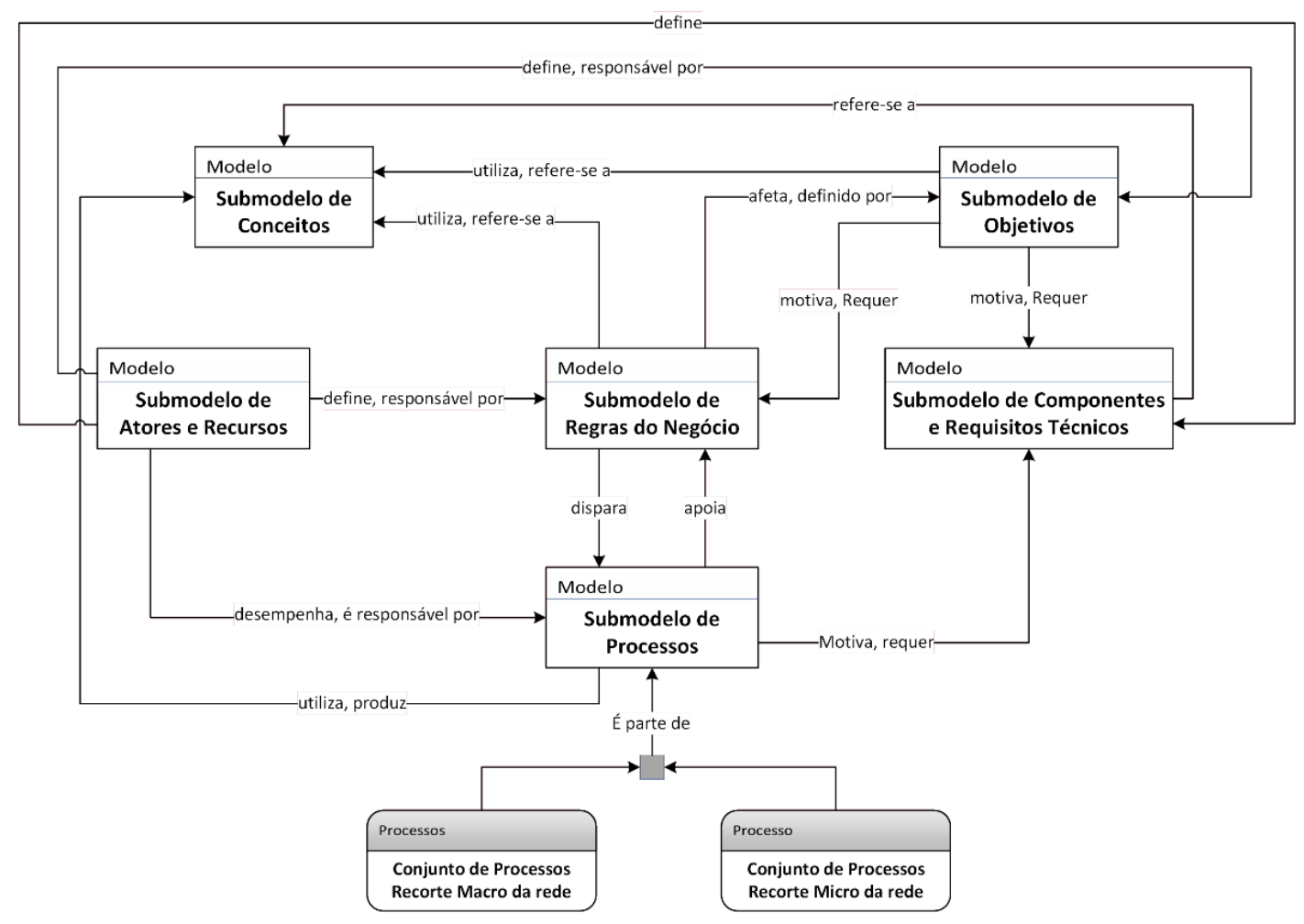

Figura 1: Metodologia 4EM.

Fonte: Adaptado de SANDKUL; STIRNA.; PERSSON; WIBOTZKI. (2014).

O modelo de objetivos descreve os objetivos prioritários da rede e de seus projetos, sua visão estratégica de negócio e os problemas, por vezes ocultos, que interferem no sucesso. É um ponto de partida importante para compreender a forma de gestão, pois define a razão para existência dos componentes dos demais modelos. O modelo de regras de negócios descreve as regras e políticas que guiam o comportamento da empresa no contexto de seus objetivos de negócios. Influencia a forma de gestão, através dos processos necessários para cumpri-las. O modelo de atores e recursos descreve os agentes/pessoas, unidades organizacionais, papéis e recursos que formam a estrutura da unidade de análise. É importante para compreender a forma de gestão, uma vez que expõe os relacionamentos que devem ser considerados. O modelo de processos de negócios, composto por um conjunto subprocessos, descreve os fluxos de material e informação que relacionam-se aos elementos dos demais modelos. É importante para compreender as rotinas que influenciam a gestão. O modelo de requisitos e componentes técnicos descreve e documenta a especificação dos requisitos técnicos levantados com base nos demais modelos, visando facilitar a adequação e/ou o desenvolvimento de um sistema de informação que auxilie na transição do modelo de gestão. É importante para colocar em práticas diretrizes da gestão ágil e abrange os requisitos funcionais (no que tange a utilização do sistema) 
e não funcionais (no que tange as medidas de segurança, usabilidade e acessibilidade, etc.) necessários. Por fim, o modelo de conceitos define os termos e conceitos utilizados nos demais modelos, visando uma base comum de entendimento que facilite a compreensão do todo. Salienta-se que nesse trabalho, esse modelo não foi abrangido na modelagem do estado atual (as-is), pois nessa fase os termos e conceitos utilizados não eram novos para o grupo de trabalho da pesquisa-ação; na modelagem do estado futuro (to-be) esse modelo fez-se necessário e foi desenvolvido.

\subsubsection{Unidade de análise}

A unidade de análise selecionada consiste em uma rede de inovação auto-organizada formada por um Centro de pesquisas, seu cliente governamental e outras empresas e instituições de pesquisa. Nesse arranjo, a empresa focal para a análise atua auxiliando na identificação de oportunidades e coordenando a realização de projetos de alto impacto, tecnológico e econômico, para o segmento de gestão de transportes e pedagiamento do Estado de São Paulo.

Com sede em Campinas - SP e filiais em São Carlos - SP e San Jose - Califórnia EUA, o Centro de pesquisas é uma instituição brasileira que projeta e desenvolve soluções tecnológicas inovadoras nas áreas de automação, informática e de física em geral para empresas de pequeno, médio e grande porte, nacionais e estrangeiras, além de governos estaduais e do governo federal.

As soluções desenvolvidas para a rede são baseadas em pesquisas e transformadas em produtos, tecnologias, processos e serviços; abrange RFID ${ }^{1}$ (Radio Frequency Identification), microeletrônica, software embarcado, hardware, sistemas de informação, entre outros. Devido a complexidade e característica inovadora das soluções, ocorrem diversas relações de parceria - internas e/ou externas - para possibilitar a realização dos projetos, garantir qualidade e cumprimento de requisitos e prazos; as internas consistem em parcerias entre as divisões técnicas e setores da empresa e; as externas compreendem as parcerias com outras instituições de pesquisa, empresas, governos e clientes.

Apesar dessa configuração, muitos envolvidos não tem total clareza sobre os desafios, impactos e benefícios de desenvolver projetos em rede, por exemplo, associados à forma de gestão da rede como um todo e dos projetos colaborativos desenvolvidos na mesma.

Assim, a unidade de análise configura-se em uma oportunidade de destaque para a identificação e sistematização dos requisitos para aplicação da gestão ágil em ambientes de redes de inovação auto-organizadas, bem como para o desenvolvimento de um modelo de

\footnotetext{
${ }^{1}$ RFID é uma tecnologia de identificação por rádio-frequência utilizada em soluções do Centro de pesquisas.
} 
gestão ágil (enterprise modeling) para tais redes e análise dos benefícios e limitações resultantes da sua aplicação.

\subsubsection{Coleta de dados}

As ações para viabilizar a modelagem da unidade de análise iniciaram-se com um seminário de apresentação da proposta de pesquisar gestão ágil em redes de inovação autoorganizadas, concomitantemente com uma entrevista para discussão da mesma, apresentação da metodologia de pesquisa e das possibilidades para os trabalhos de campo. Essa etapa envolveu o gestor da área de sistemas do Centro de pesquisas, juntamente com um engenheiro de sistemas, e possibilitou aos envolvidos obter uma compreensão geral sobre a metodologia selecionada na pesquisa, visando facilitar o entendimento sobre os resultados possíveis, bem como ampliar a participação nos mesmos.

O gerente possui o papel de coordenar projetos que envolvem desenvolvimento de software e hardware, frequentemente relacionados com inovação, que levam a atuação colaborativa junto aos principais níveis da rede, envolvendo aspectos de gestão de pessoas e de atividades. Para tal, mantém ações em todas as divisões do centro de pesquisas, bem como com clientes, fornecedores e outros institutos de pesquisa para realização de suas atividades. O engenheiro também tem ampla visibilidade e atuação na rede, auxiliando nas atividades de coordenação, mas focando-se na qualidade da solução gerada, mantendo interações técnicas, relacionada à entrega de produtos e geração de inovação. Ambos atuam na identificação de novas oportunidades.

Junto a esses perfis, foram utilizados seminários e conversas direcionadas para coletar dados sobre os projetos em desenvolvimento na empresa focal para a naálise, em prol de colaborar com a formalização da escolha da rede para análise e com o início das discussões para modelar seu estado atual. Nesse intuito, as informações de oito projetos foram analisadas para identificar a presença das características que fundamentem a aplicação da pesquisa.

Dois grandes projetos sobressaíram-se - referenciados como projetos A e B - por serem desenvolvidos em ambientes de redes de inovação, apresentarem auto-organização e possuirem complexidade que permita a análise da gestão, sob um recorte em "macro" e "micro". O Quadro 4 (página 40) apresenta uma breve descrição de cada projeto e das redes em que são desenvolvidos. 
Quadro 4 - Descrição dos projetos analisados

\begin{tabular}{|c|l|}
\hline Projeto & \multicolumn{1}{c|}{ Breve escopo } \\
\hline Projeto A & $\begin{array}{l}\text { Subdividido em seis subprojetos, abrangendo todo o Estado de São Paulo, na área de } \\
\text { gestão de transportes e soluções para pedagiamento rodoviário, desde hardware e software } \\
\text { até processos e serviços. O principal cliente é uma agência governamental e existem cerca } \\
\text { de trinta outras empresas envolvidas nesse arranjo. Passou por duas renovações } \\
\text { contratuais e evoluções, geralmente, associadas à busca de inovações para o segmento. } \\
\text { Por essa razão, o projeto é destaque no portfólio da empresa e visto como estratégico para } \\
\text { posicionamento internacional da mesma, em termos de potenciais das soluções geradas, } \\
\text { atraindo novas oportunidades nos mercados nacional e internacional. }\end{array}$ \\
\hline Projeto B & $\begin{array}{l}\text { Focado em soluções de inteligência logística para gerar inovação nas áreas de tributação } \\
\text { e rastreamento de cargas do país. Não possui cliente formal, flui mediante parcerias com } \\
\text { agências governamentais e empresas de transportes que serão afetadas pelos resultados. } \\
\text { Impulsiona a criação de novos projetos com cunho comercial em função das alterações } \\
\text { que causa no segmento. Já foi caso apresentado em feiras de tecnologia e também é } \\
\text { estratégico para posicionamento internacional da empresa. }\end{array}$ \\
\hline
\end{tabular}

Ainda na fase exploratória, para o projeto A, ocorreram reuniões para definição de problemas práticos associado à gestão, bem como para alinhamentos e tomada de decisão sobre o grupo de trabalho que participaria da pesquisa-ação e sobre as próximas atividades e; seminários para delineamento e apresentação dos problema ao grupo formado.

Para o projeto B foram realizadas reuniões iniciais e estudos sobre documentação do projeto, porém por limitações de tempo dos envolvidos, esse projeto e, consequentemente, a rede na qual insere-se, não puderam ser estudados aprofundadamente. Essa ocorrência formalizou a unidade de análise como sendo a rede do projeto A.

O grupo de trabalho composto para a pesquisa-ação, inicialmente, possuia dez representantes com pesquisador e distintos perfis da área de sistemas, entre analistas, engenheiros, apoio técnico e gerência. Posteriormente, analistas técnicos de outra unidade da empresa foram abrangidos. Os demais afetados pelas ações realizadas na pesquisa-ação, foram envolvidos com a evolução das atividades.

$\mathrm{Na}$ fase aprofundada da pesquisa-ação, diversas atividades foram realizadas para propor um plano de ação para solucionar os problemas práticos identificados. Para isso partiu-se da compreensão adequada dos efeitos dos mesmos, por meio de rodadas de entrevistas com atores chave; tais atividades foram apoiadas pelos modelos em desenvolvimento (as-is e need-forchange) e por um seminário, frequentemente atualizado para facilitar a visibilidade de objetivos, ações necessárias e em andamento.

$\mathrm{Na}$ fase de ação, com base no plano de ação criado, foram realizados seminário de apresentação da proposta, modelagem de empresas do estado futuro (to-be), planejamento da 
transição para o modelo de gestão ágil e seminários de treinamento. Também foram realizadas entrevistas e reuniões para alinhamentos, planejamentos e coleta de dados de monitoramento do novo modelo, abrangendo desde seu processo de implantação até a estabilização.

Por fim, a fase de avaliação mesclou-se com a de ação; envolveu os demais parceiros externos ao Centro de pesquisas, influenciados pelas ações realizadas na pesquisa-ação, para valiar o modelo aplicado e coletar dados para adequações. Nessa fase também foram realizados ajustes nos modelo (to-be) em uso, treinamentos e validações.

\subsection{Estrutura da dissertação}

A dissertação é estruturada pelos seguintes capítulos principais:

- Introdução: apresenta o contexto no qual a pesquisa insere-se, abrangendo objetivo, justificativa, método de pesquisa, a unidade de análise e a forma de coleta de dados;

- Revisão bibliográfica sistemática: contém a revisão da literatura sobre a gestão ágil de redes de inovação auto-organizadas, contribuindo para a compreensão da área comum às duas áreas de pesquisa, justificando sua atuação conjunta;

- Modelo atual (as-is) e identificação da necessidade de mudança (need-forchange): abrange as atividades realizadas em campo, nas duas primeiras fases da pesquisa-ação, para identificação de requisitos no ambiente que justifiquem a utilização da abordagem ágil, conforme a literatura, e pontos que requerem melhoria para solucionar problemas práticos relacionados à gestão;

- Modelo futuro (to-be): abrange as ações realizadas, nas duas últimas fases da pesquisa-ação para desenvolvimento do novo modelo de gestão com base na abordagem ágil, sua aplicação, monitoramento e validação, visando a verificação dos benefícios e limitações resultantes do mesmo;

- Considerações: discussão acerca dos dados e análise da modelagem resultante da pesquisa, em prol de verificar o cumprimento dos objetivos da mesma, suas contribuições, limitações e oportunidades futuras;

- Apêndices: contém material extra da pesquisa-ação realizada, visando facilitar o entendimento e a replicação da pesquisa conduzida; entre eles estão detalhamentos de processos, questionários, bem como documentação de alguns conceitos utilizados e exemplos de indicadores gerados nas atividades de campo. 


\section{REVISÃo BIBLIOGRÁFICA SISTEMÁTICA: GESTÃo ÁGIL DE REDES DE INOVAÇÃO AUTO-ORGANIZADAS}

O recorte analítico de gestão de redes de inovação apresenta lacunas relativas a eficiência das abordagens utilizadas. A fim de auxiliar na superação das eventuais lacunas e compreensão da utilização da abordagem de gestão ágil nesses ambientes, é apresentada uma discussão teórica construída a partir do levantamento e análise do estado da arte do tema gestão ágil de redes de inovação auto-organizadas. A análise das áreas comuns apresentada neste capítulo, provenientes de gestão de redes de inovação e gestão ágil, auxilia a compreender em que pontos as áreas podem ser combinadas, justificando sua atuação conjunta sob a expectativa de obter benefícios para os negócios. A originalidade dessa etapa da pesquisa, em relação ao tema, está na proposta de intersecção conceitual de duas áreas distintas da pesquisa acadêmica.

\subsection{Introdução}

A melhoria de desempenho e aumento da capacidade competitiva são os resultados de um cenário em que o conhecimento é compreendido como o elemento gerador de inovação (OCDE, 2005). A inovação é visualizada como a força capaz de causar transformações nas estruturas sociais, institucionais e econômicas (SCHUMPETER 1942; FAGERBERG e SRHOLEC, 2008; FAGERBERG e VERSPAGEN, 2009; FARGENBERG, FOSAAS e SAPPRASERT, 2012) e é caracterizada por novas combinações de conhecimentos e recursos para o desenvolvimento de novos produtos, processos ou serviço (CHESBROUGH e TEECE, 2002; OCDE, 2005).

Atualmente, poucas empresas inovam isoladamente (RYCROFT e KASH, 2004; ZENG, XIE e TAMC 2010). A geração e transferência de conhecimentos, bem como de tecnologias, que fomentem inovações ocorrem mediante o surgimento de elos cooperativos que permitam a interação entre vários atores e fatores (NELSON e WINTER, 1982; OCDE, 2005; FREEL e HARRISON, 2006; ZENG, XIE e TAMC, 2010; LANDRY et al., 2013) para exploração de competências e compartilhamentos com foco em vencer desafios, identificar oportunidades e novos mercados e obter flexibilidade para atuar em ambientes dinâmicos (CHOUDHARY et al., 2013), em especial no desenvolvimento de tecnologias complexas (NOOTEBOOM et al., 2007).

Em resposta a esse cenário, surgem as redes de inovação auto-organizadas (PRAHALAD e HAMEL, 1990; RYCROFT e KASH, 2004) com o intuito de proporcionar a 
transparência e flexibilidade necessárias para que os envolvidos inovem. Devido às características desses ambientes, a gestão adequada é essencial para que os objetivos sejam alcançados de forma coordenada e bem-sucedida, considerando tanto aspectos relativos ao conhecimento em fluxo, aos projetos desenvolvidos, assim como da própria rede, enquanto estrutura de estímulo. Tais aspectos despertam atenção para os desafios relacionados à confiança, comunicação, informalidade, ciclo de vida, distribuição das operações, diferentes intenções, comportamentos e culturas, bem como gestão de riscos, de incertezas e de capacidades (JANSSON et al., 2008; NEGRETTO et al., 2008; OLLUS et al., 2011; CHOUDHARY et al., 2013).

Considerando os desafios existentes, dois elementos são apontados como chave para a gestão da rede e dos projetos colaborativos: a coordenação (NEGRETTO et al., 2008) e o vasto conhecimento da área de gestão de projetos (OLLUS et al., 2011). Nesse cenário, diferentes abordagens, metodologias e ferramentas podem ser aplicadas (CAMARINHA-MATOS e AFSARMANESH, 2008; AFSARMANESH, CAMARINHA-MATOS e MSANJILA, 2009), entre eles a abordagem ágil, por possuir características que propiciam sua utilização em ambientes dinâmicos e turbulentos, visando simplificar o processo de gerenciamento. No entanto, apesar da importância da gestão nos ambientes colaborativos, não são muitas as pesquisas nesse campo (OLLUS et al., 2011), principalmente, abordando a aplicação do ágil em ambientes de redes de inovação auto-organizadas.

Deste modo, este capítulo tem o objetivo de levantar estudos abrangendo a gestão de redes de inovação e projetos colaborativos, em especial a gestão ágil de redes de inovação autoorganizadas, visando compreender as abordagens utilizadas, as características e conceitos relevantes existentes, assim como identificar aspectos do ágil que justifiquem sua aplicação nesses ambientes. De acordo com Amaral et al. (2011) a abordagem ágil é uma forma profícua de gerenciar projetos inovadores, deste modo a contribuição deste trabalho está em compreender sua aplicação no ambiente de redes de inovação e projetos colaborativos, ampliando os conhecimentos na área e fornecendo embasamento para pesquisas relacionadas.

\subsection{Método de revisão}

A identificação das fontes bibliográficas, relacionadas ao objetivo da pesquisa, foi feita mediante consulta as bases de dados Web of Science, Scopus e SciELO e com base nas leituras de referências para identificação de trabalhos relevantes e/ou clássicos. O Quadro 5 (página 45) apresenta um compilado das palavras-chave utilizadas na pesquisa, considerando os filtros de busca por título, no período de 2000 a 2015 e com artigos publicados em inglês ou português. 
Quadro 5- Palavras-chaves utilizadas na pesquisa

\begin{tabular}{|c|c|c|c|}
\hline Bases de Dados & Palavras-chave (título) & Filtros das Bases de Dados & Resultados \\
\hline \multirow[t]{2}{*}{$\begin{array}{l}\text { Web of Science } \\
\text { (Todas as bases de } \\
\text { dados) }\end{array}$} & $\begin{array}{l}\text { "innovation network*”, self- } \\
\text { organiz* innovation network*, } \\
\begin{array}{l}\text { innovation network* } \\
\text { management, collaborative } \\
\text { network* management }\end{array}\end{array}$ & $\begin{array}{l}\text { Artigos nas áreas de pesquisa: } \\
\text { Business Economics, Engineering, } \\
\text { Computer Science, Public } \\
\text { Administration, Social Sciences } \\
\text { other topics }\end{array}$ & 155 artigos \\
\hline & $\begin{array}{l}\text { agile method, agile management, } \\
\text { agile approach, agile project } \\
\text { management, apm }\end{array}$ & $\begin{array}{l}\text { Computer Science, Engineering, } \\
\text { Business Economics }\end{array}$ & 184 artigos \\
\hline \multirow[t]{2}{*}{$\begin{array}{l}\text { Scopus } \\
\text { (Physical } \\
\text { Sciences, Social } \\
\text { Sciences }\end{array}$} & $\begin{array}{l}\text { "innovation network\$", self- } \\
\text { organiz\$ innovation network\$, } \\
\text { innovation network\$ } \\
\text { management, collaborative } \\
\text { network\$ management }\end{array}$ & $\begin{array}{l}\text { Artigos nas área de pesquisa: } \\
\text { Business, Management and } \\
\text { Accounting, Computer Science, } \\
\text { Engineering, Social Sciences, } \\
\text { Multidisciplinary }\end{array}$ & 216 artigos \\
\hline & $\begin{array}{l}\text { agile method, agile management, } \\
\text { agile approach, agile project } \\
\text { management, apm }\end{array}$ & $\begin{array}{l}\text { Business, Management and } \\
\text { Accounting, Computer Science, } \\
\text { Engineering, Social Sciences, } \\
\text { Multidisciplinary }\end{array}$ & 223 artigos \\
\hline \multirow[t]{2}{*}{ SciELO } & 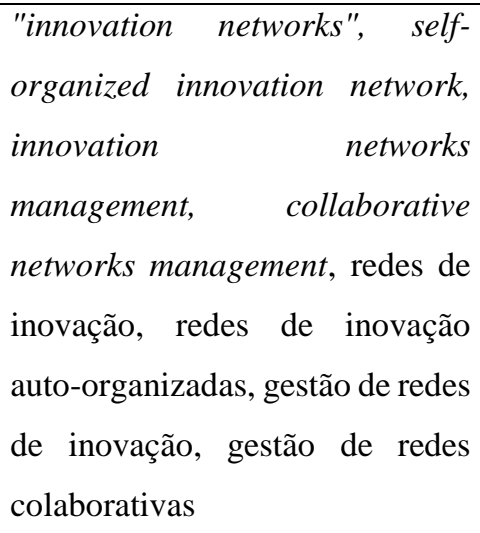 & Não se aplica a esta base de dados & 25 artigos \\
\hline & $\begin{array}{l}\text { agile method, agile management, } \\
\text { agile approach, agile project } \\
\text { management, apm, abordagem } \\
\text { ágil, gestão ágil, método ágil }\end{array}$ & Não se aplica a esta base de dados & 8 artigos \\
\hline
\end{tabular}

Como foram utilizadas três bases de dados, a primeira análise dos títulos foi feita para garantir que não haveria duplicidade de artigos resultantes. Após a eliminação de resultados duplicados, foi realizada a leitura dos títulos dos artigos para filtrar somente os artigos com títulos que indiquem relevância para a pesquisa. Em seguida, os resultados foram filtrados novamente, através da leitura dos resumos dos artigos, também sob o critério de relevância do trabalho para os objetivos da pesquisa. A análise da relevância para o artigo consistiu na 
observação do enfoque do artigo em elementos da gestão de redes, por exemplo, relevância da comunicação, dinâmica de trabalho da equipe, métodos utilizados para gestão, entre outros. $\mathrm{O}$ Quadro 6 (página 46) apresenta um compilado dos resultados.

Quadro 6 - Filtros aplicados

\begin{tabular}{|l|c|c|c|}
\hline \multicolumn{1}{|c|}{ Foco } & Filtro por duplicidade & Filtro por título & Filtro por resumo \\
\hline $\begin{array}{l}\text { Redes de inovação e redes } \\
\text { de inovação auto- } \\
\text { organizadas }\end{array}$ & 279 artigos & 139 artigos & 63 artigos \\
\hline Gestão ágil & & & \\
\hline
\end{tabular}

Como foram considerados somente artigos publicados em periódicos indexados, foram encontrados 41 artigos relacionados a redes de inovação - considerando o foco em gestão da rede e projetos colaborativos - entre eles somente 2 artigos estão diretamente relacionados à redes de inovação auto-organizadas; para o foco em gestão ágil foram encontrados 28 artigos. Deste modo, visando obter a abrangência necessária, a revisão foi complementada com a literatura sobre redes colaborativas e gestão de projetos inovadores.

\subsection{REDES DE INOVAÇÃO}

Atualmente, as empresas são pressionadas para constantemente aumentar sua vantagem competitiva e responder rapidamente às mudanças do mercado. A competittividade e sustentabilidade das organizações residem, principalmente, em sua habilidade de inovar satisfatoriamente (GUBBINS E DOOLEY, 2013), tornando essencial a existência de um processo criativo eficiente (BRENNAN e DOOLEY, 2005) para continuamente estimular novos processos de inovação que mantenham competitividade (DHANARAJ e PARKHE, 2006; LEVÉN, HOLMSTRÖM e MATHIASSEN, 2014). Para Prince, Barret e Oborn (2014), tais processos contínuos traduzem-se sob o termo de inovação estratégica que deve ocorrer nas empresas para ampliar competitividade.

Corroborando com este cenário, Harmaakorpi e Melkas (2005) destacam o aprendizado e geração de conhecimento como as forças motrizes da inovação, gerando vantagem competitiva em ambientes dinâmicos. Segundo Rycroft (2007) a competitividade de alto nível ocorre com o desenvolvimento de inovações tecnológicas complexas e intensivamente focadas em conhecimento, facilitadas mediante o poderoso e importante fenômeno de cooperação. Nesse contexto, diversos estudos compreendem a inovação como o resultado de ações colaborativas (SODA, 2011; DILK et al., 2008; CALIA, GUERRINI e MOURA, 2007; VAN VAN AKEN e WEGGEMAN, 2000; BULLINGER, AUERNHAMMER e GOMERINGER, 
2004; KAUFMANN, LEHNER e TÖDTLING, 2003; FREEL, 2003; CORSARO, CANTÙ e TUNISINI, 2012; RAMPERSAD, QUESTER e TROSHANI, 2010; HARMAAKORPI e MELKAS, 2005; RYCROFT e KASH, 2004; PEKKARINEN e HARMAAKORPI, 2006).

Conforme Gardet e Fraiha, (2012), Steiner, Gil e Ehret (2010), Batterink et al., (2010) e Masiello et al., (2015), muitas empresas, em especial pequenas e médias, recorrem a formação de redes colaborativas de inovação como uma forma de obter recursos e competências necessárias para manterem-se no mercado. As redes de inovação são consideradas redes de conhecimentos, consistindo em uma forma organizacional importante para acessar e compartilhar novos conhecimentos e riscos, facilitar a troca de informações tecnológicas e comerciais, atingir coletivamente eficiência e aprendizado e alcançar novos mercados, corroborando com a criação de um ambiente ideal para inovação, tanta na perspectiva organizacional quanto tecnológica (OCDE, 2005; TIDD e BESSANT, 2009; RAMPERSAD, QUESTER e TROSHANI, 2010; LOSS e CRAVE, 2011; CORSARO, CANTÙ e TUNISINI, 2012).

São várias as definições enfatizando as características das redes de inovação: para Van Aken e Weggeman (2000) são redes organizacionais envolvidas em inovações de produto e/ou processo; para Rycroft e Kash (2004) consistem em ligações entre organizações, em ambientes de desenvolvimento de tecnologias complexas, visando criar, capturar e integrar conhecimentos e capacidades para inovar e responder às necessidades do mercado; para Dhanaraj e Parkhe (2006) são redes de empresas individuais que estão interligadas por meio de um trabalho conjunto em prol de um objetivo, mas mantendo-se separadas; para Pekkarinen e Harmakkorpi (2006) consistem em grupos formados por atores heterogêneos, como representantes de empresas, universidades, indústrias, centros de tecnologia, agências governamentais, centros de pesquisa e muitos outros; para Dilk et al. (2008) são uma forma de organização em que duas ou mais empresas independentes realizam pesquisa conjuntamente, desenvolvendo ou disseminando inovações, caracterizada pela mistura de coordenação hierárquica e de mercado; para Batterink et al. (2010) consistem em relacionamentos cooperativos entre empresas e outros atores na busca por inovação; para Rampersad, Quester e Troshani (2010) são estruturas vivas, ou seja, conjuntos de organizações que estão ativamente interligadas e deste modo, operando conjunta e continuamente, sem necessariamente estarem em estruturas formais; para Gardet e Mothe (2011) consistem em conjuntos verticais e horizontais de relacionamentos estabelecidos entre várias organizações, orquestrados por uma figura central para obter vantagens competitivas; para Gardet e Fraiha, (2012) são um conjunto de relacionamentos entre diversas 
organizações, coordenadas por uma figura central e com o objetivo de desenvolver inovação, guiadas pelo centralizador.

Dilk et al. (2008) e Gardet e Mothe (2011) enfatizam que é possível classificar as redes de inovação, de acordo com os tipos de relacionamentos, em horizontal, vertical e lateral. A primeira consiste na cooperação de diversos parceiros do mesmo nível da cadeia de suprimentos, a segunda na cooperação de diversos parceiros da mesma cadeia de suprimentos e a terceira na cooperação de diversos parceiros que não possuem qualquer ligação econômica direta. Nesse sentido, para Corsaru e Cantù (2015) as redes de inovação incluem todos os envolvidos no processo de criação, comercialização e difusão de novos produtos, processos e serviços.

\subsubsection{Vantagens, características e desafios que influenciam na gestão da rede}

De acordo com Corsaro, Cantù e Tunisi (2012) diversas vantagens são obtidas com as redes de inovação, tanto individualmente quanto para a rede como um todo. Atualmente, as empresas veem as redes de inovação de forma atrativa e compreendem os benefícios individuais e coletivos que elas podem proporcionar (DILK et al., 2008). Entre os benefícios estão a possibilidade de obter acesso a conhecimentos e tecnologias só disponíveis internamente, o contato constante com clientes e mercados, a melhoria na qualidade da $\mathrm{P} \& \mathrm{D}$, a diminuição do lead-time e a recombinação de competências para gerar inovação (KÖNIG et al., 2011).

Tais redes ocorrem especialmente em ambientes de desenvolvimento de tecnologias complexas (DILK et al., 2008; RYCROFT e KASH, 2004). Calia, Guerrini e Moura (2007) apontaram o surgimento e as características de redes de inovação em diversas regiões como Inglaterra, Zimbabwe, França, Taiwan e Japão com destaque para as estruturas de relacionamentos que ocorrem no interior das mesmas e análise do seu comportamento dinâmico e sistêmico, evidenciando sua influência nos modelos de negócios dos envolvidos, por meio de sua alteração. Nesse sentido, Harmaakorpi e Melkas (2005) e Gebauer, Nam e Parsche (2005) destacam o surgimento de sistemas de inovação regionais que consistem de diferentes redes de inovação, atuando para ampliar a capacidade inovadora de todo o sistema.

Em redes formadas por pequenas e médias empresas e institutos de pesquisa, Masiello et al., (2015) apontam um relacionamento entre a evolução do ciclo de vida das redes, mecanismo de governança e objetivos de inovação, sendo a confiança, elemento crucial para o sucesso. Assim, o desafio maior está em criar uma atmosfera de confiança que garanta a fluidez do conhecimento. Do mesmo modo, o elevado nível de incerteza destes ambientes, causada 
pelo conhecimento tácito, baixo nível de previsibilidade dos resultados e comportamentos oportunistas, torna a coordenação adequada essencial (DHANARAJ e PARKHE, 2006).

A escolha do parceiro influencia o sucesso da rede, tornando a formação de parcerias adequadas um desafio (HANSEN e BIRKINSHAW, 2007; TIDD e BESSANT, 2009). Deste modo, uma abordagem para formação de redes consiste em escolher parceiros com competências claras, desde antes da formação das parcerias, de acordo com a maior possibilidade de criação de conhecimento (COWAN, JONARD e ZIMMERMANN, 2007). Corroborando com esse pensamento, Olaru e Purchase (2015) compreendem os conhecimentos e investimentos que fluem na rede, como elementos que influenciam sua performace ao longo do tempo e portanto, devem ser considerados na formação das mesmas, por exemplo, mediante monitoramento adequado, desde os estágios iniciais, acerca de possibilidade de ganhos a longo prazo e não somente, observando perdas e ganhos de curto prazo.

No contex to de geração de conhecimento, Corsaro, Cantù e Tunisi (2012) identificaram os atributos da heterogeneidade dos atores e os processos chave de desenvolvimento da colaboração, por meio da interação, que devem ser considerados. Atributos sendo objetivos, bases de conhecimento, capacidades e competências, percepções, culturas, poder e posição; processos chave sendo integração de conhecimento, evolução de relacionamentos sociais e de negócios, assim como desenvolvimento tecnológico. $\mathrm{O}$ entendimento adequado da heterogeneidade dos atores - levando em conta a variação da sua influencia nos contextos relacionados à geração de inovação -, é importante para alinhamento dos interesses, competências e habilidades de todos os envolvidos, minimizando divergencias negativas e ainda, permitindo a ampliação da produtividade e qualidade de resultados, bem como o incentivo a processos de aprendizado que gerem novos conhecimentos (CORSARU e CANTÙ, 2015). Para Arranz e Arroyabe (2012), compreender a sinergia entre os processos tecnológicos, estrutura e governança das redes, permite realizar uma configuração eficiente de parcerias. A primeira consiste no conjunto de atividades realizadas, o segundo no framework para organizar as parcerias e o terceiro nos contratos formais e mecanismos de relacionamentos, utilizados para coordenar as parcerias.

Contribuindo com esse pensamento, para Boehm e Hogan (2012) o sucesso da rede depende do foco da gestão em todos os agentes envolvidos. A análise da formação, gestão e manutenção da rede reflete-se na análise da motivação para formar os relacionamentos e em quem os iniciou. Esta análise, em um primeiro momento, é associada às competências identificadas e, posteriormente, à confiança (DILK et al., 2008). O desempenho e sucesso da 
rede dependem também da correta definição, alinhamento e monitoramento dos objetivos, das responsabilidades e atividades. Ações comuns nos procedimentos de gerenciamento de projetos (DILK et al., 2008) e altamente influenciadas pelos processos de comunicação e gestão do conhecimento (MASIELLO et al., 2015).

A influência da proximidade dos membros no sucesso da rede, alerta para a necessidade de utilizar ferramentas de comunicação eficientes, visando o alinhamento de atividades e resolução de conflitos (BULLINGER, AUERNHAMMER e GOMERINGER, 2004), especialmente em redes distribuídas geograficamente, possíveis mediante o uso de tecnologias para superar fronteiras temporais e geográficas, assim como para concluir tarefas (MARTINS, GILSON e MAYNARD, 2004). Nesse cenário de ambientes distribuídos, Freel (2003) destaca o relacionamento entre processos e estrutura na formação de capacidades tecnológicas, assim como o papel crítico do histórico do processo de crescimento de uma empresa em sua habilidade de ampliar as atividades inovadoras. Deste modo, é importante definir os principais processos da rede para compreender seu impacto no ambiente e otimizar a exploração das competências (PEKKARINEN e HARMAAKORPI, 2006).

Para Klerkx e Aarts (2013) atuar em redes de inovação não é fácil e são vários os desafios, dilemas e paradoxos, envolvendo relacionamentos, forma de interação e balanceamento de informalidade e formalidade. Entre os desafios, aparecem também a falta de preparo inicial dos atores para atuar neste tipo de ambiente (DILK et al., 2008); ausência de instrumentos adequados para planejar e coordenar (DILK et al., 2008); a compreensão sobre como redes de inovação amplas podem trabalhar juntas para desenvolver novas direções estratégicas, mantendo-se formalmente competitivas entre si, focando em como atores líderes coordenam e influenciam a rede e o funcionamento na ausência de figuras centrais (PRINCE, BARRET e OBORN, 2014); entender como a divisão de atividades e compartilhamento de recursos, tangíveis e intangíveis, relaciona-se com obtenção de capacidades e produtos inovadores (PERKS e MOXEY, 2011) e; compreender o papel que a heterogeneidade assume nos processos de inovação e quais seus resultados, focando nas especificidades de cada ator e no que eles geram ao interagir (DOLOREUX, 2004; CORSARU e CANTÙ, 2015).

Para Jarvenpaa e Välikangas (2014) em casos de redes com atores que colaboram, mas são competitivos entre si, a colaboração pode ser eficiente desde os estágios iniciais da rede, se forem aplicadas práticas adequadas de interação para revelar oportunidades, sem entregar conhecimentos que possam prejudicar a competitividade - indo além de buscar parcerias para solucionar problemas ou desenvolver capacidades, mas fazendo uso da heterogeneidade e 
integração para abstrair conhecimentos e trabalhar alinhamentos que revelar e combinar resultados em prol de objetivos maiores.

\subsubsection{Redes de inovação auto-organizadas}

Sistemas auto-organizados são os que formam estruturas e processos não somente em resposta a estímulos externos, mas principalmente em resposta a lógicas internas. Nesse cenário, considerando a atual importância econômica da tecnologia, é esperado que o desenvolvimento de inovação tecnológica ocorra de modo auto-organizado. Deste modo, como a inovação tecnológica é frequentemente alcançada de modo cooperativo, é esperado o surgimento de auto-organização em ambientes colaborativos, denominados redes de inovação auto-organizadas, que proliferam com o objetivo de aumentar a capacidade competitiva em resposta a um mercado dinâmico e globalizado (RYCROFT e KASH, 2004).

Conforme Hàkansson e Ford (2002) e Rycroft e Kash (2004) as redes de inovação autoorganizadas, são redes com formação voluntária em que os envolvidos escolhem compartilhar práticas e recursos para alcançar vantagens mútuas. Surgem para desenvolvimento de tecnologias complexas, por meio da obtenção de conhecimento de forma constante e interativa (RYCROFT, 2007). A capacidade de aprendizado e auto-organização destas redes é possível devido ao desenvolvimento de confiança mútua e informalidade (RYCROFT e KASH, 2004). Deste modo, caracterizam-se pela informalidade, ausência de figura central, flexibilidade, adaptabilidade e pelo compartilhamento de valores e conhecimento tácito, propiciando um ambiente de criatividade e aprendizagem no qual nenhum membro desenvolve seus objetivos de forma individual e a gestão tem suas bases na confiança mútua (HÀKANSSON e FORD, 2002; RYCROFT e KASH, 2004).

A análise das redes de inovação auto-organizadas, com base no framework de Rycroft e Kash (2004), destaca a continua interação entre o conjunto de recursos da rede e conjunto de restrições e foco que caracterizam a flexibilidade, adaptabilidade e capacidade de gerar conhecimento, existentes nestas organizações. O primeiro conjunto refere-se as competências, ativos internos e aprendizado organizacional, ao passo que o segundo relaciona-se ao que deseja-se aprender e criar.

Para Lowe et al. (2012) a mobilidade humana tem um papel significante na autoorganização das redes de inovação, relacionado à transferência de conhecimento, ao potencial de criatividade e à dinâmica reconfiguração da rede; oferecendo um escopo para que os atores criem novas identidades e combinem conhecimentos, atingindo vantagem competitiva. Nesses ambientes, mesmo integrando a rede e atuando sob suas características, é possível a cada ator 
manter sua identidade, através da criação de redes internas envolvendo acionistas, diretores e funcionários. Além disso, a flexibilidade da rede permite a ocorrência de transições, entre elas a inserção e remoção de atores, nas quais os envolvidos levam não só o conhecimento adquirido, mas a filosofia da rede (LOWE et al., 2012).

Apesar da importância destas redes, existe pouca literatura relativa ao seu gerenciamento, formação e dinamismo, este último sendo a chave para sua evolução, em especial com relação a sua capacidade de aprendizagem (LOWE et al., 2012).

\subsubsection{Gestão de redes de inovação}

O conceito de coordenação está relacionado ao quão bem diferentes partes de um relacionamento atuam juntas no cumprimento de atividades para atingir um objetivo, envolvendo procedimentos, atividades e direitos de propriedade (RAMPERSAD, QUESTER e TROSHANI, 2010; BATTERINK et al., 2010).

No contexto de redes de inovação a gestão deve ser adaptável. Na literatura relacionase com governança e/ou orquestração, envolvendo articulação da demanda, composição da rede e a gestão do processo de inovação (RYCROFT e KASH, 2004). Segundo Arranz e Arroyabe (2012) a sinergia entre processos tecnológicos, estrutura e governança de uma rede de inovação provê direções estratégicas para sua gestão, relacionadas a escolha de parceiros, mediante suas atitudes e especificidades, assim como planejamento de atividades, organização estrutural e alocação de resultados.

A coordenação adequada reduz incerteza e comportamentos oportunistas na rede, conduzindo a troca de informações e transferência de conhecimento; devendo ser realizada almejando flexibilidade para alterações, relacionadas ou não ao ciclo de vida da rede (GARDET e FRAIHA, 2012). Nesse sentido, aparecem a gestão da comunicação (formal, semi-formal ou informal), a confiança, a divisão de benefícios e as garantias de cooperação e resolução de conflitos que impactam diretamente no desenvolvimento de projetos na rede; além da necessidade de gerenciar tanto a inovação quanto sua comercialização, influenciando o desenvolvimento de capacidades, por forçar a divisão de atividades e compartilhamento de recursos adequadamente (Perks e Moxey, 2011).

Para Van Aken e Weggeman (2000) poucos esforços em gestão resultam em pouca exploração do potencial e baixa produtividade, ao passo que esforços excessivos destroem a natureza informal, prejudicando o potencial da rede. Assim, idealmente, a gestão é uma combinação entre governança e gestão operacional, analisadas também separadamente. Para Soda (2011) a gestão em ambientes colaborativos deve envolver um framework para criar 
estratégias de definição de portfólio e posicionamento na rede, aspecto estrutural importante no desempenho da rede, mas geralmente esquecido. Para Harrisson et al. (2001) o conceito de gestão de qualidade total, construído em acordo com o conceito de visão única e gestão de relacionamentos evitando conflitos, também pode ser aplicado na gestão de redes de inovação, uma vez que a própria gestão envolve cooperação entre empregados e gestores, em uma rede interna e/ou externa.

Para Muzzi e Albertini (2014) uma forma de visualizar a gestão das redes de inovação é utilizando o conceito de comunidade de inovação - redes em que o indivíduos tem pensamentos claramente similares -, nas quais o cruzamento das competências dos envolvidos com as tarefas necessárias na rede, indicam os papéis a serem assumidos por cada um, facilitando a verificação da possibilidade de um mesmo indivíduo realizar diferentes papéis; a questão da liderança também é apontada pelos autores como vinculada a uma competência, apresentada como orientação para negócios ou atitutide empreendedora.

\subsubsection{Influência do papel do coordenador na gestão da rede}

A presença de um ou mais elos fortes na rede também afeta e é afetada pela abordagem de gestão da rede. Elos podem ser compreendidos como champions, hubs, figuras centrais ou orquestradores e possuem destaque na rede de inovação, tornando-se os únicos a ter sua legitimidade reconhecida e não recair em autoridade hierárquica. Tais atores informalmente tomam decisões que promovam o crescimento da rede, agindo como coordenadores e articuladores (brokers) e assumindo um ou mais papéis, dependendo da necessidade (KLERKX e AARTS, 2013; PRINCE, BARRETT e OBORN 2014).

De modo geral, atuam para identificar as necessidades de inovação, articular as demandas por conhecimento, configurar parcerias e gerenciar os processos de cooperação, entre eles, a gestão da mobilidade de recursos, da criação de valor e apropriação, bem como da estabilidade e desenvolvimento da rede. Salienta-se que em redes nas quais os atores colaboram, mas mantendo-se competitivos entre si, cabe ao coordenador o desafio de utilizar práticas integradoras que permitam revelar oportunidades, balanceando a colaboração e o cuidado de não dispor informações que permitam apropriações indevidas (JARVENPAA e VÄLIKANGAS, 2014).

Assim, coordenadores envolvem-se com a iniciação da inovação, mediante a incorporação de necessidades; com a composição da rede, atuando com atores complementares, definindo mecanismos de coordenação e; com a gestão do processo de inovação, resolvendo conflitos, aumentando a transparência, facilitando interações. Deste modo, podem atuar de 
modo sistêmico, por meio de intermediários; influenciando a performance da rede, afetando-a de forma analítica e gerencial (DHANARAJ e PARKHE, 2006; KLERKX e AARTS, 2013; BATTERINK et al., 2010). Nesse sentido, para Olaru e Purchase (2015) apesar da pouca influência dos gestores, se analisados individualmente, acerca da quantidade de recursos disponíveis - relacionados à capacidade do ambiente de gerar inovação -, os mesmos podem influenciar outros atores para que ocorram melhorias nesse sentido; bem como, em casos de formação de parceria, influenciar o processo ao direcionar sua empresa para oportunidades em que exista maior quantidade de recursos úteis disponíveis.

\subsubsection{Influência da comunicação, da confiança e da gestão do conhecimento na gestão da rede}

A comunicação adequada, conjuntamente com a confiança, são essenciais para aquisição de inovação estratégica ao possibilitar e facilitar a formação da rede, a atuação de atores diversificados, a compreensão do papel de cada envolvido, assim como dos objetivos e ciclo de vida definidos. Deste modo, também incidem em diretrizes de gestão relativas a sua atuação (HARRIS, COLES e DICKSON, 2000; PRINCE, BARRETT e OBORN, 2014). Para CORSARU e CANTÙ (2015) as práticas de comunicação adotadas na rede são fortemente relacionadas à gestão adequada da heterogeneidade de atores citada previamente, sendo necessário desenvolver treinamentos em prol de comunicação e definir práticas que não padronizem excessiva e negativamente tal ação. A confiança, por sua vez, é um fator elementar para formação e efetividade das redes, influenciando os processos de implementação e difusão da inovação, por isso requer mecanismos - por exemplo, combinanado ações quantitativas e qualitativas - para analisar sua estruturação e compreensão (KOLLECK e BORMANN, 2014).

A criação e gestão do conhecimento, garantem a visualização, socialização, externalização, combinação, internalização e potencialização do conhecimento, seja ele tácito, explicito ou auto-transcendente ${ }^{2}$, portanto também incidem em diretrizes de gestão. Corroborando com esse pensamento, Gubbins e Dooley (2013) abordam o cruzamento entre as fases do processo de geração de inovação e a gestão do conhecimento, no qual a confiança e comunicação desempenham papéis importantes. Nesse cruzamento a fase de descoberta da inovação está associada a busca de conhecimento, captura e articulação, em prol de verificar oportunidades para inovar; a fase de realização/implementação da inovação relaciona-se com a contextualização do conhecimento necessário para implementá-la, bem como aplicação de tal conhecimento e; a fase de nutrição/fortalecimento da inovação, por sua vez, relaciona-se com

\footnotetext{
${ }^{2}$ Habilidade de sentir potencial inovador.
} 
o apoio vindo de conhecimentos diversos, inclusive de possíveis clientes, bem como replicação dos mesmos, visando facilitar a inclusão das descobertas no mercado, saindo do conceitual e tornando-a realidade. Deste modo, a criação de um sistema de gestão de conhecimento deve ser contemplada na abordagem de gestão (BRENNAN e DOOLEY, 2005; HARMAAKORPI e MELKAS, 2005).

\subsubsection{Influência das ferramentas na gestão da rede}

$\mathrm{O}$ uso de ferramentas, processos e infraestrutura adequados, facilitam o acesso à informações que auxiliem na tomada de decisões. Nesse contexto, Bullinger, Auernhammer e Gomeringer (2004) destacam a importância do surgimento da Internet e das ferramentas de comunicação atuais na dramática mudança nos relacionamentos de negócios e revolução das condições de vida e ambientes de trabalho.

Nesse contexto, Kaufmann, Lehner e Tödtling (2003), Michaelides, Morton e Liu (2013) e Loss e Crave (2011) abordam a aplicação das tecnologias de informação e da Internet nas redes de inovação, aumentando sua eficiência ao influenciar diretamente na comunicação, auxiliando no fluxo de conhecimento e apoiando modelos de negócios ágeis - novos modelos de negócios para suprir as necessidades de ambientes colaborativos - que visam facilitar a comunicação e troca de informações entre parceiros e clientes em redes colaborativas.

\subsubsection{Cenário atual da gestão de redes de inovação}

Considerando as características do ambiente e as diferentes influências relevantes para a coordenação, a gestão de redes de inovação e seus projetos é uma tarefa complexa e associada a um grande esforço de coordenação, envolvendo aspectos de transparência, comunicação, minimização de conflitos, alinhamento de objetivos, definição de tarefas, entre outros (BULLINGER, AUERNHAMMER e GOMERINGER, 2004).

Entre os modelos, métodos e ferramentas de gestão propostos para o ambiente de redes de inovação estão um framework abrangendo como diferentes tipos de esforços gerenciais podem resultar em inovações, focando na atuação de um ator como coordenador da rede, facilitando as interações e envolvendo aspectos da formação e orquestração da rede (DHANARAJ e PARKHE, 2006); um framework para gestão da rede e das pesquisas que nela desenrolam-se, considerando a fase de orquestração e mediante o uso de construções chave e proposições (LEVÉN, HOLMSTRÖM e MATHIASSEN, 2014); um framework para identificar as principais regras que influenciam a atuação em redes de inovação e a gestão da rede (SMART, BESSANT e GUPTA, 2007). 
Conforme Levén, Holmström e Mathiassen (2014), os aspectos de formação da rede relacionam-se a membros, estrutura e posição; membros envolvendo quantidade e diversidade, estrutura envolvendo densidade e autonomia da rede e posição envolvendo centralidade e status. Também conforme Levén, Holmström e Mathiassen (2014), os aspectos de orquestração relacionam-se a gestão do conhecimento, gestão da inovação e gestão da rede, sendo a primeira associada com mobilidade, a segunda com apropriabilidade e a terceira com estabilidade. As regras do framework abordado por Smart, Bessant e Gupta (2007) envolvem ciclo de vida, gestão proativa, necessidade, diversidade, envolvimento, difusão e criação de um portfólio de inovações estratégicas na rede.

Nesse contexto, existe pouca discussão relacionada a como desenhar e gerenciar operações no recorte macro da rede de inovação, em especial, as que envolvem pesquisas (DHANARAJ e PARKHE, 2006; SMART, BESSANT e GUPTA, 2007; MOLLER e SVAHN, 2009; LEVÉN, HOLMSTRÖM e MATHIASSEN, 2014), sendo que a maioria existente foca na gestão da inovação em uma única empresa e não visualizam a gestão de modo macro, ou seja, na rede como um todo (RAMPERSAD, QUESTER, TROSHANI, 2010; LEVÉN, HOLMSTRÖM e MATHIASSEN, 2014). Para Rampersad, Quester e Troshani (2010) são necessárias novas formas de melhorar as abordagens de gestão das redes de inovação, sob a perspectiva dos diferentes atores envolvidos; objetivando atender os fatores chave identificados por Rampersad, Quester e Troshani (2010) como distribuição balanceada de poder, coordenação apropriada, incentivo à práticas harmoniosas, formação de um ambiente que fortaleça a confiança, a eficiência na comunicação e na $\mathrm{P} \& \mathrm{D}$ que influenciam-se mutuamente e à rede como um todo.

\subsection{GESTÃO ÁGIL}

Os gerentes de projetos estão lidando cada vez mais com a demanda por projetos de produtos inovadores (CONFORTO e AMARAL, 2010) que resultem em vantagem competitiva para a empresa (FEKRI e ALIAHMADI, 2008). Entre os desafios desses projetos estão o alto nível de incerteza, a necessidade de cooperação em equipes multidisciplinares, a realização do projeto em ambientes de redes de inovação, o envolvimento de clientes e usuários e a complexidade do problema a ser solucionado (AMARAL et al., 2011). Nicholls et al. (2015) resumem tais desafios como sendo a ocorrência de definição precária de escopo; esforços de tempo desconhecidos e, por vezes imposssíveis de definir; volume de tarefas desconhecido, assim como suas depêndencias e por fim; disponibilidade de recursos desconhecida. 
Nesse contexto, a gestão é uma das tarefas mais críticas e desafiadoras (AUGUSTINE e PAYNE, 2005; FEKRI e ALIAHMADI, 2008; CONFORTO et al., 2014), uma vez que o uso de métodos tradicionais não entrega a flexibilidade e adaptabilidade necessárias para obter

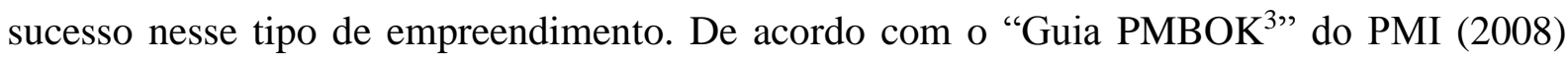
existem vários métodos e técnicas de gestão de projetos, específicos para cada processo de gerenciamento. Nos projetos inovadores tem ocorrido desde a aplicação de métodos e técnicas de gestão como lean, gestão total da qualidade e ágil, até articulações para mudança organizacional como participação em alianças estratégicas (FEKRI e ALIAHMADI, 2008).

Dessa forma, em ambientes dinâmicos o conceito de agilidade surge como uma forma de obter a flexibilidade e velocidade necessárias para responder às mudanças desses ambientes, mediante a combinação de tecnologias, métodos e técnicas associados as capacidades de exploração, adaptação e responsividade (TOLFO et al., 2011; FEKRI e ALIAHMADI, 2008; HOOPER, STEEPLE e WINTERS, 2001). De acordo com H. T. Goranson (1999) ${ }^{4}$, a agilidade consiste em um conceito rico e oportuno que não precisa ser traduzido unicamente e, entre as definições pertinentes, é compreendido como a adaptabilidade. Em outras palavras, agilidade é a capacidade de mudar para entregar resultados com menor custo, de melhor qualidade e mais rapidamente, isto é, de ser mais rentável, em ambientes dinâmicos e mutáveis (H. T. GORANSON, 1999).

Para Loss e Crave (2011) a agilidade é consequência do rápido alinhamento de organizações altamente qualificadas que tornam-se capazes de mitigar suas fraquezas e ampliar suas capacidades, visando participar de oportunidades colaborativas. Segundo Conforto, Rebentish e Amaral (2014), a agilidade é uma competência da equipe - associada a habilidades, cultura, capacidades, experiência e diversidade -, desenvolvida para torná-la capaz de atuar nos ambientes dinâmicos de projetos inovadores.

Nesse cenário, surgem as metodologias ágeis para gestão de projetos - como o Extreme Programming (XP), Scrum, Lean Development, entre outros -, visando apoiar a adaptação das práticas consolidadas na realização dos mesmos, assim como corroborar com a superação do desafio de criar novas ferramentas e métodos para especificidades dos ambientes (CONFORTO e AMARAL, 2010), focando na resolução de problemas vindos da incerteza, sendo mais adaptativas que preditivas (MISHRA e MISHRA, 2011; NOOR, RABISER e GRÜNBACHER, 2008).

\footnotetext{
${ }^{3}$ Prática de gestão de projetos propostas pelo PMI (Project Management Institute).

${ }^{4}$ Destaca-se que a referência de agilidade proposta por H. T. Goranson (1999) não está entre os resultados das pesquisas nas bases de dados, mas considerando a sua relevância para a literatura de agilidade foi inserida.
} 
De acordo com Highsmith, (2004) e Augustine e Payne (2005), o uso da gestão ágil entrega um processo de aprendizado constante ao excluir o planejamento rígido, mantendo processos realmente necessários e controle do ciclo de vida do projeto, resultando no desenvolvimento da auto-organização e autogestão. Nicholls et al. (2015) salientam que adotála não elimina totalmente a preocupação com as restrições de escopo, prazo e recursos/orçamentos, no entanto, nos ambientes aos quais se aplica, o enfoque em monitoramento frequente e reflexão sobre priorizações e entrega de valor, tornam-se mais eficientes que a tentativa de detalhar planejamento.

Deste modo, a gestão ágil consiste em um conjunto de valores, princípios e práticas, guiados por simplicidade e flexibilidade, que auxiliam os envolvidos no projeto a controlar as incertezas, lidar com as mudanças constantes e os desafios de ambientes dinâmicos como os de desenvolvimento de soluções inovadoras (HIGHSMITH, 2004; CONFORTO et al., 2014). Corroborando com esse pensamento, Amaral et al. (2011) definem a gestão ágil como uma abordagem baseada em um conjunto de princípios, focados no desenvolvimento das pessoas, da autogestão, do trabalho colaborativo e da diminuição de disfunções burocráticas para aumentar performance, minimizar esforço e ampliar os níveis de inovação e valor agregado ao usuário final.

\subsubsection{Características da gestão ágil}

Os fundamentos do ágil ${ }^{5}$, assim como os valores e princípios por trás deles, tornam evidentes as aspirações da agilidade (LAANTI, SALO e ABRAHAMSSON, 2011; BECK et al, 2001). O Manifesto Ágil (Beck et al., 2001) evidencia como valores mais importantes da abordagem: o valor das pessoas sobre processos e ferramentas; a prioridade da colaboração e comunicação sobre burocracias; a importância de desenvolver responsividade e; a importância de focar em um produto que atenda aos requisitos com excelência. Dentre os princípios da abordagem ágil, o Manifesto Ágil (Beck et al., 2001) destaca: o aumento do retorno de um investimento; o uso de entregas parciais de valor agregado; melhor resposta às mudanças; a intensa colaboração e comunicação entre equipe, parceiros e cliente; o aumento da motivação e auto-organização da equipe; o ambiente de trabalho sustentável e estável; o crescimento constante de produtividade e; o aumento da qualidade do produto final.

Em termos de utilização, a aplicação da gestão ágil é associada ao uso de práticas e a existência de possibilitadores (CONFORTO et al., 2014). Entre as práticas que diferenciam o

\footnotetext{
${ }^{5}$ Visando facilitar a leitura, ao longo desse texto o termo ágil também é utilizado como uma simplificação para abordagem ágil.
} 
ágil dos métodos tradicionais estão: uso do conceito de visão do produto; uso de ferramentas simples e visuais; uso de ciclos iterativos de desenvolvimento, com participação contínua do usuário e entregas parciais com valor agregado; envolvimento da equipe no planejamento e monitoramento do projeto; uso de equipes auto-gerenciáveis e auto-direcionáveis; aplicação frequente de monitoramento e atualizações no planejamento (CONFORTO et al., 2014; CHOW e CAO, 2008).

O conceito de visão consiste na utilização de meios para motivar a equipe, guiar planejamentos, facilitar a compreensão dos objetivos e auxiliar na visualização dos limites e condições existentes, tanto com relação ao projeto, quanto ao produto resultane dele (HIGHSMITH, 2004). Entre os meios para aplicar o conceito estão a "caixa para visão" 6 , descrição da estrutura do produto, cartão com características e desempenho, folha de dados do projeto, modelos de representação digital, modelos físicos, entre outros (AMARAL et al., 2011). Por sua vez, Pope-Ruark (2015) reforça que o conceito de ciclos iterativos está associado ao período de tempo definido para a equipe realizar um conjunto de atividades, em prol de entregar resultados vinculados aos objetivos do projeto; destaca também que o planejamento é realizado de forma que as atividades sejam "quebradas” em partes menores - passíveis de realização pela equipe no tempo requerido -, organizadas com uso de ferramentas visuais e de acordo com a visão da funcionalidade desejada; salienta que o planejamento e monitoramentos colaborativos são realizados, por exemplo, mediante diversos tipos de reuniões dinâmicas para identificação de prioridades, dificuldades, alinhamentos de objetivos, definição de tarefas, bem como revisão de artefatos entregues e reflexão sobre o andamento geral, ações necessárias para manter a motivação, a visão e cumprir os objetivos.

Com relação aos possibilitadores - pré-condições e fatores para uso do ágil - destacamse: tipo de estrutura organizacional; presença de equipes multidisciplinares; nível de aceitação de um novo processo de desenvolvimento; envolvimento do cliente/stakeholders, dos parceiros e fornecedores no processo de desenvolvimento; experiência da equipe do projeto e do gerente; tamanho (quantidade de pessoas) e dedicação total (tempo) da equipe do projeto e; localização da equipe. Outros possibilitadores com menor destaque também influenciam a escolha, como a aceitação da metodologia, capacidade de reconfiguração dos processos, acesso fácil à informação, clareza de objetivos, complexidade do projeto, grau de inovação do projeto e necessidade de atuação colaborativa (CONFORTO et al., 2014; CHOW e CAO, 2008).

\footnotetext{
${ }^{6}$ Uso de caixa física com informações descritivas do produto final.
} 


\subsubsection{Transição e conflitos associados à gestão ágil}

Atualmente, devido aos benefícios observados pelo uso da metodologia ágil, uma vasta quantidade de empresas diz-se ágeis ou manifestam interesse em adotar essa metodologia para gestão dos seus projetos. No entanto, adotar tal metodologia não é tarefa fácil (QUMER e HENDERSON-SELLERS, 2008; MISHRA e MISHRA, 2011), em especial em ambientes onde existe longa experiência com metodologias tradicionais, como grandes empresas, onde existem desafios críticos associados ao uso de gestão ágil, ligados aos processos de desenvolvimento e negócios, assim como de pessoas (BOEHM E TURNER, 2005).

No entanto, existem formas de minimizar os conflitos, balanceando controle e flexibilidade: preparação para transição, escolha adequada de processos, desenvolvimento de arquitetura que apoie a combinação de práticas do tradicional com o ágil, realinhamento de milestones, correta avaliação de riscos, renovações nas ações de recursos humanos, gestão de atitudes, questões logísticas de alocamento, realização de pilotos com a equipe e mudanças na gerência (BOEHM E TURNER, 2005; MISHRA e MISHRA, 2011). Desta forma, inclusive em ambientes difíceis, é perceptível para os envolvidos o aumento da colaboração, visibilidade e transparência no planejamento e gestão dos projetos (LAANTI, SALO e ABRAHAMSSON, 2011).

A preparação para transição na adoção do ágil é essencial para o sucesso do projeto (REIFER, 2002). Para realizá-la satisfatoriamente é preciso estimular o comportamento de auto-organização por meio do alinhamento entre agilidade, processos, pessoas, produto, ferramentas e seus relacionamentos com governança, monitoramento de recursos, riscos e gestão, assim como performance, políticas, procedimentos e estruturas organizacionais (QUMER e HENDERSON-SELLERS, 2008; MISHRA e MISHRA, 2011).

Augustine e Payne (2005) apontam que frente aos desafios, geralmente, os gerentes retornam as abordagens tradicionais. Essa realidade pode ser evitada com a composição de equipes pequenas, uso de visão como diretriz, uso de regras simples, fornecimento de informações adequadas, realização de uma gestão leve em termos de controle e incentivo a liderança adaptativa e colaborativa. Nesse contexto, Javdani Gandomani e Ziaei Nafchi (2015) propõem um framework apoiado no PDCA $^{7}$ para auxiliar no processo de transição, abrangendo duas categorias importantes: ações estruturais, envolvendo a definição dos novos valores, uso de iterações para transição, de modo contínuo e gradual e; atividades chave, envolvendo a

\footnotetext{
${ }^{7}$ PDCA é uma sigla para plan, do, check e act, representando as fases realizadas na aplicação dessa metodologia destinada à busca de melhoria contínua.
} 
seleção de práticas a serem aplicadas, adaptação da equipe e ambiente, disponibilização de apoio à transição e; realização de ajustes.

A questão do alinhamento entre projeto, cultura organizacional, equipe, clientes e estratégias, assim como o entendimento da melhor estratégia ágil a ser adotada em cada projeto é mandatório para obter resultados satisfatórios. Deste modo, por priorizar os impactos da comunicação, coordenação e controle na gestão e utilizar somente processos, ferramentas, procedimentos e documentação necessários - apesar dos questionamentos acerca da carência de documentação nos projetos - a metodologia ágil pode ser adaptável a diversos ambientes (FERNANDEZ e FERNANDEZ, 2008; MELO et al., 2013).

Com relação à carência de documentação na abordagem ágil, Amritesh e Misra (2014) abordam que isso pode tornar-se um problema para a gestão do conhecimento na rede, se não forem realizadas ações em prol de adequar e otimizar a forma com que o conhecimento é mantido. Entre as ações para contornar esse desafio, estão a manutenção de um ambiente no qual ocorra sustentabilidade da equipe, visando apoiar o processo de aprendizado em paralelo com as atividades diárias do projeto e; a combinação com abordagem tradicional, visando utilizar uma estrutura estratégica para gestão do conhecimento, bem como compartilhamento e transferência do mesmo (AMRITESH e MISRA, 2014).

\subsubsection{Adaptabilidade da gestão ágil}

Noor, Rabiser e Grünbacher (2008) ressaltam que a adaptabilidade também é um fator importante para a transição e aplicação satisfatória da gestão ágil. O uso em projetos para planejamento de linhas de produção indicou que nesses ambientes nem todos os valores e princípios do Manifesto Ágil (Beck et al., 2001) são relevantes, levando a identificação de três pontos críticos para adaptações: familiaridade da equipe sobre o contexto do projeto, preparação de todos os envolvidos e vontade de colaborar com a equipe. Corroborando com esse pensamento, Conforto e Amaral (2010), Mishra e Mishra, (2011) e Conforto et al. (2014) afirmam que adaptações podem ser realizadas mediante combinação de práticas e técnicas, assim como o casamento das abordagens tradicional e ágil, que podem ser úteis no controle do ciclo de vida de projetos inovadores.

Nesse sentido, pesquisas destacam os aspectos positivos de utilizar a gestão ágil em uma abordagem híbrida - combinada a metodologias tradicionais, de acordo com as necessidades de diferentes projetos e contextos -, tendo em vista que futuamente essa habilidade será uma competência chave para lidar com projetos inovadores (CONFORTO, REBENTISH e AMARAL, 2014). Pope-Ruark (2015) expõe que essa combinação de estratégias tem sido 
abordada inclusive em cursos acadêmicos para preparação de profisionais, em prol de melhor prepará-los para responsabilidades que terão em qualquer ambiente de atuação..

Deste modo, apesar de amplamente aplicada em projetos de software, a gestão ágil pode e tem sido aplicada em outros tipos de projetos de inovação em diferentes setores (CONFORTO, REBENTISH e AMARAL, 2014; CONFORTO et al., 2014). Nesse contexto, segundo Pope-Ruark (2015), apesar dos desafios enfrentados para transição, o foco em processos adequados, auto-organização e colaboração têm aumentado a importância dessa essa abordagem também nos setores industriais, influenciando os programas acadêmicos que treinam profissionais para os mesmos. Apesar disso, existem restrições relacionadas aos possibilitadores, como dedicação total da equipe, alocações de equipe multidisciplinares e envolvimento de clientes e parceiros e também, restrições do ambiente, como complexidade do projeto e ciclo de vida extenso (CONFORTO et al., 2014).

\subsubsection{Cotidiano prático e tomada de decisão na gestão ágil}

No cotidiano prático, a metodologia ágil exige amplo esforço de planejamento com foco no processo, almejando balancear controle e flexibilidade (PROCTER et al., 2011), e não na quantidade de documentação resultante (BOEHM; 2002). Além disso, na prática a característica que traz unicidade ao ágil reside na filosofia de tomada de decisão colaborativa da equipe, ou seja, a mudança no papel do gestor de não mais decidir sozinho, mas conjuntamente e informalmente com todos os envolvidos no empreendimento, influenciando sobremaneira o ambiente de trabalho, em termos de motivação, performance e responsabilidades. Esta nova realidade, exige alto nível de confiança e coesão na equipe para coibir conflitos (MCAVOY e BUTLER, 2009; FERNANDEZ e FERNANDEZ, 2008).

Nesse contexto, a eficiência do uso do ágil na gestão de projetos inovadores depende de como as pessoas interagem, devido a sua dependência das relações humanas. Assim, o maior desafio ao adotar essa metodologia é obter um ambiente no qual a cultura organizacional com base em seus ativos, valores e pressupostos básicos - representando a mentalidade de gerentes e trabalhadores - permita seu uso de forma positiva (TOLFO et al., 2011). Entre as implicações gerenciais do uso dessa abordagem estão: o entendimento da agilidade como competência e não método; da flexibilidade e simplicidade como elementos chave para agilidade; a necessidade de estimular a autogestão e auto-rganização nas equipes; de adaptar a abordagem para a necessidade do interessado (CONFORTO, REBENTISH e AMARAL, 2014) e; compreender como a gestão do portfólio dos projetos é influenciada pela utilização dessa abordagem e quais as melhores práticas para sua realização (Stettina e Hörz, 2014). 
A questão da performance da equipe também relaciona-se à tomada de decisão na gestão ágil. Drury-Grogan (2014) aborda essa preocupação ao relacionar objetivos que fundamentam uma iteração - em termos de funcionalidade, cronograma, qualidade e satisfação do time -, bem como as decisões críticas que devem ser tomadas na equipe - em termos de qualidade, divisão de trabalho, ajustes da iteração e satisfação do time - com aspectos chave na gestão de projetos - escopo, tempo e recursos -, chamando a atenção para a validade de realizar tal alinhamento e tratá-lo como objetivo em ações de planejamento de iteração, em prol de não deixar de lado esses importantes elementos da gestão de projetos que auxiliam no monitoramento da performance da equipe, assim como na entrega de resultados que satisfaçam todos os envolvidos.

\subsubsection{Equipe ágil}

Segundo Reifer (2002) para entender se as metodologias ágeis realmente entregam os benefícios pregados é importante verificar a satisfação dos envolvidos em projetos que utilizam suas práticas. Nesse contexto, Moe, Dingsøyr e Dybå (2010) destacam que entre os desafios enfrentados pelas equipes ágeis está o impacto da mudança de estilo de trabalho e gestão. Assim, a comunicação, orientação da equipe, liderança, monitoramento, feedback, backup e coordenação são os componentes necessários para o trabalho conjunto. Corroborando com esse pensamento, Melo et al. (2013) ressaltam a gestão da equipe como o fator que mais influencia na produtividade, em termos de necessidade de horas-extras, escolhas durante a composição da equipe e autogestão. Para Conforto, Rebentish e Amaral (2014) a experiência prévia também é relevante, em termos de desafios, riscos e ambientes já vivenciados que podem auxiliar em novos projetos inovadores; similarmente, a atitude da equipe no que tange a habilidade de tomar decisões e aceitar mudanças frequentes, fundamendada em um processo iterativo de aprendizado para resolução de problemas, não somente em processos para execução de passos, também é essencial para a equipe ágil.

Deste modo, almejando compreender a visão da equipe sobre a gestão ágil, DruryGrogan (2014) identificou que os ciclos iterativos e forma de tomada de decisões das equipes ágeis tem impacto direto no sucesso da gestão do projeto, abrangendo aspectos de cronograma, orçamento e qualidade. Nesse contexto, as equipe relacionam a utilização de ciclos iterativos à verificação de funcionalidade (atividades completadas ou não), cronograma, qualidade e nível de satisfação da equipe; enquanto a tomada de decisão é relacionada à qualidade, divisão de trabalho, ajustes na iteração e nível de satisfação da equipe. Assim, o cuidado com os ciclos iterativos e a tomada de decisão relacionam-se diretamente com a gestão. 
Para Hope e Amdahl (2011) o desafio de realizar uma colaboração satisfatória com o cliente final para especificação e desenvolvimento dos projetos, também é um ponto relevante para a eqiupe. Para minimizar problemas é essencial a gestão adequada do relacionamento, almejando garantir comunicação e alinhamento entre as partes. Além disso, é desejável que o envolvido seja qualificado o suficiente para colaborar ativamente com os objetivos do projeto sem comprometer o planejamento.

Outro aspecto prático importante relacionado à equipe, diz respeito ao desenvolvimento da agilidade como uma competência do time, por meio da aplicação de práticas, ferramentas e técnicas adequadas, combinadas à compreensão de fatores críticos inerentes à estrutura organizacional, tipo do projeto, característica do time, entre outros; o reconhecimento desses fatores é essencial para a combinação adequada e maximização da agilidade como competência (CONFORTO, REBENTISH e AMARAL, 2014). Corroborando com esse pensamento, Nicholls et al. (2015) destacam que a aplicação do ágil é mais eficiente se o mesmo, tornar-se um "estado de espírito", isto é, uma forma de pensar que faz com que a equipe constantemente busque por oportunidades de ganho de valor, mediante alterações eficientes no escopo do projeto, influenciadas por mudanças no ambiente.

\subsubsection{Cenário atual de aplicação da gestão ágil}

Atualmente, muitos projetos são realizados com equipes globais, geograficamente distribuídas (PERSSON, MATHIASSEN e AAEM, 2012), aumentando ainda mais a necessidade de colaboração e desenvolvimento de confiança (PROCTER et al., 2011). A gestão ágil auxilia a minimizar os desafios relacionados à comunicação, controle, confiança e diferenças culturais, mediante o uso de estratégias para trabalho remoto garantindo processos flexíveis; realização frequente de reuniões - em diferentes meios de comunicação - para planejamento, status e alinhamento; compartilhamentos de informações e ferramentas; comunicação eficiente e constante; gestão e apoio adequados (LEE e YONG 2009; PERSSON, MATHIASSEN e AAEM, 2012).

Contribuindo com este pensamento, em projetos de larga escala distribuídos, Ollus et al. (2011) ressalta o valor da existência de uma base de conhecimento, a conexão com sistemas legados, a avaliação de parceiros, utilização de uma ontologia de parceiros para obter capacidades e habilidades de forma semi-automática, utilização de gráficos de desenvolvimento e histórico de parceiros. Devido complexidade e particularidades desses ambientes, o método ágil destaca-se como abordagem forte para gerenciamento, em especial nos aspectos intangíveis de confiança e liderança. 
Em ambientes onde ocorre o desenvolvimento de vários projetos em paralelo, Nicholls et al. (2015) salientam a importância expressiva da execução contínua de ações para identificação e monitoramento de prazos de entregas e gerenciamento de escopo e de tarefas, em prol de realizar priorizações, decisões e alinhamentos nos tempos adequadados de cada projeto envolvido. Outro ponto de destaque, considerando as características da gestão ágil e os cenários de aplicação, é a necessidade de novas metodologias de gerenciamento das empresas ágeis no ambiente de manufatura, sob uma visão holística, devido às especificidades desses ambientes, considerando motivação, estratégia, capacidades e provedores (SHARIFI et al., 2000; HOOPER, STEEPLE e WINTERS, 2001).

Com relação às restrições do uso da gestão ágil em ambientes complexos de criação de inovação não associada a software, é esperado que a metodologia ágil evolua para sobrepor esses obstáculos e entregar resultados positivos no desenvolvimento de projetos de diversos tipos (CONFORTO et al., 2014). Tal evolução tem sido observada em diferentes setores como consultoria, serviços financeiros, telecomunicações e institutos de pesquisa e educação (CONFORTO, REBENTISH e AMARAL, 2014).

De um modo mais amplo, Loss e Crave (2011) destacam a importância do surgimento de modelos de negócios que forneçam as características necessárias para o dinamismo de ambientes colaborativos de desenvolvimento de inovações, nos quais existem altos níveis de complexidade e incerteza, constituindo-se em oportunidade de pesquisa.

\subsection{ANÁlise dA GESTÃo ÁGIL DE REDES DE INOVAÇÃo AUTO- ORGANIZADAS}

A discussão sobre a necessidade de criarem-se novos mecanismos de estímulo à inovação comumente recairá no entendimento de diversas formas de trabalhos colaborativas, relacionadas à formação e funcionamento de novas estruturas organizacionais para fomentar inovação como também, nos mecanismos de apoio à essas novas estruturas, considerando os tipos de relacionamentos, processos, objetivos, fluxos de conhecimento, desafios, entre outros, que ocorrem nessas ambientes e, portanto, influenciam e são influenciados por um sistema de gestão.

O Quadro 7 (página 66) apresenta um compilado entre os principais assuntos relevantes para a análise da gestão ágil de redes de inovação auto-organizadas, visando facilitar o entendimento. 
Quadro 7 - Principais assuntos relevantes para análise

\begin{tabular}{|c|c|c|}
\hline Item & Assunto & Referências relacionadas ao assunto \\
\hline 1 & $\begin{array}{l}\text { Mecanismos de estímulo à inovação } \\
\text { (Redes de Inovação, Redes de Inovação } \\
\text { Auto-organizadas) }\end{array}$ & $\begin{array}{l}\text { BATTERINK et al., 2010; BRENNAN e DOOLEY, } \\
\text { 2005; BULLINGER, AUERNHAMMER e } \\
\text { GOMERINGER, 2004; CALIA, GUERRINI e MOURA, } \\
\text { 2007; CORSARO, CANTÙ e TUNISINI, 2012; } \\
\text { CORSARU e CANTÙ, 2015; DILK et al., 2008; FREEL, } \\
\text { 2003; GARDET e FRAIHA, 2012; HÂKANSSON e } \\
\text { FORD, 2002; HARMAAKORPI e MELKAS, 2005; } \\
\text { KAUFMANN, LEHNER e TÖDTLING, 2003; LEVÉN, } \\
\text { HOLMSTRÖM e MATHIASSEN, 2014; LOSS e } \\
\text { CRAVE, 2011; MASIELLO et al., 2015; OCDE, 2005; } \\
\text { PEKKARINEN e HARMAAKORPI, 2006; PRINCE, } \\
\text { BARRET e OBORN, 2014; RAMPERSAD, QUESTER, } \\
\text { TROSHANI, 2010; RYCROFT e KASH, 2004; } \\
\text { RYCROFT, 2007; SODA, 2011; STEINER, GIL e } \\
\text { EHRET, 2010; TIDD e BESSANT, 2009; VAN AKEN } \\
\text { e WEGGEMAN, 2000 }\end{array}$ \\
\hline 2 & Mecanismos de apoio (Gestão Ágil) & $\begin{array}{l}\text { AMARAL et al., 2011; AUGUSTINE e PAYNE, 2005; } \\
\text { CONFORTO e AMARAL, 2010; CONFORTO et al., } \\
\text { 2014; CONFORTO, REBENTISH e AMARAL, 2014; } \\
\text { FEKRI e ALIAHMADI, 2008; HIGHSMITH, 2004; } \\
\text { HOOPER, STEEPLE e WINTERS, 2001; LOSS e } \\
\text { CRAVE, 2011; MISHRA e MISHRA, 2011; } \\
\text { NICHOLLS et al., 2015; NOOR, RABISER e } \\
\text { GRÜNBACHER, 2008; TOLFO et al., } 2011\end{array}$ \\
\hline 3 & $\begin{array}{l}\text { Definições conceituais de redes de } \\
\text { inovação }\end{array}$ & $\begin{array}{l}\text { BATTERINK et al., 2010; DHANARAJ e PARKHE, } \\
\text { 2006; DILK et al., 2008; GARDET e FRAIHA, 2012; } \\
\text { GARDET e MOTHE, 2011; PEKKARINEN e } \\
\text { HARMAKKORPI, 2006; RAMPERSAD et al., 2010; } \\
\text { RYCROFT e KASH, 2004; VAN AKEN e } \\
\text { WEGGEMAN, } 2000\end{array}$ \\
\hline 4 & Fundamentos da gestão ágil & $\begin{array}{l}\text { AMARAL et al., 2011; AUGUSTINE e PAYNE, 2005; } \\
\text { CONFORTO e AMARAL, 2010; CONFORTO et al., } \\
\text { 2014; FEKRI e ALIAHMADI, 2008; HIGHSMITH, } \\
\text { 2004; HOOPER, STEEPLE e WINTERS, 2001; LOSS e } \\
\text { CRAVE, 2011; MISHRA e MISHRA, 2011; NOOR, } \\
\text { RABISER e GRÜNBACHER, 2008; TOLFO et al., } 2011\end{array}$ \\
\hline 5 & Definições da gestão ágil & $\begin{array}{l}\text { AMARAL et al., 2011; CONFORTO et al., 2014; } \\
\text { CONFORTO, REBENTISH e AMARAL, 2014; H. T. } \\
\text { GORANSON, 1999; HIGHSMITH, 2004; NOOR, } \\
\text { RABISER e GRÜNBACHER, } 2008\end{array}$ \\
\hline 6 & $\begin{array}{l}\text { Capacidade de adaptabilidade da gestão } \\
\text { ágil }\end{array}$ & $\begin{array}{l}\text { BECK et al, 2001; BOEHM, 2002; CONFORTO e } \\
\text { AMARAL, 2010; CONFORTO et al., 2014; } \\
\text { CONFORTO, REBENTISH e AMARAL, 2014; } \\
\text { LAANTI, SALO e ABRAHAMSSON, 2011; MISHRA } \\
\text { e MISHRA, 2011; POPE-RUARK, 2015; PROCTER et } \\
\text { al., 2011; TOLFO et al., } 2011\end{array}$ \\
\hline 7 & Características das redes de inovação & $\begin{array}{l}\text { ARRANZ e ARROYABE, 2012; BULLINGER, } \\
\text { AUERNHAMMER e GOMERINGER, 2004; CALIA, } \\
\text { GUERRINI e MOURA, 2007; CORSARO, CANTÜ e } \\
\text { TUNISINI, 2012; COWAN, JONARD e } \\
\text { ZIMMERMANN, 2007; DHANARAJ e PARKHE, } \\
\text { 2006; DILK et al., 2008; DOLOREUX, 2004; FREEL, } \\
\text { 2003; Gebauer, Nam e Parsche, 2005; GUBBINS e } \\
\text { DOOLEY, 2013; HÀKANSSON e FORD, 2002; } \\
\text { HANSEN e BIRKINSHAW, 2007; HARMAAKORPI e } \\
\text { MELKAS, 2005; KÖNIG et al., 2011; KLERKX e } \\
\text { AARTS, 2013; LOWE et al., 2012; MARTINS, GILSON }\end{array}$ \\
\hline
\end{tabular}




\begin{tabular}{|c|c|c|}
\hline & & $\begin{array}{l}\text { e MAYNARD, 2004; MASIELLO et al., 2015; OLARU } \\
\text { e PURCHASE, 2015; PEKKARINEN e } \\
\text { HARMAAKORPI, 2006; PERKS e MOXEY, 2011; } \\
\text { PRINCE, BARRET e OBORN, 2014; RYCROFT e } \\
\text { KASH, 2004; RYCROFT, 2007; TIDD e BESSANT, } \\
2009\end{array}$ \\
\hline 8 & Características da gestão ágil & $\begin{array}{l}\text { AMARAL et al., 2011; BECK et al, 2001; BOEHM e } \\
\text { HOGAN, 2012; BOEHM, 2002; CHOW e CAO, 2008; } \\
\text { CONFORTO et al., 2014; HIGHSMITH, 2004; } \\
\text { LAANTI, SALO e ABRAHAMSSON, 2011; } \\
\text { NICHOLLS et al. 2015; POPE-RUARK, 2015; } \\
\text { PROCTER et al., 2011; TOLFO et al., 2011 }\end{array}$ \\
\hline 9 & Projetos distribuídos & $\begin{array}{l}\text { CONFORTO et al., 2014; HOOPER, STEEPLE e } \\
\text { WINTERS, 2001; LEE e YONG 2009; LOSS e CRAVE, } \\
\text { 2011; NICHOLLS et al., 2015; OLLUS et al., 2010; } \\
\text { PERSSON, MATHIASSEN e AAEM, 2012; PROCTER } \\
\text { et al., 2011; SHARIFI et al., } 2000\end{array}$ \\
\hline 10 & Gestão de redes de inovação & $\begin{array}{l}\text { ARRANZ e ARROYABE, 2012; BULLINGER, } \\
\text { AUERNHAMMER e GOMERINGER, 2004; } \\
\text { CORSARU e CANTÙ, 2015; GARDET e FRAIHA, } \\
\text { 2012; HARRISSON et al., 2001; JARVENPAA e } \\
\text { VÄLIKANGAS, 2014; KOLLECK e BORMANN, } \\
\text { 2014; LEVÉN, HOLMSTRÖM e MATHIASSEN, 2014; } \\
\text { MASIELLO et al., 2015; MOLLER e SVAHN, 2009; } \\
\text { MUZZI e ALBERTINI, 2014; PERKS e MOXEY, 2011; } \\
\text { RAMPERSAD, QUESTER, TROSHANI, 2010; } \\
\text { RYCROFT e KASH, 2004; SMART, BESSANT e } \\
\text { GUPTA, 2007; SODA, 2011; VAN AKEN e } \\
\text { WEGGEMAN, 2000 }\end{array}$ \\
\hline 11 & Gestão ágil: Coordenação & $\begin{array}{l}\text { BATTERINK et al., 2010; DHANARAJ e PARKHE, } \\
\text { 2006; KLERKX e AARTS, 2013; OLARU e } \\
\text { PURCHASE, 2015; PRINCE, BARRET e OBORN, } \\
2014\end{array}$ \\
\hline 12 & $\begin{array}{l}\text { Gestão ágil: Comunicação e gestão do } \\
\text { conhecimento }\end{array}$ & $\begin{array}{l}\text { BRENNAN e DOOLEY, 2005; GUBBINS e DOOLEY, } \\
\text { 2013; HARMAAKORPI e MELKAS, 2005; HARRIS, } \\
\text { COLES e DICKSON, 2000; OLLUS et al., 2010; } \\
\text { PRINCE, BARRET e OBORN, } 2014\end{array}$ \\
\hline 13 & Gestão ágil: Ferramentas & $\begin{array}{l}\text { KAUFMANN, LEHNER e TÖDTLING, 2003; } \\
\text { BULLINGER, AUERNHAMMER e GOMERINGER, } \\
\text { 2004; LOSS e CRAVE, 2011; MICHAELIDES et al., } \\
2013\end{array}$ \\
\hline 14 & Gestão ágil: Tomada de decisão & 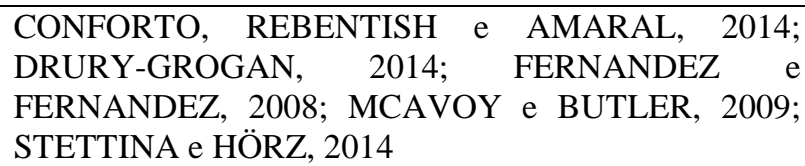 \\
\hline 15 & $\begin{array}{l}\text { Gestão ágil: Forma de trabalho da } \\
\text { equipe }\end{array}$ & $\begin{array}{l}\text { CONFORTO, REBENTISH e AMARAL, 2014; } \\
\text { CORSARU e CANTU், 2015; DRURY-GROGAN, } \\
\text { 2014; HOPE e AMDAHL, 2011; MELO et al., 2013; } \\
\text { MOE, DINGS } \varnothing Y R \text { e DYBA,, 2010; NICHOLLS et al., } \\
\text { 2015; REIFER, } 2002\end{array}$ \\
\hline 16 & Gestão ágil: Transição & $\begin{array}{l}\text { AMRITESH e MISRA, 2014; AUGUSTINE e PAYNE, } \\
\text { 2005; BOEHM e TURNER, 2005; FERNANDEZ e } \\
\text { FERNANDEZ, 2008; JAVDANI GANDOMANI e } \\
\text { ZIAEI NAFCHI, 2015; LAANTI, SALO e } \\
\text { ABRAHAMSSON, 2011; MELO et al., 2013; MISHRA } \\
\text { e MISHRA, 2011; QUMER e HENDERSON- } \\
\text { SELLERS, 2008; REIFER, } 2002\end{array}$ \\
\hline
\end{tabular}


Para facilitar o entendimento, a Figura 2 (página 72) ilustra a relação entre tais assuntos, relevantes para de análise da gestão ágil de redes de inovação auto-organizadas:

Entre os mecanismos de estímulo, as redes de inovação e, em especial, as redes de inovação auto-organizadas destacam-se por entregarem em suas características e definições o solo fértil necessário para que as empresas inovem (Item 1 do Quadro 7). Porém, inovar nesses ambientes só é possível se houverem mecanismos que apoiem a busca pela inovação, ou seja, mediante gestão eficiente. Na Figura 2 (página 72) essa dinâmica é ilustrada com os itens A, B e $\mathrm{C}$ identificados na legenda.

Nesse contexto, onde a gestão é crítica e desafiadora, a abordagem de gestão ágil possui as características e preposições necessárias para fornecer apoio a projetos de inovação em ambientes com alto nível de incerteza; com alto grau de complexidade; envolvendo diferentes interessados. Isso deve-se a entrega da flexibilidade, adaptabilidade e velocidade necessárias, por meio de um processo de aprendizado constante, coibição de planejamento rígido e estímulo à auto-organização (Item 2 do Quadro 7). Na Figura 2 (página 72) essa dinâmica é ilustrada com os itens A e B identificados na legenda.

Desse modo, um alinhamento entre as redes de inovação auto-organizáveis e a gestão ágil pode ser realizado, uma vez que ambos apresentam uma região conceitual comum: aumento da capacidade competitiva, através da inovação. Essa região comum abrange aspectos de estímulo, no caso das redes de inovação auto-organizadas, e de apoio e suporte, no caso da gestão ágil, identificadas com a análise das definições e características de ambos. Na Figura 2 (página 72) essa dinâmica é ilustrada com o item 1identificado na legenda.

Analisando as distintas definições conceituais de redes de inovação propostas (Item 3 do Quadro 7), conjuntamente com os fundamentos da gestão ágil de focar em projetos inovadores (Item 4 do Quadro 7), suas definições (Item 5 do Quadro 7) e sua capacidade de adaptabilidade (Item 6 do Quadro 7), é possível identificar a aplicabilidade do ágil nesses ambientes de elevada incerteza, complexibilidade, com intensas interações, equipes com perfis distintos e envolvimento de vários parceiros; devido a priorização do ágil na comunicação, coordenação e controle adequados para ambientes colaborativos. Na Figura 2 (página 72) essa dinâmica é ilustrada com o item 2 identificado na legenda.

A análise das distintas características das redes de inovação (Item 7 do Quadro 7) indicam que o sucesso da rede depende do foco da gestão em todos os agentes envolvidos; da correta definição, alinhamento e monitoramento dos objetivos, atividades e responsabilidades; do aprendizado constante; da otimização das interações, balanceando informalidade e formalidade; de como a liderança é realizada; da recombinação de competências; da 
adaptabilidade; do contato com clientes; do compartilhamento de conhecimentos; do comportamento dinâmico; da construção de atmosfera de confiança que garanta fluidez nas interações; da sinergia entre processos tecnológicos, estrutura e governança; do desenvolvimento de redes distribuídas geograficamente; da heterogeneidade de atores. Todos esses fatores criam a necessidade de uma gestão que minimize conflitos e forneça as ferramentas necessárias para o alinhamento de atividades e objetivos, levando ao sucesso da rede. Na Figura 2 (página 72) essa dinâmica é ilustrada com o item 3 identificado na legenda.

Nesse cenário, com base nas definições da gestão ágil (Item 5 do Quadro 7), suas características (Item 8 do Quadro 7), capacidade de adaptabilidade (Item 6 do Quadro 7) e aplicabilidade para projetos distribuídos geograficamente (Item 9 do Quadro 7) é criado o arcabouço necessário para permitir o trabalho nas redes, considerando a simplicidade e flexibilidade requeridas para lidar com alterações e desafios; um conjunto de valores, princípios, práticas e possibilitadores que auxiliam a realizar a gestão tanto no recorte macro considerando escolha de parcerias, interações entre os diversos elos, transferência de conhecimento - quanto micro - a nível de projetos na rede, envolvendo cotidiano de atividades, desenvolvimento de confiança, cronogramas, comunicação, acesso à informação, forma de trabalho e ferramentas de apoio -; assim como ferramentas e estratégias para trabalho remoto, incentivando as características de autogestão e auto-organização dos envolvidos. Na Figura 2 (página 72) essa dinâmica é ilustrada com o item 3 identificado na legenda.

Do mesmo modo, os aspectos relacionados a realização da gestão de redes de inovação (Item 10 do Quadro 7) devem ser alinhados com as características desses ambientes, compreender liderança, comunicação, gestão do conhecimento e o uso de ferramentas. Assim, a gestão deve ser adaptável; proativa; possuir um estilo de coordenação que reduza incertezas, comportamentos oportunistas e realize distribuição balanceada de poder; realizar adequadamente o planejamento de atividades e recursos; envolver grande esforço de coordenação focada em transparência, comunicação, conflitos e objetivos; deve também, considerar as necessidades dos interessados, diversidades da equipe e ciclos de vida dos projetos; manter um portfólio de estratégias adequadas para a complexidade do ambiente; incentivar práticas harmoniosas; formar um ambiente que fortaleça a confiança e criatividade; manter a eficiência da comunicação e P\&D, mesmo em cenários críticos. Na Figura 2 (página 72) essa dinâmica é ilustrada com o item 4 identificado na legenda.

Nesses ambientes a coordenação (Item 11 do Quadro 7) tem as funções de tomar decisões que promovam o crescimento da rede como um todo; atuar de forma sistêmica, por 
meio de intermediários; influenciar a rede de forma analítica e gerencial. A comunicação e gestão do conhecimento (Item 12 do Quadro 7) devem fortalecer a confiança. As ferramentas (Item 13 do Quadro 7) utilizadas devem facilitar o acesso às informações e a tomada de decisões; aumentar a eficiência da comunicação e da escolha de parceiros; auxiliar no fluxo de conhecimento e apoiar os modelos de negócios ágeis. Na Figura 2 (página 72) essa dinâmica é ilustrada com o item 4 identificado na legenda.

Nesse cenário, a gestão ágil apoiada nas suas características (Item 8 do Quadro 7), como capacidade de adaptabilidade (Item 6 do Quadro 7), modo de tomada de decisão (Item 14 do Quadro 7), forma de trabalho da equipe (Item 15 do Quadro 7) e aplicabilidade para projetos distribuídos (Item 9 do Quadro 7) entrega os elementos essenciais para a gestão das redes de inovação e dos projetos colaborativos nela realizados, destacando-se: a aplicação de seus valores, princípios, práticas e análise de possibilidades, que permitem a atuação frente a incertezas e alterações; adaptabilidade para coordenação de distintos tipos de projeto, focando em eficiência e satisfação dos envolvidos; realização de tomada de decisão colaborativa; satisfação da equipe envolvido, dada sua influencia no sucesso do empreendimento; diretrizes para envolver adequadamente clientes e outros atores externos; gestão de equipes globais, distribuídos geograficamente, com ações para coibir conflitos e improdutividade. Na Figura 2 (página 72) essa dinâmica é ilustrada com o item 4 identificado na legenda.

As questões relacionadas à transição (Item 16 do Quadro 7) da gestão tradicional para ágil também devem ser consideradas na gestão de redes de inovação auto-organizadas, uma vez que impactam diretamente na eficiência e dada a dificuldade de aplicá-la em ambientes que não possuem os possibilitadores do ágil e/ou estejam acostumados com metodologias tradicionais. Dessa forma, é importante preparar a rede de inovação para essa abordagem, estimulando o comportamento de auto-organização, por meio de alinhamentos envolvendo agilidade, processos, pessoas, riscos, gestão, performance, políticas, cultura organizacional, estratégias, entre outros; minimizando o abandono da transição. Na Figura 2 (página 72) essa dinâmica é ilustrada com o item 5 identificado na legenda.

Desse modo, com base nas análises da região comum entre as redes de inovação autoorganizadas e a gestão ágil é possível identificar elementos que justificam sua atuação conjunta. Entre eles estão: a motivação em inovar, foco em aprendizado e colaboração, tomada de decisão descentralizada, estímulo da confiança, foco na eficiência da comunicação, busca por transparência e clareza, necessidade de alinhar objetivos, envolvimento de diferentes atores, gerenciamento direcionado para minimizar e resolver conflitos, utilização de ferramentas para gestão de conhecimento e trabalho remoto, flexibilidade, adaptabilidade, auto-organização, 
balanceamento entre formalidade e informalidade e priorização para gestão coordenada e controlada, mas sem rigidez de processos. 
Redes de Inovação Auto-organizadas

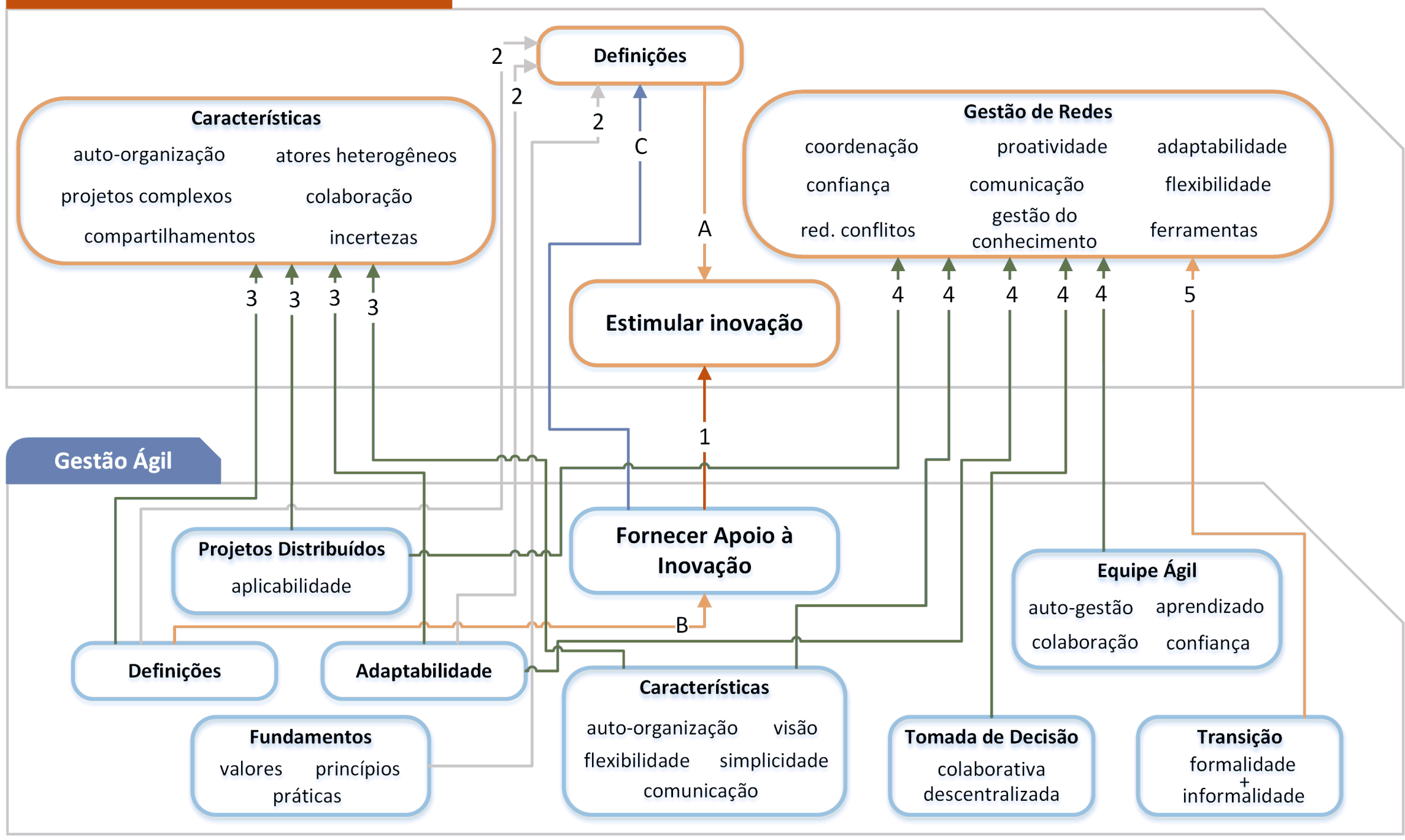

A e B Definições apontam os objetivos das redes de inovação e da gestão ágil

C Mecanismos do ágil que apoiam os objetivos das redes de inovação

2 Permitem aplicabilidade do ágil na gestão das redes de inovação

Planejar a transição do tradicional

Alinhamento de objetivos em comum

Facilitam o trabalho no ambiente de redes de inovação

Elementos essenciais para gestão de redes de inovação e dos projetos que nela ocorrem

Figura 2- Gestão ágil de redes de inovação auto-organizadas (áreas comuns/aplicabilidade) 


\subsection{CONSIDERAÇÕES DA REVISÃO}

O aumento nos níveis de competitividade fomenta as ações em prol de inovações que entreguem diferenciais para vencer desafios, atingir novos mercados e atender as necessidades e exigências dos consumidores, alinhadas às questões de viabilidade de custo, recursos e timeto-market.

Frente a esse cenário, as organizações têm buscado novas formas de estimular a criação de inovação, mediante a utilização de novas estruturas organizacionais, facilitadas pelos avanços tecnológicos. As redes de inovação auto-organizadas e a gestão ágil surgem em resposta à essa necessidade, influenciando a forma de desenvolvimento de inovações e realização de negócios.

Atuar em redes de inovação significa atuar colaborativamente, mediante o compartilhamento de riscos, conhecimentos, recursos e objetivos. Apesar dos benefícios desses ambientes, diversos fatores precisam ser considerados para que a rede resulte em sucesso, refletido na criação de inovações.

Devido à alta quantidade de interações, processos, interesses e culturas organizacionais envolvidos, a gestão das redes de inovação auto-organizadas é um dos fatores decisivos para a eficiência da rede e alcance dos objetivos definidos, mediante correto balanceamento entre formalidade e informalidade.

Apesar da importância dessas redes, existe pouca literatura nesse campo, assim como instrumentos adequados para planejamento e coordenação, sendo que as propostas existentes não fornecerem todas as características necessárias. Desse modo, a gestão ágil aparece como possibilidade para suprir essa lacuna, devido as suas características de flexibilidade e adaptabilidade.

Assim, a contribuição deste capítulo está na identificação e apresentação de justificativas que corroborem com a aplicabilidade da gestão ágil nos ambientes de redes de inovação auto-organizadas. Para isso, procurou-se identificar uma região comum entre as duas áreas e dessa forma, colaborar com literatura da área de gestão de redes de inovação. 


\section{MODELO ATUAL E IDENTIFICAÇÃO DAS NECESSIDADES DE MUDANÇA}

Conforme previamente abordado, existem vários desafios associados à redes de inovação, tornando a coordenação adequada essencial para o alcance do sucesso e fundamentada no foco dado a todos os envolvidos, em temos de definição, alinhamento e monitoramento de objetivos, tarefas e responsabilidades. Também foi salientada a possibilidade de aplicação da abordagem ágil nesses ambientes, tendo em vista sua flexibilidade e adaptabilidade.

Apesar da possibilidade de aplicação, é importante verificar previamente se o ambiente no qual deseja-se realizar a transição apresenta ou não os possibilitadores, apontados pela literatura, para uso da abordagem ágil, suavizando o processo de mudança, por meio de planejamento adequado e; minimizando as chances de uma possível transição resultar em esforços perdidos e frustrações nos agentes envolvidos. Esses possibilitadores podem ser traduzidos como requisitos que motivam e facilitam a implantação e; sua identificação recai no processo de planejamento da transição - requerendo atenção e disposição dos envolvidos.

Nesse contexto, apresenta-se neste capítulo as fases exploratória e aprofundada de uma pesquisa-ação para planejamento da transição, abrangendo a identificação dos requisitos que justificam a aplicação da abordagem ágil para solucionar problemas práticos relacionados à gestão, no ambiente observado. Isso é feito por meio da modelagem de dois estados da unidade de análise: atual e da necessidade de mudança. Os Apêndices A e B apresentam detalhamento dos questionários e dos processos que serão apresentados nas próximas seções.

\subsection{ANÁLISE DE DADOS E RESULTADOS DE UMA PESQUISA AÇÃO}

A modelagem dos estados atual e da necessidade de mudança da unidade de análise, envolveu a aplicação de questionários para coleta de dados. Entre eles um conjunto de questões verificou: as características de redes de inovação auto-organizadas identificadas na unidade de análise; a visão sobre a forma de gestão da rede e dos projetos conduzidos na mesma; os elementos que apoiam a gestão ágil nesse ambiente e; os principais elementos que otimizariam a gestão da rede e de seus projetos. 


\subsubsection{Análise dos questionários}

Com a análise dos dados dos treze participantes ${ }^{8}$ do Centro de pesquisas - com perfis divididos entre analista, auxiliar administrativo ${ }^{9}$, engenheiro e gerente - verifica-se que $61,5 \%$ não possuem conhecimento sobre o que é uma rede de inovação; 53,8\% tiveram algum contato prévio com gestão ágil ${ }^{10} \mathrm{e} ; 92,3 \%$ observam a atuação de atores internos e externos nos projetos em desenvolvimento. Os participantes também identificam características de redes de inovação no ambiente, bem como de auto-organização. Dentre as características de redes de inovação, 92,3\% acreditam atuar em projetos para inovação; $100 \%$ verificam relações de parceria nos mesmos; 76,9\% observam que existem ações de compartilhamento; 84,6\% destacam o forte trabalho colaborativo; $61,5 \%$ indicam a elevada capacidade para geração de conhecimento e; $100 \%$ verificam o desenvolvimento de mais de um projeto em ambiente de rede. Dentre as características associadas à auto-organização, 92,3\% dos participantes acreditam que os atores tem iniciativas próprias nos projetos; $61,5 \%$ veem mudanças espontâneas na estrutura e; 76,9\% observam espontaneidade nos atores para solucionar problemas. Verifica-se também, que apesar de não ter conhecimento especializado sobre redes de inovação, 76,9\% dos participantes têm consciência de atuar em um ambiente colaborativo e, parcelas pouco expressivas, dividiram-se entre afirmar que muitos dos colegas na rede tem essa mesma visão $(38,5 \%)$ ou que poucos tem consciência (38\%).

Com relação a visão sobre a forma de gestão vigente na rede, ao conduzir vários projetos: 46,2\% não identificam uma forma definida. Entre os comentários fornecidos, estão a visualização de gestão baseada na execução, no senso de urgência e com análise dos requisitos e tomada de decisão fundamentada na experiência do grupo; ocorrência de tarefas e atividades "soltas" e não há uma metodologia bem definida; existe "um modo de fazer", mas sem padronização; cada pessoa executa sua tarefa de forma individual, minimizando o acesso ou visão dos acontecimentos pelos demais. Com relação a gestão dos projetos que ocorrem na rede: $84,6 \%$ os compreende como sendo colaborativos, tendo o esforço em comunicação como elemento principal para solução de problemas $(61,5 \%)$, com compartilhamento de recursos e tarefas $(61,5 \%)$ e desenvolvidos por atores com sentimento de equipe $(69,2 \%)$ e solicitos para ajudar (61,5\%); por outro lado, somente 38,5\% acreditam que a definição de atividades ocorre colaborativamente, que a forma de gestão para os projetos da rede é sempre a mesma $(15,4 \%)$

\footnotetext{
${ }^{8}$ Oriundos da unidade da empresa na qual a pesquisa-ação é realizada, com perfis distintos em que 46,2\% atuam nos projetos da rede desde seu início, $46,2 \%$ não atuam e 7,7\% não sabem.

${ }^{9}$ Atuam como apoio técnico na unidade de análise.

${ }^{10} 46,2 \%$ dos participantes não tiveram contato prévio com gestão ágil.
} 
e, ainda, que leva em conta as características da rede de inovação (7,7\%). A porcentagem de participantes que acreditam que gestão deve ser otimizada é elevada $(84,6 \%)$.

Os comentários indicam centralização de ações e informações em poucos, dificultando a gestão de conhecimento e consequentemente a inserção de outros membros na equipe; existe resistência à mudanças em alguns, por apego a rotina ou por imaginar que mudanças podem tornar a tarefa ainda mais complexa; ocorrem falhas na adoção de ferramentas em todos os setores envolvidos; separação entre os setores prejudica o projeto; falta formalização sobre como lidar com os problemas operacionais e falta equipe dedicada para tal; ocorre sobrecarga em alguns para tarefas que poderiam ser feitas por outras pessoas.

Com relação a aplicabilidade da gestão ágil, os participantes apontaram a ocorrência de diversos elementos que apoiam a transição: incerteza nos projetos, refletida por mudanças frequentes e gestão do conhecimento ineficiente (100\%); responder mais rapidamente a demandas (92,3\%); necessidade de adaptabilidade e flexibilidade (76,9\%); ocorrência e necessidade de envolvimento dos clientes e outros atores, otimizar prazos e falta de clareza sobre os objetivos $(84,6 \%)$; gestão crítica e desafiadora $(53,8 \%)$; necessidade de minimizar burocracrias (46,2\%); dificuldade em acessar informações (76,9\%). Com relação aos principais elementos que otimizariam a gestão: uso de ferramentas visuais para organização de tarefas e comunicação, a formação de equipes auto-organizadas e a adaptação da gestão ágil de acordo com cada subprojeto (100\%); uso de conceito de visão pode auxiliar a equipe e envolvimento de clientes e demais parceiros e atualização frequente do planejamento (92,3\%); foco nas pessoas e uso de ciclos iterativos de desenvolvimento e presença de influenciadores (equipe de planejamento e monitoramento) (84,6\%); realização de entregas parciais com valor agregado $(61,5 \%)$.

Entre os comentários sobre otimização, estão a visualização global de ocorrências e objetivos, ampliação da participação da equipe para entender o funcionamento da rede, os papéis e as inter-relações; combinação de estratégias e ferramentas de acordo com os distintos perfis; aplicação de abordagens distintas para os distintos tipos de demandas - desenvolvimento de inovações e operacionais.

\subsubsection{Modelagem de empresas da pesquisa-ação (AS-IS)}

Para facilitar a verificação dos elementos associados à gestão que afetam o desempenho da unidade de análise e como eles estão vinculados ao cotidiano prático do projeto, o conjunto de submodelos segue o recorte em "macro" - foco na rede - e "micro" - foco nos projetos colaborativos da mesma, relacionados ao Centro de pesquisas. Salienta-se que os elementos 
representados em cor azul nos submodelos estão associados à análise da necessidade de mudança que será apresentada posteriormente.

\subsubsection{Modelo de Objetivos}

Conforme a Figura 3 (página 79), para gerar inovação no segmento de gestão de transportes (Objetivo 1) é preciso gerar e transferir conhecimento (Objetivo 1.1). A existência de atores motivados e com meios para inovar (Oportunidade 1), a necessidade de soluções que otimizem o segmento (Oportunidade 2), bem como os demais objetivos da rede (Objetivos 2 a 5) apoiam esse objetivo (Objetivo 1); enquanto as regras para ação e divulgação em prol de alcançá-lo podem restringi-lo (Política 1).

Demandas por melhoria da visibilidade de atuação dos envolvidos (Objetivo 2.1), por reconhecimento das diferentes necessidades e vontades (Objetivo 2.2), por aumento na qualidade dos serviços (Objetivo 2.3), por compartilhamento de resultados (Objetivo 2.4) e por garantia de apoio técnico (Objetivo 2.5) impulsionam a aplicação de novas tecnologias para gestão de transporte (Objetivo 2). Esse objetivo (Objetivo 2) é apoiado por eventos de premiação que ocorrem no segmento (Oportunidade 3) para motivar o investimento em melhores tecnologias e serviços.

Por sua vez, o objetivo de gerar padrões para disseminar melhores práticas no segmento (Objetivo 3), visa estimular ambientes similares a buscar melhorias para prestação de serviços de transporte no país (Oportunidade 4). 
Modelo de Objetivos - Parte 1/2

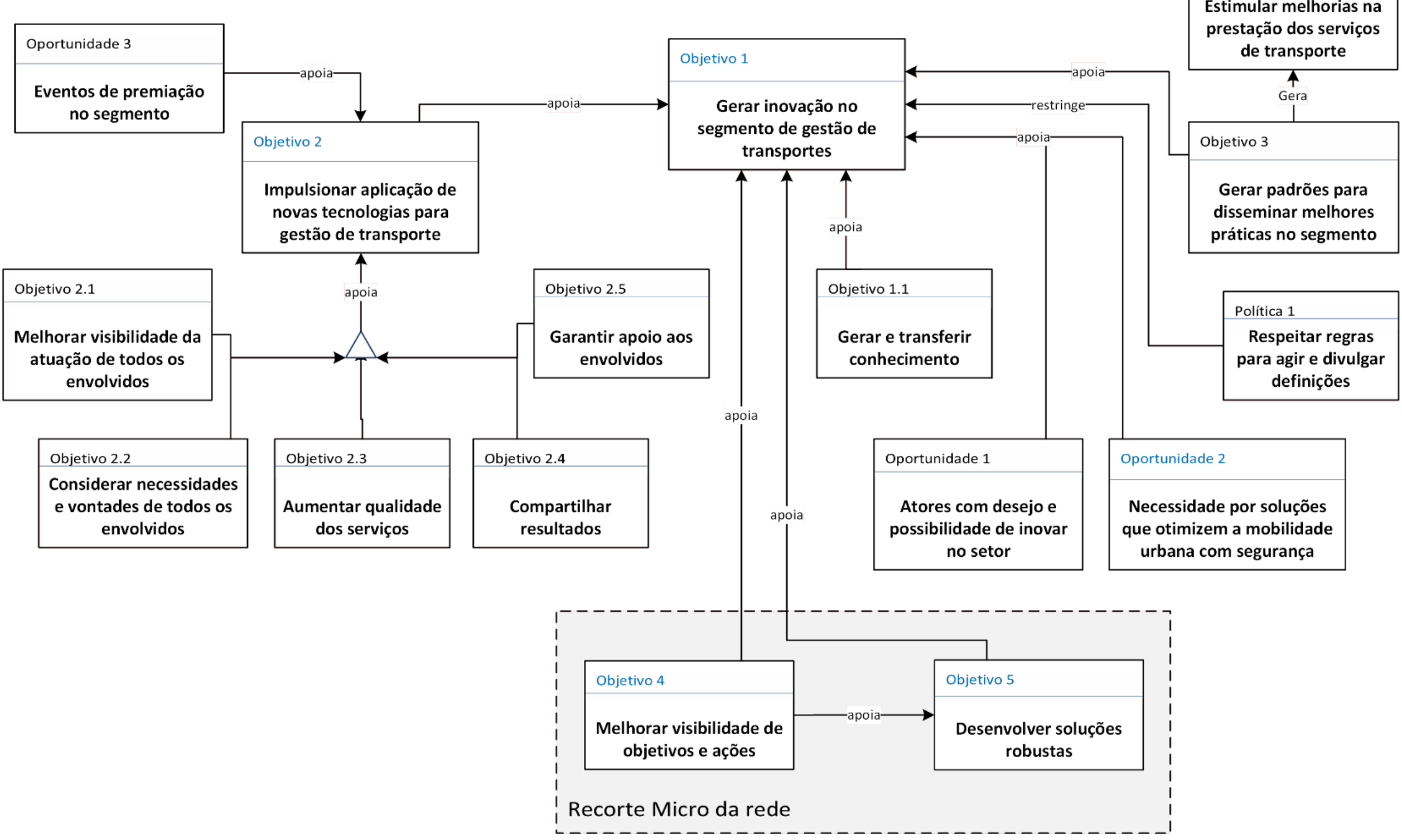

Figura 3 - Modelo de objetivos - asis (Parte 1/2) 
Conforme a Figura 4 (página 81), o objetivo de melhorar a visibilidade na rede (Objetivo 4) apoia o desenvolvimento de soluções robustas (Objetivo 5) e, juntos, apoiam a geração de inovação (Objetivo 1). Tais objetivos podem ser analisados no detalhamento dos projetos colaborativos que ocorrem na rede, em especial, no âmbito do Centro de pesquisas.

Para melhorar a visibilidade (Objetivo 4) é necessário que esse ator facilite a identificação de problemas (Objetivo 4.2) e auxílie no controle das atividades (Objetivo 4.1) sem imposições, respeitando a transferência mensal do conhecimento gerado (Política 2) e compreendendo que a liberação de recursos está atrelada aos resultados alcançados e entregues (Política 3). 


\section{Modelo de Objetivos - Parte 2/2}
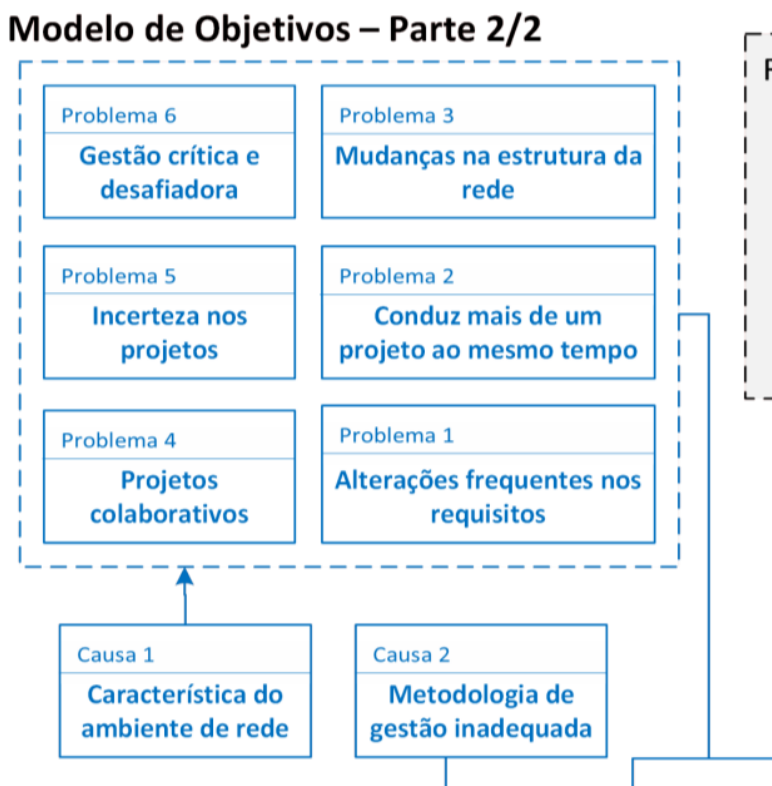

- -----------1 ecorte Macro da rede Objetivo 1

Gerar inovação no segmento de gestão de transportes

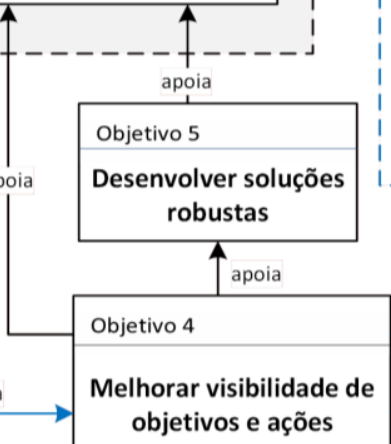
\begin{tabular}{|c|}
\hline \\
e compartilhamento nas \\
tarefas e relações
\end{tabular} Oportunidade 5.8
que permite uso de
novas metodologias Oportunidade 5.9 Compartilhamento de recursos $\mathrm{e}$ tarefas

\begin{tabular}{|c|}
\hline Oportunidade 5.4 \\
Capacidade de \\
adaptação dos processos
\end{tabular}

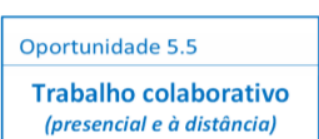

Oportunidade 5.6 Informalidade entre as relações

\section{Oportunidade 5.1 \\ Envolvimento de clientes e outros atores \\ Oportunidade 5.2 \\ Estímulo a troca de \\ Oportunidade 5.3 experiências organização}

- - - - - - - - -

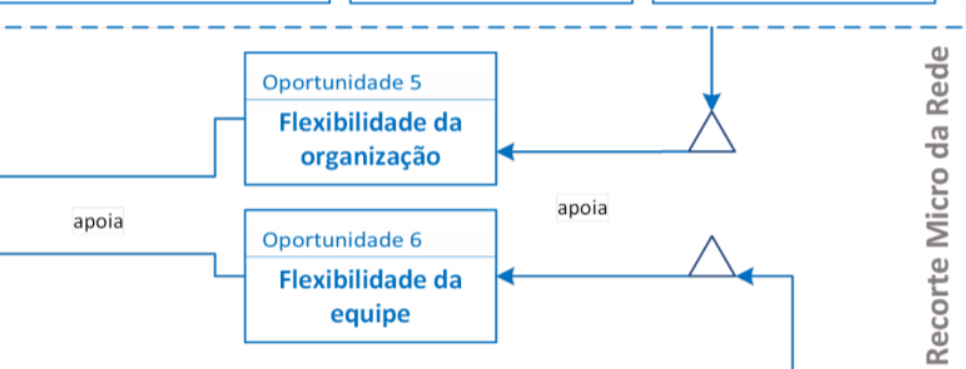

\begin{tabular}{|c|c|c|c|}
\hline Problema 7 & \multicolumn{2}{|c|}{ Problema 11} & Problema 14 \\
\hline $\begin{array}{l}\text { Difícil acesso as } \\
\text { informações }\end{array}$ & \multicolumn{2}{|c|}{$\begin{array}{l}\text { Falta clareza de } \\
\text { objetivos }\end{array}$} & $\begin{array}{l}\text { Dificuldade de controlar } \\
\text { todas as solicitações }\end{array}$ \\
\hline Problema 8 & \multicolumn{2}{|c|}{ Problema 12} & Problema 15 \\
\hline $\begin{array}{l}\text { Distintas formas } \\
\text { de gestão no } \\
\text { ambiente }\end{array}$ & \multicolumn{2}{|c|}{$\begin{array}{l}\text { Dificuldade de } \\
\text { mensurar todas as } \\
\text { atividades }\end{array}$} & $\begin{array}{c}\text { Atrasos no envio dos } \\
\text { relatórios e demais } \\
\text { artefatos }\end{array}$ \\
\hline Problema 9 & \multicolumn{2}{|c|}{ Problema 13} & Problema 16 \\
\hline $\begin{array}{c}\text { Equipe não tem } \\
\text { visibilidade sobre o } \\
\text { formato de gestão }\end{array}$ & \multicolumn{2}{|c|}{$\begin{array}{l}\text { Gestão do } \\
\text { conhecimento } \\
\text { ineficiente }\end{array}$} & $\begin{array}{l}\text { Falta estímulo paras } \\
\text { definição de atividades } \\
\text { em conjunto }\end{array}$ \\
\hline \multirow{2}{*}{\multicolumn{2}{|c|}{$\begin{array}{l}\text { Problema } 10 \\
\text { Não levava em conta } \\
\text { o ambiente de rede } \\
\text { de inovação }\end{array}$}} & \multicolumn{2}{|c|}{ Problema 17} \\
\hline & & \multicolumn{2}{|c|}{$\begin{array}{c}\text { Concentração de atividades } \\
\text { e conhecimento em poucos } \\
\text { atores da equipe }\end{array}$} \\
\hline
\end{tabular}

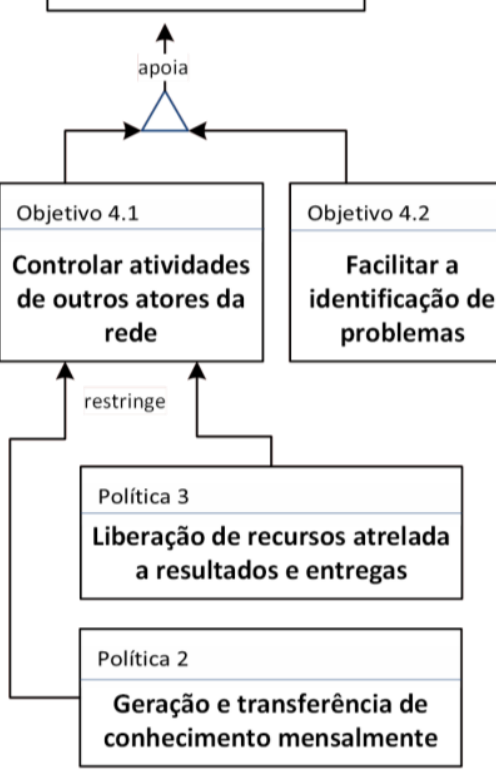

Figura 4 - Modelo de objetivos - asis (Parte 2/2) 


\subsubsection{Modelo de Regras de Negócios}

Conforme a Figura 5 (página 83), para gerar inovação no segmento de gestão de transportes e pedagiamento (Objetivo 1) é importante estimular livre concorrência e dinâmica de preços favorável (Regra 1) e também, a $\mathrm{P} \& \mathrm{D}^{11}$ (Regra 6). A aplicação de novas tecnologias (Objetivo 2) ocorre mediante o estímulo da livre concorrência e dinâmica de preços favorável no segmento (Regra 1), promoção de eventos de premiação para motivação (Regra 5) e também, devido a ocorrência de P\&D (Regra 6).

Para gerar padrões para disseminar melhores práticas no segmento (Objetivo 3) é necessário buscar qualidade nas soluções desenvolvidas (Regra 2), regulamentar e fiscalizar adequadamente os serviços (Regra 3), estimular P\&D (Regra 6) e considerar os requisitos e opiniões vindos de todos os atores envolvidos na rede (Regra 4), através do uso de canais claros para comunicação (Regra 4.1) e da promoção de fóruns e workshops para acompanhamento e discussões (Regra 4.2).

No recorte dos projetos colaborativos que ocorrem na rede, para melhorar a visibilidade de objetivos e ações (Objetivo 4) é importante que Centro de pesquisas atue com imparcialidade nas definições (Regro 8), transparência (Regra 12), utilize os meios de comunicação acordados (Regra 13) e alerte sobre os problemas (Regra 7), visando auxiliar na busca por soluções (Regra 7.1) e na formalização da situação para interessados (Regra 7.2).

Ainda no âmbito dos projetos, a junção dos compromissos de responder os requisitos dos envolvidos (Regra 9), buscar qualidade (Regra 10) e, sempre que possível, promover o uso de softwares livres e tecnologias homologadas (Regra 11), apoiam o desenvolvimento de soluções robustas para o segmento (Objetivo 5).

\footnotetext{
${ }^{11}$ P\&D é uma sigla para Pesquisa e Desenvolvimento.
} 


\section{Modelo de Regras do Negócio}

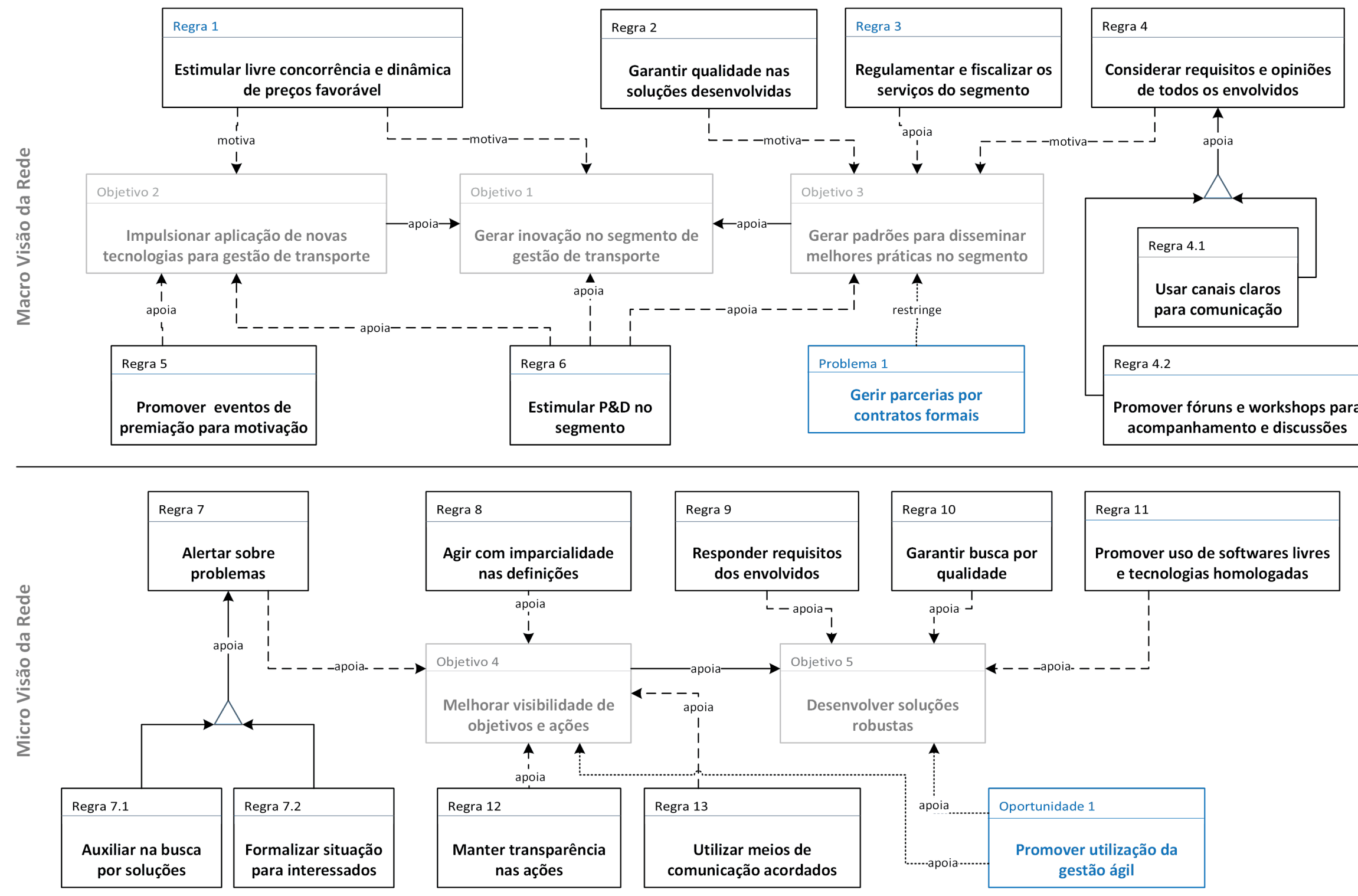

Figura 5- Modelo de regras do negócio - asis 


\subsubsection{Modelo de Atores e Recursos}

Conforme o recorte macro na Figura 6 (página 85), a Agência Reguradora de transportes (Unidade organizacional 1) provê sistemas e serviços (Recursos 1 e 3) para o segmento; estimula e provê tecnologias (Recurso 2) e; gerencia e provê recursos financeiros (Recurso 4). Para atingir os objetivos, relaciona-se diretamente (Unidades organizacionais 2, 3, 4 e 5) e indiretamente (Unidades organizacionais 6 e 7) com os outros atores.

O Centro de pesquisas (Unidade organizacional 2) desenvolve e mantém sistemas e tecnologias (Recursos 1 e 2); provê serviços (Recurso 3) e; necessita de recursos financeiros (Recurso 4). Também relaciona-se com os demais atores para atingir os objetivos da rede (Unidades organizacionais 1, 3, 4, 5, 6 e 7), por vezes assumindo o papel de OCD ${ }^{12}$ (Unidade Organizacional 7).

A Prestadora de Serviços (Unidade organizacional 3) provê serviços (Recurso 3) e necessita de recursos financeiros (Recurso 4). Mantém os dois relacionamentos já citados.

A Concessionária de rodovias (Unidade organizacional 4) provê e necessita de serviços (Recurso 3), bem como provê recursos financeiros (Recurso 4). Além dos dois relacionamento já citados, mantém outros (Unidades organizacionais 5 e 6). Por sua vez, a Operadora de serviços (Unidade organizacional 5) necessita dos serviços da rede (Recurso 3) e mantém três relacionamentos já mencionados.

O Fornecedor (Unidade organizacional 6) provê tecnologias (Recurso 2) para a rede, mediante recursos financeiros (Recurso 4). Mantém os três relacionamentos citados, conforme demanda dos outros atores.

Por fim, a OCD (Unidade organizacional 7) fornece serviços (Recurso 3) para homologação de tecnologias, mediante o recebimento de recursos financeiros (Recurso 4) e sob demanda da Agência Reguladora (Unidade organizacional 1).

\footnotetext{
12 OCD é uma abreviação para Órgão Certificador Designado que homologa softwares e hardwares.
} 


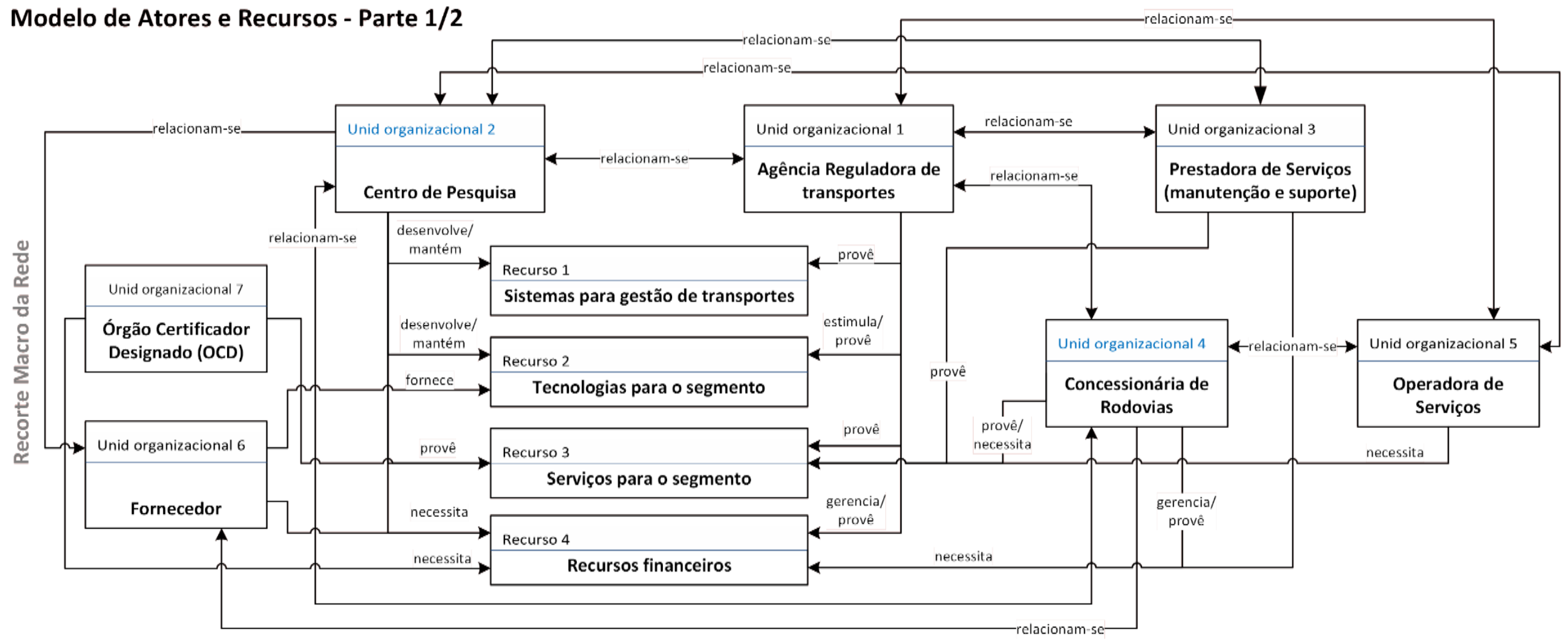

Figura 6 - Modelo de atores e recursos - asis (parte 1/2) 
Conforme a Figura 7 (página 87), três atores principais são identificados no projeto analisado. A Agência Reguladora (Unidade organizacional 1) com três diretorias principais envolvidas: a Administrativa (Unidade individual 1) que cuida de aprovações (Papel 1), propagações (Papel 2), eventos (Papel 3), decisões técnicas (Papel 4) e participa no planejamento de inovações (Papel 6); a de Tecnologia da Informação e Operações (Unidade individual 2) que realiza acompanhamentos (Papel 5), controla ações necessárias (Papel 10), participa do planejamento de inovações (Papel 6), regula e fiscaliza (Papel 8) e; a Financeira (Unidade individual 3) que participa do planejamento de inovações (Papel 6), realiza pagamentos (Papel 7) e libera recursos (Papel 9).

O Centro de pesquisas (Unidade organizacional 2) envolve três setores no projeto. $\mathrm{O}$ primeiro setor é o de Sistemas (Unidade organizacional 2.1) com gerente (Unidade individual 7) comunicando e controlando ações (Papel 13), participando do planejamento de inovações (Papel 6), definindo tarefas e alocações (Papel 14) e gerando relatórios e análises (Papel 16). A equipe de analistas (unidade individual 8) participa do planejamento de inovações (Papel 6), gera relatórios e análises (Papel 16), atua em tarefas e atendimentos (Papéis 15 e 17), no desenvolvimento de novas tecnologias (Papel 24) e em visitas técnicas (Papel 25). A equipe de suporte (Unidade individual 9), por sua vez, realiza tarefas fixas diariamente (Papael 15). O segundo setor é o Administrativo Financeiro (Unidade organizacional 2.2) com gerente (Unidade individual 10) controlando recursos (Papel 18) e formalizando entregas (Papel 19) e analistas (Unidade individual 11) também associados ao controle de recursos (Papel 18). O terceiro setor é a Diretoria (Unidade organizacional 2.3) com diretor (Unidade individual 6) prospectando novas oportunidades na rede (Papel 11) e orientando a equipe de modo geral (Papel 12).

Por fim, a Prestadora de Serviços (Unidade organizacional 3), dispolibiliza a gerência (Unidade Individual 4) que controla a equipe técnica (Papel 20) e planeja ações de manutenção nos ambientes físicos (Papel 21). Também disponibiliza uma equipe técnica (Unidade Individual 5) para atuar no projeto executando ações planejadas (Papel 22), reportando-as (Papel 23) e controlando inventário de equipamentos em campo (Papel 26). 
Modelo de Atores e Recursos - Parte 2/2

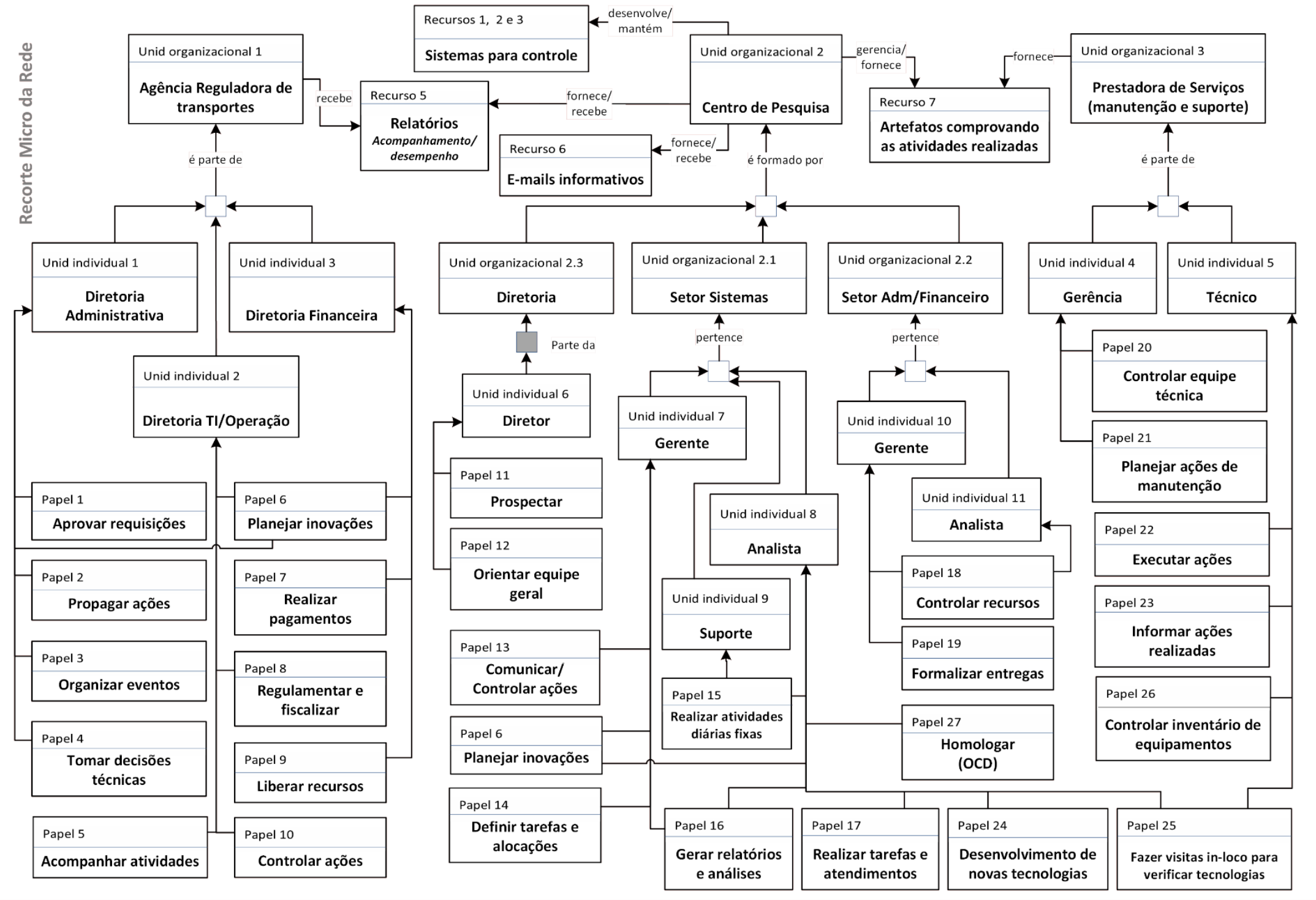

Figura 7 - Modelo de atores e recursos - asis (parte 2/2) 


\subsubsection{Modelo de Processos}

Conforme a Figura 8 (página 89), existem diversos processos no âmbito de demandas que podem resultar em inovação na rede. Tais processos são iniciados por meio de ações de acompanhamento (Infoset 1) que servem de entrada para um processo, por meio do qual as demandas são geradas nos recortes macro e micro da rede (Processo 1), através de atuação colaborativa dos atores. Esse processo resulta em uma lista de itens (Infoset 2) e relatórios (Infoset 3) para melhorias que ao serem recebidos e tratados como demandas nos subprojetos vinculados ao Centro de pesquisas (Processo 2), podem evoluir para inovações.

O processo de tratamento resulta em uma lista de atividades para realizar (Infoset 4) e, ao longo do tempo, em artefatos resultantes da evolução das atividades (Infoset 5) que devem ser acompanhados e comunicados (Processo 3) aos diferentes interessados. O acompanhamento e comuncação ocorrem por relatórios (Infoset 6), reuniões (Infoset 7), visitas técnicas (Infoset 8) e registros diários das atividades (Infoset 9), esse último associado ao recorte micro da rede.

Em alguns casos, as demandas podem requerer recursos técnicos e financeiros que uma vez solicitados, devem ser acompanhados pelo requerente (Processo 4), até sua liberação ou negativa (Infoset 10) e também, devidamente formalizados (Infoset 11), geralmente por e-mail.

Ao término da referida demanda, novamente, os envolvidos devem ser comunicados e os resultados entregues (Processo 5), incidindo em novos artefatos (Infoset 12) e documentação oficializando a liberação dos novos itens (Infoset 13) que podem disparar novos processos para utilização efetiva dos artefatos na rede.

Contratualmente, a transferência do conhecimento (Processo 6) gerado nos subprojetos associados ao Centro de pesquisas, ocorre com relatórios mensais (Infoset 14) que são acompanhados de documentação e artefatos de evidência das ações realizadas. Isso não impede que artefatos finalizados sejam enviados fora do período do relatório mensal. 
Modelo de Processos - Parte (1/2)

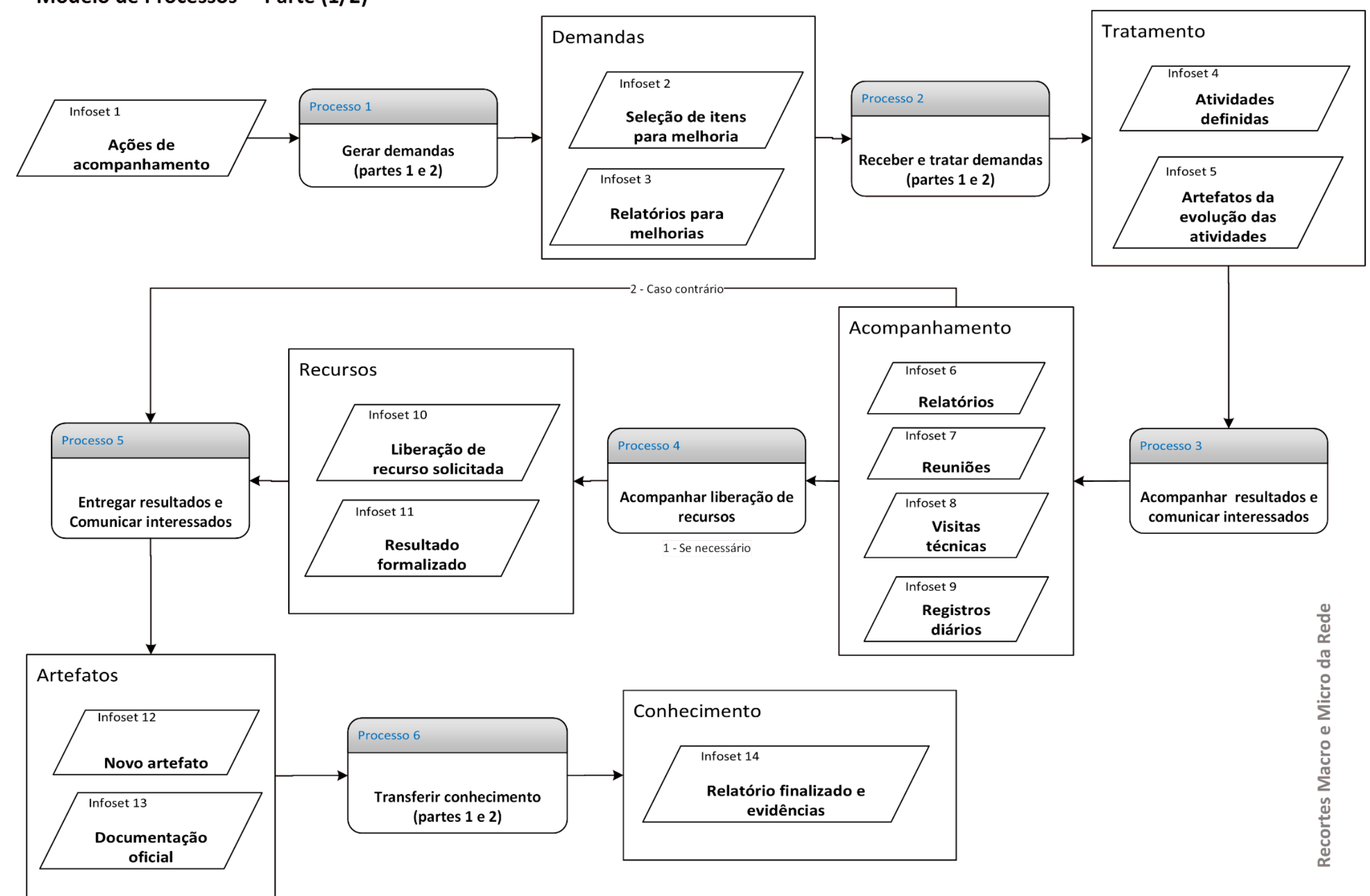

Figura 8 - Modelo de processos - asis (parte 1/2) 
Conforme a Figura 9 (página 91), além das operações em prol das demandas por inovação, existem processos no âmbito de motivar, disseminar e gerir parcerias na rede que também são necessários para cumprimento dos objetivos dos envolvidos.

O desejo de estimular melhorias (Infoset 1) pode manifestar-se com a realização de eventos para premiar os melhores resultados obtidos ao longo do ano (Processo 1), por atores que participam da rede. A divulgação de tais eventos (Infoset 2) e o plano de marketing que pode ser desenvolvido para tal (Infoset 3) são formas visuais de motivar e estimular os parceiros a buscarem excelência ao aplicarem as soluções desenvolvidas na rede, bem como a sugerirem demandas que levem a inovação no segmento, não somente em prol de resultados financeiros, mas do desenvolvimento técnológico do país.

A visão de ser referência no segmento (Infoset 4) reflete-se no modelo de processos, através da disseminação de melhores práticas (Processo 2), por meio da promoção e participação em ações em busca de inovação tecnológica para gestão de transportes e pedagiamento. Essas ações baseiam-se na divulgação adequada dos resultados obtidos na rede que destaquem os ganhos e fortaleçam o modelo criado, por meio da divulgação em mídias distintas (Infoset 5) e exibição de casos de sucesso em eventos (Infoset 6).

Por sua vez, as demandas por parcerias na rede ${ }^{13}$ (Infoset 7), assim como as demandas por alocação de recursos humanos nos subprojetos no Centro de pesquisas (Infoset 8) disparam operações para gerenciamento das mesmas (Processo 3) que resultam na oficialização das novas parcerias formadas (Infoset 9) e consequente acompanhamento, por meio de relatórios (Infoset 10); e também, na alocação de novos atores (Infoset 11) na equipe dos subrprojetos.

\footnotetext{
${ }^{13}$ Com Concessionárias de rodovias, Operadoras de serviços, Prestadora de serviços e Parceiros tecnológicos.
} 
Modelo de Processos - Parte (2/2)

Recortes Macro e Micro da Rede

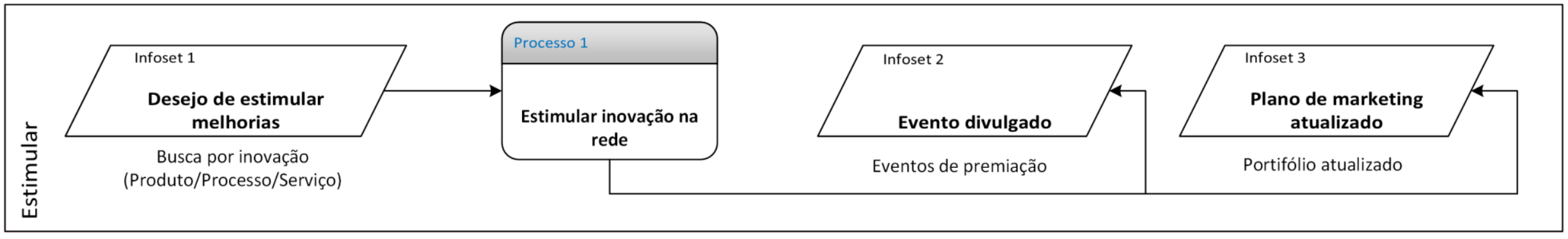

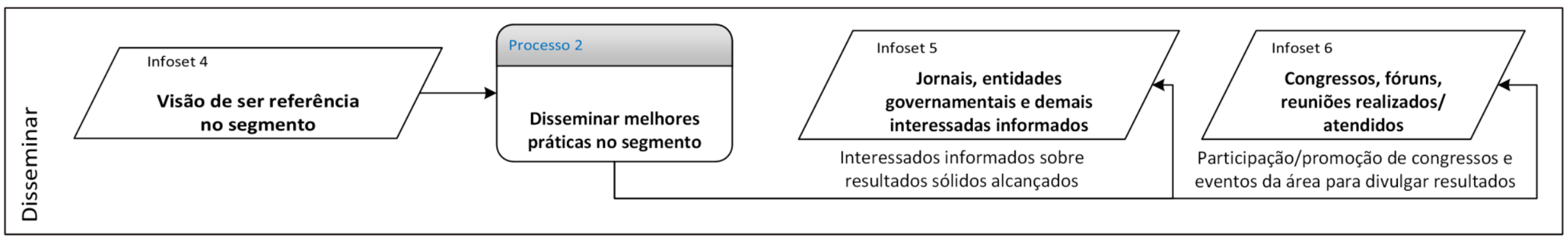

\begin{tabular}{|c|c|c|c|c|}
\hline \multirow{3}{*}{ 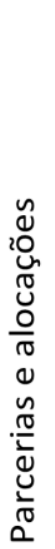 } & \multirow{2}{*}{ 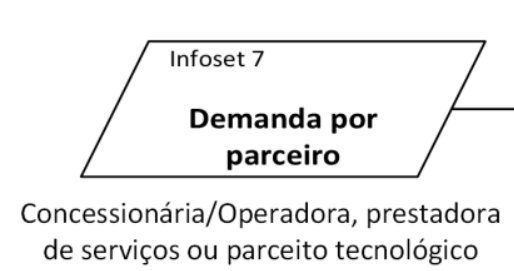 } & \multirow{2}{*}{$\begin{array}{l}\text { Processo } 3 \\
\text { Realizar gestão de } \\
\text { parcerias e RH } \\
\text { (Partes 1 e e 2) }\end{array}$} & $\begin{array}{r}\text { Infoset } 9 \\
\text { Parcerias } \\
\text { formadas }\end{array}$ & \multirow{2}{*}{$\begin{array}{c}\begin{array}{c}\text { Infoset } 10 \\
\text { Relatórios de } \\
\text { andamento e resultado }\end{array} \\
\begin{array}{c}\text { Acompanhamento de ações } \\
\text { na rede }\end{array}\end{array}$} \\
\hline & & & & \\
\hline & $\begin{array}{c}\text { Infoset } 8 \\
\text { Demanda por RH } \\
\text { Geralmente reflexo de } \\
\text { demandas por atividades }\end{array}$ & & $\begin{array}{r}\text { Infoset } 11 \\
\begin{array}{c}\text { Atores } \\
\text { alocados }\end{array} \\
\end{array}$ & \\
\hline
\end{tabular}

Figura 9 - Modelo de processos - asis (parte 2/2) 


\subsubsection{Modelo de Componentes e Requisitos Técnicos}

Conforme o recorte macro ${ }^{14}$ na Figura 10 (página 93), o sistema de informação da rede tem seis objetivos principais. O primeiro apoia os demais e consiste em supervisionar todos os processos operacionais (Objetivo de Sistemas de Informação ${ }^{15}$ 1), através de ferramentas para gerenciar atividades (Requisito Funcional 1), inventários de equipamentos (Requisito Funcional 2) e recursos financeiros e humanos (Requisito Funcional 3).

O segundo (Objetivo SI 2) visa gerenciar demandas, usando ferramentas para controle de requisições e incidentes (Requisito Funcional 4) e para planejamento e controle de novas funcionalidades (Requisito Funcional 7), facilitando o acompanhamento e identificação de oportunidades (Objetivo SI 2.1).

O terceiro (Objetivo SI 3) foca em estimular a comunicação dos atores, usando ferramentas para comunicação (Requisitos Funcionais 5 e 6 ), planejamento e controle de funcionalidades (Requisito Funcional 7), visando supervisionar os relacionamentos da rede (Objetivo SI 3.1).

O quarto (Objetivo SI 4) foca em estimular gestão do conhecimento, através de ferramentas para disponibilização de tarefas (Requisito Funcional 8) e para comunicação (Requisitos Funcionais 5 e 6) - visando manter atores alinhados (Objetivo SI 4.1) -, bem como ferramentas para planejamento e controle de funcionalidades (Requisito Funcional 7) para facilitar acompanhamentos (Objetivo SI 4.2) e documentação de ações (Objetivo SI 4.3).

O quinto (Objetivo SI 5) visa apoiar tomada de decisão com ferramentas para planejamento e controle de novas funcionalidades (Requisito Funcional 7) e para obter dados para eventos de premiação (Requisito Funcional 9).

O sexto (Objetivo SI 6) foca em divulgar evoluções, também com uso de ferramentas para apoiar a realização de eventos (Requisito Funcional 9) que estimulem o crescimento da rede (Objetivo SI 6.1). As ferramentas utilizadas podem ser resultado de demandas no recorte micro da rede como exemplificado pelas ferramentas com traços em cor cinza na figura.

\footnotetext{
14 A primeira parte (1/3) das três figuras que compõem o modelo de compontes e requisitos técnicos está representada na seção de Apêndice, pois sua análise não era essencial para o entendimento desse artigo.

${ }^{15}$ Para facilitar a leitura, a expressão Sistema de Informação foi abreviada como SI.
} 
Modelo de Componentes e Requisitos Técnicos - Parte 2/3

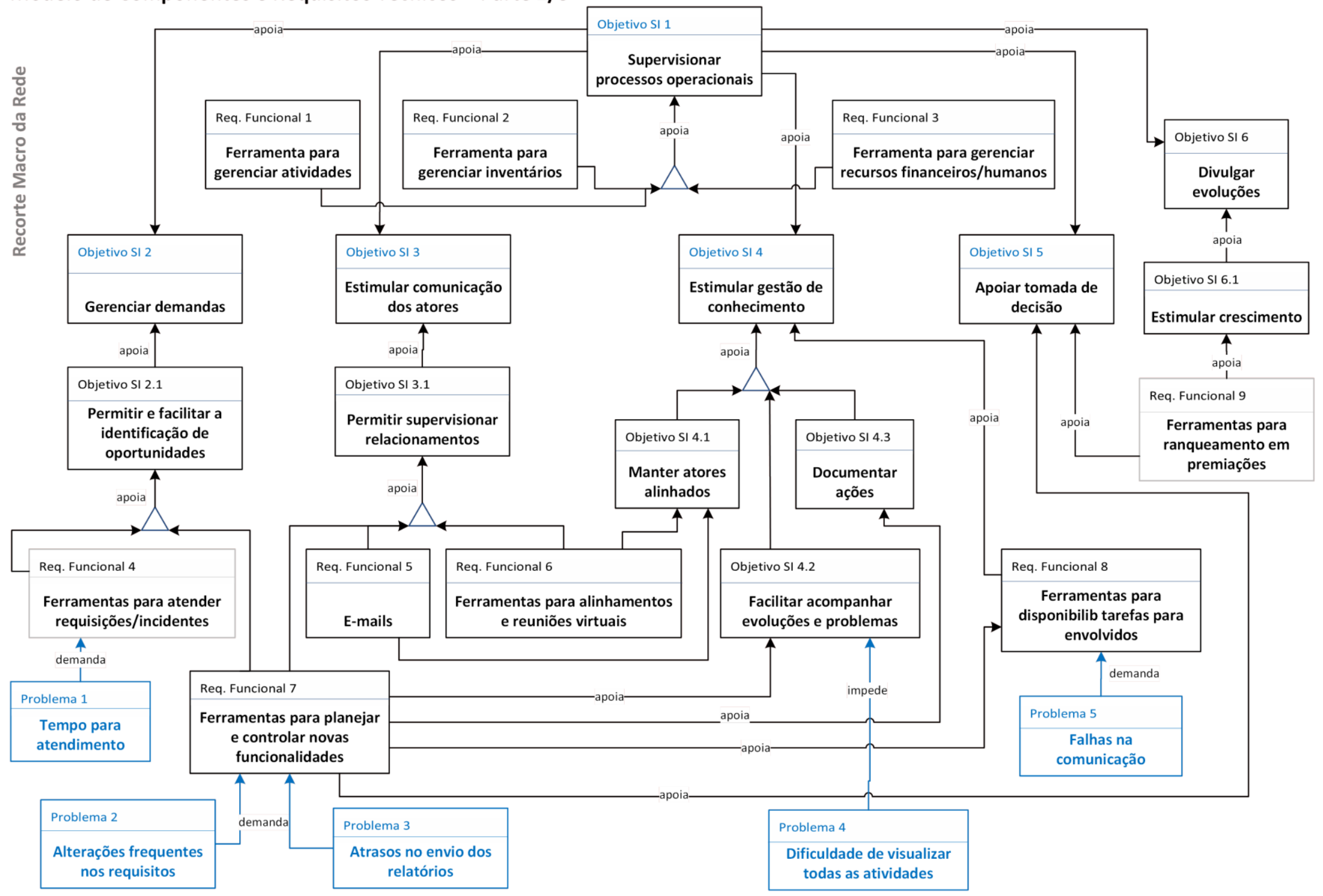

Figura 10 - Modelo de componentes e requisitos técnicos - asis (2/3) 
Conforme o recorte micro na Figura 11 (página 95), o sistema de informação, focado nos subprojetos relacionados com o Centro de pesquisas, tem cinco objetivos principais interrelacionados. O primeio consiste em supervisionar as rotinas dos processos operacionais (Objetivo SI 1) com ferramentas para gerenciar atividades (Requisito Funcional 1), inventários de equipamentos (Requisito Funcional 2) e recursos financeiros e humanos (Requisito Funcional 3).

O segundo (Objetivo SI 2) foca em receber e tratar as demandas, usando ferramentas para criar, disponibilizar e manter funcionalidades (Requisito Funcional 10) com forte preocupação em segurança (Requisito Não Funcional 1).

O terceiro (Objetivo SI 7) visa manter os envolvidos alinhados com uso de e-mails e comunicadores instântaneos (Requisito Funcional 11) e também, sistemas para coletar e armazenar dados e informações (Requisito Funcional 12), viabilizando fóruns (Objetivo SI 7.1), canais para esclarecimentos (Objetivo SI 7.2) e relatórios (Objetivo SI 7.3), bem como facilitando a transferência de conhecimento (Objetivo SI 7.4).

O quarto (Objetivo SI 5) visa apoiar a tomada de decisão na rede e seus subprojetos, através da propagação de ferramentas com apelo visual (Requisito Funcional 14), ferramentas para facilitar a identificação de oportunidades (Requisito Funcional 15) e para realizar análises de desempenho (Requisito Funcional 13) e ainda, sistemas para coletar e armazenar dados (Requisito Funcional 12) que podem ser utilizados em eventos de premiação (Objetivo SI 5.1).

O quinto (Objetivo SI 8) foca em manter os ambientes operacionais com ferramentas para atender requisições e incidentes (Requisito Funcional 4), para facilitar a identificação de oportunidades (Requisito Funcional 15) e para comunicação (Requisito Funcional 11), auxiliando na resolução de problemas (Objetivo SI 8.1). 
Modelo de Componentes e Requisitos Técnicos - Parte 3/3

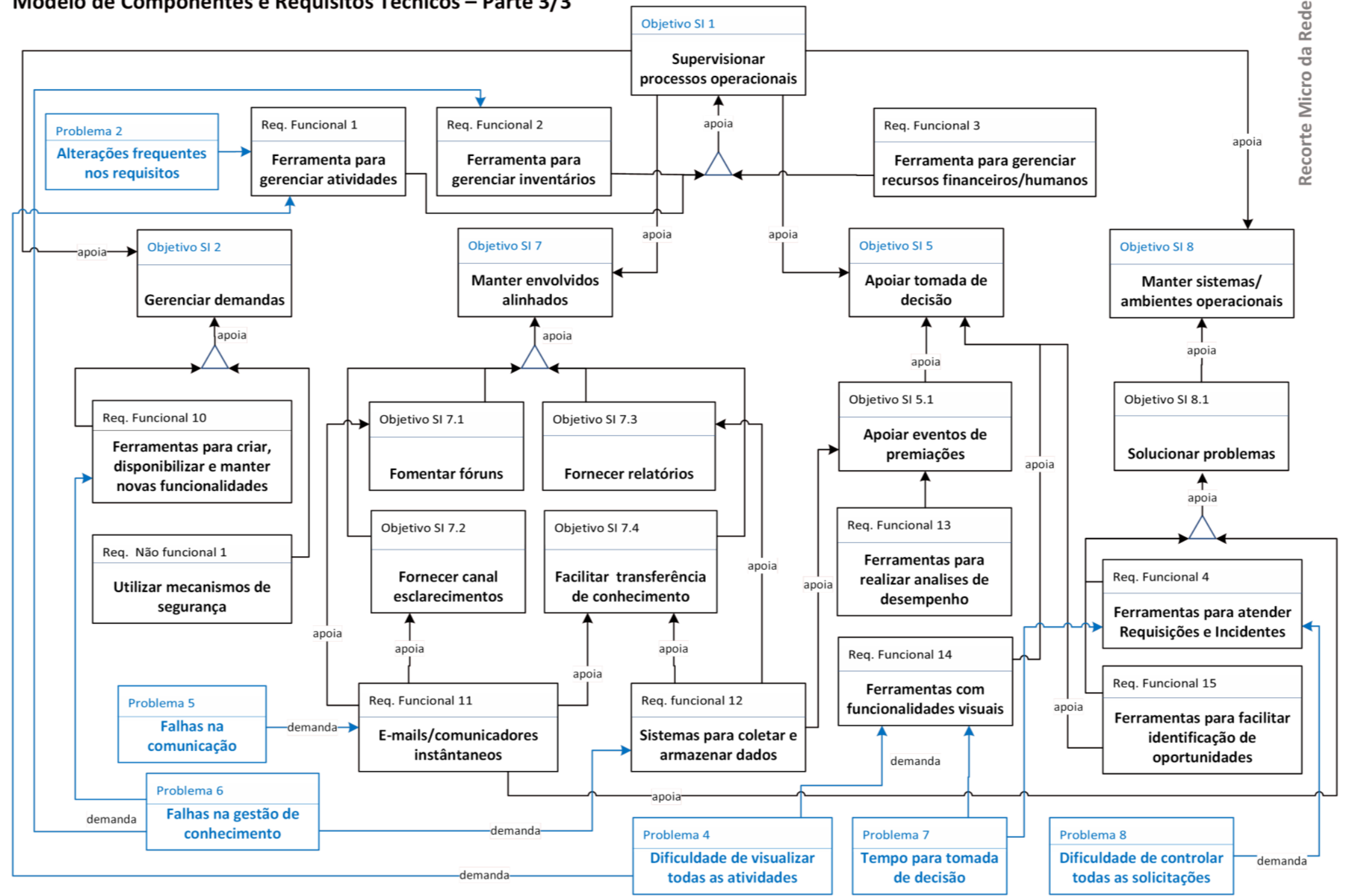

Figura 11 - Modelo de componentes e requisitos técnicos - asis (3/3) 


\subsection{ANÁLISE DA NECESSIDADE DE MUDANÇA (NEED-FOR-CHANGE)}

A análise da necessidade de mudança, baseia-se na discussão dos questionários apresentada na seção 3.1.1, frente aos submodelos "as-is" expostos na seção 3.1.2. O objetivo da análise é identificar os principais problemas e oportunidades, associados à gestão, que ocorrem na unidade de análise e estimulam a aplicação da gestão ágil.

Para auxiliar a compreensão, os elementos afetados pela análise da necessidade de mudança são representados em cor azul nos submodelos da seção 3.1.2 e quadros sumarizando as informações serão apresentados nesta seção, contendo os elementos identificados e seu amparo na literatura.

\subsubsection{Necessidade de mudanças para o Modelo de Objetivos}

Com a análise do modelo de objetivos, frente às informações coletadas nos questionários - em especial, a falta de consciência dos envolvidos sobre sua atuação em ambiente de rede de inovação e sua visão sobre a forma de gestão vigente na rede - foram identificados os principais problemas práticos associados à gestão que ocorrem na unidade de análise. A Figura 3 (página 79) ilustra esses elementos e suas causas e o Quadro 8 e Quadro 9 o cruzamento dos mesmos com a literatura.

O Quadro 8 (página 96) aponta que o baixo nível de previsibilidade dos resultados; as alterações resultantes da formação de parcerias; as interações entre diferentes atores e; a necessidade de gerir todos os envolvidos, bem como seus objetivos, capacidades e diferenças, estão entre as características do ambiente de redes que relefetem-se como problemas na unidade de análise (Problemas 1 a 6).

Quadro 8 - Problemas relacionados à características do ambiente

\begin{tabular}{|l|l|}
\hline \multicolumn{2}{|c|}{ Causa 1 - Característica do ambiente de rede } \\
\hline Problema identificado & Literatura \\
\hline 1 - Alterações frequentes nos requisitos & DHANARAJ e PARKHE, 2006 \\
\hline 2 - Condução de múltiplos projetos em paralelo & NICHOLLS et al. (2015) \\
\hline 3 - Mudanças na estrutura da rede & TIDD e BESSANT, 2009 \\
\hline $\begin{array}{l}4-\text { Realização de projetos colaborativos (presencial e à } \\
\text { distância) }\end{array}$ & DILK et al., 2008; RYCROFT e KASH, 2004 \\
\hline 5 - Incerteza nos projetos & DHANARAJ e PARKHE, 2006 \\
\hline 6 - Gestão crítica e desafiadora & $\begin{array}{l}\text { AUGUSTINE e PAYNE, 2005; BOEHM e } \\
\text { HOGAN, 2012 }\end{array}$ \\
\hline
\end{tabular}

O Quadro 9 (página 97) indica que o uso de uma metodologia de gestão inadequada, também está associada aos problemas identificados na rede (Problemas 7 a 17), através da 
carência de ferramentas eficientes para planejamento e coordenação, visando comunicação e alinhamento de atividades; na falta de investimento em um sistema de gestão de conhecimento adequado; na falta de preparo dos atores para atuar neste tipo de ambiente; na falta de transparência, alinhamento de objetivos e definição de tarefas; na falta de definição de processos que otimizem a exploração de competências e; na falta de monitoramento e coordenação dos níveis de confiança, aprendizado e auto-organização.

Quadro 9 - Problemas relacionados à metodologia de gestão inadequada

\begin{tabular}{|c|c|}
\hline \multicolumn{2}{|c|}{ Causa: 2 - Metodologia de gestão inadequada para o ambiente } \\
\hline Problema identificado & Literatura \\
\hline 7 - Difícil acesso às informações & $\begin{array}{l}\text { BULLINGER, AUERNHAMMER e } \\
\text { GOMERINGER, 2004; HARMAAKORPI e } \\
\text { MELKAS, 2005 }\end{array}$ \\
\hline 8 - Variações na forma de gestão no ambiente & - \\
\hline 9 - Equipe não tem visibilidade sobre o formato utilizado & DILK et al., 2008 \\
\hline 10 - Não leva em conta a específicidade do ambiente & LOSS e CRAVE, 2011; OLLUS et al., 2010 \\
\hline 11 Falta de clareza de objetivos & $\begin{array}{l}\text { BULLINGER, AUERNHAMMER e } \\
\text { GOMERINGER, } 2004\end{array}$ \\
\hline $\begin{array}{l}12 \text { - Dificuldade de mensurar as atividades (necessárias e } \\
\text { em andamento) }\end{array}$ & $\begin{array}{l}\text { BULLINGER, AUERNHAMMER e } \\
\text { GOMERINGER, 2004; DILK et al., 2008; } \\
\text { PERKS e MOXEY, } 2011\end{array}$ \\
\hline 13 - Gestão do conhecimento ineficiente & $\begin{array}{l}\text { DILK et al., 2008; HARMAAKORPI e } \\
\text { MELKAS, } 2005\end{array}$ \\
\hline 14 - Dificuldade de controlar todas as solicitações & $\begin{array}{l}\text { BULLINGER, AUERNHAMMER e } \\
\text { GOMERINGER, 2004; DILK et al., } 2008\end{array}$ \\
\hline 15 - Atrasos na entrega de resultados & $\begin{array}{l}\text { BULLINGER, AUERNHAMMER e } \\
\text { GOMERINGER, 2004; DILK et al., 2008; } \\
\text { PEKKARINEN e HARMAAKORPI, } 2006\end{array}$ \\
\hline 16 - Falta de estímulo para definição conjunta de tarefas & $\begin{array}{l}\text { PERKS e MOXEY, 2011; PRINCE, BARRET e } \\
\text { OBORN, 2014; RYCROFT e KASH, } 2004\end{array}$ \\
\hline 17 - Sobrecarga em perfis chave da equipe & $\begin{array}{l}\text { BOEHM e HOGAN, 2012; BULLINGER, } \\
\text { AUERNHAMMER e GOMERINGER, 2004; } \\
\text { DHANARAJ e PARKHE, 2006; PERKS e } \\
\text { MOXEY, 2011; PRINCE, BARRETT e } \\
\text { OBORN } 2014\end{array}$ \\
\hline
\end{tabular}

A ocorrência desses problemas (Problemas 1 a 17) dificulta a visibilidade de objetivos e ações nos subprojetos (Objetivo 4) e, devido aos relacionamentos existes entre os objetivos da rede, influencia negativamente os demais (Objetivos 1, 2 e 5). Por outro lado, também com a análise dos objetivos apresentados, frente as informações vindas dos questionários - em especial, a aplicabilidade da gestão ágil e o desejo da equipe de otimizar o modelo de gestão foram identificadas oportunidades que podem estimular e facilitar a transição. A Figura 3 (página 79) ilustra esses elementos e o Quadro 10 e Quadro 11 o cruzamento dos mesmos com a literatura. 
O Quadro 10 (página 98) aponta que a unidade de análise apresenta flexibilidade, ao permitir alocação de esforços para realizar colaboração satisfatória com o clientes e parceiros para especificação e desenvolvimento dos projetos, mesmo em ambientes distribuídos; não barrar a tomada de decisão colaborativa; permitir a busca por auto-organização e combinação de práticas e técnicas de gestão; coibir ações que minimizam a confiança na equipe; não impor medidas burocraticas para comunicação; permitir a realização de ações em busca de flexibilidade e; ver o compartilhamento de recursos e informações de forma natural, mesmo que não realizando- de forma satisfatória. Corroborando com a composição de oportunidades, a cultura organizacional e mentalidade das pessoas, mesmo que não generalizada, permite a plicação de abordagens ágeis.

Quadro 10 - Oportunidades relacionadas à flexibilidade da organização

\begin{tabular}{|c|c|}
\hline \multicolumn{2}{|c|}{ Oportunidade 5 - Flexibilidade da organização } \\
\hline Oportunidade secundária & Literatura \\
\hline 5.1 - Envolvimento de clientes e outros atores nas ações & $\begin{array}{l}\text { HOPE e AMDAHL, 2011; PERSSON, } \\
\text { MATHIASSEN e AAEM, } 2012\end{array}$ \\
\hline 5.2 - Estímulo a troca de experiências & $\begin{array}{l}\text { AMARAL et al., 2011; MCAVOY e BUTLER, } \\
2009\end{array}$ \\
\hline 5.3 - Auto-organização & $\begin{array}{l}\text { BECK et al., 2001; HIGHSMITH, 2004; } \\
\text { MISHRA e MISHRA, 2011; QUMER e } \\
\text { HENDERSON-SELLERS, } 2008\end{array}$ \\
\hline 5.4 - Capacidade de adaptação dos processos & CONFORTO et al., 2014 \\
\hline 5.5 - Trabalho colaborativo (presencial e à distância) & $\begin{array}{l}\text { BECK et al., 2001; CHOW e CAO, 2008; } \\
\text { CONFORTO et al., 2014; MCAVOY e } \\
\text { BUTLER, } 2009\end{array}$ \\
\hline 5.6 - Informalidade nas relações & BECK et al., 2001 \\
\hline $\begin{array}{l}5.7 \text { - Flexibilidade, adaptabilidade e compartilhamento nas } \\
\text { tarefas e relações (pouca burocracia) }\end{array}$ & $\begin{array}{l}\text { BECK et al., 2001; CONFORTO, 2014; } \\
\text { FERNANDEZ e FERNANDEZ, } 2008 \\
\end{array}$ \\
\hline 5.8 - Abertura para utilização de novas metodologias & CONFORTO, 2014; TOLFO et al., 2011 \\
\hline 5.9 - Compartilhamento de recursos e tarefas & PERSSON, MATHIASSEN e AAEM, 2012 \\
\hline
\end{tabular}

A presença dessas oportunidades no Centro de pesquisas e nas equipes dos subprojetos (Oportunidades 5.1 a 5.9 e 6.1 a 6.12) revelam a existência de flexibilidade no ambiente e equipes (Oportunidades 5 e 6), mesmo que requeiram otimizações. Essas oportunidades apoiam a busca por melhoria de visibilidade na rede (Objetivo 4). Novamente, o relacionamento entre os objetivos, reflete as oportunidades aos demais (Objetivos 1, 2 e 5).

O Quadro 11 (página 99) aponta que equipe também apresenta flexibilidade, na visão possitiva sobre a necessidade de envolvimento de clientes e parceiros nos processos de planejamento, monitoramento e desenvolvimento dos subprojetos; nível de aceitação alto para um novo processo de desenvolvimento, em especial, o ágil; aceitação para atuar em prol da tomada de decisão colaborativa, refletindo características de auto-organização e autogestão, 
mesmo que não estejam presentes em todas as equipes envolvidas; visão positiva sobre otimizar o modelo de gestão para minimizar conflitos e balancear controle e flexibilidade; presença de senso de equipe, alcançado por meio da confiança; visão positiva sobre o uso da comunicação para solucionar problemas; nível alto de aceitação para mudanças pela maioria; desejo de reduzir disfunções burocráticas, priorizando colaboração, comunicação, adaptabilidade e flexibilidade; elevada capacidade para geração de conhecimento, fundamentada nas experiências prévias da equipe. Corroborando com a composição de oportunidades, estão o tamanho compacto das equipes dos subprojetos, composição multidisciplinar e sua capacidade para geração de conhecimento.

Quadro 11 - Oportunidades relacionadas à flexibilidade da equipe

\begin{tabular}{|l|l|}
\hline \multicolumn{2}{|c|}{ Oportunidade 6 - Flexibilidade da equipe } \\
\hline Oportunidade secundária & Literatura \\
\hline 6.1 - Busca envolvimento de clientes/parceiros & CHOW e CAO, 2008; CONFORTO et al., 2014 \\
\hline 6.2 - Visão positiva sobre a gestão ágil & $\begin{array}{l}\text { CHOW e CAO, 2008; CONFORTO et al., 2014; } \\
\text { TOLFO et al., 2011 }\end{array}$ \\
\hline 6.3 - Inexistência de figura centralizadora de poder & $\begin{array}{l}\text { CHOW e CAO, 2008; CONFORTO et al., 2014; } \\
\text { MCAVOY e BUTLER, 2009 }\end{array}$ \\
\hline 6.4 - Visão de que a gestão pode ser otimizada & - \\
\hline 6.5 - Equipes compactas & CHOW e CAO, 2008; CONFORTO et al., 2014 \\
\hline 6.6 - Forte presença de senso de equipe & MCAVOY e BUTLER, 2009 \\
\hline 6.7 - Visão de comunicação como ferramenta & BECK et al., 2001 \\
\hline 6.8 - Equipes multidisciplinares & CHOW e CAO, 2008; CONFORTO et al., 2014 \\
\hline 6.9 - Aceitação para mudanças & $\begin{array}{l}\text { CHOW e CAO, 2008; CONFORTO et al., 2014; } \\
\text { CONFORTO, REBENTISH e AMARAL, 2014; } \\
\text { TOLFO et al., 2011 }\end{array}$ \\
\hline 6.10 - Desejo por redução de burocracias & BECK et al., 2001 \\
\hline 6.11 - Visão por adaptabilidade e flexibilidade & $\begin{array}{l}\text { CHOW e CAO, 2008; CONFORTO et al., 2014; } \\
\text { NOOR, RABISER e GRÜNBACHER, 2008 }\end{array}$ \\
\hline 6.12 -Elevada capacidade para geração de conhecimento & CONFORTO, REBENTISH e AMARAL, 2014 \\
\hline
\end{tabular}

Considerando a importância que o modelo de objetivos exerce sobre os demais submodelos, representando a ação da unidade de análise, é necesário que adequações focadas na gestão visem solucionar tais problemas, aproveitando as oportunidades no âmbito da gestão ágil, reflitando-as sistêmicamente, porém sem alterações bruscas. As adequações podem abranger a inserção de objetivos em prol de inserir os princípios, valores e práticas da gestão ágil no cotidiano da unidade de análise. Salienta-se que os objetivos, oportunidades e políticas existentes não necessitam de alterações bruscas para transição e ainda, que a caracterização do segmento como gestão de transportes e pedagiamento, não foi identificada como problema e/ou oportunidade - nem pela literatura analisada, nem nos questionários - assim, o segmento pode 
ser descaracterizado, aumentando a abrangência do modelo para outros com características semelhantes. Essa descaracterização implica em remoção e/ou ajuste de oportunidades (Oportunidades 2 e 4), bem como em objetivos (Objetivos 2 e 1).

Dois elementos - um identificado como problema e um como oportunidade - não encontraram amparo na literatura, mas estavam presentes na unidade de análise: distintas formas de gestão no ambiente (Problema 8), visão de que a gestão pode ser otimizada (Oportunidade 6.4).

\subsubsection{Necessidade de mudanças para o Modelo de Regras de Negócios}

Com a análise do modelo de regras, as informações coletadas nos questionários e os pontos apresentados no "need-for-change" do modelo de objetivos, foram identificados os principais aspectos que precisam ser alterados no modelo de regras para viabilizar a transição do modelo de gestão.

Conforme destacado na Figura 5 (página 83), a característica de formação de parcerias por contratos formais (Problema 1) incide em disfunções burocráticas no ambiente que estimulam o desejo da maioria de minimizá-las. Mesmo que não seja possível eliminar completamente disfunções burocráticas contratuais, seu peso pode ser amenizado com a combinação de práticas do tradicional com o ágil (CONFORTO et al., 2014), consistindo em uma oportunidade (Oportunidade 1) para promoção dos valores, princípios e práticas do ágil, em especial, no cotidiano dos projetos da unidade de análise.

Para transição, a combinação de práticas fundamenta-se com a visão positiva da maioria dos participantes sobre: utilização de ferramentas visuais, conceito de visão, foco nas pessoas, ciclos iterativos, maior envolvimento de clientes, entregas parciais com valor agregado, uso de influenciadores (equipe de planejamento e monitoramento), incentivo a auto-organização e autogestão, atualização frequente no planejamento e adaptação do modelo de gestão de acordo com a necessidade de cada subprojeto.

Salienta-se que esse modelo também não necessita de alterações bruscas e, novamente, pode ser descaracterizado do segmento da unidade de análise, por meio da eliminação de regras específicas (Regras 1 e 3).

\subsubsection{Necessidade de mudanças para o Modelo de Atores e Recursos}

Com a análise do modelo de atores, as informações coletadas nos questionários - em especial sobre a forma de gestão vigente e aplicabilidade do ágil - e os pontos apresentados no "need-for-change" dos modelos de objetivos e regras, foram identificados os principais 
aspectos que precisam ser alterados no modelo de atores para viabilizar a transição do modelo de gestão.

Conforme destacado na Figura 6 (página 85), com a pesquisa foram identificadas ações importantes para o projeto, realizadas por atores até então despercebidos no recorte micro (Unidade organizacional 4) ou até mesmo “esquecidos" entre as divisões da empresa focal (Unidade organizacional 2). A devida compreensão dos relacionamentos existentes, bem como dos papéis de cada ator, auxília no processo de transição (QUMER e HENDERSONSELLERS, 2008; MISHRA e MISHRA, 2011), permitindo adequar os processos para o devido cumprimento dos objetivos.

Essa adequação vai ao encontro às práticas da gestão ágil, como uso do conceito de visão da rede e dos subprojetos e incide em reorganização dos papéis, bem como criação de novos. Também influência na criação de equipes ágeis no ambiente, na combinação de abordagens e no fortalecimento da auto-organização e autogestão. Essa mudança estrutural, requer preparo dos envolvidos (NOOR, RABISER e GRÜNBACHER, 2008; MISHRA e MISHRA, 2011; CONFORTO et al., 2014), em termos de compreensão das diferenças de atuação entre equipes ágeis e tradicionais no projeto, até treinamento nos valores, princípios e práticas que serão utilizados.

\subsubsection{Necessidade de mudanças para o Modelo de Processos}

Com a análise do modelo de processos, as informações coletadas nos questionários e os pontos apresentados no "need-for-change" dos modelos prévios, foram identificados as principais otimizações que precisam ser realizadas no modelo de processos para viabilizar a transição do modelo de gestão. Os pontos de melhoria identificados estão relacionados aos problemas e oportunidades discutidos previamente.

A definição dos principais processos da rede é importante para compreender sua influência no ambiente e otimizar a exploração das competências (PEKKARINEN e HARMAAKORPI, 2006), com base nisso a Figura 10 (página 93) e Figura 11 (página 95) destacam os processos que precisam sofrer alterações:

Processo para gerar demandas: no recorte micro, os problemas - de gestão do conhecimento, visão, comunicação, transferência de conhecimento, alterações frequentes nos requisitos e falta de envolvimento de toda a equipe - não são devidamente analisados e tratados pelo modelo de gestão atual, dificultando a visualização de necessidades que originam demandas na rede. Devido a importância das ações do Centro de pesquisas no projeto, tais problemas refletem-se sistêmicamente. 
Processo para receber e tratar demandas: também foram apontadas falhas de gestão do conhecimento, modo de priorização, na motivação e alocação da equipe, na forma de comunicação, transferência de conhecimento, acompanhamento de cronograma e alterações. As ações são realizadas de forma isolada, envolvendo poucos atores da equipe e, geralmente, sem planejamento e documentação adequados, gerando falta de visão dos objetivos, atrasos e descontentamento. Similar ao processo anterior há influência na entrega de resultados ao recorte macro - do produto final, e/ou de relatórios do andamento -, minimizando as chances de toda a equipe tratar conjuntamente de alterações necessárias e sobrecarregando os gerentes.

Processo para acompanhar resultados e comunicar interessados: o recorte macro sofre com atrasos e despriorização no envio de relatórios; falhas de comunicação, devido à falta de atenção à importancia das reuniões de alinhamento entre as equipes - as que ocorrem envolvem, em sua mairoia, gerentes que não repassam todas as deliberações aos demais - e também, falha na gestão de conhecimento, característica necessária para realização das visitas técnicas. Apesar do atual desempenho satisfatório, essas falhas causam desmotivação, problemas e correrias desnecessárias no ambiente.

No recorte micro o registro de atividades diariamente tornou-se um peso para a equipe que acaba duplicando informações em ferramentas distintas e, para o gerente, por não ser possível fornecer parecer sobre tudo é exposto. Alguns atores abandonaram essa atividade e são cobrados. Quanto à forma de realização de reuniões, é vista como positiva e válida para a maioria, mas a frequência é baixa e, geralmenete, não há pauta para guiar as ações, bem como não é incentivado o uso de ferramenta para documentar as deliberações de forma centralizada e de fácil acesso.

Processo de acompanhamento e liberação de recursos: o acompanhamento da evolução da requisição também pode ser otimizado. Por vezes, essa demanda fica esquecida entre as muitas atividades, por não estar devidamente documentada e não ter pessoas alocadas e treinadas para conduzir adequadamente as ações. No recorte macro o recebimento de requisições mais rapidamente e com maior qualidade no conteúdo pode acelerar o processo de liberação.

Processo para entregar resultados e comunicar interessados: os atrasos nas entregas, resultantes de falhas no recorte micro, são os principais problemas, bem como a falta de entregas parciais para acompanhamento das ações e tomada de decisão. A comunicação e transferência do conhecimento na equipe não é otimizada, ocorrendo quase que majoritariamente, através do gerente do projeto e/ou atores chave, minimizando a visão, aprendizado e atuação da equipe sobre a situação e demandas. 
Processo para transferência do conhecimento mensal: falhas na gestão de conhecimento, comunicação, uso inadequado de ferramentas e concentração de responsabilidades em poucos atores, resultam em atrasos, perda de atividades e evidências das mesmas, bem como desmotivação, desgastes pela forma de requisição e, menos frequente, perdas financeiras.

Apesar de ser um processo relativamente simples, ele necessita que todos os demais estejam afinados e otimizados para que a geração e entrega de resultados mensalmente seja eficiente e praticamente automatizada. A ineficiência desse processo foi apontada como um dos principais problemas práticos para a pesquisa-ação.

Processo para estimular inovação na rede: não foram identificados problemas críticos para esse processo, mas falhas nos processo do Centro de pesquisas influenciam a rede, como atrasos, falta de entregas pontuais, carência de reuniões de alinhamento e afins.

Processo para disseminar melhores práticas no segmento: aqui também não foram identificados problemas críticos, mas falhas nos processo de recebimento e tratamento de demandas no Centro de pesquisas influenciam toda a rede, uma vez que os resultados atingidos são utilizados no processo de disseminação de melhores práticas no segmento.

Processo para gestão de parcerias e recursos humanos: devido aos tipos de parcerias contratuais formadas, os elementos que podem ser otimizados no caso do recorte macro, residem no processo de avaliação de permanência na rede, uma vez que a visibilidade adequada de atividades, comunicação eficiente e celeridade na entrega de resultados, podem auxiliar na identificação de parcerias que não estejam fluindo como o esperado. No recorte micro, existem falhas de comunicação, transferência de conhecimento, acompanhamento, motivação e possibilidade de aprendizado na equipe, devido a ineficiências no processo.

De modo geral, os processos existentes não são complexos e não existe, em especial no recorte micro, obrigatoriedades contratuais para utilização de um padrão processual. As otimizações necessárias envolvem o ajuste dos processos existentes - utilizando as oportunidades existentes para solucionar os problemas -, bem como a remoção de subprocessos de acompanhamento desnecessários e a criação de novos processos que sejam identificados como necessários - como processos para planejar a transição (JAVDANI GANDOMANI e ZIAEI NAFCHI, 2015) e para tratar demandas que não requerem a utilização das praticas do ágil (CONFORTO, REBENTISH e AMARAL, 2014).

Apesar de antes das ações da pesquisa-ação, não existir documentação sobre os processos, é perceptível que o foco está nos resultados e nas pessoas (BECK et al., 2001), sendo 
este um facilitador para a transição às práticas do ágil que podem auxiliar nas adequações, aumentando a eficiência da rede, a motivação e aprendizado da equipe, bem como minimizando sobrecarga em atores chave.

\subsubsection{Necessidade de mudanças para o Modelo de Componentes e Requisitos Técnicos}

Por fim, com a análise apresentada para o modelo de componentes e requisitos técnicos, frente as informações coletadas nos questionários e aos pontos apresentados no "need-forchange" dos demais modelos, foram identificados os principais problemas práticos associados à ferramentas que ocorrem na unidade de análise e influenciam a gestão. As Figura 10 (página 93) e Figura 11 (página 95) ilustram esses elementos e o Quadro 12 o cruzamento dos mesmos com a literatura.

O Quadro 12 (página 104) indica que o uso de ferramentas de sistema de informação inadequadas e ineficientes para comunicação, planejamento, coordenação e, gestão de conhecimento, em especial, quando ocorre trabalho colaborativo distribuído - envolvendo fronteiras temporais e geográficas - também está associado aos problemas identificados no modelo de gestão (Problemas 1 a 8).

Quadro 12 - Problemas relacionados à ferramentas inadequadas

\begin{tabular}{|c|c|}
\hline Problema identificado & Literatura \\
\hline 1 - Tempo de atendimento/resposta & $\begin{array}{l}\text { BULLINGER, AUERNHAMMER e } \\
\text { GOMERINGER, } 2004\end{array}$ \\
\hline 2 - Alterações frequentes nos requisitos & $\begin{array}{l}\text { BULLINGER, AUERNHAMMER e } \\
\text { GOMERINGER, 2004; DILK et al., 2008; } \\
\text { MARTINS, GILSON e MAYNARD, } 2004\end{array}$ \\
\hline 3 - Atrasos no compartilhamento & $\begin{array}{l}\text { BULLINGER, AUERNHAMMER e } \\
\text { GOMERINGER, 2004; DILK et al., 2008; } \\
\text { MARTINS, GILSON e MAYNARD, } 2004\end{array}$ \\
\hline 4 - Dificuldade de visualizar todas as atividades & $\begin{array}{l}\text { BULLINGER, AUERNHAMMER e } \\
\text { GOMERINGER, 2004; DILK et al., 2008; } \\
\text { MARTINS, GILSON e MAYNARD, } 2004\end{array}$ \\
\hline 5 - Falhas na comunicação & $\begin{array}{l}\text { KAUFMANN, LEHNER e TÖDTLING, 2003; } \\
\text { BULLINGER, AUERNHAMMER e } \\
\text { GOMERINGER, 2004; MARTINS, GILSON e } \\
\text { MAYNARD, 2004; DILK et al., 2008; }\end{array}$ \\
\hline 6 - Falhas na gestão do conhecimento & $\begin{array}{l}\text { BULLINGER, AUERNHAMMER e } \\
\text { GOMERINGER, 2004; DILK et al., 2008; } \\
\text { KAUFMANN, LEHNER e TÖDTLING, 2003; } \\
\text { MARTINS, GILSON e MAYNARD, } 2004\end{array}$ \\
\hline 7 - Tempo para tomada de decisão & $\begin{array}{l}\text { BULLINGER, AUERNHAMMER e } \\
\text { GOMERINGER, 2004; DILK et al., 2008; } \\
\text { KAUFMANN, LEHNER e TÖDTLING, 2003; } \\
\text { MARTINS, GILSON e MAYNARD, } 2004\end{array}$ \\
\hline 8 - Dificuldade de controlar todas as solicitações & $\begin{array}{l}\text { BULLINGER, AUERNHAMMER e } \\
\text { GOMERINGER, 2004; DILK et al., } 2008\end{array}$ \\
\hline
\end{tabular}


$\mathrm{Na}$ unidade de análise o tempo de resposta é importante para manutenção dos serviços dos envolvidos, desde o atendimento de requisições e tratamento de incidentes, passando pelo envio de artefatos resultantes das atividades, até a tomada de decisão. Esse tempo deve ser otimizado, por exemplo, com a combinação de processos e ferramentas adequadas que ampliem o envolvimento dos atores e a frequência nos compartilhamentos de informações, ações, recursos e resultados, minimizando atrasos, falhas no atendimento, eventuais perdas financeiras e, ampliando a colaboração para resolução de problemas.

Similarmente, as alterações frequentes nos requisitos, afetam diretamente a motivação da equipe, planejamento e andamento das atividades. A dificuldade na visualização de atividades também é preocupante, considerando os vários relacionamentos e os subprojetos existentes. Tais problemas incidem, entre outros, em dificuldades para controlar todas as solicitações, portanto é essencial estimular adaptabilidade e flexibilidade com a o uso adequado de ferramentas que permitam absorver o impacto de alterações e aumentem a visibilidade de tarefas e objetivos, por exemplo, facilitando atualizações de planejamento e acesso à informação.

Falhas na comunicação também são recorrentes e tem efeitos cruciais no desempenho da rede; de modo similar, a gestão do conhecimento inadequada incide em sérios problemas. Ambos requerem combinação de mudanças de hábito e uso de ferramentas simples e acessíveis, em especial, devido a existência de colaboração à distância.

Salienta-se que na situação atual, as melhorias não requerem investimentos grandes em ferramentas, mas em ajustes nas ferramentas que já são utilizadas, juntamente com mudanças de hábitos relacionadas às demais necessidades de mudança, em prol de realizar a transição para o modelo de gestão ágil.

\subsection{CONTRIBUIÇÕES DO NEED-FOR-CHANGE: REQUISITOS PARA APLICAÇÃo da GESTÃo ÁGIL EM REDES DE INOVAÇÃo AUTO- ORGANIZADAS}

Diante dos modelos e das necessidades de mudança, é possível visualizar que a forma de gestão conduzida na situação atual, contém problemas refletidos no cotidiano prático da unidade de análise. Apesar disso, a unidade de análise apresenta oportunidades que podem facilitar a transição para um modelo de gestão mais flexível e adaptado a sua realidade.

Dessa forma, ao analisar os requisitos que estimulam a aplicação da gestão ágil em ambientes de redes de inovação auto-organizadas, recai-se na execução de duas ações principais: identificação de problemas recorrentes no ambiente e; identificação de 
características que convertem-se em oportunidades para buscar solução a tais problemas. Essa análise pode ser realizada através da modelagem de empresas com auxílio da equipe envolvida.

Por meio do modelo de objetivos foram identificados os problemas listados no Quadro 8 e Quadro 9; o modelo de regras indica limitações que devem ser consideradas - combinação de técnicas do tradicional com o ágil; o modelo de atores aponta o problema da falta de compreensão sobre todos os relacionamentos existentes na rede, bem como dos papéis de cada ator; os submodelos de processos apontam a necessidade de otimizar os processos existentes que na situação atual: evidenciam os problemas elencados, tornando-os sistêmicos, desmotivam e sobrecarregam a equipe, evidenciam o uso inadequado de ferramentas, não organizam informações importantes, não apoiam o trabalho colaborativo e impulsionam a alocação de RH sem considerar capacidades e vontades dos indíviduos e; por fim, o modelo de componentes e requisitos técnicos reafirma os demais, sumarizando-os em problemas relacionados à ferramentas: não otimizam tempo de resposta, não facilitam atendimentos, a gestão de alterações em requisitos, a visualização das atividades por estagios (novas, em andamento, concluidas), o acesso à informação, a comunicação e a gestão do conhecimento.

Similarmente, por meio do modelo de objetivos foram identificadas as oportunidades listadas no Quadro 10 e Quadro 11, relacionadas à flexibilidade e adaptabilidade do ambiente e da equipe, bem como a existência de contato prévio com o ágil. O modelo de regras é influenciado por tais oportunidades, por não conter elementos que forcem a manutenção do modelo atual, possibilitando a promoção da gestão ágil, bem como a combinação de práticas. A estrutura da equipe do Centro de pesquisas apresentada no modelo de atores, também é uma oportunidade, devido a flexibilidade já citada, bem como a existência de auto-organização no ambiente. $\mathrm{O}$ modelo de processos indica que não existem padrões contratuais e/ou excesso de complexidade e disfunções burocráticas que impeçam otimizações, limitando a transição e também, que não são necessários investimentos pesados - tempo e financeiro - para ajustar as ferramentas existentes e entregar o necessário.

Os problemas e oportunidades confirmam a necessidade de melhorias no modelo de gestão do projeto para entregar resultados úteis com celeridade, frequência e qualidade e, no caso do relatório mensal (demanda contratual), sem atrasos; influenciando a gestão da rede e garantindo a evolução dos objetivos. Essas características vão ao encontro aos valores, princípios e práticas da gestão ágil. Assim, após a identificação dos requisitos - problemas e oporunidades - na unidade de análise que destacam a aplicabilidade da abordagem ágil, um plano de ação foi estruturado, apresentado e discutido com todos os envolvidos, para viabilizar 
a transição para um modelo de gestão ágil, levando em conta os desafios existentes (QUMER e HENDERSON-SELLERS, 2008; MISHRA e MISHRA, 2011).

O plano baseou-se em um conjunto de ações, amparados na literatura, envolvendo a modelagem de empresas da situação futura para: otimizar comunicação; obter rapidez na identificação de necessidades/oportunidades; intensificar colaboração com atores externos ao Centro de pesquisas e de outras unidades do mesmo; ajustar alocações e motivar equipe; melhorar atendimentos; organizar gestão do conhecimento com uso de ferramentas simples; realizar treinamentos constantes; fortalecer a importância dos princípios de visão; intensificar a transferência de conhecimento; aumentar frequência de planejamentos e alinhamentos e obter processos que permitam a combinação de abordagens ágeis com tradicionais. O próximo capítulo parte desse plano para dar seguimento na pesquisa.

Diante dos dados coletados, analisados e gerados nas etapas exploratória e aprofundada da pesquisa-ação, organizados através da modelagem, foi possível verificar a situação atual da unidade de análise e reponder a primeira das questões (Quadro 2) da pesquisa - (1) foram observados elementos que justificam a aplicação da gestão ágil; os mesmos foram sistematizados como problemas e oportunidades (seção 3.2) -, cumprindo o objetivo estabelecido para este capítulo.

Salienta-se que não é necessário a presença total de problemas e oportunidades listados para verificar a necessidade de transição e ainda, que o entendimento da situação atual em recortes "macro" e "micro", facilita a visualização de problemas e também de oportunidades associados aos valores, princípios, práticas e possibilitadores que sustentam a abordagem ágil que podem otimizar o cotidiano do projeto e da rede como um todo. As questões abordadas no protocolo da pesquisa e na seção 3.23.1.1 nortearam o processo de modelagem e podem auxiliar em uma possível replicação da pesquisa em redes com características similares, auxiliando no planejamento da transição do modelo de gestão.

Por fim, este capítulo contribui com pesquisas na área de gestão ágil e de redes de inovação auto-organizadas, no que tange a forma de realizar análise prática da necessidade de mudança em modelos de gestão utilizados em redes, por meio de modelagem de empresas. 


\section{MODELAGEM DE EMPRESAS PARA GESTÃo ÁGIL DE REDES DE INOVAÇÃO AUTO-ORGANIZADAS}

Em ambientes de redes de inovação o sucesso depende do foco da gestão em todos os agentes envolvidos e ainda, da correta definição, alinhamento e monitoramento dos objetivos, responsabilidades e atividades. Combinar todas essas necessidades não é tarefa fácil e tendo em vista a aplicabilidade da abordagem ágil para esses cenários, verificada previamente, tentativas podem ser realizadas em prol de desenvoler modelos ágeis de gestão que forneçam a flexibilidade e adaptabilidade necessárias para o dinamismo desses ambientes.

Nesse contexto, este capítulo tem como propósito apresentar a modelagem de empresas (enterprise modeling) utilizada na aplicação da abordagem ágil na rede de inovação autoorganizada observada. O modelo representa o estado futuro da unidade de análise e é resultado da pesquisa-ação, em especial, das fases de ação e avaliação, executadas após a identificação dos requisitos para transição. Também são apresentadas discussões sobre o modelo proposto, a forma de validação utilizada, bem como os benefícios e limitações identificados na sua aplicação, em prol de contribuir com a literatura da área.

\subsection{MODELAGEM DE EMPRESAS PROPOSTA A PARTIR DA PESQUISA-AÇÃO (TO-BE)}

Para facilitar a visualização da aplicação da gestão ágil em ambientes de redes de inovação auto-organizadas, o conjunto de submodelos deste capítulo também segue o recorte em "macro" - foco na rede - e "micro" - foco nos projetos colaborativos da mesma, relacionados ao Centro de pesquisas.

Os modelos apresentado para o estado "to-be" consistem nos modelos do "as-is" acrescidos dos elementos identificados em campo com a análise do "need-for-change", resultando em alterações, inclusões e remoções. Esses elementos são representados em cor azul para facilitar a visualização.

\subsubsection{Modelo de Objetivos}

Conforme a Figura 12 (página 111), os principais objetivos no recorte macro (Objetivos 1, 2 e 3) são apoiados pelos principais objetivos do recorte micro (Objetivos 4 e 5). Dessa forma, a aplicação de valores e princípios da gestão ágil na micro, reflete-se na macro através de melhorias nos objetivos existentes e inclusão de novos objetivos secundários. 
Para gerar inovação no segmento (Objetivo 1), além de gerar e transferir conhecimento (Objetivo 1.1) é necessário otimizar as entregas resultantes das atividades (Objetivo 1.2), acelerando o prazo e aumentando a frequência com que chegam aos interessados para que ações provenientes das mesmas sejam realizadas em tempo hábil. De modo similar, para impulsionar a aplicação de novas tecnologias no segmento (Objetivo 2), é necessário manter os objetivos relacionado à qualidade (Objetivo 2.3) e apoio (Objetivo 2.5), bem como fortalecer os demais (Objetivos 2.1, 2.2 e 2.4), por exemplo, através de otimização nos atendimentos na rede (Objetivo 2.6). O objetivo de gerar padrões para disseminar melhores práticas no segmento (Objetivo 3), estimula a aplicação de melhorias na prestação de serviços (Oportunidade 3), entre essas melhorias encontra-se a busca por um modelo de gestão mais ágil e adaptável à realidade do segmento explorado. 
Modelo de Objetivos - Parte 1/2

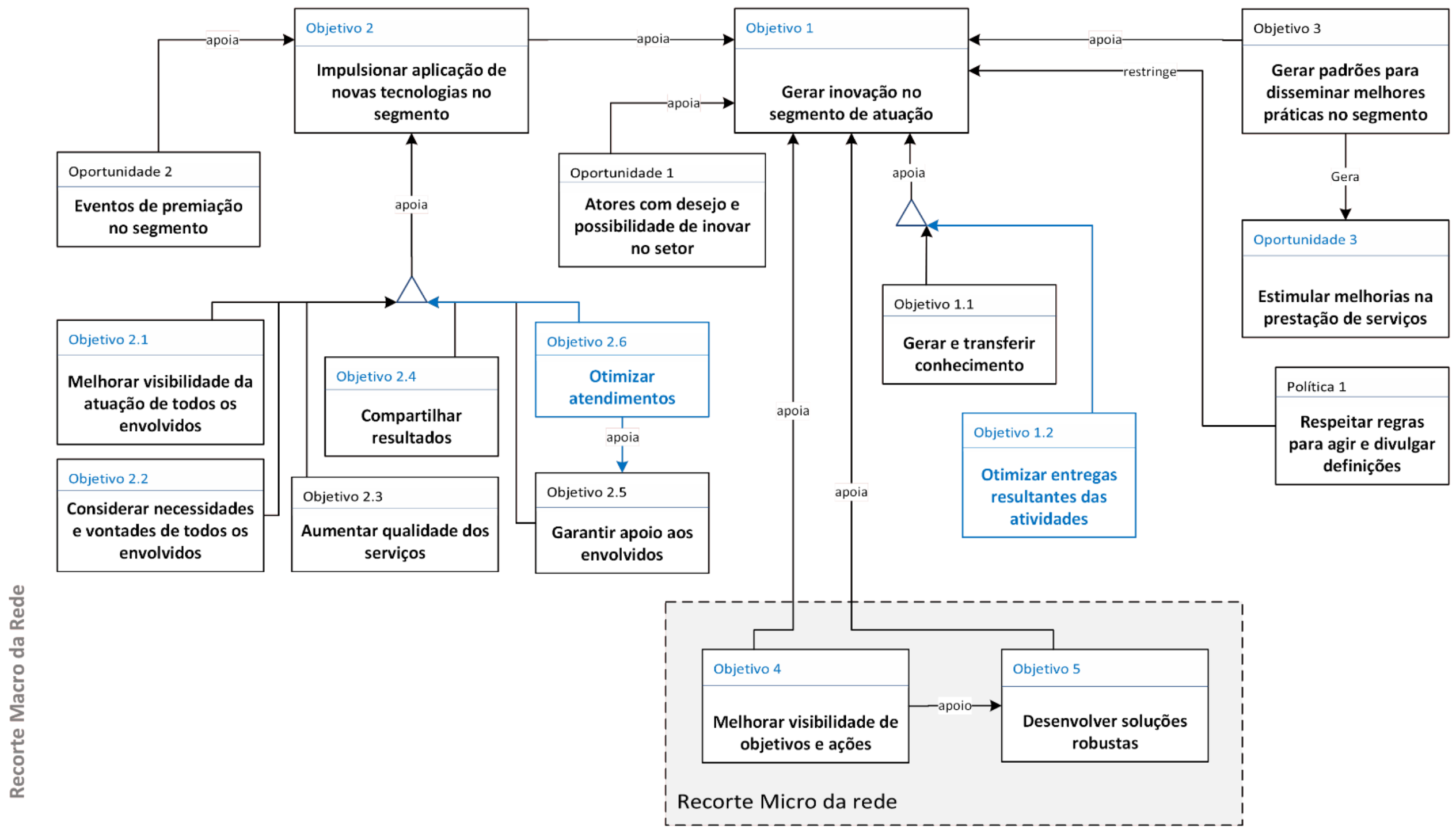

Figura 12 - Modelo de objetivos - tobe (Parte 1/2) 
Conforme a Figura 13 (página 113), para melhorar a visibilidade (Objetivo 4), além de controlar atividades (Objetivo 4.1) e facilitar a identificação de problemas (Objetivo 4.2), um novo conjunto de objetivos secundários faz-se necessário e também influencia a robustez das soluções geradas (Objetivo 5), devido ao relacionamento existente entre os objetivos 4 e 5 .

Esse novo conjunto visa influenciar a forma de gestão realizada nos subprojetos, em prol de melhorar a organização geral na rede (Objetivo 4.3), em termos de processos, gestão adequada de equipamentos, ambientes e afins; melhorar comunicação (Objetivo 4.4) interna e externa; motivar equipe (Objetivo 4.5); aumentar confiança (Objetivo 4.6) interna e externa; otimizar ferramentas de controle (Objetivo 4.7), almejando simplicidade e flexibilidade; promover o foco nas pessoas, em lugar de disfunções burocráticas (Objetivo 4.8); aplicar o conceito de visão no planejamento de ações (Objetivo 4.9); aumentar o envolvimento de toda equipe nas ações de planejamento e monitoramento (Objetivo 4.10) e; minimizar o que for possível de disfunções burocráticas (Objetivo 4.11), mediante combinação de práticas de gestão tradicional com ágil. 
Modelo de Objetivos - Parte 2/2

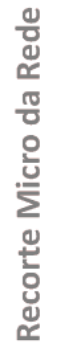

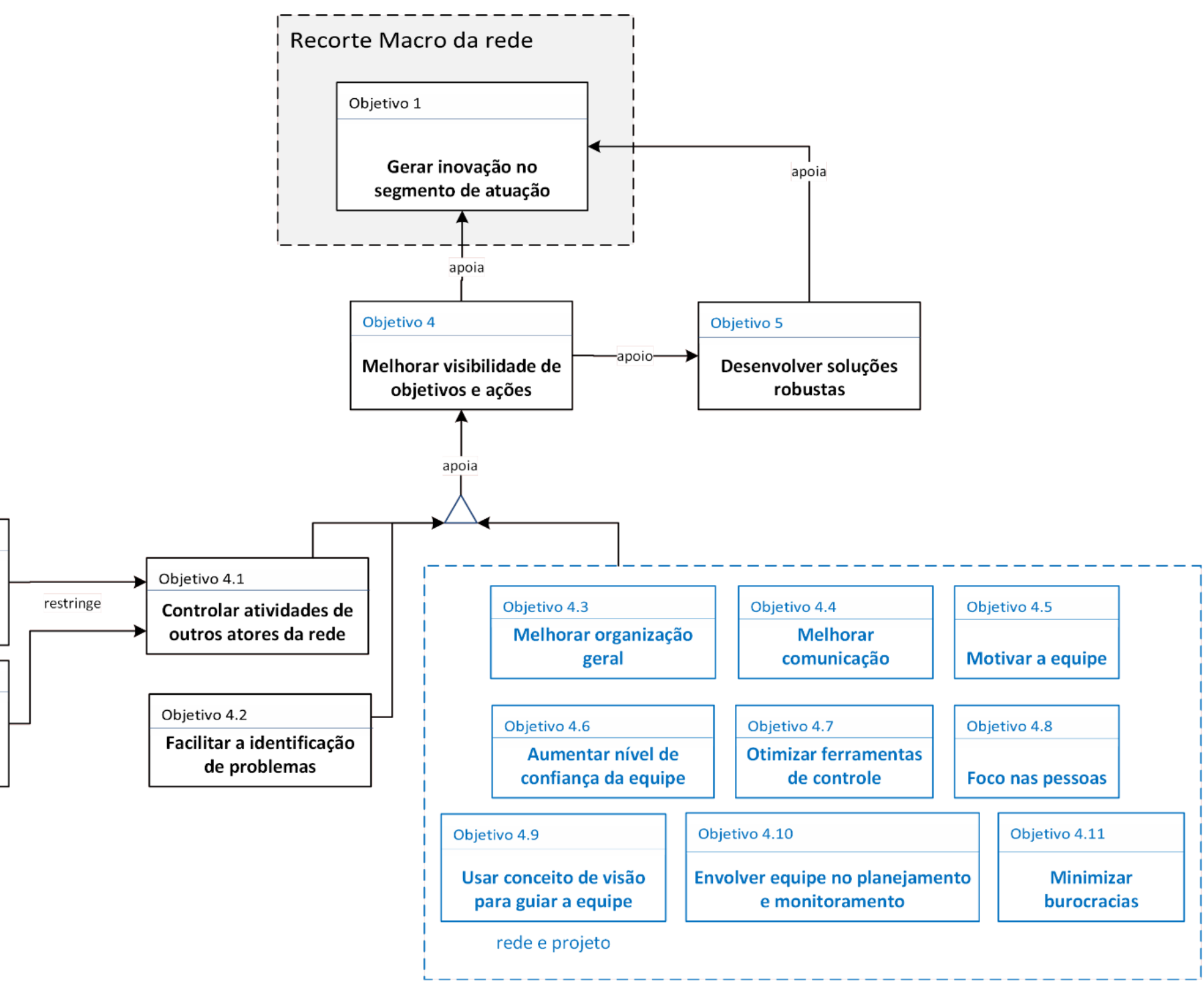

Figura 13 - Modelo de objetivos - tobe (Parte 2/2) 


\subsubsection{Modelo de Regras do Negócio}

Conforme a Figura 14 (página 115), para gerar inovação no segmento (Objetivo 1) é importante estimular $\mathrm{P} \& \mathrm{D}^{16}$ (Regra 4); o estímulo a P\&D (Regra 4), juntamente com a promoção de eventos de premiação para motivação (Regra 1) impulsionm a aplicação de novas tecnologias (Objetivo 2).

Para gerar padrões para disseminar melhores práticas no segmento (Objetivo 3), além de buscar qualidade nas soluções desenvolvidas (Regra 2), estimular P\&D (Regra 4) e considerar os requisitos e opiniões de todos os envolvidos na rede (Regra 3), um nova regra faz-se necessária para balancear controle e flexibilidade (Regra 5) nas ações realizadas.

Essa regra age em prol de adaptar o modelo de gestão para combinar tradicional e ágil ao incentivar o trabalho colaborativo (Regra 5.1); manter e divulgar processos otimizados (Regra 5.2); manter a gestão de parcerias por contratos (Regra 5.3); responder demandas com celeridade (Regra 5.4); monitorar a evolução de ações (Regra 5.5); manter planejamento atualizado (Regra 5.6) e; estimular a formalização de ações realizadas (Regra 5.7) através da utilização de documentação de evidência.

Considerando que os objetivos (Objetivos 1, 2 e 3 ) são influenciados pelos valores e princípios da gestão ágil, o mesmo ocorre com as regras (Regras 2, 3 e 5) e, no âmbito dos projetos da rede, são influenciadas também pelas práticas da gestão ágil.

${ }^{16}$ P\&D é a sigla para Pesquisa e Desenvolvimento. 
Modelo de Regras do Negócio - Parte 1/2

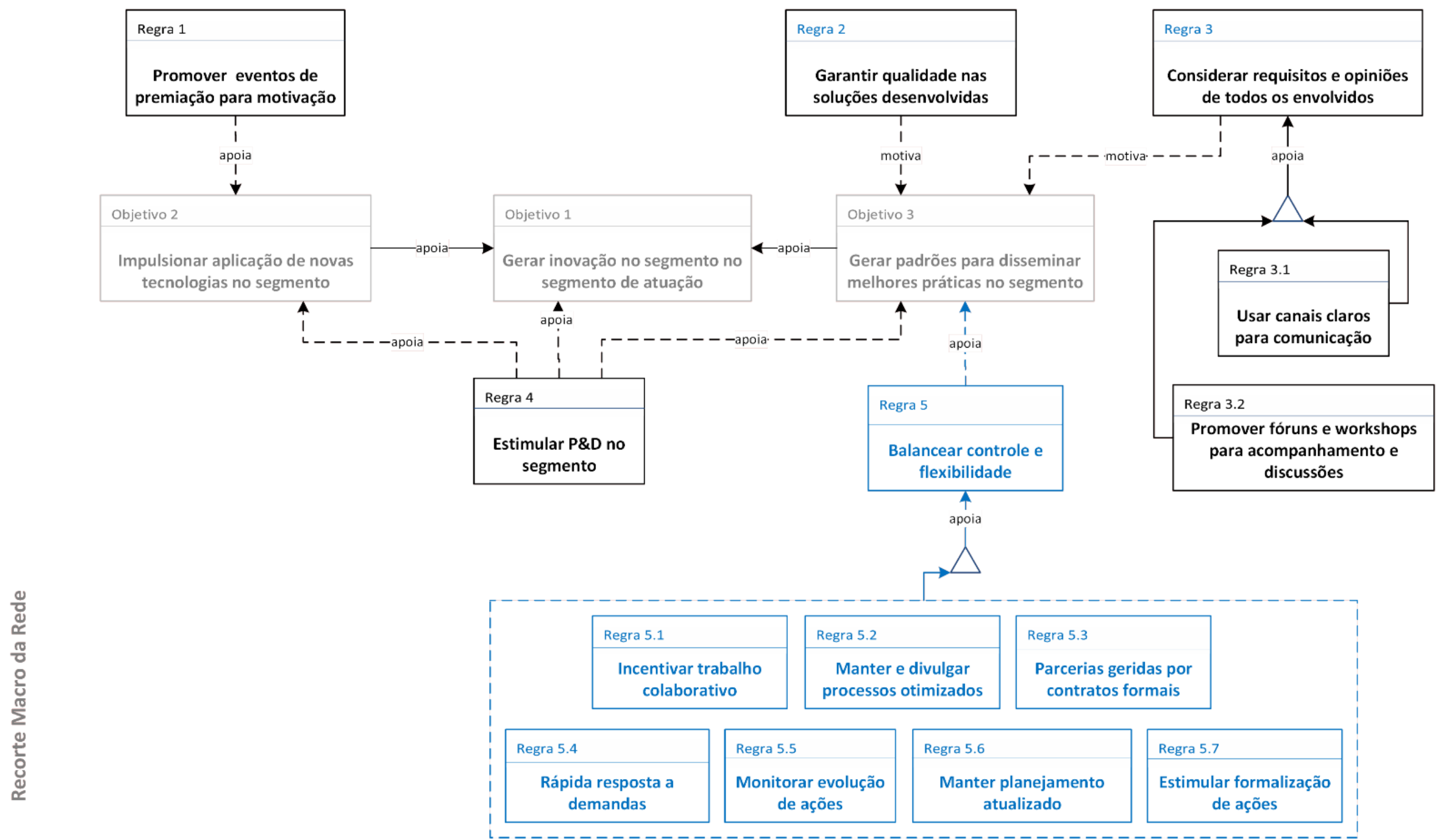

Figura 14- Modelo de regras do negócio - tobe (Parte 1/2) 
No detalhe dos projetos colaborativos da rede, conforme a Figura 15 (página 118), para melhorar a visibilidade de objetivos e ações (Objetivo 4) além das regras visando alertar sobre os problemas (Regra 6), manter transparência (Regra 12), agir com imparcialidade nas definições (Regro 8) e utilizar os meios de comunicação acordados (Regra 12), é necessário uma regra para promover a utilização das práticas da gestão ágil (Regra 13).

De modo similar, o desenvolvimento de soluções robustas para o segmento (Objetivo 5) é afetado por regras para responder os requisitos dos envolvidos (Regra 9), buscar qualidade (Regra 10), promover o uso de softwares livres e tecnologias homologadas (Regra 11) e além dessas, regras para promover a utilização das práticas da gestão ágil (Regra 13) e para realizar treinamentos (Regra 14). As duas novas regras inseridas no modelo visam: treinar a equipe do projeto (Regra 14) em torno dos elementos da gestão ágil, das adaptação realizadas ${ }^{17}$, de específicidades da rede e seus projetos e das ferramentas e processos necessários, bem como incentivar o uso de práticas da gestão ágil (Regra 13), através da realização de planejamento com uso de ciclos iterativos ${ }^{18}$ (13.1); incentivo ao uso de ferramentas simples e visuais (13.2); manutenção da organização dos ambientes do projeto (13.3); incentivo à comunicação e colaboração (13.4) internas e externas; realização de entregas parciais (13.5); incentivo à autoorganização (13.6) e autogestão da equipe; envolvimento de todos os interessados no processo de decisão (13.7); exposição da visão e objetivo dos subprojetos e seu funcionamento (13.8); promoção de reuniões ajustadas a diferentes propósitos (13.9) e; atualização frequente do planejamento (13.10).

A promoção de reuniões (Regra 13.9), segue o seguinte direcionamento: planejamento da iteração com toda equipe (utilizam-se cartões de documentação, lista de demandas, quadro de tarefas, entre outros); alinhamento diário com equipe, acerca dos pontos que estão sendo desenvolvidos e dificuldades (curta duração, no máximo 20 minutos pela manhã); alinhamento conforme necessidade; retrospeção da iteração, para que a equipe exponha os pontos que deseja que sejam melhorados e mantidos (toda equipe participa, geralmente ocorre ao início de uma reunião de planejamento, elege pontos para melhoria e tem curta duração - 20 minutos) e; revisão com patrocinador da demanda (ocorre ao final da iteração, geralmente com clientes ou representantes internos que estejam associados com as demandas geradas na iteração e foca na revisão do resultado gerado e na definição de novas demandas para a próxima iteração. Tais

\footnotetext{
${ }^{17}$ Combinação de abordagens de gestão tradicional com ágil.

${ }^{18}$ Tempo definido para entrega de resultados com valor ao interessado, como iteração de um mês com entrega de três artefatos que possam ser utilizados na rede (relatórios, produtos, serviços e afins), mesmo que não estejam no estado final.
} 
práticas da gestão ágil almejam facilitar a obtenção dos objetivos definidos para a rede, diretamente no âmbito dos subprojetos e indiretamente, como influência aos objetivos do recorte macro. 
Modelo de Regras do Negócio - Parte 2/2

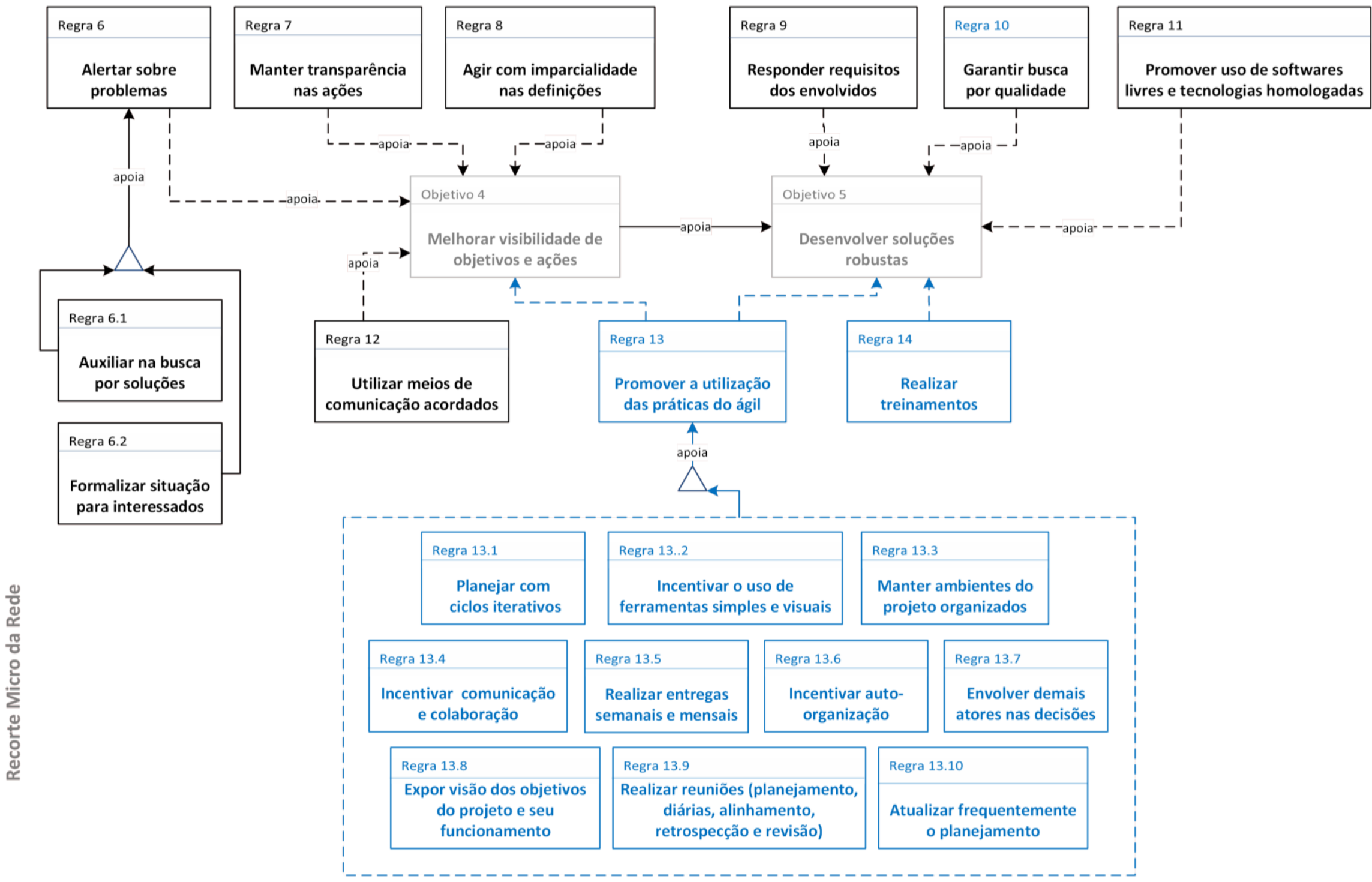

Figura 15 - Modelo de regras do negócio - tobe (Parte 2/2) 


\subsubsection{Modelo de Atores e Recursos}

Conforme a Figura 16 (página 120), o recorte macro não sofreu alterações provenientes da aplicação dos valores, princípios e práticas da gestão ágil, porém o incentivo a característica de auto-organização e autogestão que acentuam-se na configuração do recorte micro, influencia o ambiente da macro.

No recorte micro observa-se que atores necessários para o cumprimento dos objetivos foram devidamente reinseridos no contexto dos subprojetos, conforme análise realizada no "need-for-change", consistindo no setor de Microeletrônica e RFID ${ }^{19}$ do Centro de pesquisas e a Concessionária de rodovias.

Com relação ao setor de microeletrônica e RFID, a intenção é aproximar equipes que eventualmente trabalham juntas nos subprojetos da rede, por meio da intensificação da comunicação, participação conjunta na tomada de decisão e tratamento de demandas, bem como na geração de novos processos e artefatos.

Com relação à Concessionária de rodovias, apesar de sua importância no cotidiano de um dos subprojetos, a equipe envolvida não tinha clareza sobre sua influência, sendo que somente um dos atores da equipe relaciona-va com a mesma, portanto, não foi considerada nas ações do "as-is". Essa inserção visa eliminar tal isolamento e sobrecarga em um ator, por meio do alinhamento de toda a equipe acerca de sua atuação conjunta para o cumprimento dos objetivos, bem como dos papéis direcionados a cada um.

Tais aproximações são importantes para o modelo ágil de gestão para aumentar a qualidade das soluções desenvolvidas, otimizar prazos e incentivar novas oportunidades de P\&D em decorrência da colaboração mais aproxidada, mesmo que à distância. Sem isso, as capacidades de auto-organização e autogestão são prejudicadas e as equipes mantém relações em prol de solucionar demanda, mas não partilham os mesmos objetivos e visão, necessários para o crescimento.

\footnotetext{
${ }^{19}$ No contexto refere-se ao setor que lida com tecnologia de identificação por rádio-frequência no Centro de pesquisas.
} 

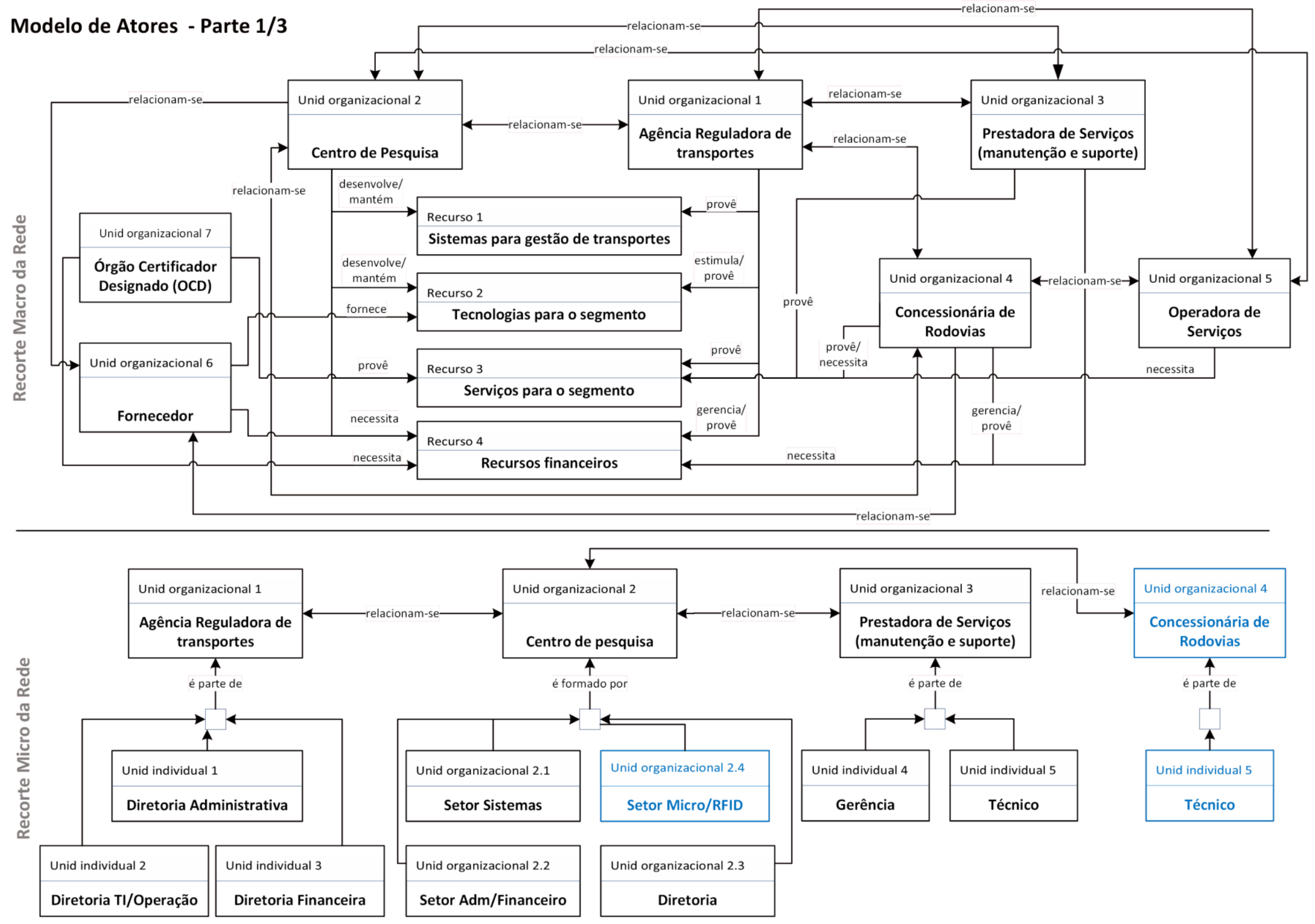

Figura 16 - Modelo de atores e recursos - tobe (parte 1/3) 
Conforme a Figura 17 (página 123), a inclusão do setor de Microeletrônica e RFID do Centro de Pesquisas (Unidade Organizacional 2), refletiu na estrutura da equipe dos subprojetos, bem como nos papéis. Os recursos utilizados pelo Centro de Pesquisas foram mantidos (Recursos 1, 2, 3, 6 e 7), a forma de tratar os relatórios foi alterada (Recurso 5) para contemplar as entregas parciais ${ }^{20}$ de valor agregado e, novos recursos visuais (Recurso 8) foram adicionados no cotiano dos subprojetos, como resultado da aplicação dos valores, princípios e práticas da gestão ágil. Por sua vez, os setores Administrativo-Financeiro e Sistemas, assim como a Diretoria mantiveram-se sem alterações estruturais, mas com alterações nos papéis.

O setor de Microeletônica (Unidade organizacional 2.4) possui analistas (Unidade individual 12), gerência (Unidade individual 14) e engenheiros (Unidade individual 13) que eventualmente são alocados no projeto da rede para tratar demandas e, em especial os analistas, participaram de adequações nos processos para otimizar o trabalho colaborativo e a geração de resultados. Essa ação unifica as equipes, mesmo separadas geograficamente, facilitando a gestão das capacidades e papéis, resultando na equipe ágil necessária para as ações colaborativas do novo modelo de gestão.

A disposição dos papéis sofreu otimizações que influenciam positivamente na qualidade dos artefatos gerados. Além disso, novos papéis foram incorporados como resultado das adaptações e maior entendimento das necessidades.

No setor de sistemas:

- a gerência (Unidade individual 7) age em prol da auto-organização e autogestão, auxiliando nos seguintes papeis: planejar inovações (Papel 6), comunicar e controlar ações (Papel 13) como novas demandas, definir tarefas e alocações (Papel 14), gerar relatórios e análises e, realizar visitas técnicas (Papel 25) com a equipe;

- os analistas (Unidade individual 8) colaboram ativamente com os demais atores no planejamento (Papel 6), comunicação e controle (Papel 13), definições (Papel 14), realização de demandas fixas (Papel 15), geração de artefatos (Papel 16), realização de tarefas e auxiliando nos atendimentos (Papel 17), realização de visitas (Papel 25), desenvolvimento de novas tecnologias (Papel 24), homologações ${ }^{21}$ (Papel 27), testes (Papel 29) e contato com fornecedores (Papel 32);

- o suporte (Unidade individual 9) passou a colaborar ativamente e aprender com o restante da equipe, auxiliando no planejamento (Papel 6), comunicação e controle

\footnotetext{
${ }^{20}$ Foram definidas para serem semanais, mensais e conforme evolução útil de artefatos.

${ }^{21}$ Homologação dos produtos (softwares e hardwares) desenvolvidos.
} 
(Papel 13), definições (Papel 14), realização de atividades fixas (Papel 15), realização de tarefas e atendimentos (Papel 17), geração de artefatos (Papel 16), testes (Papel 29), controle de inventário (Papel 28), comunicação de demanda para parceiros (Papel 30) internos e externos e contato com fornecedores (Papel 32);

No setor de microeletrônica e RFID:

- os analistas (Unidade individual 12) colaboram, conforme demanda, no planejamento (Papel 6), realização de visitas técnicas (Papel 25), testes com laudos (Papel 29), controle de inventário (Papel 28), configuração de equipamentos (Papel 31) e disponibilização de demandas (Papel 30) para parceiros externos;

- os engenheiros (Unidade individual 13) auxiliam, conforme demanda, no planejamento (Papel 6), desenvolvimento de novas tecnologias (Papel 24), realização de visitas técnicas (Papel 25), homologações(Papel 17), testes (Papel 29), configurações (Papel 31) e disponibilização de demandas (Papel 30) para parceiros externos;

- a gerência (Unidade individual 14) colabora, conforme demanda, no planejamento (Papel 6) e no acompanhamento de visitas técnicas (Papel 25).

Tais otimizações minimizam o isolamento e sobrecarga de trabalho em poucos atores, promovendo crescimento, confiança colaboração e motivação, com maior preocupação na trasferência de conhecimento, balanceamento de responsabilidades e enfoque nas capacidades individuais de cada um.

Outra adaptação realizada foi a identificação clara de responsáveis para cada subprojeto, facilitando a atuação e comunicação de particularidades em situações nas quais a equipe completa não pode estar presente, porém com monitoramento e manutenção da atuação normal desses atores na equipe para não recair em centralizações. Similarmente, incentivou-se a presença de atores vinculados a monitoramento e planejamento na equipe, para auxiliar na manutenção do modelo de gestão e motivação dos demais.

Salienta-se que a Diretoria e Setor Administrativo - Financeiro mantiveram-se como equipe tradicional, mas são beneficiados pelas alterações vindas da equipe ágil formada. 


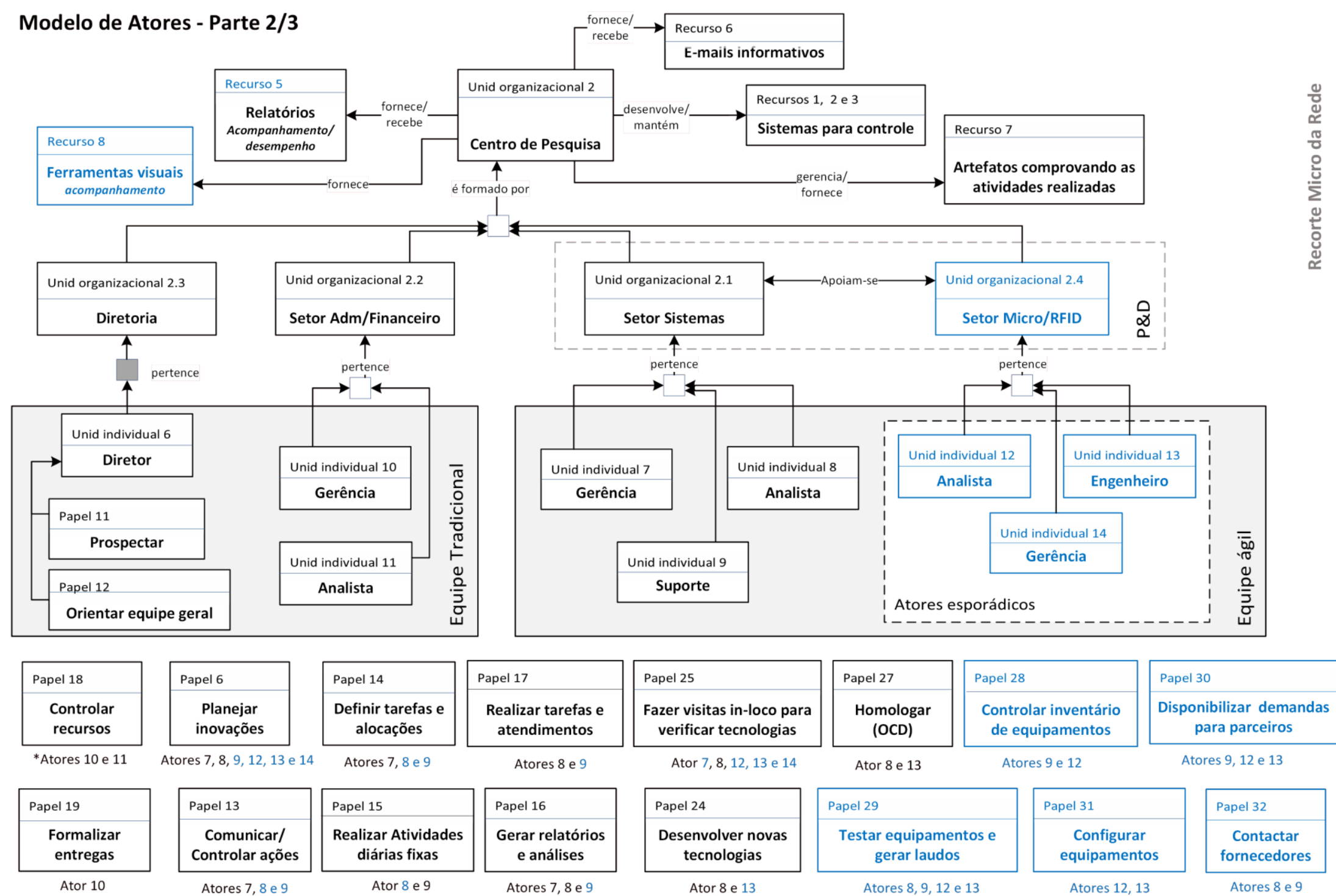

*Ator representa as diversas Unidades Individuais apresentadas que desempenham diversos papéis

Figura 17 - Modelo de atores e recursos - tobe (parte 2/3) 
Conforme a Figura 18 (página 125), a inclusão da equipe técnica (Unidade individual 5) da Concessionária de rodovias (Unidade organizacional 4) no recorte micro, refletiu na estrutura. Esse ator realiza conforme demanda do Centro de pesquisas, atividades relacionadas à manutenção de serviços (Papel 33), controle de recursos (Papel 18) e contato com fornecedores (Papel 32), requerendo acesso a ferramentas visuais (Recurso 8) para auxiliar na visualização de ações necessárias. Junto à Prestadora de Serviços (Unidade organizacional 3), mantém-se como ator parceiro no modelo de gestão ágil.

Por sua vez, a Agência Reguladora de transportes (Unidade organizacional 1) não sofreu alterações na sua estrutura e papéis, mas sim na forma com que é visualizada pela equipe ágil, agindo como parceiro patrocinador dos subprojetos, provendo demandas e recebendo os artefatos gerados. Dessa forma, a comunicação foi intensificada com esse ator e ferramentas visuais (Recurso 8) foram disponibilizadas pelo Centro de pesquisas para auxiliar no acompanhamento, planejamento e controle de ações nos subprojetos da rede. 


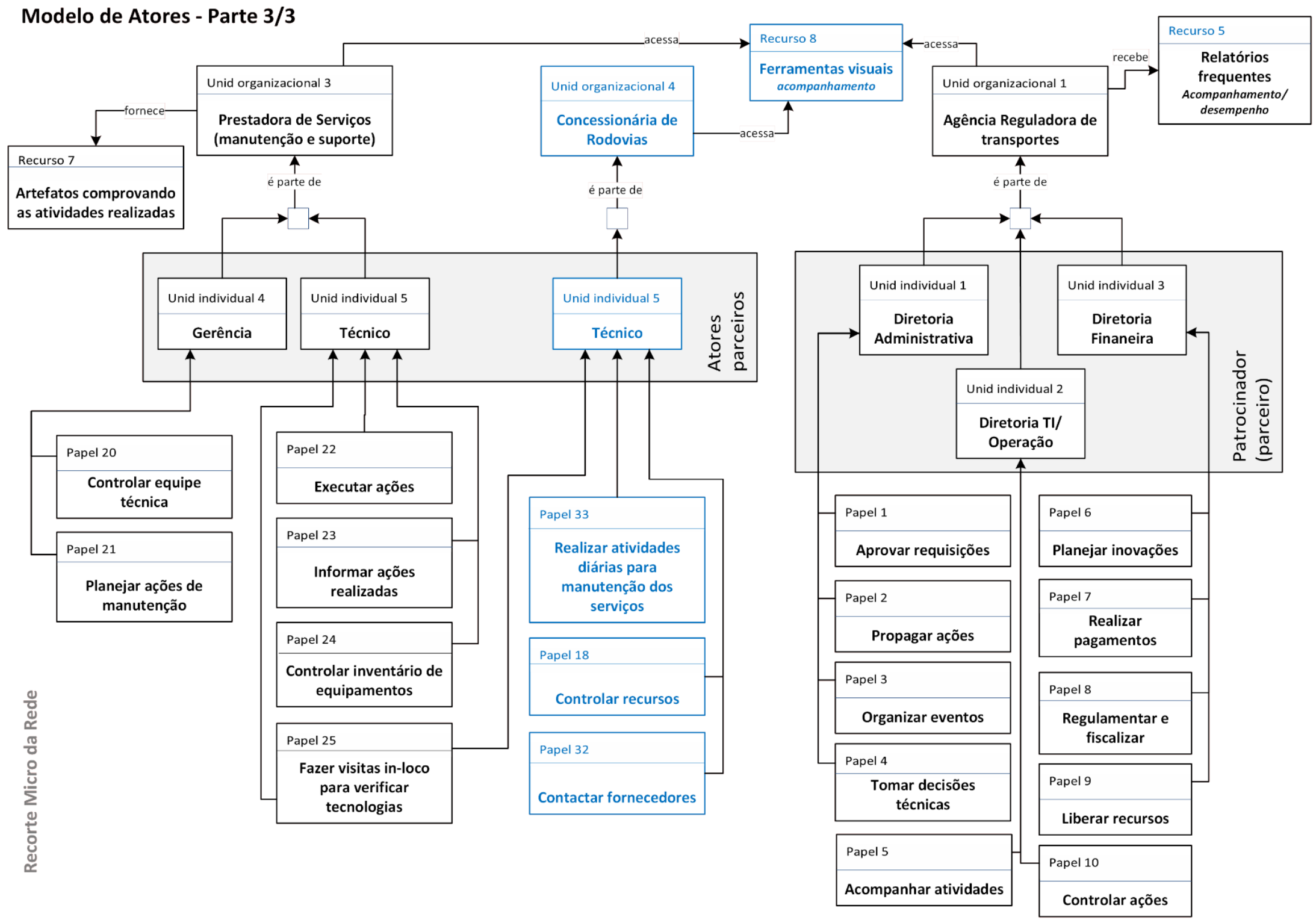

Figura 18 - Modelo de atores e recursos - tobe (parte 3/3) 


\subsubsection{Modelo de Processos}

Conforme a Figura 19 (página 128), os processos no âmbito de demandas que podem resultar em inovações sofreram adaptações em função dos valores, princípios e práticas da gestão ágil. As operações por meio das quais as demandas são geradas (Processo 1) no recorte macro são influenciadas pelas alterações que ocorreram na micro, visando agilidade com uso combinado de abordagens; ciclos iterativos com entregas parciais que ampliam a visibilidade sobre os resultados e; ferramentas adequadas.

O mesmo ocorre com as operações de recebimento e tratamento de demandas nos subprojetos vinculados ao Centro de pesquisas (Processo 2), em especial, no que tange a otimização da forma de documentação, priorização, seleção, detalhamento e acompanhamento da demanda; assim como o envolvimento de toda equipe com uso da prática de planejar em reuniões dedicadas e estruturadas para esse fim, bem como de aplicar o conceito de visão de objetivos para motivar e guiar as ações.

Como reflexo das adaptações no recorte micro, foi mapeado e aplicado um novo processo para tratamento de demandas diárias fixas ${ }^{22}$ (Processo 3). Baseou-se na combinação da abordagem ágil com diretrizes do ITIL $^{23}$ para tratamento de incidentes e requisições, relacionados aos sistemas da rede, permitindo a utilização das mesmas ferramentas da gestão ágil, centralizando informações e facilitando seu acesso. Sua viabilização exigiu o desenvolvimento de uma lista de procedimentos com passos para correta detecção, envolvendo monitoramento e uso do canal de apoio disponibilizado, e fornecimento de suporte técnico.

O processo de acompanhamento e comunicação dos resultados (Processo 4) sofreu influência em termos de visibilidade das atividades em andamento e da intensificação da comunicação. Os meios de acompanhamento foram mantidos ${ }^{24}$, exceto o de geração de registros diários das atividades (Infoset 9) no recorte micro da rede. Essa forma de acompanhamento foi removida como resultado da análise do "need-for-change", otimizando o tempo da equipe, uma vez que a nova forma de tratamento das demandas, comunicação e práticas de reuniões já permitem a visualização da alocação e da necessidade de ações motivacionais.

O processo de acompanhamento da liberação dos recursos técnicos e financeiros (Processo 5) também é influenciado pela velocidade na divulgação da requisição, assim como

\footnotetext{
${ }^{22}$ Demanda que que não exigem planejamento, mas sim procedimentos estruturados para tratá-las.

23 Abreviação para Information Technology Infrastructure Library, consiste em um conjunto de práticas para gestão de serviços de Tecnologia da Informação (PEREIRA e DA SILVA, 2011). Mais informações em: https://www.axelos.com/best-practice-solutions/itil, último acesso em 20 de Outubro de 2015.

${ }^{24}$ Os meios utilizados são relatórios, reuniões e visitas técnicas, planejadas por iteração.
} 
no aumento da qualidade do material de justificativa da mesma, devido ao intensa ação colaborativa na sua criação. A ação de acompanhar também passa a ser tratada como demanda, recaindo no fluxo de envio de informações atualizadas aos envolvidos, como entregas parciais semanais e/ou mensais.

O processo de entrega do resultado, mantendo os envolvidos atualizados (Processo 6), também foi adaptado para que os resultados sigam um fluxo constante (semanal e mensal) e não atinjam os demais interessados somente ao término da referida demanda. A reorganização da equipe no recorte micro, permite o acompanhamento e atualização mais frequentes para envio de informações. Essa celeridade, possibilita aos envolvidos realizar ajustes, adaptações e até mesmo, seleção de novas demandas resultantes das em andamento, antes do término do que foi planejado para a iteração vigente.

Por sua vez, o processo de transferência do conhecimento (Processo 7) foi atualizado para abranger as operações de entregas semanal e mensal, citadas previamente. Junto a aplicação de um ciclo de desenvolvimento mensal - iteração - foi aplicado um subciclo semanal para entregar resultados de todos os subprojetos em andamento, na forma de artefatos e materiais visuais que possam ser utilizados prontamente no processo de tomada de decisão, fortalecendo a comunicação, colaboração e visibilidade da situação.

O fluxo de geração do relatório mensal também foi reformulado, por meio de ferramentas adequadas para controle de tarefas, documentação eficiente, comunicação constante, armazenamento de evidências em ambiente de fácil acesso e uso de scripts computacionais para captura de dados. Por ser uma atividade fortemente burocrática que desmotiva a equipe, requereu otimizações em todos os processos relacionados para que os resultados sejam gerados e informados ao longo da iteração, tornando o fluxo de redigir o relatório um oficializador de tudo que já está visível e aplicável na rede.

Para isso, foi essencial a mobilização e treinamento de toda equipe na forma de utilizar ferramentas, gerar evidências, documentar ações e comunicar interessados, contribuindo com a otimização da redação de tal relatório. Entre as ações está a alocação de atores envolvidos com planejamento e monitoramento para redigir o relatório e guiar a equipe em etapas de revisão.

O gestor assume o papel de revisor final do resultado, mas contribuindo com a equipe ao longo de todos os processos que fornecem as bases para a redação do artefato, porém sem centralização. As otimizações tornaram o processo um resultado natural das atividades diárias da equipe, com minimização acentuada de esforços e tempo para redação e disponibilização. 


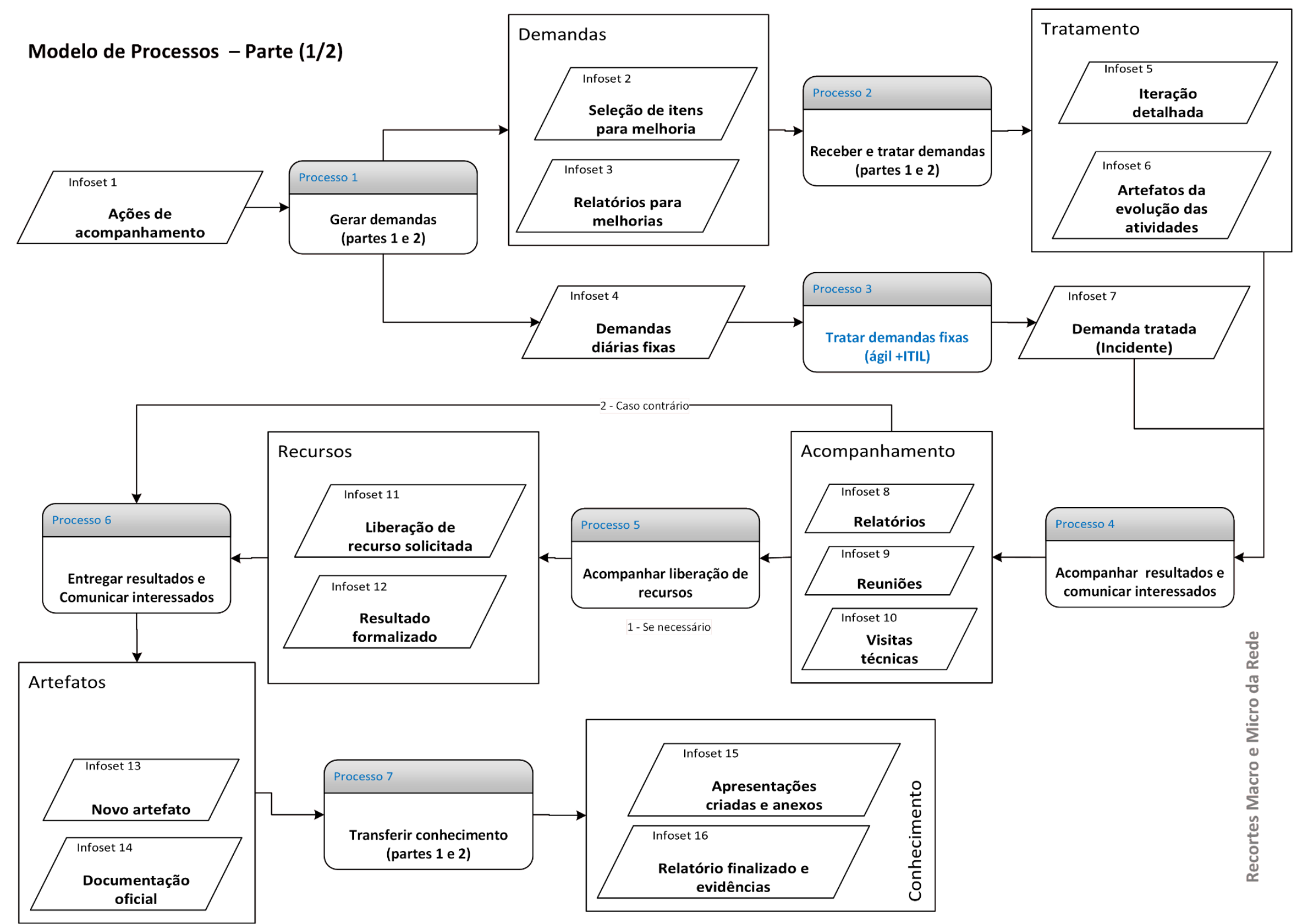

Figura 19 - Modelo de Processos - tobe (Parte 1/2) 
Conforme a Figura 20 (página 131), os processos no âmbito de motivação, disseminação e gestão de parcerias também sofreram alterações. Entre elas, está o mapeamento e aplicação de um processo para planejar a melhor forma de realizar a transição do modelo de gestão no ambiente analisado (Processo 1). Esse processo partiu de uma lista de motivadores para a mudança e considerou os desafios; objetivos; esforços ${ }^{25}$; adaptações e novidades; ações necessárias e; validações que podem ocorrer ao longo da transição. Novamente, foi fortemente guiado pelos valores, princípios e práticas da gestão ágil, mas atentando-se às combinações necessárias e particularidades da rede, do cotidiano prático dos subprojetos e das equipes envolvidas. Por sua vez, a gestão do conhecimento no processo para estimular inovações (Processo 2) foi otimizada como resultado da eficiência na organização e disponibilização de dados e critérios, necessários para planejamento de eventos, que são obtidos no nível micro da rede. Similarmente, a comunicação adequada e uso de ferramentas visuais que permitam trabalho colaborativo à distância, refletiram na qualidade dos resultados entregues. Disseminar as melhores práticas no segmento (Processo 3) está associado com a entrega frequente de resultados para apresentações de inovação tecnológica. Similar ao relatório mensal, essa ação requer organização e otimização dos processos como base para divulgação. Por fim, o processo para gerenciamento de parcerias e recursos humanos (Processo 3) não sofreu alterações diretas no recorte macro. De forma indireta, a organização em prol de exibir resultados sólidos pode ser benéfica na seleção de parceiros, que é realizada com base na análise de capacidades. Da mesma forma, as ações de acompanhamento que influênciam a permanência na rede também são afetadas pela organização e celeridade na entrega de resultados.

No recorte micro as alterações na forma de alocação são mais evidentes, relacionadas a análise de prioridades, capacidades e vontades, uso de reuniões de alinhamento e transferência de conhecimento aprofundada com foco na visão, bem como a correta integração do recém alocado na equipe, através da reunião de planejamento, comunicação eficiente e acompanhamento constante. Salienta-se que ao longo dos processos apresentados na Figura 18 (página 125) e Figura 19 (página 128), a combinação com o tradicional dá-se com a visita mesmo que informal - às áreas de integração, escopo, tempo, custo, qualidade, recursos humanos, comunicação, riscos e aquisições, abrangidas pelo Guia PMBOK, porém sem a preocupação de gerar exaustivamente todos os artefatos específicos, mas sim em direcionar com parcimônia o desenvolvimento da demanda, por meio da iteração ágil. Essa combinação é

\footnotetext{
${ }^{25}$ Esforços em termos de analisar a mobilização, treinamentos, acompanhamento e controle de mudanças que serão necessários.
} 
necessária, em especial, em casos de criação de editais técnicos, resoluções, processos de homolação, relatórios de visitas técnicas, planos de lançamento oficiais e afins. 

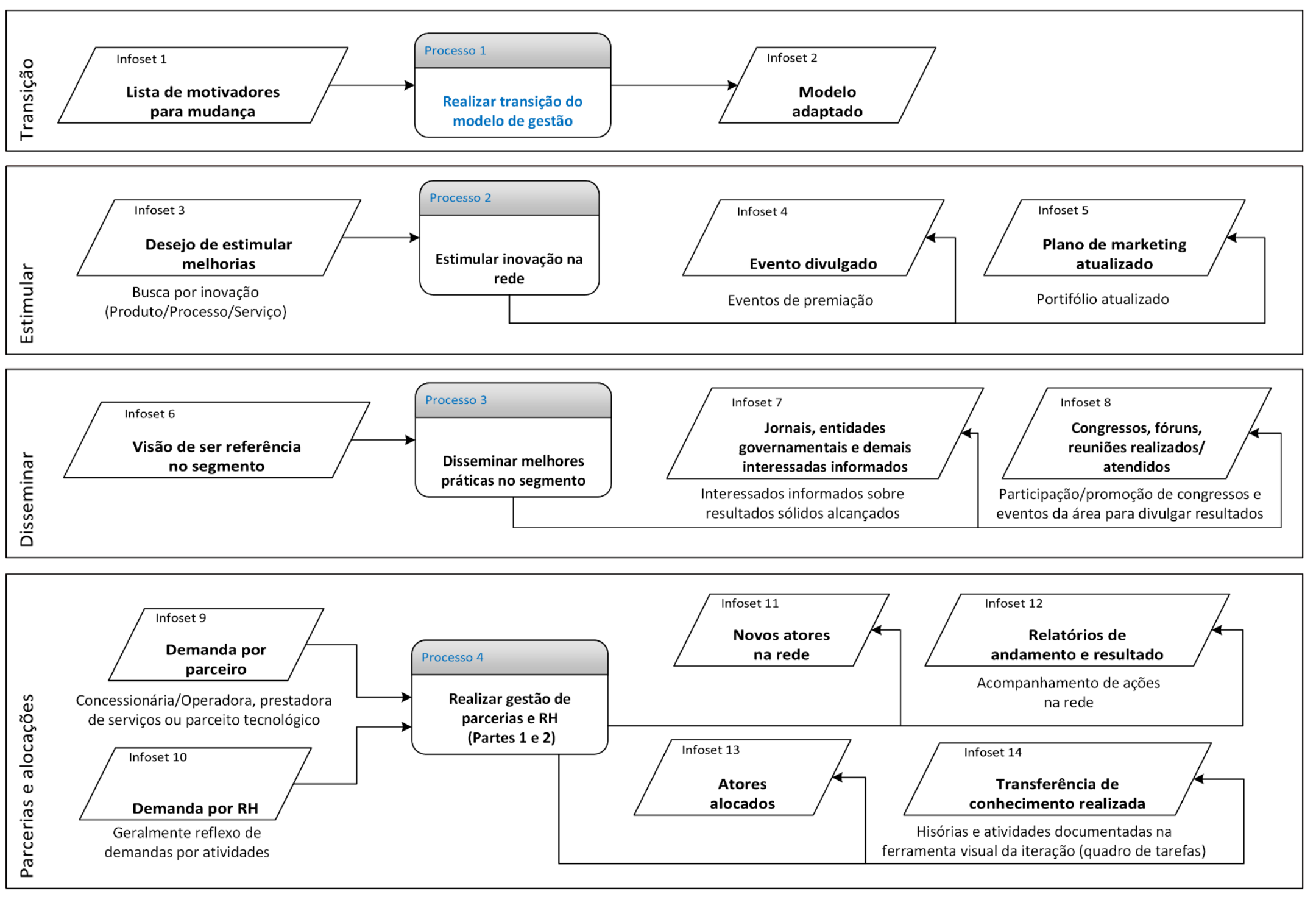

Figura 20 - Modelo de Processos - tobe (Parte 2/2) 


\subsubsection{Modelo de Componentes e Requisitos Técnicos}

Conforme a Figura 21 (página 133), após a análise do "need-for-change" os objetivos de sistema de informação foram mantidos, pois são factíveis e necessários para o cumprimento dos objetivos da rede, facilitando o cotidiano prático do projeto e também, por estarem alinhados aos valores e príncipios da gestão ágil.

Apesar disso, foram necessárias otimizações na forma de entender e utilizar as ferramentas associadas a tais objetivos, em ambos os recortes da rede - macro e micro - com o objetivo de torná-las acessíveis aos diversos interessados, simples de compreender e utilizar, devidamente organizadas por subprojetos e, sempre que possível, com forte apelo visual. Salienta-se que similar aos objetivos, as ferramentas com os requisitos funcionais mapeados são complementares, apesar de discutidas em separado nesta seção. 
Modelo de Componentes e Requisitos Técnicos - Parte 1/3
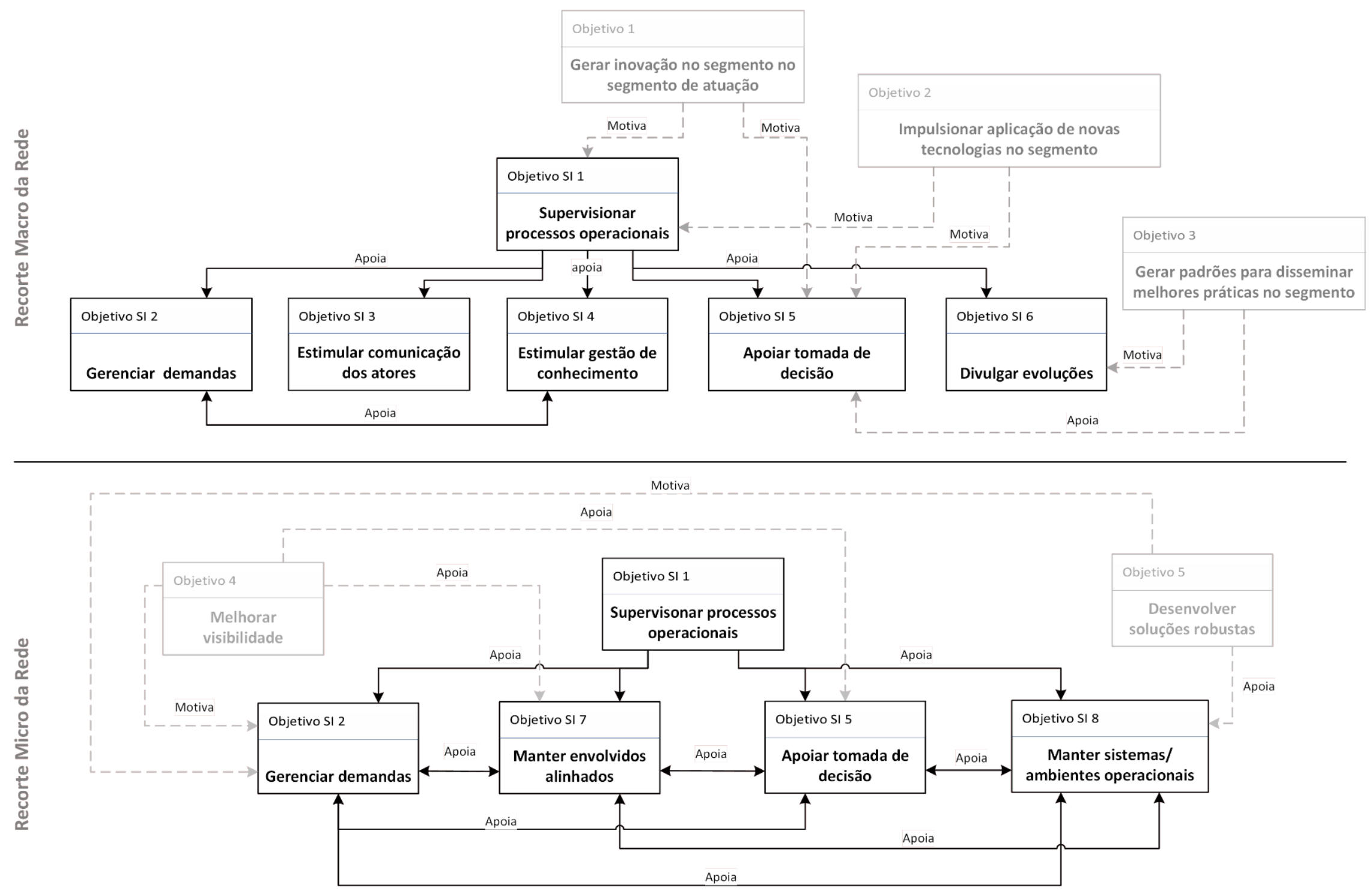

Figura 21 - Modelo de componentes e requisitos técnicos - tobe (1/3) 
A Figura 22 (página 136) ilustra o recorte macro dos sistemas de informação, com as alterações realizadas nos requisitos funcionais destacados. O objetivo de supervisionar os processos operacionais (Objetivo de Sistemas de Informação ${ }^{26} 1$ ) é apoiado pela utilização de planilhas com inventários de equipamentos (Requisito Funcional 2) que foram atualizadas e adaptadas para permitir ação colaborativa da equipe. As planilhas originais cederam lugar a planilhas de controle em repositório "em nuvem" 27 ", facilitando o acesso, a qualquer momento, pelos diferentes interessados e facilitando o trabalho colaborativo em tempo real, inclusive de equipes separadas geograficamente.

O objetivo secundário de facilitar a identificação de oportunidades (Objetivo SI 2.1) é apoiado por ferramentas para controle de requisições e incidentes (Requisito Funcional 4) que foram reformuladas para atuação no modelo adaptado, organizadas por subprojetos da rede e atualizadas para facilitar a utilização de atores externos ao Centro de Pesquisas. Os objetivos secundários de facilitar a identificação de oportunidades (Objetivo SI 2.1) e permitir a supervisão dos relacionamentos da rede (Objetivo SI 3.1) são apoiados por ferramentas para planejar e controlar novas funcionalidades (Requisito Funcional 7) que no recorte macro, aumentam a visibilidade da situação nos subprojetos. Dessa forma, semanalmente, foram disponibilizadas apresentações em um repositório "em nuvem" e por e-mail, com a intenção de facilitar a visualização de problemas, pontos de atenção e resultados alcançados que são importantes para decisão; os canais de comunicação utilizados também foram organizados em função de auxiliar no planejamento. O objetivo secundário de estimular gestão do conhecimento (Objetivo SI 4) é apoiado por ferramentas para disponibilizar tarefas para os envolvidos (Requisito Funcional 8) que no modelo de gestão ágil, requer facilidade de acesso as informações e organização simples e objetiva. Assim, foi implementado ${ }^{28}$ o uso de cartão de característica para descrever a funcionalidade, permitindo a correta documentação na ferramenta de gestão das demandas e norteando a escrita, em prol de atrelar o subprojeto envolvido, atores, funcionalidade necessária, prazos e prioridades. Por fim, os objetivos de apoiar a tomada de decisão (Objetivo SI 5) e facilitar o acompanhamento de evoluções e problemas (Objetivo SI 4.2) são apoiados por ferramentas visuais (Requisito Funcional 16). Apesar de todas as alterações realizadas priorizarem essa característica, nesse caso foram disponibilizadas novas ferramentas visuais, especialmente para a Agência Reguladora de

\footnotetext{
${ }^{26}$ Sistemas de Informação é abreviado como SI nesse material.

${ }^{27}$ Termo em portugês para cloud computing, tecnologia que permite a utilização de diversas aplicações, sem que precisem estar instaladas em máquina local.

${ }^{28}$ Foi aplicado no recorte micro, mas reflete-se na macro com o envio de apresentações de resultados desenvolvidas com base em tais cartões.
} 
transportes, destacando-se a disponibilização de painéis de situação com informações em tempo real dos diferentes sistemas, bem como as apresentações previamente citadas com diversos pontos de atenção. 


\section{Modelo de Componentes e Requisitos Técnicos - Parte 2/3}

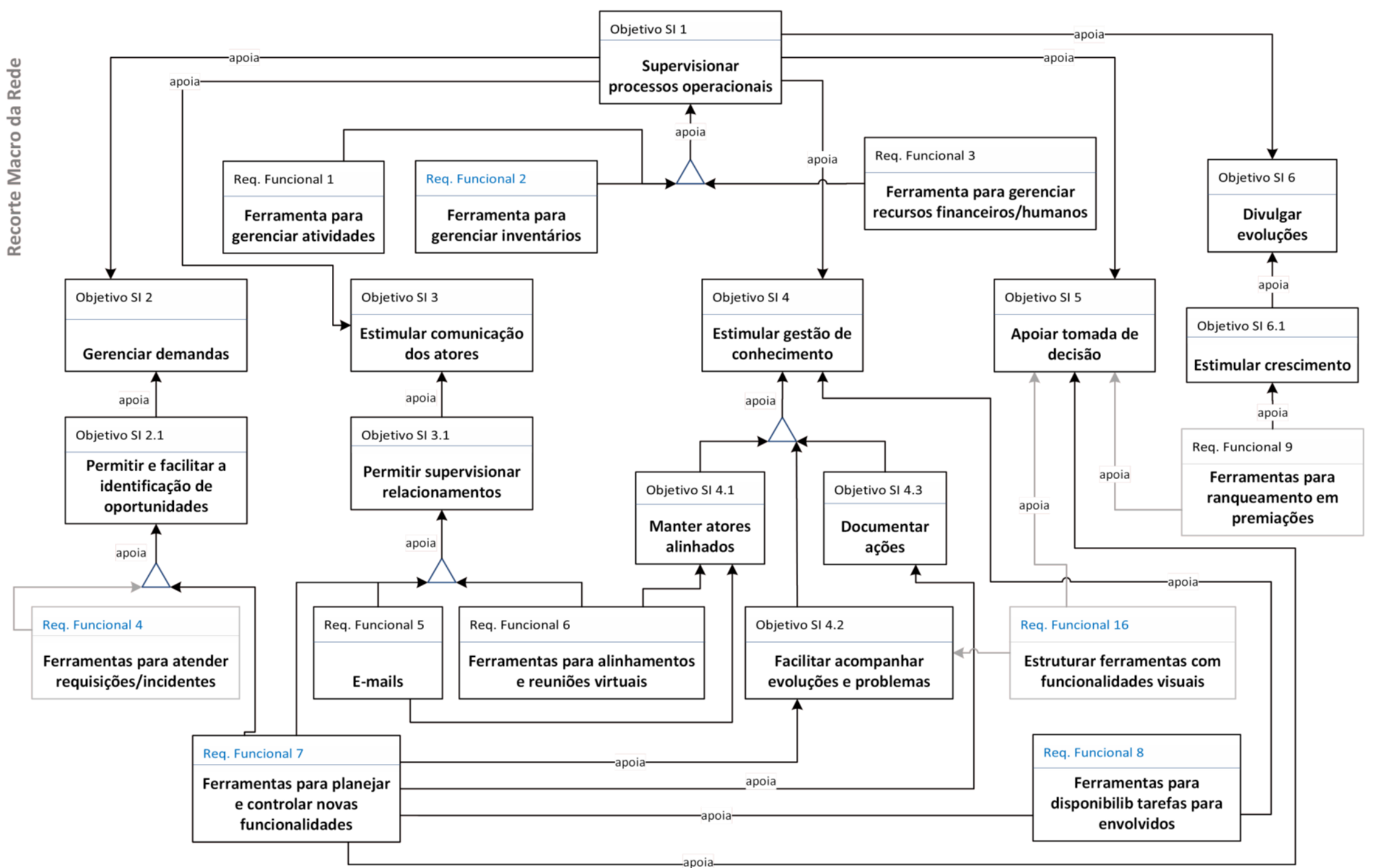

Figura 22 - Modelo de componentes e requisitos técnicos - tobe (2/3) 
A Figura 23 (página 139) ilustra os ajustes realizados no recorte micro dos sistemas de informação. O objetivo de supervisionar todos os processos operacionais (Objetivo de SI 1) é apoiado pela utilização de ferramentas (Requisitos Funcionais 1, 2 e 3) que auxiliam a gerenciar as atividades do projeto.

A ferramenta para gerenciar atividades (Requisito Funcional 1) é a principal ferramente adaptada para suprir a necessidade de documentação de demandas associadas à gestão ágil ${ }^{29}$ e; demandas fixas ${ }^{30}$ tratadas com diretrizes do ITIL (Requisito Funcional 4), conforme o objetivo secundário de solucionar problemas (Objetivo SI 8.1). Tornou-se a principal fonte de informações para companhamento das ações e possibilita a combinação de práticas da gestão ágil com tradicional, bem como o trabalho colaborativo (Requisito Funcional 17). Permite centralizar a documentação das informações (Requisito Funcional 12), organizando-as por subprojetos e aplicando forte apelo visual (Requisito Funcional 14) ao manter um quadro de tarefas virtual com as devidas alocações e o estado de cada atividade ${ }^{31}$, bem como impedimentos e demandas ainda não selecionadas para a iteração corrente. Também é por meio dela que são controlados os recursos humanos e financeiros em termos de projeto (Requisito Funcional 3), o primeiro, através da visualização das alocações em cada subprojeto, das tarefas e de seu desempenho, através do estado no quadro de tarefas e; o segundo através de cartões para acompanhamento de requisições de recurso financeiro.

Conforme citado previamente, as planilhas com inventários de equipamentos (Requisito Funcional 2) originais deram lugar a planilhas de controle em repositório "em nuvem". Tais planilhas foram reorganizadas pela equipe do Centro de pesquisas, em prol da clareza de compreensão com disponibilização de informações simples e frequentemente atualizadas para localização dos ativos desejados nos diferentes ambientes relacionados ao projeto. Essa ação, apesar de simples, otimiza o tempo da equipe. Além disso, um diretório de apoio visual, frequentemente atualizado, foi criado para as planilhas de inventário, contendo imagens reais dos tipos de equipamentos e demais ativos listados, facilitando a atuação de novos integrantes nos processos, incentivando a transferência de conhecimento e minimizando problemas por interpretação incorreta dos dados.

O objetivo de gerenciar demandas (Objetivo SI 2) é apoiado por ferramentas relacionadas com novas funcionalidades (Requisito Funcional 10), novamente a ferramenta central de informações (Requisito Funcional 1) auxilia nessas ações, combinada a outras

\footnotetext{
${ }^{29}$ Resultantes de reuniões internas e externas.

${ }^{30}$ Como requisições e incidentes que chegam de atores externos e internos.

${ }^{31}$ Estados mapeados: à iniciar, em andamento, em revisão e finalizadas.
} 
ferramentas. Na adaptação do modelo e gestão, foi necessário listar, organizar e documentar adequadamente as informações sobre cada ferramenta, forma de acesso, aplicabilidade e guia de uso. Essas informações foram armazenadas em um repositório "em nuvem" (Requisito Funcional 12) para facilitar o trabalho e acesso das equipes.

Ainda no intuito de gerenciar demandas (Objetivo SI 2) as ferramentas para comunicação (Requisito Funcional 11) instantâneas foram reorganizadas em função dos subprojetos e, os e-mails receberam padrões para que a equipe responsável pelo tratamento de requisições e incidentes pudesse realizar adequadamente os atendimentos, por meio de uso de protocolos - gerados na ferramenta de gerenciamento de atividades (Requisito Funcional 1) e padrões de resposta. Entre as funcionalidades visuais, similar aos painéis de situação disponibilizados ao recorte macro, foram criados novos para as equipes do recorte micro acompanharem diariamente a situação dos ambientes do projeto, em tempo real (Requisito Funcional 14). Com relação ao objetivo secundário de fornecer relatórios (Objetivo SI 7.3) os sistemas para coletar e armazenar dados (Requisito Funcional 12) consistem em repositórios locais e um "em nuvem" para centralizar informações e distintos artefatos, devido ao fácil acesso e possibilidade de trabalho colaborativo em tempo real. Por fim, também relacionao ao objetivo solucionar problemas (Objetivo SI 8.1), observa-se que todas as ferramentas citadas no recorte micro corroboram para facilitar a identificação de oportunidades (Requisito Funcional 15).

Os sistemas e ferramentas aplicados visam o gerenciamento de atividades $\left(\right.$ Redmine $^{\odot}$ com Backlogs ${ }^{32}$ ); de calendários e agendas (Redmine com Backlogs e Google Calendar ${ }^{\circledR 33}$ ); de recursos (Redmine com Backlogs, Google Drive ${ }^{\mathbb{3} 4}$, Repositórios locais e planilhas) e; de custos (Redmine com Backlogs, Planilhas e Google Drive); bem como, monitoramento com comunicação frequente (painéis de situação personalizados com Grafana ${ }^{\circledR 35}$; Redmine com Backlogs; Google Drive; Skype ${ }^{\circledR 36}$; E-mail). Salienta-se que foram organizados em função de todos os subprojetos e que a combinação foi a forma identificada para suprir as necessidades da unidade de análise estudada.

\footnotetext{
${ }^{32}$ Redmine com plugin Backlogs para gestão ágil: http://www.redmine.org/ e http://www.redminebacklogs.net/, último acesso em 20 de Outubro de 2015.

${ }^{33}$ Google Calendar: https://calendar.google.com/calendar, último acesso em 20 de Outubro de 2015.

${ }^{34}$ Google Drive: https://www.google.com/intl/pt-BR/drive/, último acesso em 20 de Outubro de 2015.

${ }^{35}$ Grafana: http://grafana.org/, último acesso em 20 de Outubro de 2015.

${ }^{36}$ Skype: http://www.skype.com/pt-br/, último acesso em 20 de Outubro de 2015.
} 
Modelo de Componentes e Requisitos Técnicos - Parte 3/3

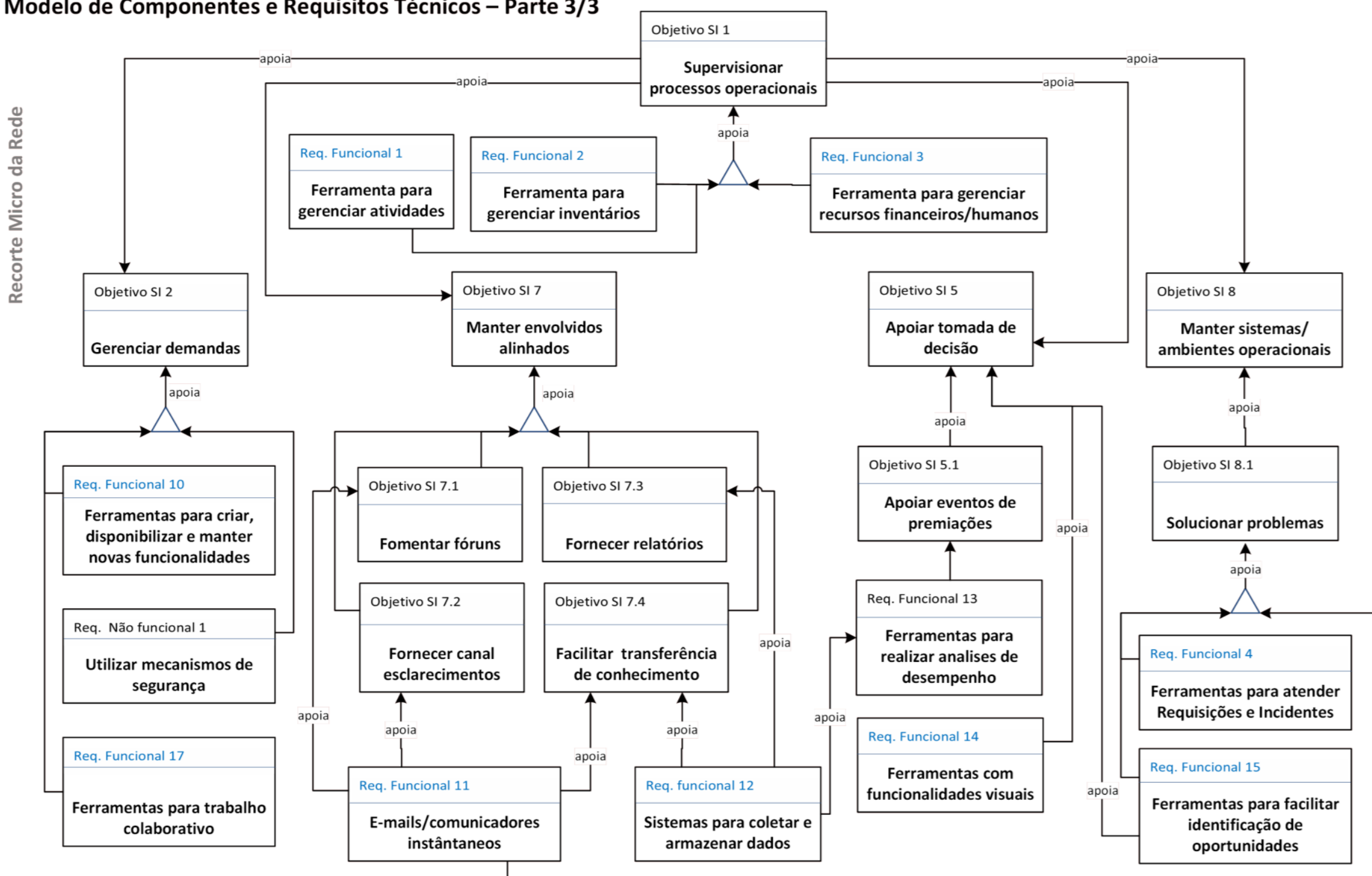

Figura 23 - Modelo de componentes e requisitos técnicos - tobe (3/3) 


\subsubsection{Modelo de Conceitos}

O entendimento dos principais constructos facilita a compreensão dos resultados obtidos com a pesquisa. Nesse sentido, a Figura 24 (página 141) apresenta o modelo de conceitos gerado para a unidade de análise, no qual a inovação é o conceito focal (Conceito 1) e requer geração e transferência de conhecimento (Conceito 2), motivando a formação de redes (Conceito 3). Tais redes em prol de inovação, são formadas por parcerias que podem ser formalizadas com contratos (Conceito 4) para realizar projetos colaborativos (Conceito 6) de P\&D (Conceito 5).

Nesses ambientes a gestão é desafiadora e crítica (Conceito 7) - analisada em função da rede e de seus projetos colaborativos - requerendo esforços por melhoria contínua (Conceito 8), flexibilidade (Conceito 9) e adaptabilidade (Conceito 10) para superar as dificuldades.

A gestão ágil (Conceito 11) com base em seus valores (Conceito 12), práticas (Conceito 13) e possibilitadores (Conceito 14) é uma abordagem fortemente apoiada na geração e transferência de conhecimento, por meio de artefatos como: visão (Conceito 15); planejamento e controle (Conceito 16) e; produtos (Conceito 17); visando tornar a gestão menos crítica e desafiadora.

Na unidade de análise o conceito de visão é aplicado para motivar a equipe (Conceito 18), influenciando diretamente nos processos de planejamento e controle dos projetos que, por sua vez, são norteados por estímulo à autogestão (Conceito 20) e auto-organização (Conceito 21); simplicidade (Conceito 26); foco nas pessoas (Conceito 21); ampliação da visibilidade (Conceito 24) de tarefas e objetivos, mas também e termos de interfaces gráficas; análise e estímulo de capacidades (Conceito 27); uso de ciclos iterativos evolutivos (Conceito 22) para as demandas; forte trabalho colaborativo (Conceito 25) e; intensa comunicação (Conceito 28).

Dessa forma são entregues a flexibilidade, adaptabilidade, preocupação com melhoria contínua e auto-organização, necessários para desenvolver produtos inovadores com qualidade (Conceito 19) em ambientes de redes de inovação. 
Modelo de Conceitos

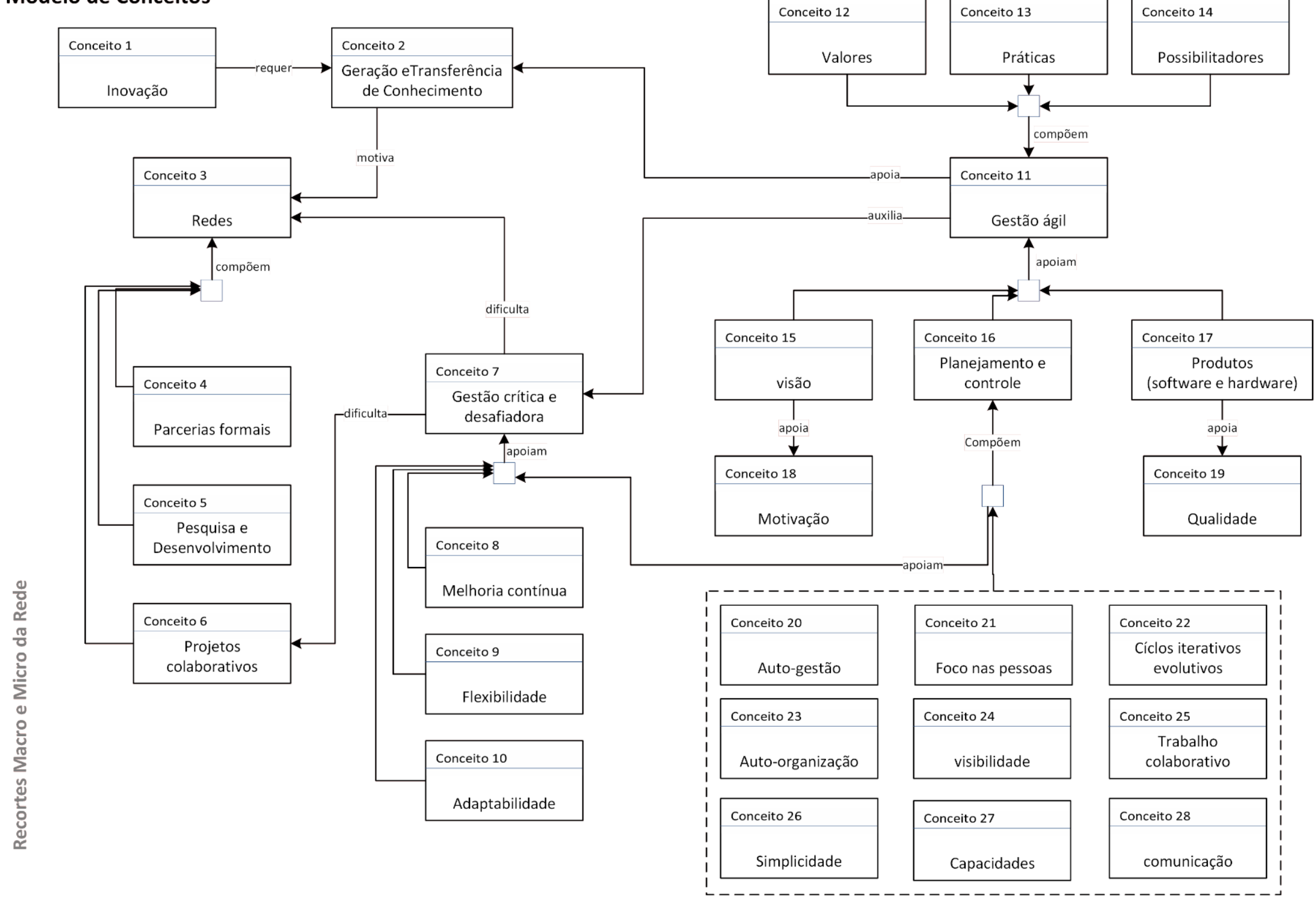




\subsection{DISCUSSÃO DOS RESULTADOS}

A análise dos modelos evidencia que as adaptações planejadas com o processo de transição foram realizadas em função dos valores (BECK et al., 2001), princípios e práticas (CONFORTO et al., 2014; CHOW e CAO, 2008) da gestão ágil e são associadas a artefatos de visão; planejamento e controle e; produtos de valor agregado (AMARAL et al., 2011).

Segundo Highsmith (2004) o conceito de visão facilita a compreensão e auxília na visualização dos limites e condições existentes no projeto. Na unidade de análise o conceito de visão é aplicado para motivar a equipe e guiar planejamentos, sendo analisado em função dos objetivos da rede (1), dos subprojetos (2) e dos resultados (3) alcançados em cada demanda planejada. O primeiro é evidênciado e documentado com a modelagem, enquanto o segundo e terceiro, com uso de ferramentas visuais, ciclos iterativos e forma de documentação clara, objetiva e organizada, permitindo o uso prático e assimilação do conceito pela equipe.

A documentação é feita utilizando cartões com características, requisitos e desempenho desejados (HIGHSMITH, 2004), em especial, no caso de software. Tais cartões são detalhados de acordo com a complexidade da demanda e gerenciados por meio de um quadro de tarefas ${ }^{37}$. Devido a combinação de modelos de gestão, dependendo do objetivo - por exemplo em demandas de hardware - podem ser utilizadas folha de dados do projeto e protótipos para provas de conceito. A captação das necessidades é realizada através dos diferentes processos e tipos de reuniões mapeados no processo de transição, envolvendo equipes internas e externas ao Centro de pesquisas.

Para Highsmith (2004) as ações de planejamento e controle devem entregar um plano mutável, flexível e simples. Essa preocupação foi considerada na modelagem com a proposta de planejar a transição e aplicar ferramentas e processos simples que contemplem a identificação de todos os interessados, comunicação, uso de cronogramas, alocação adequada da equipe ${ }^{38}$ e adequação dos pocessos para utilização das práticas da gestão ágil.

Entre as técnicas aplicadas no planejamento e controle estão: a definiçãa e uso de visão; de um plano de iterações e entregas, evolutivo e cíclico, em função da quantidade de meses contratuais totais dos subprojetos e prevendo entregas mensais, semanais e conforme evolução útil da demanda; uso de quadro de tarefas visual e virtual; uso de repositórios locais e "em nuvem"; documentação com cartões; realização periódica de diferentes tipos de reuniões internas e externas; avaliação de desempenho com foco na motivação das pessoas e resultados

\footnotetext{
${ }^{37} \mathrm{O}$ quadro de tarefas contém diferentes estados para indicar a situação - novo, em andamento, em revisão, concluído e rejeitado - e permitem criar, manusear e visualizar os cartões de documentação da demanda.

${ }^{38}$ Em prol de estimular autogestão e auto-organização da equipe.
} 
entregues - reuniões de restropecção e individuais -; acompanhamento frequente com relatórios direcionados, ferramentas visuais - painéis de situação e quadro de tarefas - e, em alguns casos, uso de gráficos para verificar evolução do projeto.

Por sua vez, a execução do plano de ação resultante da pesquisa-ação identificou como produtos dos subprojetos da rede os relatórios, apresentações, softwares, hardware, processos e serviços, relacionados ao objetivo de busca por robustez e excelência tecnológica no segmento. Esses produtos devem ser devidamente compartilhados com os interessados, conforme os pontos já citados, requerendo a escolha correta dos sistemas de informação.

A forma de seleção das ferramentas foi considerada no processo de transição e levou em conta, além de aspectos como custo e possibilidade de personalização, os requisitos identificados na modelagem e na literatura (AMARAL et al., 2011):

- Funcionais - permitir registro e controle de usuários; apoiar a elaboração e uso da visão; apoiar a simplificação do processo de planejamento; facilitar o acompanhamento do andamento do projeto; auxiliar no processo de finalização do projeto e; facilitar comunicação e integração da equipe;

- Não funcionais - usar interface baseada na web; combinar diferentes ferramentas para comunicação; possuir interfaces visuais simples; permitir integração com ambientes de desenvolvimento de software; permitir descentralização dos dados exportar para trabalhar sem conectividade; permitir rastreabilidade - discussões e demandas; ser flexível para tratar mudanças; ser segura; permitir controle de versão; gerar indicadores de desempenho gráficos; permitir atuar com vários projetos e; otimizar o tempo de realização das rotinas das atividades.

\subsubsection{Validação do modelo $T O-B E$}

Ao longo da pesquisa-ação realizada, os modelos gerados foram ajustados, tornando-os abstratos o suficiente - independentes do segmento da rede e relacionados às características, problemas e oportunidades encontrados na mesma - para validar sua aplicabilidade em outras redes de inovação auto-organizadas. A validação foi realizada no Centro de pesquisas, através de apresentação, discussões e preenchimento de um questionário ${ }^{39}$, envolvendo o pesquisador e quatro participantes chave na pesquisa ${ }^{40}$ e possibilitou a realização de ajustes finais ao modelo proposto, conforme a análise dos dados obtidos:

\footnotetext{
${ }^{39}$ Detalhamento disponibilizado no Apêndice A.

${ }^{40}$ Junto ao pesquisar participaram um gerente, um analista sênior, um analista pleno e um analista trainee.
} 
Com relação ao modelo de objetivos: $100 \%$ dos participantes concordam integralmente com os Objetivos 1 e 4 (Gerar inovação no segmento e Melhorar visibilidade de objetivos e ações); $75 \%$ concordam integralmente e $25 \%$ parcialmente com os Objetivos 2 e 3 (Impulsionar aplicação de novas tecnologias para o segmento e Gerar padrões para disseminar melhores práticas no segmento) e; $100 \%$ concordam parcialmente com o Objetivo 5 (Desenvolver soluções robustas). A aceitação parcial no recorte macro está associada a observação de que a transferência de conhecimento, necessária para cumprimento pleno dos objetivos, é dificultada pela organização das entidades, demandando esforços das demais unidades organizacionais para cumpri-los. A aceitação parcial no recorte micro está associada à observação de que o tempo e recursos nem sempre permitem desenvolver soluções robustas e também; que apesar da melhoria na prestação dos serviços (em termos de governança e visibilidade), a robustez não depende somente da tecnologia, mas da organização das inter-relações dos parceiros e das políticas existentes, novamente demandando esforços das demais unidades organizacionais.

Com relação ao modelo de regras do negócio: No recorte macro - 50\% concordam integralmente e 50\% parcialmente com as Regra 1 e 3 (Promover eventos de premiação para motivação e Considerar requisitos e opiniões de todos os envolvidos); 100\% concordam integralmente com as Regras 2 e 4 (Garantir qualidade nas soluções desenvolvidas e Estimular $P \& D$ no segmento) e; $75 \%$ concordam integralmente e $25 \%$ parcialmente com a Regra 5 (Balancear controle e flexibilidade). A aceitação parcial está associada à observação de que a premiação faz parte das regras, mas não é algo frequente; nem sempre é possível considerar os requisitos de todos os envolvidos. A flexibilidade depende do fator humano, da capacidade de adaptação e resposta a situações novas, exigindo coesão dos demais envolvidos na rede.

No recorte micro - 100\% concordam integralmente com as Regra 6 e 13 (Alertar sobre problemas e Promover a utilização das práticas do ágil); 50\% concordam integralmente e 50\% parcialmente com as Regras 7 e 11 (Manter transparência nas ações e Promover uso de softwares livres e tecnologias homologadas ); $75 \%$ concordam integralmente e $25 \%$ parcialmente com as Regras 8, 9, 10 e 12 (Agir com imparcialidade nas definições, Responder requisitos dos envolvidos, Garantir busca por qualidade e Utilizar meios de comunicação acordados) e; $25 \%$ concordam integralmente e $75 \%$ parcialmente com a Regra 14 (Realizar treinamentos). A aceitação parcial está associada a dificuldade de utilizar softwares livres em algumas ações; a pouca frequência de treinamentos, em especial, treinamentos em ambientes externos à rede - em ferramentas, metodologias - necessários para ampliar o conhecimento; a necessidade de investir ainda mais em padronização dos canais de comunicação utilizados; a carência de governança de TI que garanta transparência em todas as ações do recorte macro 
para que a qualidade seja priorizada em todas as demandas e; a necessidade de mensurar as práticas com uso de indicadores numéricos para ver o efeito real das mudanças nos subprojetos.

Com relação ao modelo de atores e recursos: $75 \%$ dos participantes concordam integralmente e $25 \%$ parcialmente com o recorte macro e; $100 \%$ concordam integralmente com o recorte micro. A aceitação parcial está associada a presença do Órgão Certificador Designado (Unidade organizacional 7) como um perfil também assumido pelo Centro de Pesquisas (Unidade organizacional 2) na rede. Essa adequação foi realizada no modelo apresentado nesse trabalho, durante o processo de validação, mas a resposta desse ponto não foi refeita formalmente no questionário.

Com relação ao modelo de processos, salienta-se que a validação foi feita com base no detalhamento de cada processo do estado to-be exposto no Apêndice B desse material:

- $100 \%$ concordam integralmente com os processos para transição do modelo de gestão; para gerar demandas (recortes macro e micro); para receber e tratar demandas; para tratar demandas fixas (ágil +ITIL); para acompanhar resultados e comunicar interessados (recortes macro e micro); para entregar resultados $e$ comunicar interessados e de acompanhamento e liberação de recursos (recortes macro e micro) e;

- $75 \%$ concordam integralmente e $25 \%$ parcialmente com o recorte macro, enquanto $100 \%$ concordam integralmente com o recorte micro dos processos para transferência do conhecimento, para estimular inovação na rede, para disseminar melhores práticas no segmento e para gestão de parcerias e recursos humanos.

A aceitação parcial está associada à fraqueza observada na transferência do conhecimento, o que requer investimento mais frequente em treinamentos; a observação, que pode ser contemplada em uma evolução da pesquisa, de que a inovação dá-se por estímulo a eventos de premiação, mas também pela abertura a entrada de novos atores (concorrentes); a necessidade de mensurar prazo, esforço e recursos nas demandas com indicadores numéricos para ver o efeito real das mudanças nos subprojetos, uma vez que os processos já estão estabelecidos e ainda; a observação de que a disseminação de práticas no segmento depende do desejo de todas as entidades, requerendo ações para reforçar essa necessidade no recorte macro da rede.

Com relação ao modelo de componentes e requisitos técnicos: $100 \%$ dos participantes concordam integralmente com os Objetivos SI 1, 2, 4, 6, 7 e 8 (Supervisionar processos operacionais, Gerenciar demandas, Estimular gestão de conhecimento, Divulgar evoluções, 
Manter envolvidos alinhados e Manter sistemas/ambientes operacionais) e; 75\% concordam integralmente e $25 \%$ parcialmente com os Objetivos SI 3 e 5 (Estimular comunicação dos atores e Apoiar tomada de decisão). A aceitação parcial está associada ao objetivo de estimular comunicação que pode depender mais dos valores e princípios da gestão ágil que das ferramentas utilizada, apesar de ser um objetivo válido para o mapeamento.

Com relação a aplicabilidade para replicabilidade em outras redes: 50\% dos participantes concordam integralmente e 50\% parcialmente que o conjunto de modelos reflete a realidade da rede e dos subprojetos analisado, bem como que pode ser adaptado para gestão de outras redes e projetos com características similares a da unidade de análise e; 75\% concordam integralmente e $25 \%$ parcialmente que o conjunto de modelos facilita a visualização da estrutura da rede e de seus processos. Aqui a aceitação parcial está associada ao reforço que deve ser dado à adaptabilidade como uma pré-condição para que o modelo possa ser utilizado em replicações em ambientes com características similares.

Conforme apontado ao longo dessa seção, como resultado da ação de validação foram obtidos retornos gerais do modelo proposto na forma de limitações, pontos a melhorar e benefícios que podem auxiliar na evolução da pesquisa e na busca por melhoria contínua, bem como na adaptação dos modelos para outros ambientes.

\subsubsection{Benefícios e limitações}

Uma vez que as quatro fases da pesquisa-ação foram cumpridas com aplicação e validação dos modelos no cotidiano do Centro de pesquisas, influenciando os demais atores por cerca de seis meses, questionários foram aplicados na unidade de análise - Centro de Pesquisas, Concessionária de rodovia, Agência Reguladora de transportes e Prestadora de serviços ${ }^{41}$ visando verificar: os benefícios e limitações observados com a aplicação da gestão ágil.

No Centro de Pesquisas foram quinze participantes, envolvendo duas unidades da empresa, com perfis divididos entre analista, auxiliar administrativo ${ }^{42}$, engenheiro e gerente, sendo que a maioria trabalha nos subprojetos da rede desde o início ${ }^{43}$. Com a análise dos dados verifica-se que após as ações da pesquisa-ação: $60 \%$ dos participantes afirmam possuir conhecimento sobre o que é uma rede de inovação; 66,7\% tiveram contato com gestão ágil, previamente à pesquisa e; 93,3\% identificam benefícios com a aplicação da gestão ágil.

\footnotetext{
${ }^{41}$ Salienta-se que o formulário enviado ao parceiro Prestador de serviços não foi preenchido e retornado em tempo que permitisse sua apresentação neste material.

${ }^{42}$ Atuam como apoio técnico na unidade de análise.

${ }^{43}$ Houve variação nessa questão em relação ao dado apresentado no artigo da modelagem as-is, uma vez que a amostra de respondentes teve variação de um modelo para o outro, devido a saída e entrada de novas pessoas no ambiente.
} 
Destaca-se o aumento de $21.5 \%$ na conscientização sobre atuação em redes de inovação, em relação ao mesmo parâmetro na modelagem as-is.

Com relação aos benefícios: 93,3\% observam melhoria na comunicação; 66,7\% na confiança; $100 \%$ na visibilidade de tarefas; $66,7 \%$ na visibilidade de objetivos; $93,3 \%$ no controle de tarefas; $100 \%$ na organização dos processos; $73,3 \%$ na responsividade; $100 \%$ no trabalho colaborativo; $66,7 \%$ na produtividade; $80 \%$ na qualidade dos entregáveis; $60 \%$ na visibilidade e conscientização da atuação em rede e; $80 \%$ no cumprimento de prazos. Os comentários também indicam aumento da interação entre todos os envolvidos, refletindo no aumento da confiabilidade acerca da qualidade, celeridade e controle do trabalho realizado e; com relação a produtividade, observa-se pode expandir a melhoria, otimizando continuamente as relações com atores externos. Por outro lado, devido as características da unidade de análise ${ }^{44}$ $73,3 \%$ não observam redução de disfunções burocráticas e; 73,3\% não tem visibilidade sobre a ocorrência de melhorias financeiras, enquanto $20 \%$ dos participantes - com perfil que os permite ter acesso a esse tipo de informação no Centro de pesquisas - afirmam ter observado melhorias financeiras.

Com relação ao alcance dos benefícios observados: $86,7 \%$ acreditam que abrangem o nível de suporte; $100 \%$ o de desenvolvimento; 73,3\% a Agência Reguladora de transportes (cliente); 53,3\% os fornecedores; $60 \%$ os prestadores de serviço e; 53,3\% os demais parceiros da rede (Concessionária de rodovias, Operadora de Serviços e OCD). Para o nível administrativo e para atores de outras unidades do Centro de pesquisas, 53,3\% e 46,7\%, respectivamente, não sabem se foram obtidos benefícios. Os comentários sobre o alcance dos benefícios apontam que a influência foi maior na unidade onde a pesquisa-ação é conduzida;

Com relação às limitações no modelo, foram identificadas por 86,7\% dos participantes. As citadas são: acelerar o tempo para estruturação das informações de gestão coletadas ${ }^{45}$; o processo de detalhar as tarefas na reunião de planejamento precisa ser melhorado; incorporar mais ferramentas visuais; incorporar a subdivisão das equipes por papéis ${ }^{46}$; existe um risco de banalização das reuniões e fluxo de comunicação que podem resultar em despercídio de tempo; dificuldade de planejar demandas/tarefas que tem dependência de informações temporais - que expiraram ou foram alterados e, de compreender que demandas fixas necessitam de processo

\footnotetext{
44 Apesar de apresentar características de auto-organização, é gerida por contratos formais que refletem-se em demandas envolvendo documentação.

${ }^{45}$ A pesquisa-ação foi conduzida na prática nos subprojetos da rede, requerendo tempo de transição e estruturação de informações para participantes da equipe que não estavam diretamente associado ao grupo de trabalho da transição.

${ }^{46}$ Como ação em prol da auto-organização essa divisão ficou sútil.
} 
específico, apesar de usar as mesmas ferramentas; ainda existem funções/assuntos que ficam concentrados em poucas pessoas, resitência à mudanças, dificuldade de cumprir todas as demandas mapeadas para uma iteração, bem como estimar o esforço real de realização das tarefas.

Com relação à possibilidade de solucionar as limitações com o modelo ágil de gestão, 78,6\% dos participantes acredita ser possível. Os comentários citados são: o modelo atual está em evolução, envolvendo a documentação de todos os processos, tornando-os claros, com amplo e fácil acesso a todos; a comunicação é a base para um bom trabalho em qualquer tipo de projeto e tem sido priorizada no modelo de gestão com tipos distintos de reuniões para coletar informações e; as limitações são inevitáveis ao considerar o curto tempo de transição do modelo de gestão e a complexidade das demandas, mas o mapeamento adequado das falhas, em prol de melhorias refletirá em aumento de qualidade nos resultados alcançados.

Nesse sentido, também foi citado: é necessário manter o investimento em aumento de confiabilidade entre os diferentes perfis na equipe; esforços em comunicação ${ }^{47}$; treinamentos e capacitações para estimular os aprimoramentos nos artefatos utilizados; gestão de pessoas e capacidades na alocação e distribuição de atribuições; treinamentos e auto-organização da equipe; ações para identificar os pontos que motivam ou desmotivam a equipe; visão das atividades e objetivos futuros e; em ações em prol da verificação frequente do desempenho da iteração que podem ser úteis para verificar falhas.

Entretanto, existe a opinião de um participante de que os processos de gestão são importantes para níveis de gerência acompanharem o andamento, mas para o restante da equipe não é tão útil, pois trazem disfunções burocráticas e com a simples troca de informações já seria possível saber o que fazer. A maior limitação apontada é a inserção de medidas burocráticas para gerar evidências das ações, recaindo em imposição de ferramentas e procedimentos.

Por fim, com relação a visão de que os contratos minimizam a flexibilidade de escopo e prazos, dificultando a implantação de métodos totalmente ágeis e forçando a adaptação para responder a tais disfunções burocráticas; um participante acredita que o modelo de gestão não terá influência positiva sobre esse aspecto, pois uma mudança de postura em todos os níveis precisaria ser implantada, gerando resistência por insegurança, desencorajando-a.

$\mathrm{Na}$ Concessionária de rodovias foram dois participantes, ambos com perfil de líder técnico, sendo que um trabalha nos subprojetos da rede desde o início. Com a análise dos dados

\footnotetext{
${ }^{47}$ Foi feito um comentário com relação aos espaços virtuais divididos por subprojetos (chats no Skype) que foram criados com as respectivas equipes que poderiam ser otimizados para que nem todos os assuntos sejam tratados por todos.
} 
verifica-se que após as ações da pesquisa-ação: ambos observam melhorias na comunicação; na confiança; no controle de ações necessárias; na rapidez para solucionar problemas e; no cumprimento de prazos. Com relação a visibilidade de objetivos, os participantes divergem de opinião acerca da melhoria ou não.

Com relação ao alcance dos benefícios observados: ambos acreditam que abrangem a Agência Reguladora de transportes; a própria Concessionária de rodovias e; o Centro de pesquisas. Diferem com relação a abrangência dos benefícios para outras Concessionárias de rodovias e para outros parceiros da rede (Operadora de serviços, Fornecedores, Prestadores de serciços e OCD). Não foram elencadas limitações pelos participantes.

Na Agência Reguladora de transportes o participante foi um diretor que trabalha nos subprojetos da rede desde o início. Com a análise dos dados verifica-se que após as ações da pesquisa-ação, o participante oberva melhoria na comunicação; porém não observou melhoria no nível de confiança, visibilidade de objetivos, controle de ações e, na velocidade para solucionar problemas e cumprir prazos.

Com relação ao alcance da melhoria na comunicação: o participante acredita que abrange a Agência Reguladora de transportes e o Centro de pesquisas. A limitação indicada pelo participante é com relação a frequência nas reuniões presenciais que deve ser de ao menos uma ao mês para estimular o trabalho mais próximo, afinidade entre as equipes e identificação de demandas de melhoria contínua.

Como reflexo da modelagem e análise da literatura (AMARAL et al., 2011), também foi possível identificar limitações com relação aos sistemas e ferramentas utilizados:

- Funcionais - não é possível realizar a comparação facilitada da situação atual com a planejada; a geração de indicadores com os dados coletados terá que ser realizada em ferramenta de mineração de dados à parte, usando a mesma base de dados das ferramentas citadas; a avaliação do andamento do projeto e de suas entregas, pela equipe e pelo cliente, pode ser realizada nas ferramentas, mas não existe uma área específica para isso e; as ferramentas não solicitam avaliação final, mas pode ser inserida, caso desejado;

- Não funcionais - por serem baseadas em web pode haver problemas de conectividade nos casos de ferramenta "em nuvem"; até o momento não foi necessária a integração com sistemas de engenharia como o $\mathrm{CAD}$, mas não identificou-se essa funcionalidade; as ferramentas "em nuvem" como o Google Drive $^{\odot}$, não utilizam repositórios locais, gerando preocupação com segurança, 
porém o acordo de confidencialidade de conta empresarial com o fornecedor foi considerado satisfatório e; o Redmine ${ }^{\odot}$ permite a geração de gráficos associados ao ágil, mas indicadores específicos estão em estudo e serão gerados com ferramentas de mineração de dados específicas.

Similarmente, foi possível observar como benefício que o modelo de gestão aplicado estruturou os subprojetos e a equipe de forma que mesmo a saída de pessoas influentes e entrada de outras ${ }^{48}$, não influenciou negativamente no cotidiano e nos resultados e prazos planejados. Nesse sentido, o cronograma de férias da equipe - ponto fraco e desestabilizador dos processos - também refletiu melhorias, devido a auto-organização e autogestão da equipe. Um outro ponto observado, foi citado por uma pessoas que eventualmente auxilia a equipe do projeto com ações técnicas, isto é, não está alocada frequentemente no mesmo, mas percebeu melhorias na gestão e transferência de conhecimento, bem como na redução de sobrecarga de trabalho em poucos e ainda, os benefícios do uso do conceito de visão para guiar a realização de suas atividades.

Diante dos dados coletados, analisados e gerados na pesquisa-ação, em especial, nas fases de ação e avaliação, organizados através da modelagem, foi possível verificar a nova situação da unidade de análise e reponder as duas questões restantes (Quadro 2) da pesquisa (2) foram identificados benefícios com a aplicação do modelo proposto (seção 4.2.2) e; (3) foram identificadas limitações com a aplicação do modelo proposto (seção 4.2.2) -, cumprindo o objetivo estabelecido para este capítulo. Uma questão levantada neste capítulo, pertinente para a pesquisa, diz respeito a validação e também foi satisfatória, confirmando a aplicabilidade do modelo proposto em redes com características similares.

De modo geral, os resultados deste capítulo refletem melhoria nos problemas práticos de gestão que foram mapeados em etapas prévias da pesquisa-ação e que são comuns em ambientes dinamicos como o análisado. A validação destaca a possibilidade para que o modelo proposto seja utilizado em ambientes semelhantes, mediante a devida adaptação. Novamente, O entendimento da situação atual em recortes "macro" e "micro" facilita o monitoramento da situação alcançada - relacionada aos valores, princípios, práticas que sustentam a abordagem ágil - possibilitando a melhoria contínua. As questões abordadas no protocolo e nas seções 4.2.1 e 4.2.2 nortearam os processos de validação e levantamento de opiniões acerca do modelo aplicado e, juntamente com a exposição da forma de condução da pesquisa - em especial, por meio de um processo com os princípais elementos que devem ser considerados - podem auxiliar

\footnotetext{
${ }^{48}$ Três analistas e um gerente deixaram a equipe na qual a pesquisa-ação foi delineada, para irem para outros locais; um novo gerente foi alocado.
} 
em replicações da pesquisa em redes com características similares que desejem realizar o processo da transição do modelo de gestão.

As limitações e melhorias para trabalhos futuros são esperadas em processos de transição e indicam que a equipe está atenta a todos os novos elementos focais que precisam sofrer otimizações. A conscientização de melhoria contínua é um reflexo positivo do fortalecimento da auto-organização e autogestão na rede que faz com que o processo seja reiniciado para implementar ajustes, em especial, no âmbito dos pontos negativos indicados pelo parceiro Agência Reguladora e pelos dois integrantes da equipe do Centro de pesquisas. Evoluções na utilização da nova abordagem de gestão, visam a intensificação da participação de atores de níveis gerenciais de outras unidades organizacionais nas reuniões de planejamento, bem como a aplicação de indicadores de desempenho - que não entrem em conflitos com a nova mentalidade da equipe - e definição de cronograma para que a equipe selecione e participe de treinamentos em ambientes externos.

Por fim, esse capítulo também contribui com pesquisas na área de gestão ágil e de redes de inovação auto-organizadas, bem como com a sistematização de formas práticas para realizar transição do modelo de gestão e análisar os efeitos dessa ação, por meio da modelagem de empresas e imersão na situação do ambiente. 


\section{CONSIDERAÇÕES FINAIS}

Em mercados dinâmicos a busca por inovação rege os modelos de negócios, incidindo em desafios para obtenção de conhecimentos que ampliem a competitividade das empresas. As redes de inovação são reflexos dessa realidade, alterando a forma com que novos produtos e, até mesmo, processos e serviços são criados; tornando a capacidade de colaborar para atingir conhecimento - que fomente o processo criativo de inovação - um diferencial competitivo. Como resultado desses arranjos surgem diversos desafios gerenciais, tanto no cotidiano dos projetos, quanto na própria estrutura de formação e manutenção da rede. Tais desafios requerem coordenação adequada, para que os objetivos da rede sejam atingidos e inovações entregues.

Diferentes abordagens podem ser utilizadas para gestão nesses ambientes, porém trabalhos recentes indicam a necessidade por abordagens que permitam dar atenção a todos os elementos que influenciam a rede e seus projetos, não somente na esfera de uma única empresa, mas na rede como um todo. Essa forma de analisar requer abordagens mais flexíveis e adaptáveis para gestão, uma vez que as redes e seus projetos possuem particularidades inerentes ao segmento na qual se encontram e sofrem diversos tipos de influências - diferentes culturas organizacionais, localizações de equipes, formas de trabalho e conjunto de regras - que influenciam a forma de formar e manter parcerias, bem como de gerar, criar e disseminar conhecimento.

Nesse contexto, o desenvolvimento de modelos ágeis de gestão brindam as redes com as características necessárias para fornecer aos parceiros flexibilidade e adaptabilidade, elementos essenciais para atuar em ambientes dinâmicos e turbulentos, gerando resultados satisfatórios. Tais modelos tem sido criados mediante a combinação com outras abordagens de gestão - como as tradicionais -, configurando-se em modelos híbridos, adaptados a realidade de cada projeto e ambiente, mas fundamentados nos valores, princípios e práticas da gestão ágil.

Em prol de auxiliar na superação de eventuais lacunas de pesquisa acerca da gestão de redes de inovação auto-organizadas, bem como verificar a aplicabilidade da abordagem ágil para esses ambientes, um dos pilares desta pesquisa foi identificar e discutir, por meio de revisão da literatura, quais as áreas comuns entre ambos, isto é, quais necessidades e características das redes fomentam a aplicação de modelos ágeis, e quais características e possibilitadores da abordagem ágil, justificam sua aplicação à tais contextos, combinando-os sob a expectativa de obter benefícios para os negócios. A proposta de intersecção conceitual de 
duas áreas distintas da pesquisa acadêmica, permitiu identificar elementos que justicam sua aplicação conjunta e corroborou com o cumprindo dos objetivos desta pesquisa, uma vez que a revisão de literatura adequada fornece a base para a sequência dos trabalhos.

O próximo passo abrangido na pesquisa diz respeito a verificação da aplicabilidade conjunta da abordagem ágil e redes de inovação auto-organizadas, conforme apontado pela literatura, em um ambiente real, por meio de uma pesquisa-ação e modelagem de empresas. A modelagem da situação atual, apoiada pelo uso de questionários, permitiu a identificação e sistematização de problemas e oportunidades no ambiente - tratados nesta pesquisa como requisitos -, que confrontados com os valores, princípios, práticas e possibilitadores do ágil, confirmaram a possibilidade de utilização da gestão ágil no ambiente analisado, resultando na identificação das necessidades de mudanças. Os problemas e oportunidades abordados são comuns em ambientes dinâmicos de busca por inovação, portanto sua identificação também corroborou com os objetitvos da pesquisa.

A finalização da etapa de campo da pesquisa-ação diz respeito a transição do modelo de gestão em uma unidade organizacional da rede analisada, através de um plano de ação, modelagem da situação futura com implantação e aplicação de questionários. Entre as contribuições dessa fase estão a modelagem de empresas resultante, abrangendo recortes "macro" e "micro" da rede; sua validação positiva com a equipe participante, acerca da aplicabilidade para gestão de redes de inovação auto-organizadas e; o processo de transição utilizado, conjuntamente com os questionários para documentação dos benefícios e limitações observados após a transição. Essas contribuições também foram ao encontro aos objetivos da pesquisa, completando-os.

A escolha do método de pesquisa-ação também foi uma contribuição, pois permitiu a imersão do pesquisador na unidade de análise, facilitando e intensificando o processo de levantamento de dados, bem como corroborando com a resolução de problemas práticos do ambiente, através da completude das fases mapeadas - exploratória, aprofundada, ação e avaliação. Com relação aos modelos gerados, destaca-se que facilitaram a sistematização e documentação das informações, cumprindo com o proposto na seção 1.3.2 e ainda; que sua descaracterização, em termos de segmento aplicável, amplia sua abrangência para outras redes. Nesse contexto, a instanciação da modelagem de empresas proposta, deve considerar os seguintes pontos: o modelo de objetivos destacou o enfoque em prol de inovação que ocorre na rede; o modelo de regras de negócios auxiliou na identificação de maneiras de combinar abordagens, tornando o modelo híbrido; o modelo de atores e recursos faciliou a identificação de novos papéis e estruturas que permitem a combinação de abordagens e a definição de equipes 
ágeis; o modelo de processos focou no cotidiano práticos de atividades da rede - recortes macro e micro -; o modelo de componentes e requisitos técnicos indicou as ferramentas utilizadas para cumprir as práticas do ágil e sua forma de uso, levando em conta a minimização de investimentos financeiros e necessidade de treinamentos em itens complexos e; o modelo de conceitos auxiliou no fortalecimento e entendimento dos conceitos aplicados na modelagem.

Desse modo, foi possível responder as três questões que nortearam a pesquisa - (1) foram identificados elementos que apoiam a utilização da abordagem ágil; (2) foram identificados benefícios com a aplicação do modelo proposto; (3) foram identificadas limitações com a aplicação do modelo proposto - e, portanto, cumprir com os objetivos da mesma - compreender e sistematizar o gerenciamento de redes de inovação auto-organizadas com uso da abordagem ágil -, através da pesquisa-ação e proposta de uma modelagem de empresas. Salienta-se que a modelagem proposta permite visualizar os estados atual e futuro da gestão de redes de inovação auto-organizadas, visando facilitar a utilização da mesma em um ambiente real e ainda; conforme ilustrado na Figura 25 (página 155), que seu desenvolvimento cumpriu com todas as fases propostas no EKD-CMM (Processos 1 a 4), compreendendo ações de planejamento, construção, validação, teste e documentação.

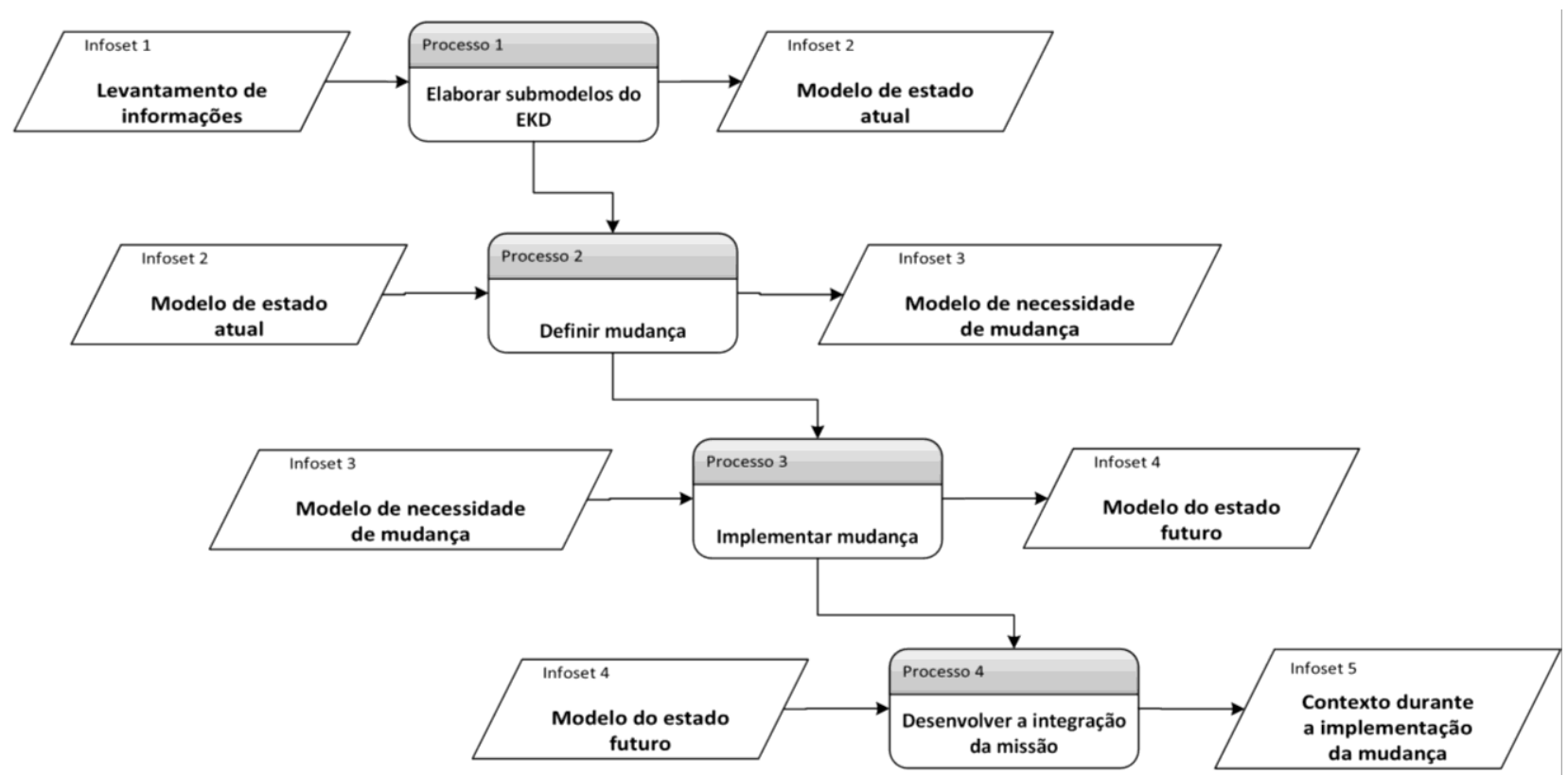

\section{Figura 25 - Processos abrangidos no EKD-CMM}

Fonte: Adaptado de Nurcan e Rolland (2003).

Entre as limitações gerais, podem ser citadas a impossibilidade de coletar um maior volume de dados, mediante envio de questionários a mais envolvidos, o que poderia expandir os resultados da pesquisa e; a impossibilidade de uso de indicadores mapeados nas fases da 
pesquisa-ação, visando mensurar e auxiliar no monitoramento do desempenho. A particularidade que a característica de auto-organização assume na unidade de análise também merece destaque, tendo em vista que a entrada de novos elementos na rede ocorre mediante contratos formais, porém sem deixar de considerar a real necessidade do ambiente e desejo dos interessados. Essa formalização, somanda às demais disfunções burocráticas que tiveram que ser mantidas no ambiente, reforçam a necessidade de modelos híbridos, pois não extinguem a auto-organização do ambiante, mas restringem e direcionam as ações. Observa-se que deve haver coesão entre os envolvidos para que a auto-organização seja mantida.

Entre as oportunidades existentes para a pesquisa, estão a atualização da revisão de literatura com novos resultados que surgem ao longo do tempo, dado que as áreas são ativas nas pesquisas; com relação às contribuições da modelagem as-is e do need-for-change existe a possibilidade de replicação das ações conduzidas - questionários, modelagem e confronto com a literatura da área - para identificar requisitos que indiquem a aplicabilidade da gestão ágil em outras redes de inovação e, conforme citado previamente, os dois elementos identificados que não encontraram amparo na literatura - tratados na seção 3.2.1 -, consistem em oportunidade para novas análises, em termos de verificação da sua influência na gestão desses ambientes; com relação à modelagem de empresas proposta, as oportunidades residem na instanciação da mesma em outras redes de inovação com características similares, mediante adaptação, visando solucionar problemas relacionados à gestão. Nesse sentido, a gerência do Centro de pesquisas, empresa focal na análise deste trabalho, manifestou interesse em replicar a pesquisa, através de instanciação na rede identificada pelo projeto B (Quadro 4).

Por fim, espera-se contribuir com a literatura da área de gestão de redes de inovação, em especial, auto-organizadas, bem como despertar o interesse de outros pesquisadores no tema, em prol de solucionar eventuais lacunas da mesma e ainda aprofundá-la em outros cenários. 


\section{REFERÊNCIAS}

AFSARMANESH H.; CAMARINHA-MATOS, L. M.; MSANJILA, S. S.; On management of 2nd generation virtual organizations breeding environments. Annual Reviews in Control, v. 33, n. 2, p. 209-219, 2009.

AMARAL, D. C. et al. Gerenciamento ágil de projetos - aplicação em produtos inovadores. São Paulo: Saraiva, 2011.

AMRITESH; MISRA, S. C. Conceptual modeling for knowledge management to support agile software development. The Knowledge Engineering Review, v. 29, n. 04, p. 496-511, 2014.

ARRANZ, N.; FDEZ. DE ARROYABE, J. C. Can innovation network projects result in efficient performance? Technological Forecasting and Social Change, v. 79, n. 3, p. 485497, 2012.

AUGUSTINE, S.; PAYNE, B. Agile project management: steering from the edges. Communications of the ACM, v. 48, n. 12, p. 85-89, 2005.

BATTERINK, M. H. et al. Orchestrating innovation networks: the case of innovation brokers in the agri-food sector. Entrepreneurship \& Regional Development, v. 22, n. 1, p. 47-76, 2010 .

BECHEIKH, N.; LANDRY, R.; AMARA, N. Lessons from innovation empirical studies in the manufacturing sector: a systematic review of the literature from 1993-2003. Technovation, v. 26, n. 5, p. 644-664, 2006.

BECK, K. et al. Manifesto for agile software development, 2001. Disponível em: http://www.agilemanifesto.org/. Acesso em: 6 nov. 2015.

BOEHM, B. Get ready for agile methods, with care. Computer, v. 35, n. 1, p. 64-69, 2002.

BOEHM, D. N.; HOGAN, T. "A jack of all trades": the role of PIs in the establishment and management of collaborative networks in scientific knowledge commercialisation. The Journal of Technology Transfer, v. 39, n. 1, p. 134-149, 2012.

BOEHM, B.; TURNER, R. Management challenges to implementing agile processes in traditional development organizations. IEEE Software, v. 22, n. 5, p. 30-39, 2005.

BUBENKO, J.; PERSSON, A.; STIRNA, J. EKD D3: User guide of the knowledge management approach using enterprise knowledge patterns. Stockholm (Sweden), Department of Computer and Systems Science, Royal Institute of Technology, 2001.

BRENNAN, A.; DOOLEY, L. Networked creativity: a structured management framework for stimulating innovation. Technovation, v. 25, n. 12, p. 1388-1399, 2005. 
BULLINGER, H.-J.; AUERNHAMMER, K.; GOMERINGER *, A. Managing innovation networks in the knowledge-driven economy. International Journal of Production Research, v. 42, n. 17, p. 3337-3353, 2004.

CALIA, R. C.; GUERRINI, F. M.; MOURA, G. L. Innovation networks: From technological development to business model reconfiguration. Technovation, v. 27, n. 8, p. 426-432, 2007.

CAMARINHA-MATOS L. M.; AFSARMANESH, H. The virtual enterprise concept. In: Camarinha-Matos LM, Afsarmanesh H, editors. Pro-VE'99 book, Infrastructure for virtual enterprises: networking industrial enterprises. Boston Dordrecht London: Kluwer Academic Publishers, p. 3-14, 1999.

CAMARINHA-MATOS, L. M.; AFSARMANESH, H. On reference models for collaborative networked organizations. International Journal of Production Research, v. 46, n. 9, p. 2453 2469, 2008.

CAMARINHA-MATOS, L. M. et al. Collaborative networked organizations-Concepts and practice in manufacturing enterprises. Computers \& Industrial Engineering, v. 57, n. 1, p. 46-60, 2009.

CAMARINHA-MATOS, L. M.; BOUCHER, X. Sustainable collaborative networks-case studies. Production Planning \& Control, v. 23, n. 4, p. 237-239, 2012.

CHESBROUGH, H. W.; TEECE, David J. Organizing for innovation: when is virtual virtuous?.Harvard Business School Pub., 2002.

CHOUDHARY, A. K. et al. Knowledge management and supporting tools for collaborative networks. International Journal of Production Research, v. 51, n. 7, p. 1953-1957, 2013.

CHOW, T.; CAO, D. B. A survey study of critical success factors in agile software projects. Journal of Systems and Software, v. 81, n. 6, p. 961-971, 2008.

CONFORTO, E.; AMARAL, D. Evaluating an agile method for planning and controlling innovative projects. Project Management Journal, v. 41, n. 2, p. 73-80, 2010.

CONFORTO, E. C. et al. Can Agile Project Management Be Adopted by Industries Other than Software Development? Project Management Journal, v. 45, n. 3, p. 21-34, 2014.

CONFORTO, E. C.; REBENTISH, E.; AMARAL, D. C. Project Management Agility Global Survey. Massachusetts Institute of Technology, Consortium for Engineering Program Excellence - CEPE, Cambridge, Massachusetts, U.S.A, 2014.

CORSARO, D.; CANTÙ, C.; TUNISINI, A. 'Actors' Heterogeneity in Innovation Networks. Industrial Marketing Management, v. 41, n. 5, p. 780-789, 2012.

CORSARO, D.; CANTÙ, C. Actors' heterogeneity and the context of interaction in affecting innovation networks. Journal of Business and Industrial Marketing, v. 30, n. (3-4), p. 246$258,2015$.

COUGHLAN, P.; COUGHLAN, D. Action Research for operations management. International Journal of Operations \& Production Management, v. 22, n. 2, p. 220-240, 2002. 
COWAN, R.; JONARD, N.; ZIMMERMANN, J.-B. Bilateral Collaboration and the Emergence of Innovation Networks. Management Science, v. 53, n. 7, p. 1051-1067, 2007.

DHANARAJ, C.; PARKHE, A. Orchestrating innovation networks. Academy of Management Review, v. 31, n. 3, p. 659-669, 2006.

DILK, C. et al. State and development of innovation networks: Evidence from the European vehicle sector. Management Decision, v. 46, n. 5, p. 691-701, 2008.

DOLOREUX, D. Regional networks of small and medium sized enterprises: evidence from the Metropolitan Area of Ottawa in Canada1. European Planning Studies, v. 12, n. 2, p. 173-189, 2004.

DRURY-GROGAN, M. L. Performance on agile teams: Relating iteration objectives and critical decisions to project management success factors. Information and Software Technology, v. 56, n. 5, p. 506-515, 2014.

FAGERBERG, J.; SRHOLEC, M. National innovation systems, capabilities and economic development. Research Policy, v. 37, n. 9, p. 1417-1435, 2008.

FAGERBERG, J., VERSPAGEN, B. Innovation studies - The emerging structure of a new scientific field. Research Policy, v. 38, n. 2, p. 218-233, 2009.

FAGERBERG, J.; SRHOLEC, M.; VERSPAGEN, Bart. Innovation and economic development. Handbook of the Economics of Innovation, v. 2, p. 833-872, 2010.

FAGERBERG, J.; FOSAAS, M.; SAPPRASERT, K. Innovation: Exploring the knowledge base. Research Policy, v. 41, n. 7, p. 1132-1153, 2012.

FEKRI, R.; ALIAHMADI, A.; FATHIAN, M. Identifying the cause and effect factors of agile NPD process with fuzzy DEMATEL method: the case of Iranian companies. Journal of Intelligent Manufacturing, v. 20, n. 6, p. 637-648, 2008.

FERNANDEZ, D.; FERNANDEZ, J. Agile project management-agilism versus traditional approaches. Journal of Computer Information Systems, v. 49, n. 2, p. 10-18, 2008.

FREEL, M. S. Sectoral patterns of small firm innovation, networking and proximity. Research Policy, v. 32, n. 5, p. 751-770, 2003.

FREEL, M.S.; HARRISON, R.T. Innovation and cooperation in the small firm sector: Evidence from 'Northern Britain'. Regional Studies, v. 40, n. 4, p. 289-305, 2006.

FRAIHA, S. Coordination Modes Established by the Hub SME Bearer, Journal of Small Business Management, v. 50, n. 2, p. 216-238, 2012.

GARDET, E.; MOTHE, C. The Dynamics of Coordination in Innovation Networks. European Management Review, v. 8, n. 4, p. 213-229, 2011. 
GEBAUER, A.; NAM, C.; PARSCHE, R. Regional technology policy and factors shaping local innovation networks in small German cities. European Planning Studies, v. 13, n. 5, p. 661$683,2005$.

GIL, A. C. Como elaborar projetos de pesquisa. $5^{\text {a }}$ ed. São Paulo: Atlas, 2010.

GUBBINS, C.; DOOLEY, L. Exploring Social Network Dynamics Driving Knowledge Management for Innovation. Journal of Management Inquiry, v. 23, n. 2, p. 162-185, 2013.

HÅKANSSON, H., FORD, D.; HÃ¥KANSSON, Hã¥. How should companies interact in business networks? Journal of Business Research, v. 55, n. 2, p. 133-139, 2002.

HANSEN, M. T.; BIRKINSHAW, J. The innovation value chain. Harvard business review, v. 85 , n. 6 , p. 121, 2007.

HARMAAKORPI, V.; MELKAS, H. Knowledge management in regional innovation networks: The case of Lahti, Finland. European Planning Studies, v. 13, n. 5, p. 641-659, 2005 .

HARRIS, L.; COLES, A.-M.; DICKSON, K. Building Innovation Networks: Issues of Strategy and Expertise. Technology Analysis \& Strategic Management, v. 12, n. 2, p. 229-241, 2000.

HARRISSON, D.; LAPLANTE, N.; LOUIS St-Cyr. Cooperation and resistance in work innovation networks. Human Relations, v. 54, n. 2, p. 215-255, 2001.

H. T. GORANSON, The agile virtual enterprise: cases, metrics, tools, Quorum Books, Westport, CT, 1999.

HIGHSMITH, J. Agile Project Management: creating innovative products. Boston: AddisonWesley, 2004.

HOOPER, M. J.; STEEPLE, D.; WINTERS, C. N. Costing customer value: an approach for the agile enterprise. International Journal of Operations \& Production Management, v. 21, n. 5, p. 630-644, 2001.

HOPE, K. L.; AMDAHL, E. Configuring designers? Using one agile project management methodology to achieve user participation. New Technology, Work and Employment, v. 26, n. 1, p. 54-67, 2011.

JANSSON, K. et al. Governance and management of virtual organizations. In: L.M. Camarinha-Matos, H. Afsarmanesh, and M. Ollus, eds. Methods and tools for collaborative networked organizations. New York: Springer, p. 431-462, 2008.

JARVENPAA, S. L.; VÄLIKANGAS, L. Opportunity Creation in Innovation Networks. California Management Review, v. 57, n. 1, p. 67-87, 2014.

JAVDANI GANDOMANI, T.; ZIAEI NAFCHI, M. An empirically-developed framework for Agile transition and adoption: a grounded theory approach. Journal of Systems and Software, v. 107, p. 204-219, 2015. 
KASH, D. E.; RYCROFT, R. W. To manage complex innovation, ask the right questions. Research-Technology Management, v. 46, n. 5, p. 29-33, 2003.

KAUFMANN, A.; LEHNER, P.; TÖDTLING, F. Effects of the Internet on the spatial structure of innovation networks. Information Economics and Policy, v. 15, n. 3, p. 402-424, 2003.

KLERKX, L.; AARTS, N. The interaction of multiple champions in orchestrating innovation networks: Conflicts and complementarities. Technovation, v. 33, n. 6-7, p. 193-210, 2013.

KOLLECK, N.; BORMANN, I. Analyzing trust in innovation networks: combining quantitative and qualitative techniques of Social Network Analysis. Zeitschrift Für Erziehungswissenschaft, vol. 17, n. 5, p. 9-27, 2014.

KÖNIG, M. D. et al. Recombinant knowledge and the evolution of innovation networks. Journal of Economic Behavior \& Organization, v. 79, n. 3, p. 145-164, 2011.

LAANTI, M.; SALO, O.; ABRAHAMSSON, P. Agile methods rapidly replacing traditional methods at Nokia: A survey of opinions on agile transformation. Information and Software Technology, v. 53, n. 3, p. 276-290, 2011.

LANDRY, R. et al. Technology transfer organizations: Services and business models. Technovation, v. 33, n. 12, p. 431-449, 2013.

LEE, S.; YONG, H.-S. Distributed agile: project management in a global environment. Empirical Software Engineering, v. 15, n. 2, p. 204-217, 2009.

LEVÉN, P.; HOLMSTRÖM, J.; MATHIASSEN, L. Managing research and innovation networks: Evidence from a government sponsored cross-industry program. Research Policy, v. 43 , n. 1, p. 156-168, 2014.

LOSS, L.; CRAVE, S. Agile business models: an approach to support collaborative networks. Production Planning \& Control, v. 22, n. 5-6, p. 571-580, 2011.

LOWE, M. S. et al. Self-organizing innovation networks, mobile knowledge carriers and diasporas: insights from a pioneering boutique hotel chain. Journal of Economic Geography, v. 12, n. 5, p. 1113-1138, 2012.

MARTINEZ-ROS, E. Explaining the decisions to carry out product and process innovations: the Spanish case. The Journal of High Technology Management Research, v. 10, n. 2, p. 223-242, 1999.

MARTINS, R. A. Abordagens quantitative e qualitative. In: MIGUEL, P. A. C. (Org.). Metodologia de pesquisa em engenharia de produção e gestão de operações. $2^{\circ}$ ed. Rio de Janeiro: Elsevier: ABEPRO, 2012.

MARTINS, L. L.; GILSON, L. L.; MAYNARD, M. T. Virtual teams: what do we know and where do we go from here? Journal of Management, v. 30, n. 6, p. 805-835, 2004. 
MASIELLO, B.; IZZO, F.; CANORO, C. The structural, relational and cognitive configuration of innovation networks between SMEs and public research organisations. International Small Business Journal, v. 33, n. 2, p. 169-193, 2015.

MCAVOY, J.; BUTLER, T. The role of project management in ineffective decision making within Agile software development projects. European Journal of Information Systems, v. 18, n. 4, p. 372-383, 2009.

MELO, C. DE O. et al. Interpretative case studies on agile team productivity and management. Information and Software Technology, v. 55, n. 2, p. 412-427, 2013.

MISHRA, D.; MISHRA, A. Complex software project development: agile methods adoption. Journal of Software Maintenance and Evolution: Research and Practice, v. 23, n. 8, p. 549-564, 2011.

MICHAELIDES, R.; MORTON, S. C.; LIU, W. A framework for evaluating the benefits of collaborative technologies in engineering innovation networks. Production Planning \& Control, v. 24, n. 2-3, p. 246-264, 2013.

MOE, N. B.; DINGS $\varnothing$ YR, T.; DYBÅ, T. A teamwork model for understanding an agile team: a case study of a scrum project. Information and Software Technology, v. 52, n. 5, p. 480 491, 2010.

MÖLLER, K.; SVAHN, S. How to influence the birth of new business fields - network perspective. Industrial Marketing Management, v. 38, p. 450-458, 2009.

MUZZI, C.; ALBERTINI, S. Communities and managerial competencies supporting SMEs innovation networking: a longitudinal case study. $\boldsymbol{R} \& \boldsymbol{D}$ Management, v. 45, n. 2, p. 196-211, 2014.

NEGRETTO, U. et al. VO-management solutions; VO management e-services. In: L.M. Camarinha-Matos, H. Afsarmanesh, and M. Ollus, eds. Methods and tools for collaborative networked organizations. New York: Springer, p. 257-274, 2008.

NELSON, R.; WINTER, S. An evolutionary theory of economic change, Belknap Press, Cambridge, 1982.

NICHOLLS, G. M.; LEWIS, N. A.; ESCHENBACH, T. Determining when simplified agile project management is right for small teams. Engineering Management Journal, v, 27, n. 1, p. $3-10,2015$.

NONAKA, Ikujiro. A dynam AFSARMANESHic theory of organizational knowledge creation. Organization Science, v. 5, n. 1, p. 14-37, 1994.

NOOR, M. A.; RABISER, R.; GRÜNBACHER, P. Agile product line planning: A collaborative approach and a case study. Journal of Systems and Software, v. 81, n. 6, p. 868$882,2008$.

NONAKA, I. A empresa criadora de conhecimento. In: HARVARD BUSSINESS REVIEW. Gestão do conhecimento. Rio de Janeiro: Campus, p. 27-49, 2000. 
NOOTEBOOM, B. Innovation and diffusion in small firms: theory and evidence. Small Business Economics, v. 6, n. 5, p. 327-347, 1994.

NOOTEBOOM, B. et al. Optimal cognitive distance and absorptive capacity. Research Policy, v. 36, n. 7, p. 1016-1034, 2007.

NURCAN, S.; ROLLAND, C. A multi-method for defining the organizational chance. Information and Software Techonology, v. 45, n2, p. 61-82, 2003.

OLARU, D.; PURCHASE, S. Innovation network trajectories: the role of time and history. Journal of Business \& Industrial Marketing, v. 30, e. 3/4, p. 342-353, 2015.

OLLUS, M. et al. Supporting collaborative project management. Production Planning \& Control, v. 22, n. 5-6, p. 538-553, 2011.

ORGANIZAÇÃO PARA A COOPERAÇÃO E DESENVOLVIMENTO ECONÔMICO OCDE. Manual de Oslo: proposta de diretrizes para coleta e interpretação de dados sobre inovação tecnológica. $3^{\text {a }}$ ed. Brasília: OCDE: FINEP, 2005.

PÁDUA, S. I. D. Estudo sobre a aplicação do método de avaliação do modelo de processos de negócio do EKD. Produção, v. 22, n. 1, p. 155-172, 2012.

PÁDUA, S. I. D.; CAZARINI, E. W.; INAMASU, R. Y. Modelagem organizacional: captura dos requisitos organizacionais no desenvolvimento de sistemas de informação. Gestão \& Produção, v. 11, n. 2, p. 197-209, 2004.

PEKKARINEN, S.; HARMAAKORPI, V. Building regional innovation networks: The definition of an age business core process in a regional innovation system. Regional Studies, v. 40, n. 4, p. 401-413, 2006.

PEREIRA, R.; DA SILVA, M. M. A maturity model for implementing ITIL V3 in practice. Proceedings - IEEE International Enterprise Distributed Object Computing Workshop, EDOC, p. 259-268, 2011.

PERKS, H.; MOXEY, S. Market-facing innovation networks: How lead firms partition tasks, share resources and develop capabilities. Industrial Marketing Management, v. 40, n. 8, p. 1224-1237, 2011.

PERSSON, J. S.; MATHIASSEN, L.; AAEN, I. Agile distributed software development: enacting control through media and context. Information Systems Journal, v. 22, e. 6, p. 411433, 2012.

POPE-RUARK, R. Introducing agile project management strategies in technical and professional communication courses. Journal of Business and Technical Communication, v. 29, e. 1, p. 112-133, 2015.

PRAHALAD, C.; HAMEL, G. The core competencies of the corporation. Harvard Business Review, v. 68, n. 3, p. 79-91, 1990. 
PRINCE, K.; BARRETT, M.; OBORN, E. Dialogical strategies for orchestrating strategic innovation networks: The case of the Internet of Things. Information and Organization, v. 24, n. 2, p. 106-127, 2014.

PROCTER, R. et al. Agile Project Management: A Case Study of a Virtual Research Environment Development Project. Computer Supported Cooperative Work (CSCW), v. 20, n. 3, p. 197-225, 2011.

PROJECT MANAGEMENT INSTITUTE - PMI. PMBOK Guide. A guide to the project Management Body of Knowledge. Pennsylvania: Project Management Institute, 4. ed., 2008.

QUMER, A.; HENDERSON-SELLERS, B. A framework to support the evaluation, adoption and improvement of agile methods in practice. Journal of Systems and Software, v. 81, n. 11, p. 1899-1919, 2008.

RAMPERSAD, G.; QUESTER, P.; TROSHANI, I. Managing innovation networks: Exploratory evidence from ICT, biotechnology and nanotechnology networks. Industrial Marketing Management, v. 39, n. 5, p. 793-805, 2010.

REIFER, D. How good are agile methods? IEEE Software, v. 19, n. 4, p. 16-18, jul. 2002.

RYCROFT, R. W. Does cooperation absorb complexity? Innovation networks and the speed and spread of complex technological innovation. Technological Forecasting and Social Change, v. 74, n. 5, p. 565-578, 2007.

RYCROFT, R. W.; KASH, D. E. Self-organizing innovation networks: implications for globalization. Technovation, v. 24, n. 3, p. 187-197, 2004.

SHARIFI, H. et al. Agile manufacturing: a management and operational framework. Proceedings of the Institution of Mechanical Engineers, Part B: Journal of Engineering Manufacture, v. 215, n. 6, p. 857-869, 2001.

SMART, P.; BESSANT, J.; GUPTA, A. Towards technological rules for designing innovation networks: a dynamic capabilities view. International Journal of Operations \& Production Management, v. 27, n. 10, p. 1069-1092, 2007.

SCHUMPETER, J. A. Capitalism, Socialism and Democracy. New York: Harper and Brothers, 1942.

SANDKUL; K.; STIRNA, J.; PERSSON, A.; WIBOTZKI, M. (2014). Enterprise modeling: tackling business challenges with 4EM method. Springer verlang, 2014.

SODA, G. The management of firms' alliance network positioning: Implications for innovation. European Management Journal, v. 29, n. 5, p. 377-388, 2011.

STEINER, M.; GIL, J.; EHRET, O. European medium-technology innovation networks: a multi-methodological multi-regional approach. International Journal of Technology Management, v. 50, p. 229-262, 2010. 
STETTINA, C. J.; HÖRZ, J. Agile portfolio management: an empirical perspective on the practice in use. International Journal of Project Management, v. 33, e. 1, p. 140-152, 2014.

TIDD, J.; BESSANT, J. Managing innovation, integrating technological, market and organizational change. Chichester: John Wiley \& Sons, e. 4, 2009.

THIOLLENT, Michel. Pesquisa-ação nas organizações. 2. Ed. São Paulo: Atlas, 2009.

THIOLLENT, M. Metodologia da pesquisa-Ação. 18. Ed. São Paulo: Cortez, 2011.

TOLFO, C. et al. Agile methods and organizational culture: reflections about cultural levels. Journal of Software Maintenance and Evolution: Research and Practice, v. 23, n. 6, p. 423-441, 2011.

TURRIONI, J. B.; MELLO, C. H. P. Metodologia de pesquisa em engenharia de produção: estratégias, métodos e técnicas para condução de pesquisas quantitativas e qualitativas. Apostila do curso de Especialização em Qualidade e Produtividade. Universidade Federal de Itajubá, Itajubá, MG, 2012.

VAN AKEN, J. E.; WEGGEMAN, M. P. Managing learning in informal innovation networks: overcoming the Daphne-dilemma. R and D Management, v. 30, n. 2, p. 139-150, 2000.

ZENG, S.X.; XIE, X.M.; TAMC, C.M. Relationship between cooperation networks and innovation performance of SMEs. Technovation, v. 30, n. 3, p. 181-194, 2010. 


\section{APÊNDICE A - QUESTIONÁRIOS}

Este apêndice contém os resultados de cinco questionários aplicados na pesquisa-ação, relacionados aos estados atual, de necessidade de mudança e futuro, envolvendo diferentes atores mapeados. As informações apresentadas aos respondentes para nortear o preenchimento são apresentadas no início de cada questionário.

\section{Questionário Modelagem As-Is e Need-for-Change}

Este questionário está relacionado às modelagens do estado atual e de necessidade de mudança da unidade de análise e foi aplicado no Centro de Pesquisas. Para facilitar a leitura e centralizar as respostas ele foi dividido em cinco seções principais e uma seção inicial para identificação do respondente. Esta abordagem visa checar variações na percepção da pesquisa, de acordo com o perfil afetado. Explicações fornecidas aos respondentes para cada questão:

O conjunto de perguntas da Questão 1 almeja confirmar se a unidade de análise consiste em uma rede de inovação auto-organizada e se a equipe possui consciência disso (Questões 1.1 a 1.6). O conjunto de perguntas da Questão 2 almeja verificar a visibilidade dos atores acerca da forma de gestão da rede como um todo - recorte macro - (Questões 2.1 a 2.3). O conjunto de perguntas da Questão 3 almeja verificar a visibilidade dos atores acerca da forma de gestão dos projetos da rede - recorte micro - (Questões 3.1 a 3.4). O conjunto de perguntas da Questão 4 almeja verificar a existência de elementos na rede e em seus projetos que apoiam a aplicação da gestão ágil em tais ambientes, de acordo com a visão dos envolvidos (Questões 4.1 a 4.4). O conjunto de perguntas da Questão 5 almeja verificar quais as principais práticas da gestão ágil que trariam benefícios para a rede e seus projetos, de acordo com a visão dos envolvidos (Questões 5.1 e 5.2). 


\section{3 respostas}

\section{Resumo}

\section{Identificação do respondente}

\section{Função na empresa}

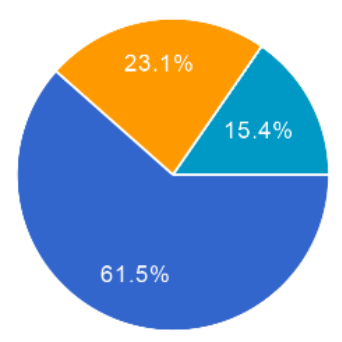

$\begin{array}{rcr}\text { Analista } & \mathbf{8} & 61.5 \% \\ \text { Administrador financeiro } & \mathbf{0} & 0 \% \\ \text { Auxiliar administrativo } & \mathbf{3} & 23.1 \% \\ \text { Diretor } & \mathbf{0} & 0 \% \\ \text { Engenheiro } & \mathbf{0} & 0 \% \\ \text { Gerente } & \mathbf{2} & 15.4 \%\end{array}$

Projeto A [Trabalhou no(s) projeto(s) desde o início da configuração da(s) rede(s)?]

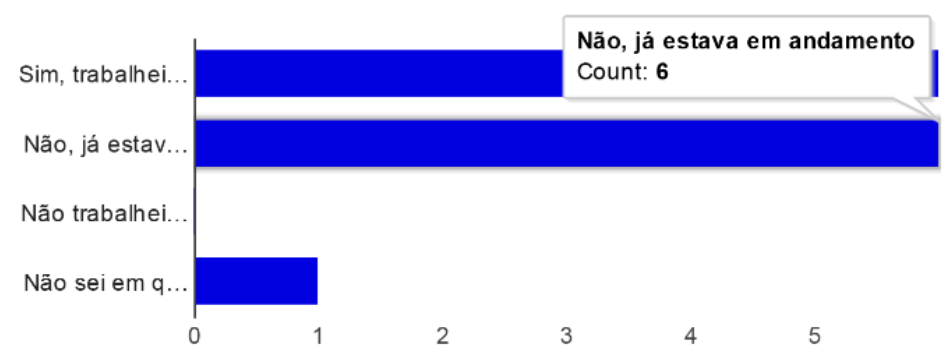

Sim, trabalhei desde o início $6 \quad 46.2 \%$

Não, já estava em andamento $6 \quad 46.2 \%$

Não trabalhei neste projeto $\mathbf{0} \quad 0 \%$

Não sei em que fase o projeto estava $1 \quad 7.7 \%$ 
Projeto B [Trabalhou no(s) projeto(s) desde o início da configuração da(s) rede(s)?]

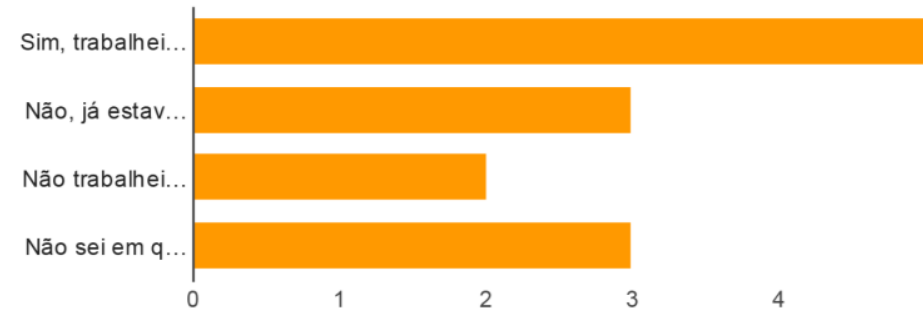

$\begin{array}{rrr}\text { Sim, trabalhei desde o início } & \mathbf{5} & 38.5 \% \\ \text { Não, já estava em andamento } & \mathbf{3} & 23.1 \% \\ \text { Não trabalhei neste projeto } & \mathbf{2} & 15.4 \% \\ \text { ei em que fase o projeto estava } & \mathbf{3} & 23.1 \%\end{array}$

Possuia conhecimento sobre o que é uma rede de inovação? (Relacionamentos cooperativos entre setores de uma mesma empresa ou entre várias empresas e/ou outros atores na busca por inovação em prol de um objetivo comum)

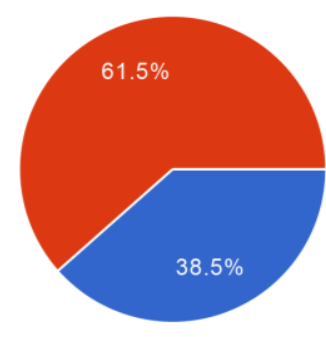

$\operatorname{Sim} 538.5 \%$

Não $8 \quad 61.5 \%$

Já tinha tido contato prévio com gestão ágil?

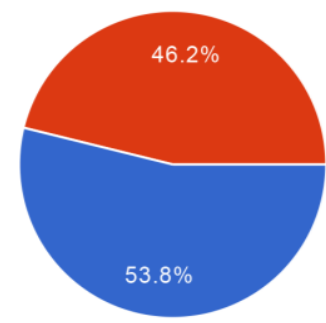

\footnotetext{
Sim $753.8 \%$

Não $6 \quad 46.2 \%$

Não sei $\quad \mathbf{0} \quad 0 \%$
} 
Q1 - A unidade de análise apresentou características de redes de inovação auto-organizadas?

Projetos direcionados para soluções inovadoras [Q1.1 - Quais características ocorrem no ambiente do(s) projeto(s)?]

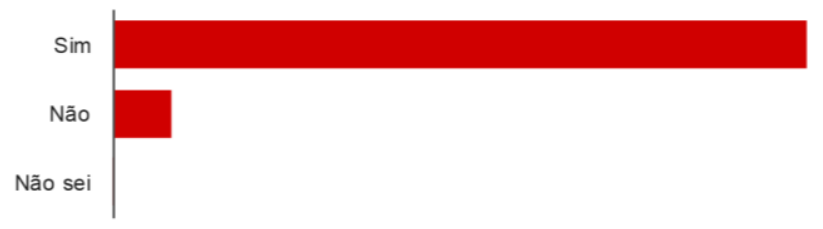

$\begin{array}{rrr}\text { Sim } & \mathbf{1 2} & 92.3 \% \\ \text { Não } & \mathbf{1} & 7.7 \% \\ \text { Não sei } & \mathbf{0} & 0 \%\end{array}$

Ambiente formado por ligações entre diferentes atores (unidades da empresa e outras organizações) em prol de um objetivo comum [Q1.1 Quais características ocorrem no ambiente do(s) projeto(s)?]

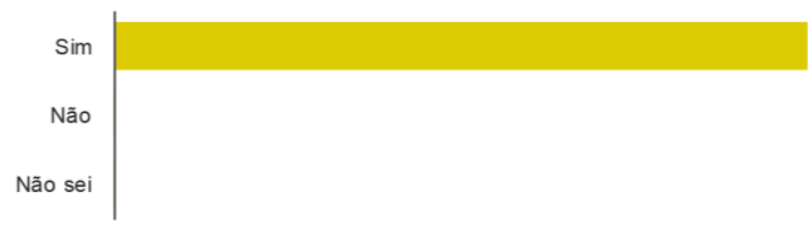

$\begin{array}{rrr}\text { Sim } & \mathbf{1 3} & 100 \% \\ \text { Não } & \mathbf{0} & 0 \% \\ \text { Não sei } & \mathbf{0} & 0 \%\end{array}$

Equipes formadas por atores com diferentes perfis (equipe multidisciplinar) [Q1.1 - Quais características ocorrem no ambiente do(s) projeto(s)?]

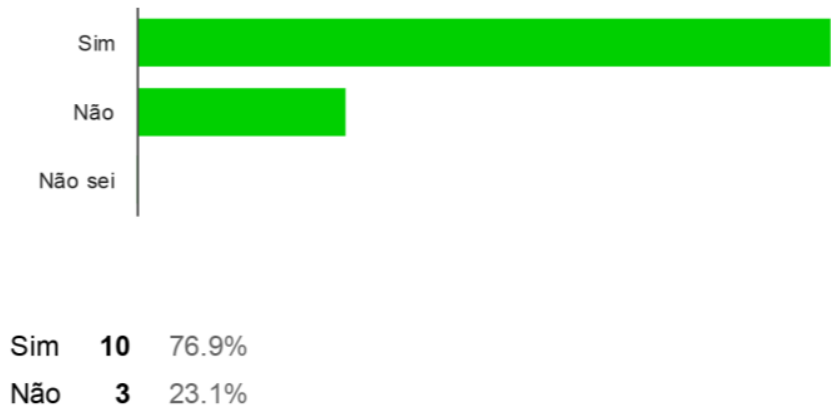


Não sei $\quad 0 \quad 0 \%$

Ambiente com atmosfera de confiança entre os atores [Q1.1 - Quais características ocorrem no ambiente do(s) projeto(s)?]

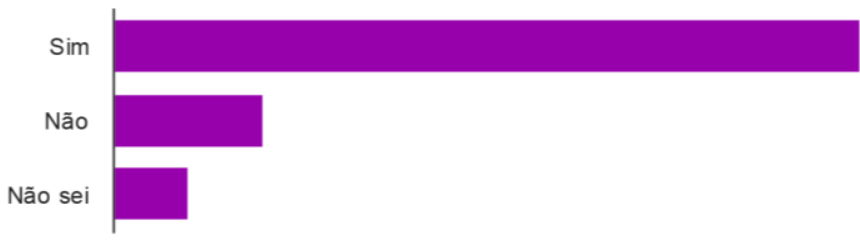

$\begin{array}{rrr}\text { Sim } & \mathbf{1 0} & 76.9 \% \\ \text { Não } & \mathbf{2} & 15.4 \% \\ \text { Não sei } & \mathbf{1} & 7.7 \%\end{array}$

Presença de informalidade entre as relações [Q1.1 - Quais características ocorrem no ambiente do(s) projeto(s)?]

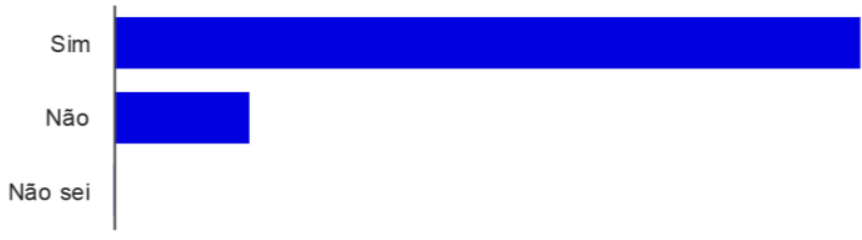

$\begin{array}{rrr}\text { Sim } & \mathbf{1 1} & 84.6 \% \\ \text { Não } & \mathbf{2} & 15.4 \% \\ \text { Não sei } & \mathbf{0} & 0 \%\end{array}$

Existência de uma figura forte centralizadora de poder [Q1.1 - Quais características ocorrem no ambiente do(s) projeto(s)?]

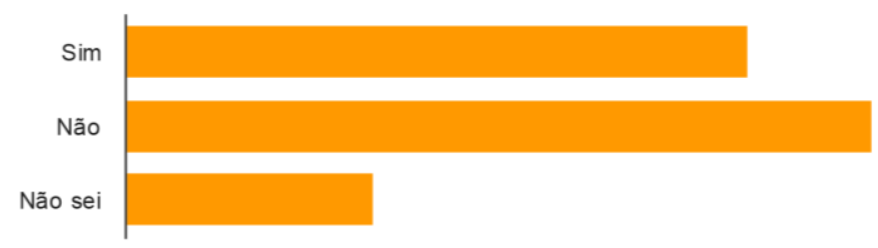

$\begin{array}{rrr}\text { Sim } & \mathbf{5} & 38.5 \% \\ \text { Não } & \mathbf{6} & 46.2 \% \\ \text { Não sei } & \mathbf{2} & 15.4 \%\end{array}$


Existência de flexiblidade nas tarefas e relacionamentos [Q1.1 - Quais características ocorrem no ambiente do(s) projeto(s)?]

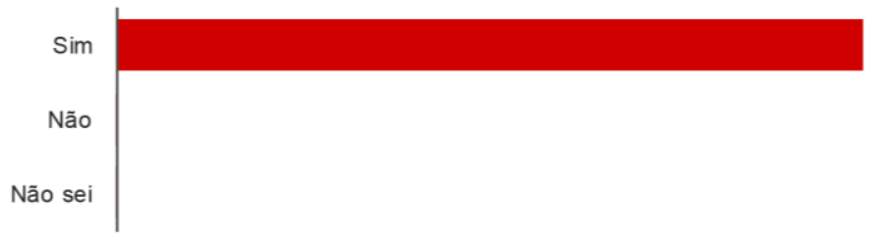

$\begin{array}{rrr}\text { Sim } & \mathbf{1 3} & 100 \% \\ \text { Não } & \mathbf{0} & 0 \% \\ \text { Não sei } & \mathbf{0} & 0 \%\end{array}$

Existência de adaptabilidade nas tarefas e relacionamentos [Q1.1 - Quais características ocorrem no ambiente do(s) projeto(s)?]

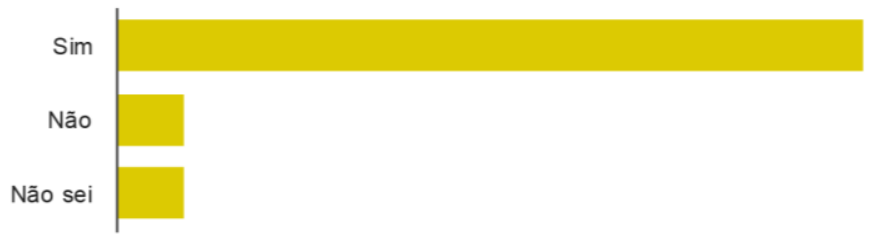

$\begin{array}{rrr}\text { Sim } & \mathbf{1 1} & 84.6 \% \\ \text { Não } & \mathbf{1} & 7.7 \% \\ \text { ão sei } & \mathbf{1} & 7.7 \%\end{array}$

Existência de compartilhamento nas tarefas e relacionamentos [Q1.1 - Quais características ocorrem no ambiente do(s) projeto(s)?]

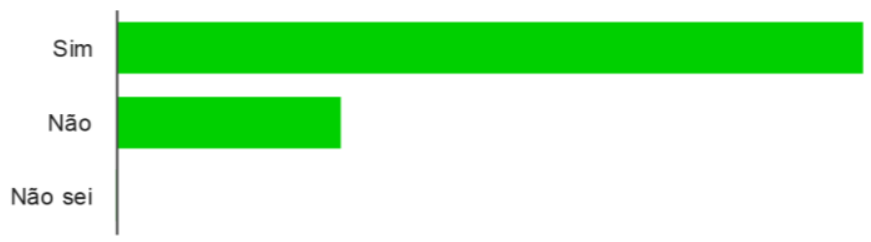

$\begin{array}{rrr}\text { Sim } & \mathbf{1 0} & 76.9 \% \\ \text { Não } & \mathbf{3} & 23.1 \% \\ \text { Não sei } & \mathbf{0} & 0 \%\end{array}$

Presença de forte trabalho colaborativo [Q1.1 - Quais características ocorrem no ambiente do(s) projeto(s)?] 


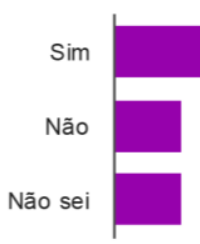

$\begin{array}{rrr}\text { Sim } & \mathbf{1 1} & 84.6 \% \\ \text { Não } & \mathbf{1} & 7.7 \% \\ \text { Não sei } & \mathbf{1} & 7.7 \%\end{array}$

Elevada capacidade para geração de conhecimento [Q1.1 - Quais características ocorrem no ambiente do(s) projeto(s)?]

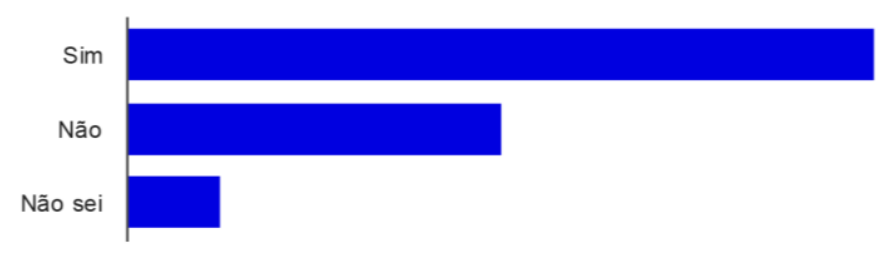

Sim $8 \quad 61.5 \%$

Não $4 \quad 30.8 \%$

Não sei $1 \quad 7.7 \%$

Q1.2 - A unidade de análise está envolvida em mais de um projeto vinculado a redes de inovação?

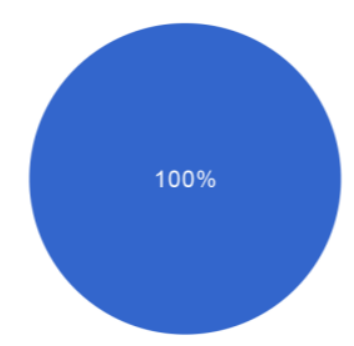

$\begin{array}{rrr}\text { Sim } & \mathbf{1 3} & 100 \% \\ \text { Não } & \mathbf{0} & 0 \% \\ \text { Não sei } & \mathbf{0} & 0 \%\end{array}$

Existência de atores com iniciativas próprias [Q1.3 - A rede de inovação observada é auto-organizada(s)?] 


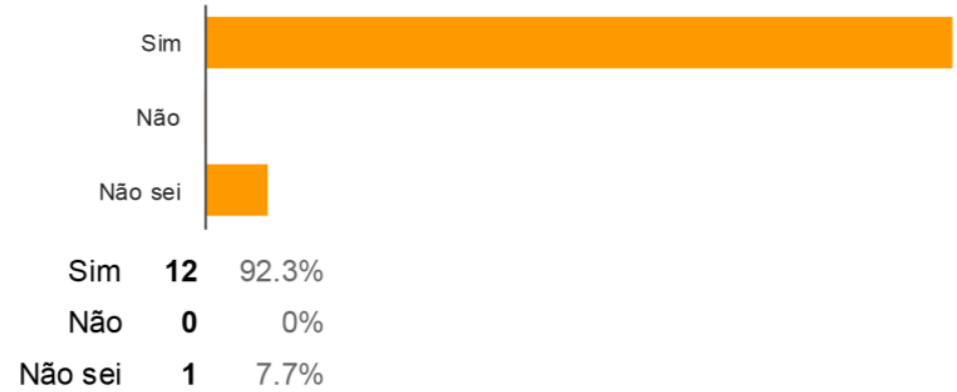

Vínculos fortes entre os atores que fomentam o fluxo de conhecimento e troca de experiências [Q1.3 - A rede de inovação observada é autoorganizada(s)?]

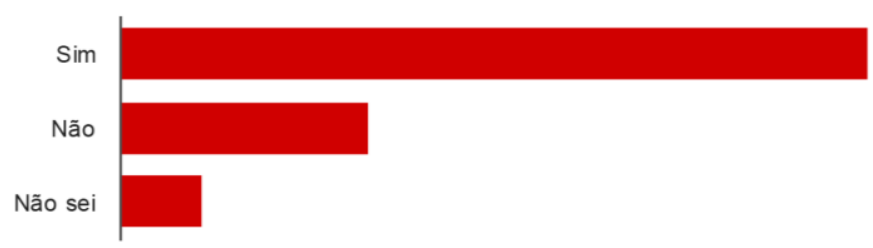

$\begin{array}{rrr}\text { Sim } & \mathbf{9} & 69.2 \% \\ \text { Não } & \mathbf{3} & 23.1 \% \\ \text { Não sei } & \mathbf{1} & 7.7 \%\end{array}$

Ocorrência de mudanças espontâneas na estrutura da rede/projeto(s) [Q1.3 - A rede de inovação observada é auto-organizada(s)?]

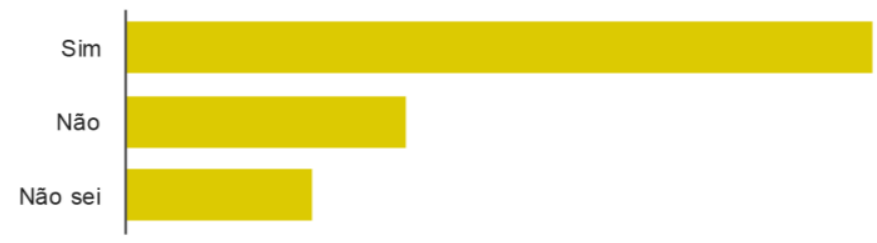

$\begin{array}{rrr}\text { Sim } & \mathbf{8} & 61.5 \% \\ \text { Não } & \mathbf{3} & 23.1 \% \\ \text { Não sei } & \mathbf{2} & 15.4 \%\end{array}$

Comportamento espontâneo dos atores para resolução de problemas [Q1.3 - A rede de inovação observada é auto-organizada(s)?] 


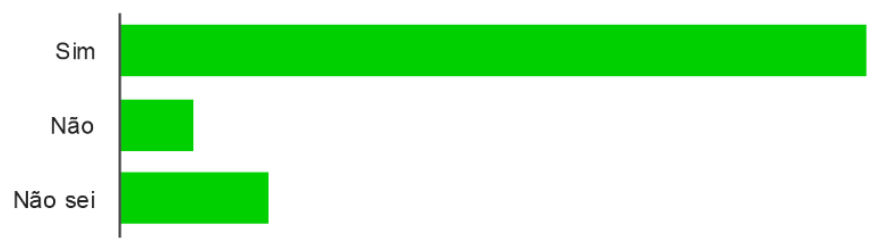

Não sei $2 \quad 15.4 \%$

Q1.4 - A rede é formada por atores internos e externos à unidade de análise?

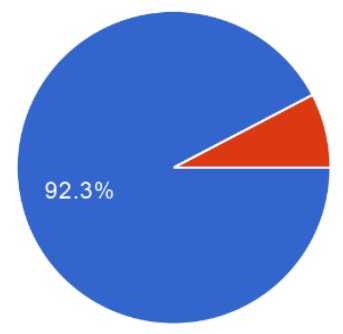

$\begin{array}{rrr}\text { Sim } & \mathbf{1 2} & 92.3 \% \\ \text { Não } & \mathbf{1} & 7.7 \% \\ \text { Não sei } & \mathbf{0} & 0 \%\end{array}$

Q1.5 - Você acredita estar participando de uma rede de inovação?

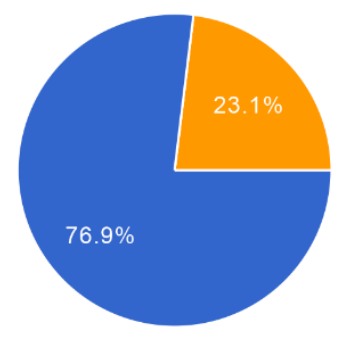

$\begin{array}{rrr}\text { Sim } & \mathbf{1 0} & 76.9 \% \\ \text { Não } & \mathbf{0} & 0 \% \\ \text { Não sei } & \mathbf{3} & 23.1 \%\end{array}$

Q1.6 - Os envolvidos tem consciência sobre a participação em uma rede de inovação? 


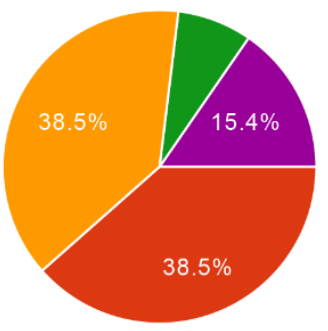

Ninguém tem consciência $\mathbf{1} \quad 7.7 \%$

Não se aplica $2 \quad 15.4 \%$

\section{Q2 - Qual é a forma de gestão da rede observada?}

Q2.1 - A mesma rede conduz mais de um projeto ao mesmo tempo?

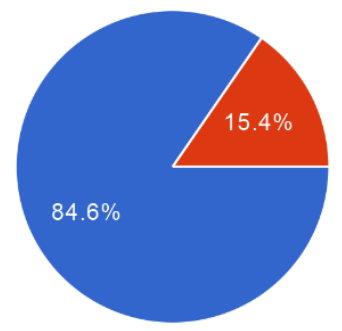

$\begin{array}{rrr}\text { Sim } & \mathbf{1 1} & 84.6 \% \\ \text { Não } & \mathbf{2} & 15.4 \% \\ \text { Não Sei } & \mathbf{0} & 0 \%\end{array}$

Q2.2 - Existe uma forma definida para gestão da rede?

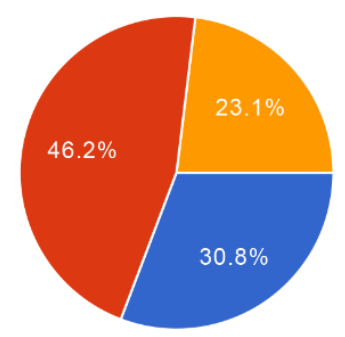

\footnotetext{
Sim $430.8 \%$

Não $6 \quad 46.2 \%$

Não sei $3 \quad 23.1 \%$
}

Q2.3 - A forma de gestão impacta o desempenho da rede? 


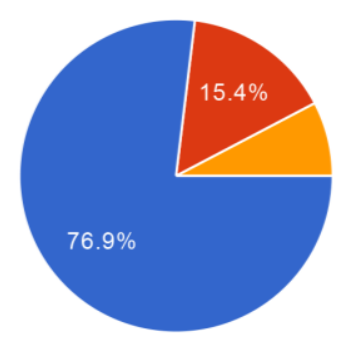

$\begin{array}{rrr}\text { Sim } & \mathbf{1 0} & 76.9 \% \\ \text { Não } & \mathbf{2} & 15.4 \% \\ \text { Não sei } & \mathbf{1} & 7.7 \%\end{array}$

\section{Q3 - Qual a forma de gestão dos projetos da rede observada?}

Atores ligados pelo mesmo objetivo de cumprimento do projeto [Q3.1 Foram identificados projetos colaborativos na unidade de análise? ]

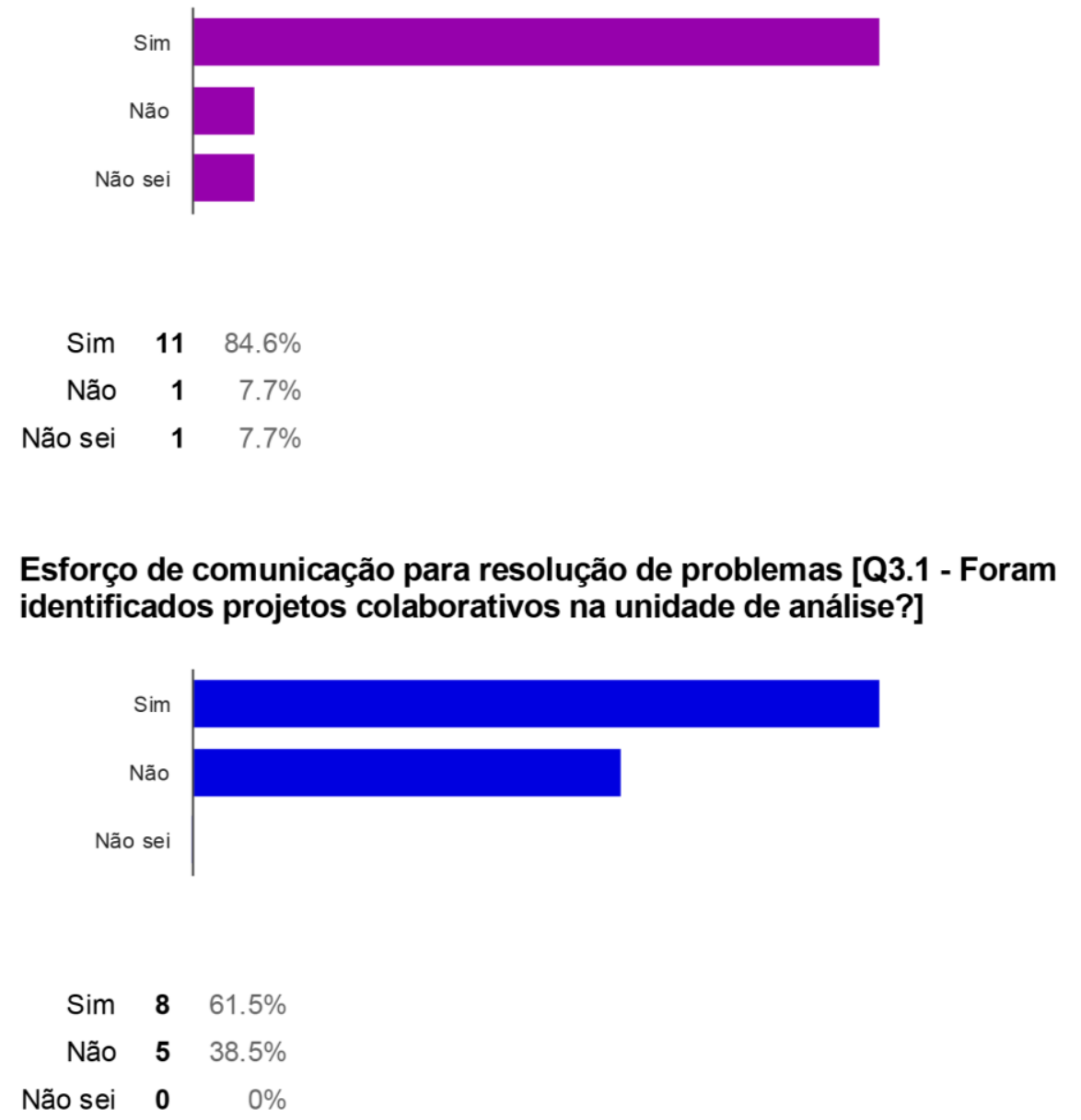


Definição de atividades em conjunto [Q3.1 - Foram identificados projetos colaborativos na unidade de análise?]

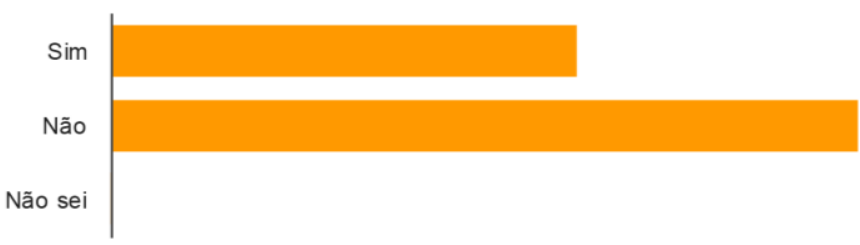

$\begin{array}{rrr}\text { Sim } & \mathbf{5} & 38.5 \% \\ \text { Não } & \mathbf{8} & 61.5 \% \\ \text { Não sei } & \mathbf{0} & 0 \%\end{array}$

Compartilhamento de recursos e tarefas [Q3.1 - Foram identificados projetos colaborativos na unidade de análise?]

$\begin{array}{rrr}\text { Sim } & \mathbf{8} & 61.5 \% \\ \text { Não } & \mathbf{4} & 30.8 \% \\ \text { Não sei } & \mathbf{1} & 7.7 \%\end{array}$

Visão e sentimento de "equipe" [Q3.1 - Foram identificados projetos colaborativos na unidade de análise?]

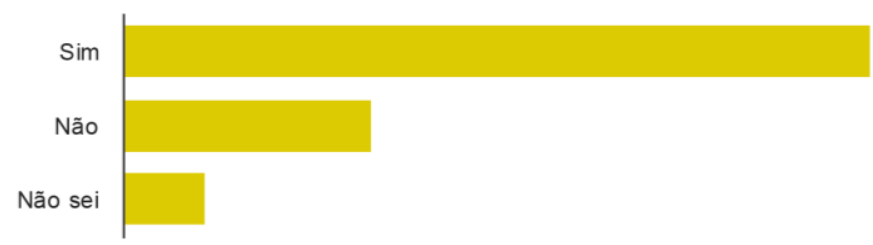

$\begin{array}{rrr}\text { Sim } & \mathbf{9} & 69.2 \% \\ \text { Não } & \mathbf{3} & 23.1 \% \\ \text { Não sei } & \mathbf{1} & 7.7 \%\end{array}$

Atores solicitos para auxiliar colegas, mesmo quando não estão interagindo no mesmo projeto [Q3.1 - Foram identificados projetos colaborativos na 
unidade de análise?]

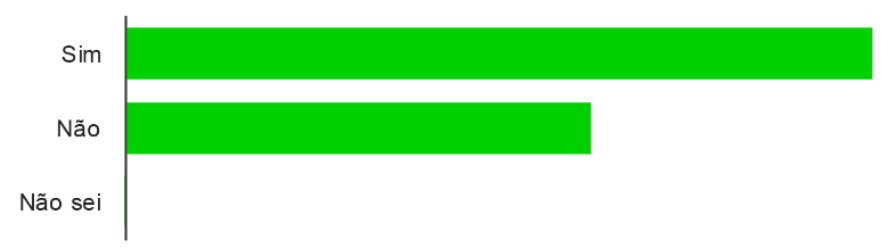

$\begin{array}{rrr}\text { Sim } & \mathbf{8} & 61.5 \% \\ \text { Não } & \mathbf{5} & 38.5 \% \\ \text { Não sei } & \mathbf{0} & 0 \%\end{array}$

Q3.2 - A forma de gestão dos projetos é a mesma?

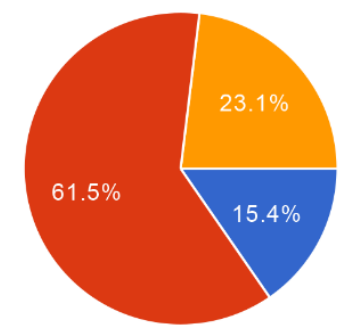

$\begin{array}{rrr}\text { Sim } & \mathbf{2} & 15.4 \% \\ \text { Não } & \mathbf{8} & 61.5 \% \\ \text { Não sei } & \mathbf{3} & 23.1 \%\end{array}$

Q3.3 - A forma de gestão dos projetos leva em conta as características da rede de inovação na qual se inserem?

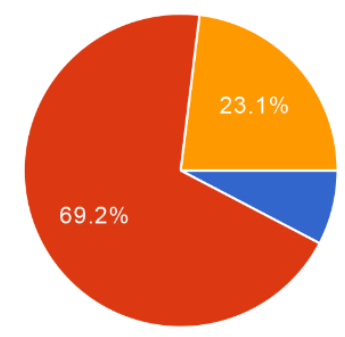

$\begin{array}{rrr}\text { Sim } & \mathbf{1} & 7.7 \% \\ \text { Não } & \mathbf{9} & 69.2 \% \\ \text { Não sei } & \mathbf{3} & 23.1 \%\end{array}$

Q3.4 - A gestão pode ser otimizada? 


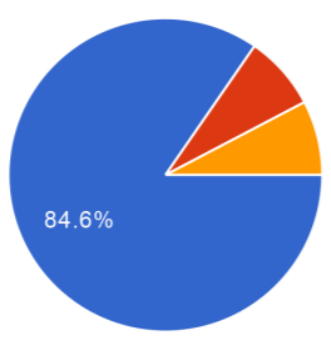

$\begin{array}{rrr}\text { Sim } & \mathbf{1 1} & 84.6 \% \\ \text { Não } & \mathbf{1} & 7.7 \% \\ \text { Não sei } & \mathbf{1} & 7.7 \%\end{array}$

\section{Q4 - Existem elementos para apoiar a aplicação de gestão ágil?}

Existência de incerteza nos projetos [Q4.1 - Quais elementos podem ser observados na rede e nos projetos observados?]

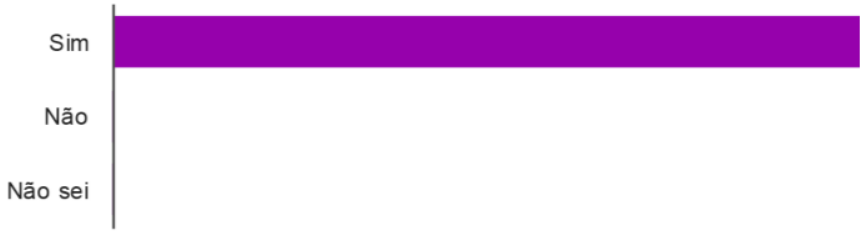

$\begin{array}{rrr}\text { Sim } & \mathbf{1 3} & 100 \% \\ \text { Não } & \mathbf{0} & 0 \% \\ \text { Não sei } & \mathbf{0} & 0 \%\end{array}$

Necessidade por ambiente que entregue adaptabilidade e flexibilidade [Q4.1 - Quais elementos podem ser observados na rede e nos projetos observados?]

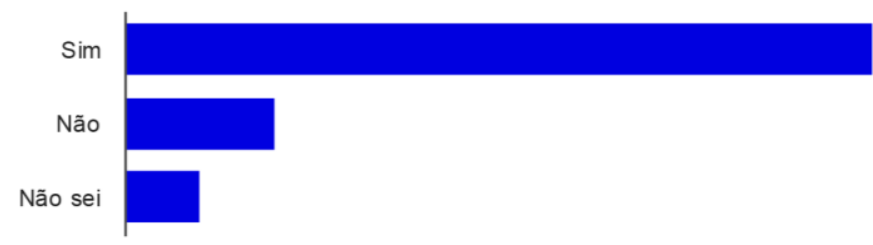

$\begin{array}{rrr}\text { Sim } & \mathbf{1 0} & 76.9 \% \\ \text { Não } & \mathbf{2} & 15.4 \% \\ \text { Não sei } & \mathbf{1} & 7.7 \%\end{array}$


Existência de equipes multidiciplinares [Q4.1 - Quais elementos podem sı observados na rede e nos projetos observados?]

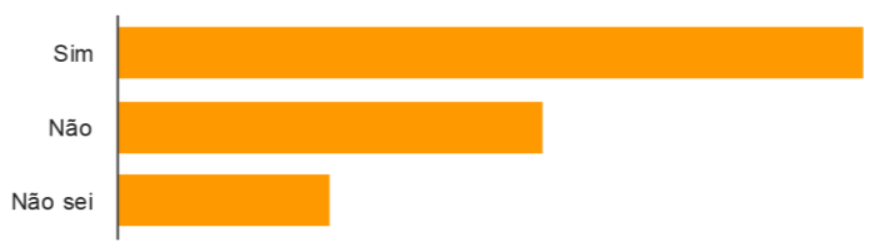

$\begin{array}{rrr}\text { Sim } & \mathbf{7} & 53.8 \% \\ \text { Não } & \mathbf{4} & 30.8 \% \\ \text { Não sei } & \mathbf{2} & 15.4 \%\end{array}$

Necessidade de colaboração para resolução de problemas [Q4.1 - Quais elementos podem ser observados na rede e nos projetos observados?]

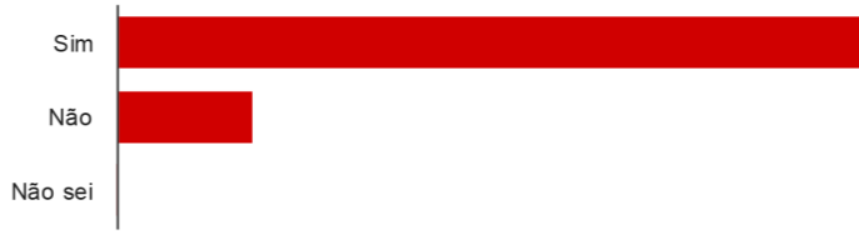

$\begin{array}{rrr}\text { Sim } & \mathbf{1 1} & 84.6 \% \\ \text { Não } & \mathbf{2} & 15.4 \% \\ \text { Não sei } & \mathbf{0} & 0 \%\end{array}$

Necessidade de envolvimento de clientes e outros atores [Q4.1 - Quais elementos podem ser observados na rede e nos projetos observados?]

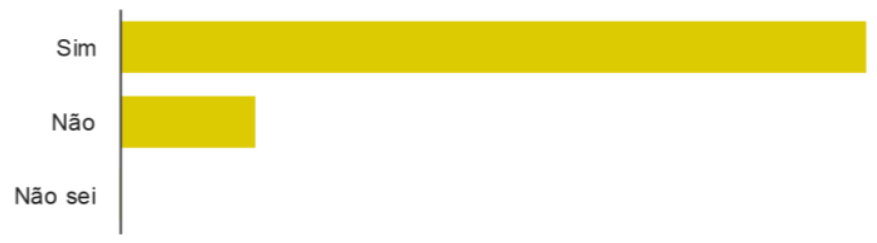

$\begin{array}{rrr}\text { Sim } & \mathbf{1 1} & 84.6 \% \\ \text { Não } & \mathbf{2} & 15.4 \% \\ \text { Não sei } & \mathbf{0} & 0 \%\end{array}$

Projetos de natureza inovadora [Q4.1 - Quais elementos podem ser 
observados na rede e nos projetos observados?]

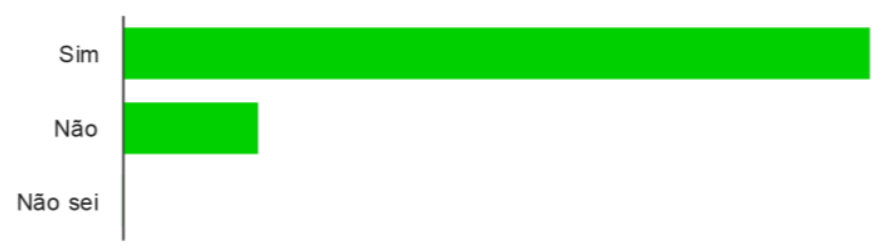

$\begin{array}{rrr}\text { Sim } & \mathbf{1 1} & 84.6 \% \\ \text { Não } & \mathbf{2} & 15.4 \% \\ \text { Não sei } & \mathbf{0} & 0 \%\end{array}$

Gestão crítica e desafiadora [Q4.1 - Quais elementos podem ser observados na rede e nos projetos observados?]

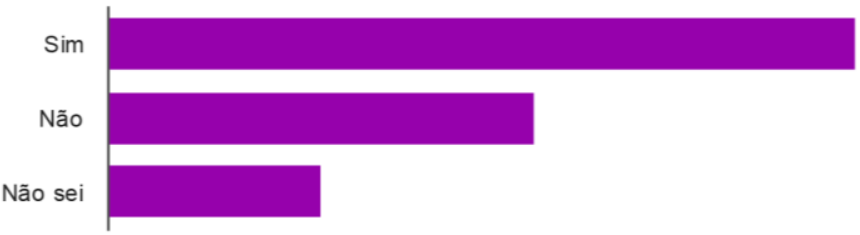

$\operatorname{Sim} 753.8 \%$

Não $430.8 \%$

Não sei $2 \quad 15.4 \%$

Mudanças nos requisitos [Q4.1 - Quais elementos podem ser observados na rede e nos projetos observados?]

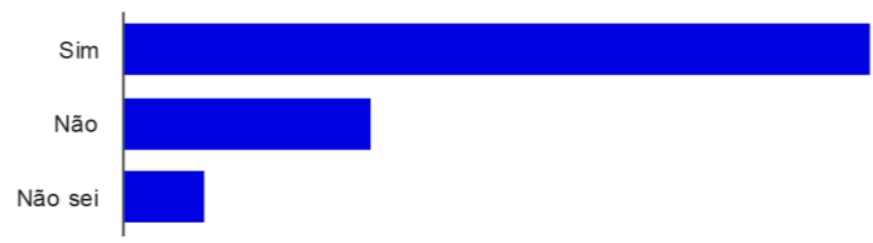

$\begin{array}{rrr}\text { Sim } & \mathbf{9} & 69.2 \% \\ \text { Não } & \mathbf{3} & 23.1 \% \\ \text { Não sei } & \mathbf{1} & 7.7 \%\end{array}$

Necessidade de minimizar burocracias [Q4.1 - Quais elementos podem ser observados na rede e nos projetos observados?] 


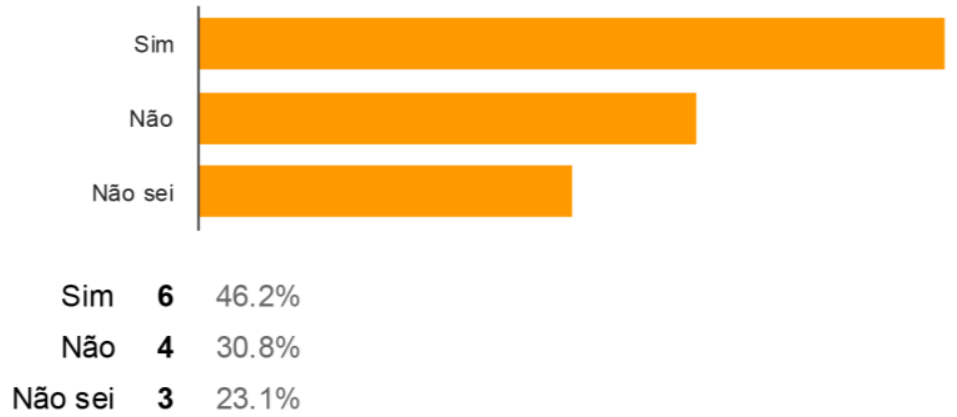

Necessidade por ferramentas visuais para controle de atividades [Q4.1 Quais elementos podem ser observados na rede e nos projetos observados?]

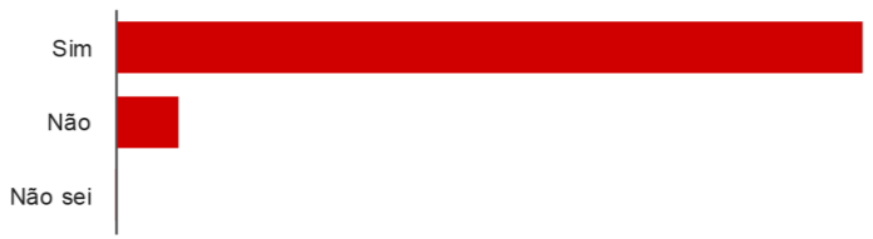

$\begin{array}{rrr}\text { Sim } & \mathbf{1 2} & 92.3 \% \\ \text { Não } & \mathbf{1} & 7.7 \% \\ \text { Não sei } & \mathbf{0} & 0 \%\end{array}$

Necessidade por otimização de prazos [Q4.1 - Quais elementos podem ser observados na rede e nos projetos observados?]

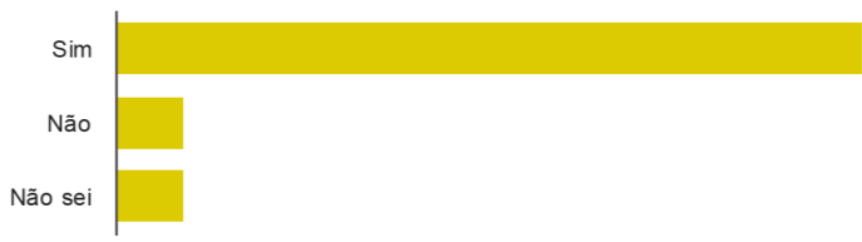

$\begin{array}{rrr}\text { Sim } & \mathbf{1 1} & 84.6 \% \\ \text { Não } & \mathbf{1} & 7.7 \% \\ \text { Não sei } & \mathbf{1} & 7.7 \%\end{array}$

Necessidade de rápida resposta a demandas [Q4.1 - Quais elementos podem ser observados na rede e nos projetos observados?] 


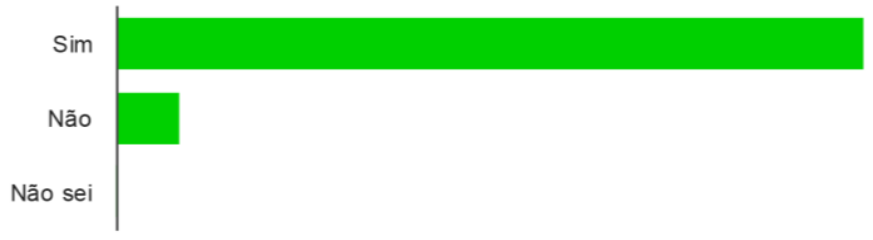

Não sei $\quad \mathbf{0} \quad 0 \%$

Estrutura organizacional que permite o uso de novas metodologias [Q4.1 Quais elementos podem ser observados na rede e nos projetos observados?]

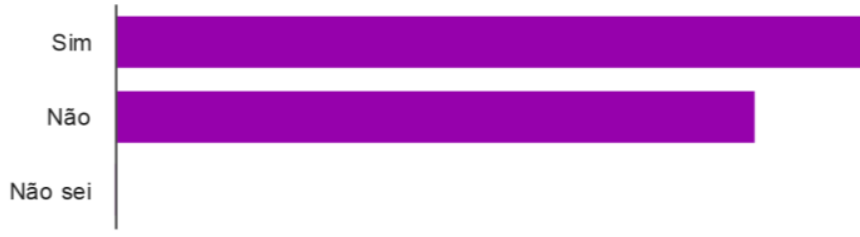

$\begin{array}{rrr}\text { Sim } & \mathbf{7} & 53.8 \% \\ \text { Não } & \mathbf{6} & 46.2 \% \\ \text { Não sei } & \mathbf{0} & 0 \%\end{array}$

Presença de trabalho colaborativo a distância [Q4.1 - Quais elementos podem ser observados na rede e nos projetos observados?]

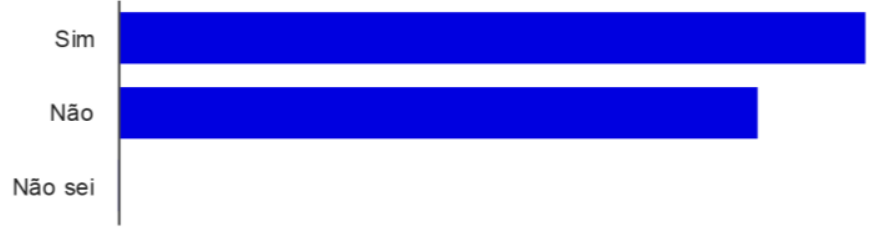

$\begin{array}{rrr}\text { Sim } & \mathbf{7} & 53.8 \% \\ \text { Não } & \mathbf{6} & 46.2 \% \\ \text { Não sei } & \mathbf{0} & 0 \%\end{array}$

Equipe de tamanho compacto [Q4.1 - Quais elementos podem ser observados na rede e nos projetos observados?] 


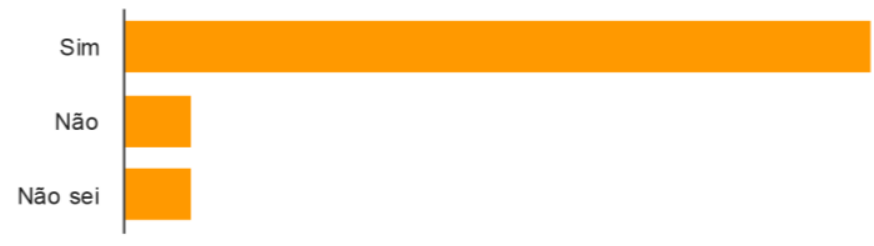

Fácil acesso a informação [Q4.1 - Quais elementos podem ser observados na rede e nos projetos observados?]

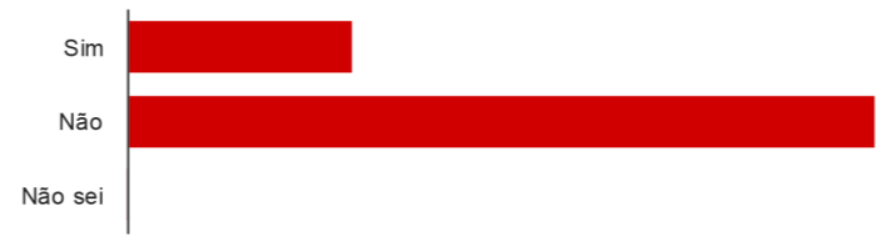

$\begin{array}{rrr}\text { Sim } & \mathbf{3} & 23.1 \% \\ \text { Não } & \mathbf{1 0} & 76.9 \% \\ \text { Não sei } & \mathbf{0} & 0 \%\end{array}$

Existência de clareza de objetivos [Q4.1 - Quais elementos podem ser observados na rede e nos projetos observados?]

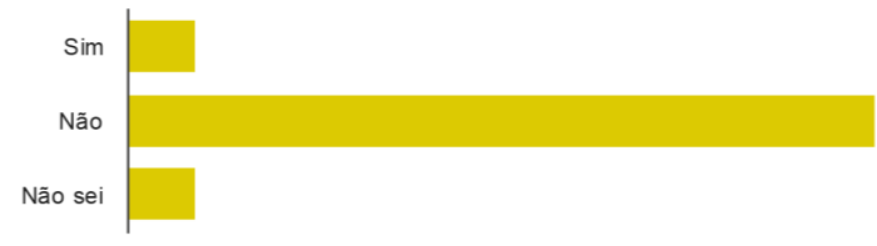

$\begin{array}{rrr}\text { Sim } & \mathbf{1} & 7.7 \% \\ \text { Não } & \mathbf{1 1} & 84.6 \% \\ \text { Não sei } & \mathbf{1} & 7.7 \%\end{array}$

Q4.2 - É realizada uma adequada gestão do conhecimento?

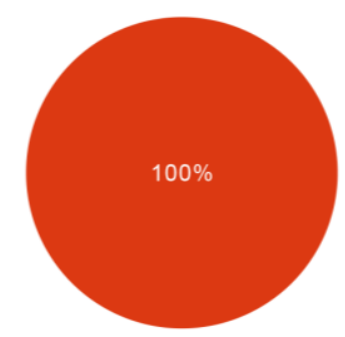




$\begin{array}{rrr}\text { Sim } & \mathbf{0} & 0 \% \\ \text { Não } & \mathbf{1 3} & 100 \% \\ \text { Não sei } & \mathbf{0} & 0 \%\end{array}$

Q4.3 - A possibilidade de aplicação da gestão ágil é uma visão positiva para a Rede?

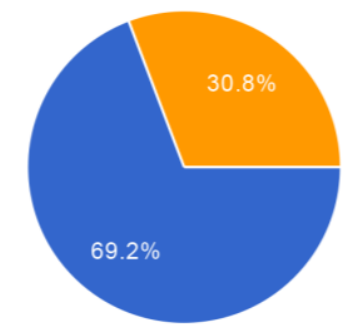

$\begin{array}{rrr}\text { Sim } & \mathbf{9} & 69.2 \% \\ \text { Não } & \mathbf{0} & 0 \% \\ \text { Não sei } & \mathbf{4} & 30.8 \%\end{array}$

Q4.4 - A possibilidade de aplicação da gestão ágil é uma visão positiva para os Projetos da rede?

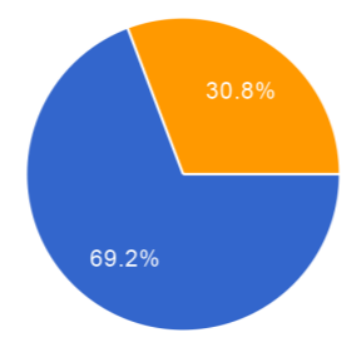

$\begin{array}{rrr}\text { Sim } & \mathbf{9} & 69.2 \% \\ \text { Não } & \mathbf{0} & 0 \% \\ \text { Não sei } & \mathbf{4} & 30.8 \%\end{array}$

Q5 - Quais os principais elementos que otimizariam a gestão da rede e dos projetos?

Ferramentas visuais para organização de tarefas e comunicação [Q5.1 Quais as principais práticas da gestão ágil que deveriam ser aplicadas?] 


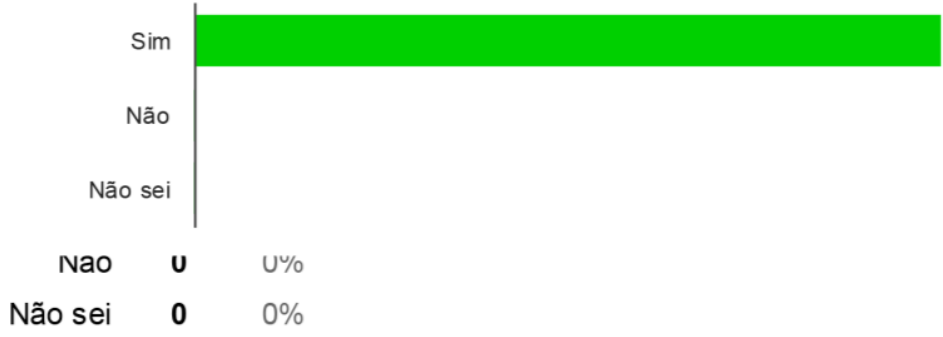

Uso do conceito de visão (da rede e do projeto) [Q5.1 - Quais as principais práticas da gestão ágil que deveriam ser aplicadas?]

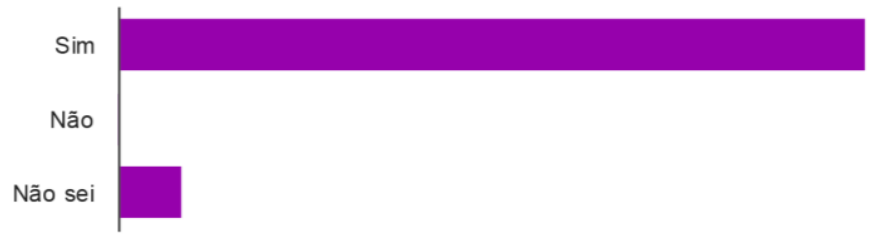

$\begin{array}{rrr}\text { Sim } & \mathbf{1 2} & 92.3 \% \\ \text { Não } & \mathbf{0} & 0 \% \\ \text { Não sei } & \mathbf{1} & 7.7 \%\end{array}$

Foco nas pessoas [Q5.1 - Quais as principais práticas da gestão ágil que deveriam ser aplicadas?]

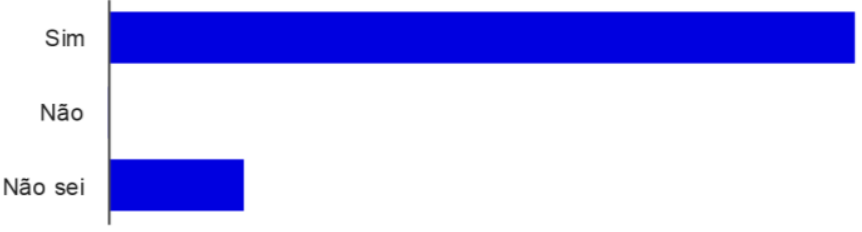

$\begin{array}{rrr}\text { Sim } & \mathbf{1 1} & 84.6 \% \\ \text { Não } & \mathbf{0} & 0 \% \\ \text { Não sei } & \mathbf{2} & 15.4 \%\end{array}$

Ciclos iterativos de desenvolvimento [Q5.1 - Quais as principais práticas da gestão ágil que deveriam ser aplicadas?]

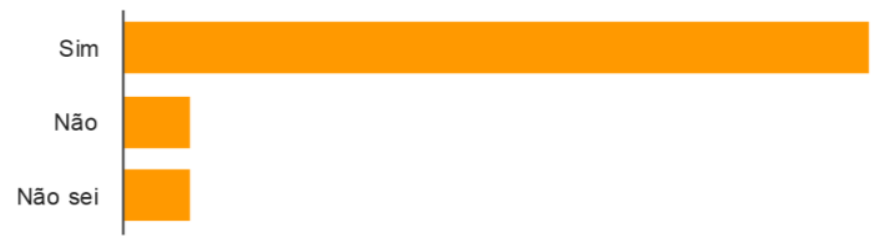




$\begin{array}{rrr}\text { Sim } & \mathbf{1 1} & 84.6 \% \\ \text { Não } & \mathbf{1} & 7.7 \% \\ \text { Não sei } & \mathbf{1} & 7.7 \%\end{array}$

Envolvimento do cliente [Q5.1 - Quais as principais práticas da gestão ágil que deveriam ser aplicadas?]

$\begin{array}{rrr}\text { Sim } & \mathbf{1 2} & 92.3 \% \\ \text { Não } & \mathbf{1} & 7.7 \% \\ \text { Não sei } & \mathbf{0} & 0 \%\end{array}$

Entregas parciais de valor agregado [Q5.1 - Quais as principais práticas da gestão ágil que deveriam ser aplicadas?]

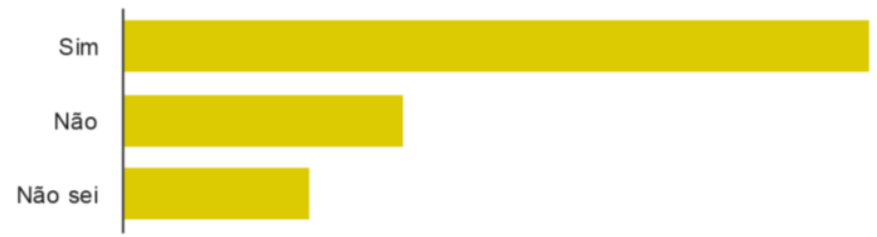
Sim $8 \quad 61.5 \%$
Não $3 \quad 23.1 \%$
Não sei $2 \quad 15.4 \%$

Forte presença da equipe de planejamento e monitoramento [Q5.1 - Quais as principais práticas da gestão ágil que deveriam ser aplicadas?]

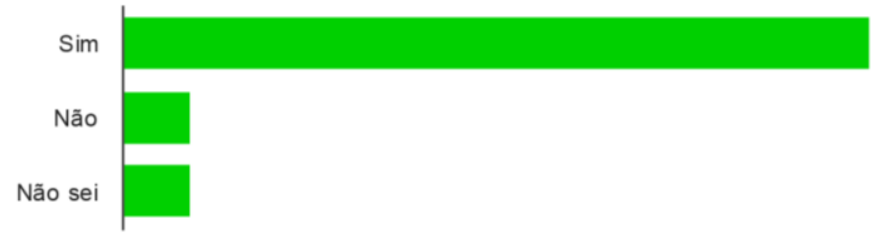




$\begin{array}{rrr}\text { Não } & \mathbf{1} & 7.7 \% \\ \text { Não sei } & \mathbf{1} & 7.7 \%\end{array}$

Criação de equipes auto-organizáveis [Q5.1 - Quais as principais práticas da gestão ágil que deveriam ser aplicadas?]

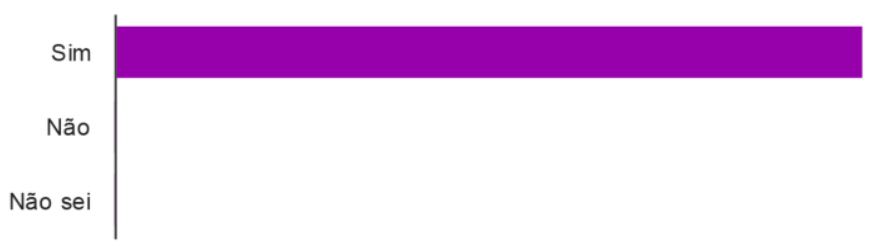

$\begin{array}{rrr}\text { Sim } & \mathbf{1 3} & 100 \% \\ \text { Não } & \mathbf{0} & 0 \% \\ \text { Não sei } & \mathbf{0} & 0 \%\end{array}$

Frequente atualização no planejamento [Q5.1 - Quais as principais práticas da gestão ágil que deveriam ser aplicadas?]

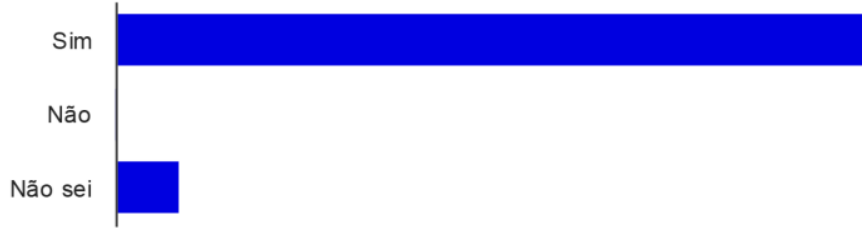

$\begin{array}{rrr}\text { Sim } & \mathbf{1 2} & 92.3 \% \\ \text { Não } & \mathbf{0} & 0 \% \\ \text { Não sei } & \mathbf{1} & 7.7 \%\end{array}$

Q5.2 - A adaptação da gestão ágil de acordo com a necessidade de cada projeto é aplicável?

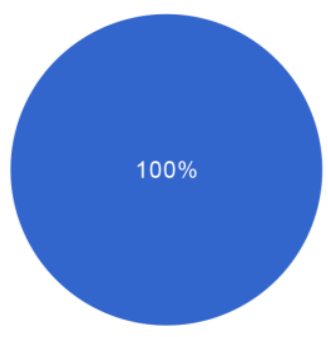

$\begin{array}{rrr}\text { Sim } & \mathbf{1 3} & 100 \% \\ \text { Não } & \mathbf{0} & 0 \% \\ \text { Não sei } & \mathbf{0} & 0 \%\end{array}$




\section{Questionário Modelagem To-Be (Parte 1/3)}

Este questionário está relacionado à modelagem do estado futuro da unidade de análise e foi aplicado no Centro de Pesquisas. Para facilitar a leitura e centralizar as respostas ele foi dividido em duas seções principais e uma seção inicial para identificação do respondente. Esta abordagem visa checar variações na percepção da pesquisa, de acordo com o perfil afetado. Explicações fornecidas aos respondentes para cada questão:

O conjunto de perguntas da Questão 1 almeja verificar os benefícios obtidos na rede e nos projetos, vindos da aplicação da gestão ágil (Questões 1.1 e 1.2) e a extensão dos benefícios observados - diferentes perfis de pessoas, unidades da empresa, clientes (por exemplo, agência reguladora), fornecedores, prestadores de serviços, outros parceiros - (Questão 1.3). O conjunto de perguntas da Questão 2 almeja verificar as limitações observadas na aplicação da gestão ágil, de acordo com a observação dos atores envolvidos e modificações aplicadas (Questões 2.1 e 2.2) e a possibilidade para solucioná-las com o modelo aplicado (Questão 2.3). 


\section{5 respostas}

Resumo

\section{Identificação}

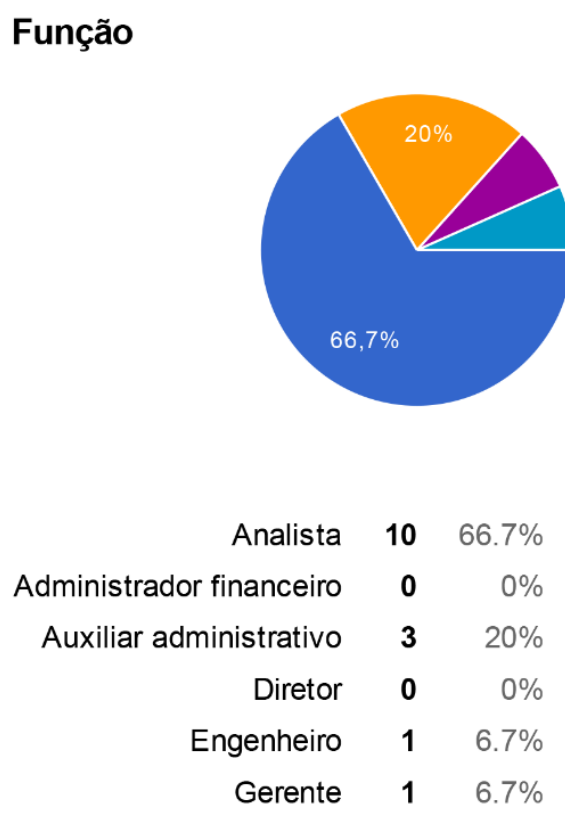

Projeto A [Trabalha no(s) projeto(s) desde o início da configuração da(s) rede(s)?]
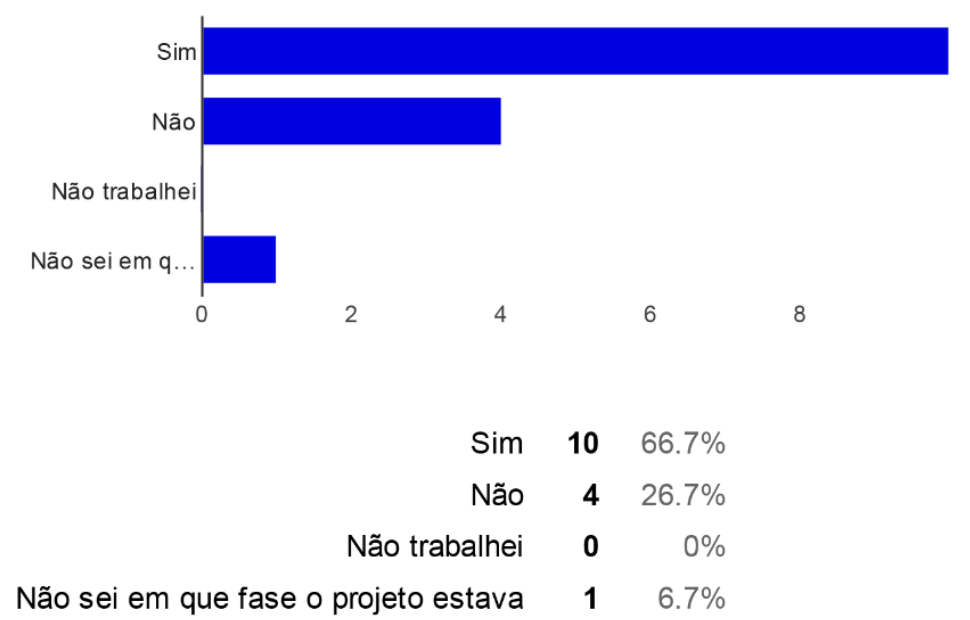
Projeto B [Trabalha no(s) projeto(s) desde o início da configuração da(s) rede(s)?]

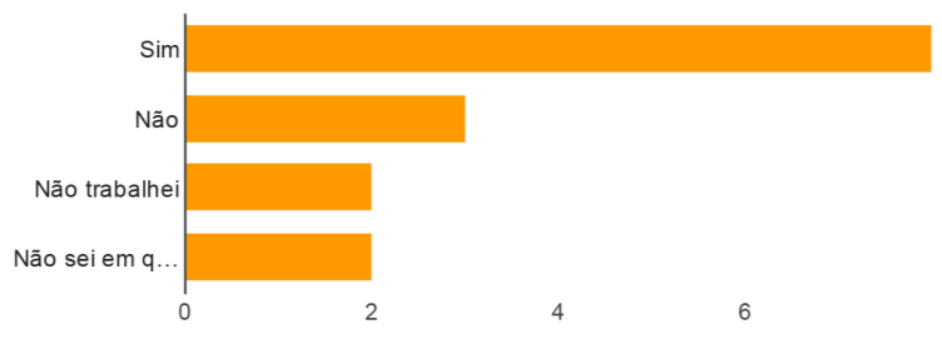

$\begin{array}{rrr}\text { Sim } & \mathbf{8} & 53.3 \% \\ \text { Não } & \mathbf{3} & 20 \% \\ \text { Não trabalhei } & \mathbf{2} & 13.3 \% \\ \text { Não sei em que fase o projeto estava } & \mathbf{2} & 13.3 \%\end{array}$

Possui conhecimento sobre o que é uma rede de inovação? ("Relacionamentos cooperativos entre setores de uma mesma empresa ou entre várias empresas e/ou outros atores na busca por inovação em prol de um objetivo comum")

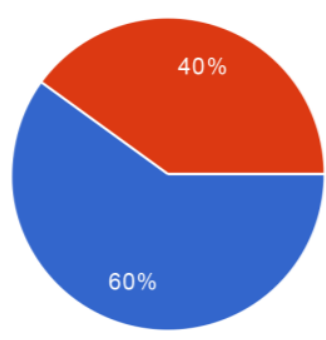

Sim $960 \%$

Já teve contato prévio com gestão ágil?

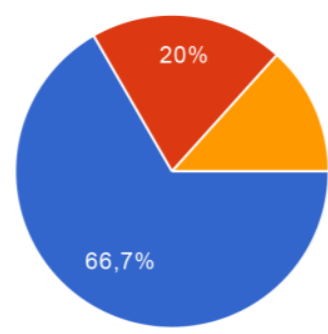

$\begin{array}{rrr}\text { Sim } & \mathbf{1 0} & 66.7 \% \\ \text { Não } & \mathbf{3} & 20 \% \\ \text { Não sei } & \mathbf{2} & 13.3 \%\end{array}$


Q1 -Benefícios da aplicação da gestão ágil no ambiente de redes de inovação auto-organizadas

Q1.1 - Foram identificados benefícios com a utilização da gestão ágil?

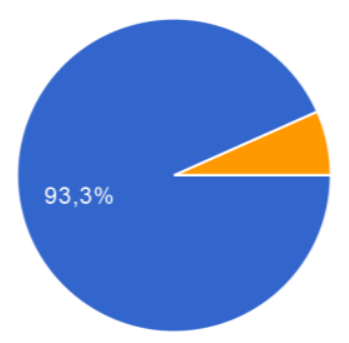

$\begin{array}{rrr}\text { Sim } & \mathbf{1 4} & 93.3 \% \\ \text { Não } & \mathbf{0} & 0 \% \\ \text { Não sei } & \mathbf{1} & 6.7 \%\end{array}$

Comunicação [Q1.2 - Quais benefícios foram identificados?]

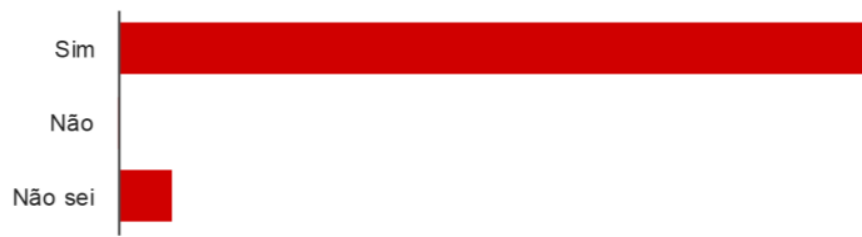

$\begin{array}{rrr}\text { Sim } & \mathbf{1 4} & 93.3 \% \\ \text { Não } & \mathbf{0} & 0 \% \\ \text { Não sei } & \mathbf{1} & 6.7 \%\end{array}$

Confiança [Q1.2 - Quais benefícios foram identificados?]

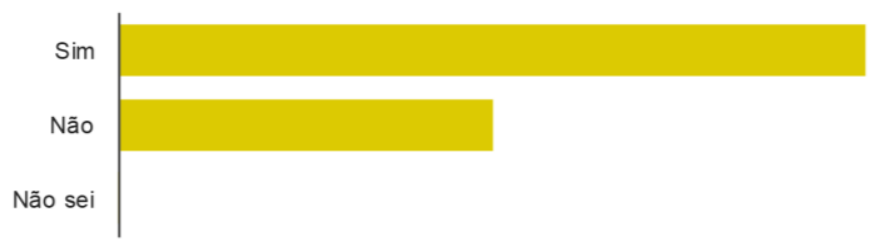

$\begin{array}{rrr}\text { Sim } & \mathbf{1 0} & 66.7 \% \\ \text { Não } & \mathbf{5} & 33.3 \% \\ \text { Não sei } & \mathbf{0} & 0 \%\end{array}$


Visibilidade de tarefas [Q1.2 - Quais benefícios foram identificados?]

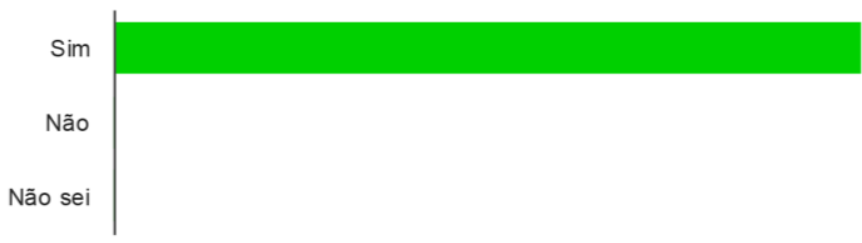

$\begin{array}{rrr}\text { Sim } & \mathbf{1 5} & 100 \% \\ \text { Não } & \mathbf{0} & 0 \% \\ \text { Não sei } & \mathbf{0} & 0 \%\end{array}$

Visibilidade de objetivos [Q1.2 - Quais benefícios foram identificados?]

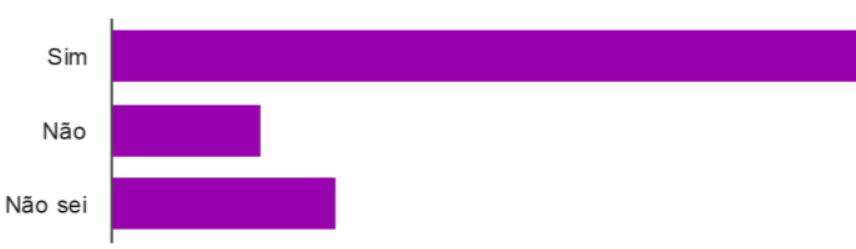

$\begin{array}{rrr}\text { Sim } & \mathbf{1 0} & 66.7 \% \\ \text { Não } & \mathbf{2} & 13.3 \% \\ \text { Não sei } & \mathbf{3} & 20 \%\end{array}$

Controle de tarefas [Q1.2 - Quais benefícios foram identificados?]

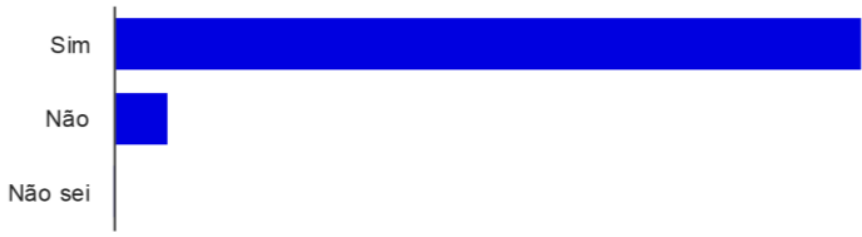

$\begin{array}{rrr}\text { Sim } & \mathbf{1 4} & 93.3 \% \\ \text { Não } & \mathbf{1} & 6.7 \% \\ \text { Não sei } & \mathbf{0} & 0 \%\end{array}$

Organização de processos [Q1.2 - Quais benefícios foram identificados?] 


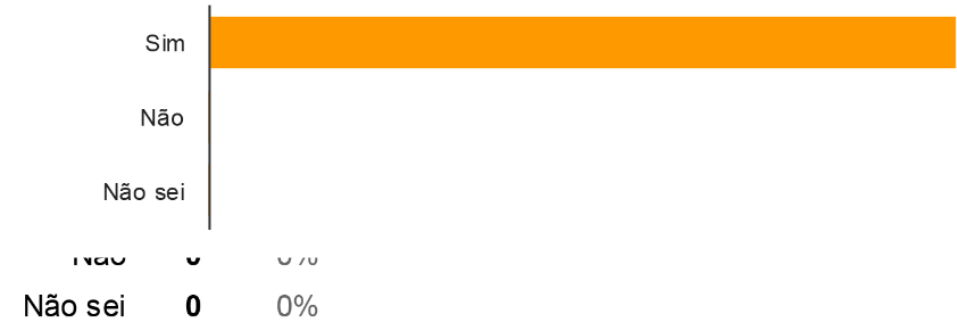

Responsividade [Q1.2 - Quais benefícios foram identificados?]

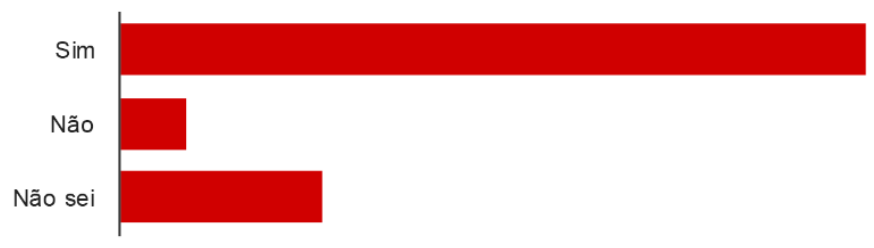

$\begin{array}{rrr}\text { Sim } & \mathbf{1 1} & 73.3 \% \\ \text { Não } & \mathbf{1} & 6.7 \% \\ \text { Não sei } & \mathbf{3} & 20 \%\end{array}$

Trabalho colaborativo [Q1.2 - Quais benefícios foram identificados?]

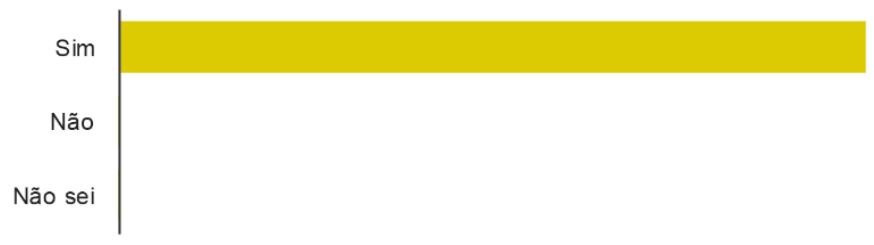

$\begin{array}{rrr}\text { Sim } & \mathbf{1 5} & 100 \% \\ \text { Não } & \mathbf{0} & 0 \% \\ \text { Não sei } & \mathbf{0} & 0 \%\end{array}$

Redução de burocracias [Q1.2 - Quais benefícios foram identificados?]

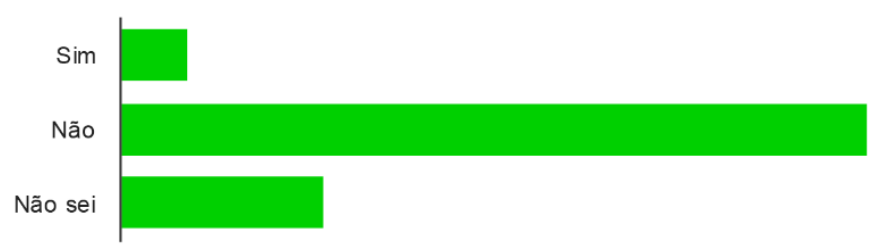

Sim $1 \quad 6.7 \%$ 


$\begin{array}{rrr}\text { Não } & \mathbf{1 1} & 73.3 \% \\ \text { Não sei } & \mathbf{3} & 20 \%\end{array}$

Aumento de produtividade [Q1.2 - Quais benefícios foram identificados?]

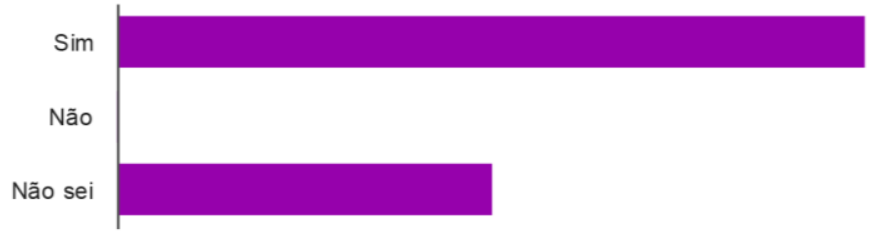

$\begin{array}{rrr}\text { Sim } & \mathbf{1 0} & 66.7 \% \\ \text { Não } & \mathbf{0} & 0 \% \\ \text { Não sei } & \mathbf{5} & 33.3 \%\end{array}$

Aumento de qualidade dos entregáveis [Q1.2 - Quais benefícios foram identificados?]

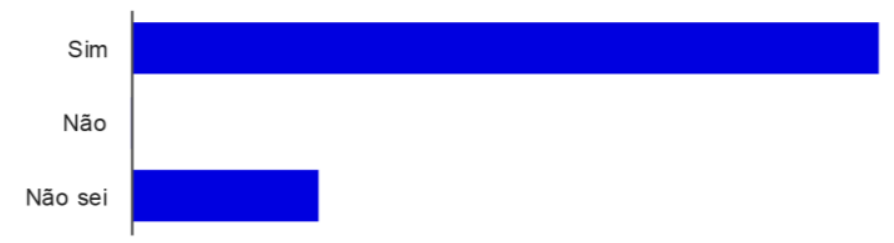

$\begin{array}{rrr}\text { Sim } & \mathbf{1 2} & 80 \% \\ \text { Não } & \mathbf{0} & 0 \% \\ \text { Não sei } & \mathbf{3} & 20 \%\end{array}$

Melhoria da visibilidade da rede de inovação [Q1.2 - Quais benefícios foram identificados?]

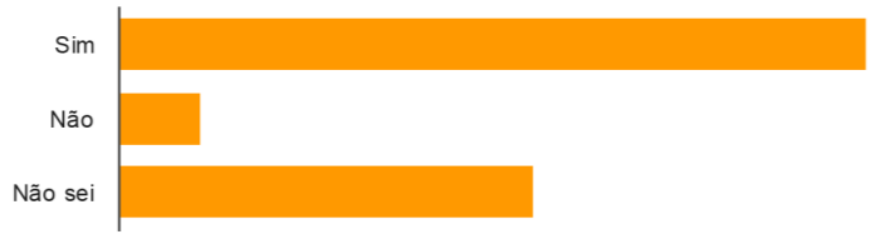

$\begin{array}{rrr}\text { Sim } & \mathbf{9} & 60 \% \\ \text { Não } & \mathbf{1} & 6.7 \% \\ \text { Não sei } & \mathbf{5} & 33.3 \%\end{array}$


Aumento da conscientização sobre atuar em uma rede de inovação [Q1.2 Quais benefícios foram identificados?]

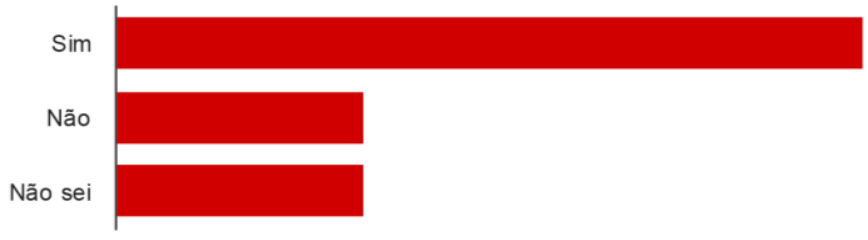

$\begin{array}{rrr}\text { Sim } & \mathbf{9} & 60 \% \\ \text { Não } & \mathbf{3} & 20 \% \\ \text { Não sei } & \mathbf{3} & 20 \%\end{array}$

Melhoria no cumprimento de prazos [Q1.2 - Quais benefícios foram identificados?]

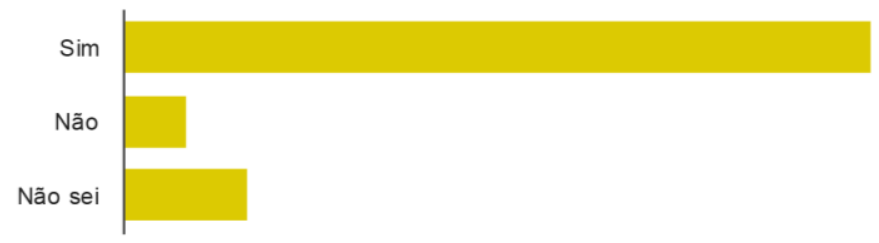

$\begin{array}{rrr}\text { Sim } & \mathbf{1 2} & 80 \% \\ \text { Não } & \mathbf{1} & 6.7 \% \\ \text { Não sei } & \mathbf{2} & 13.3 \%\end{array}$

Melhorias financeiras [Q1.2 - Quais benefícios foram identificados?]

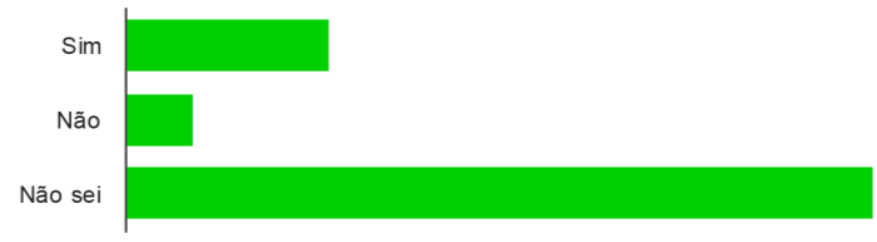

$\begin{array}{rrr}\text { Sim } & \mathbf{3} & 20 \% \\ \text { Não } & \mathbf{1} & 6.7 \% \\ \text { Não sei } & \mathbf{1 1} & 73.3 \%\end{array}$

Nível de suporte [Q1.3 - Os benefícios impactaram todos os envolvidos no projeto?] 


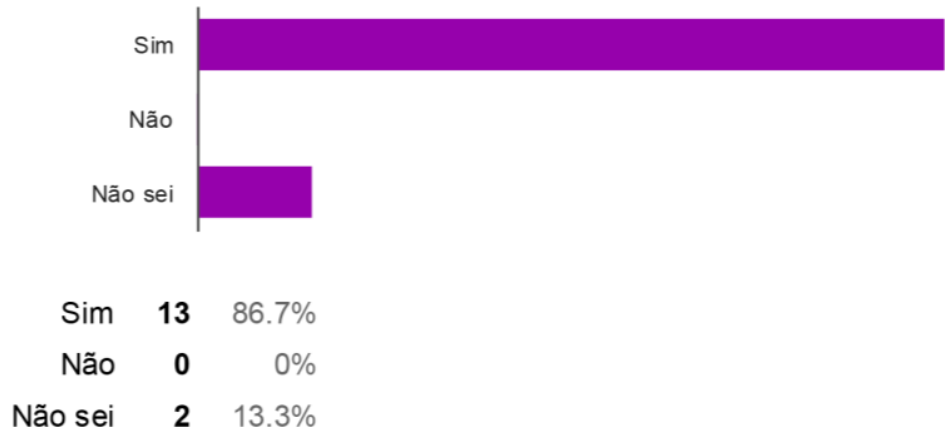

Nível de desenvolvimento [Q1.3 - Os benefícios impactaram todos os envolvidos no projeto?]

$\begin{array}{rrr}\text { Sim } & \mathbf{1 5} & 100 \% \\ \text { Não } & \mathbf{0} & 0 \% \\ \text { Não sei } & \mathbf{0} & 0 \%\end{array}$

Nível administrativo [Q1.3 - Os benefícios impactaram todos os envolvidos no projeto?]

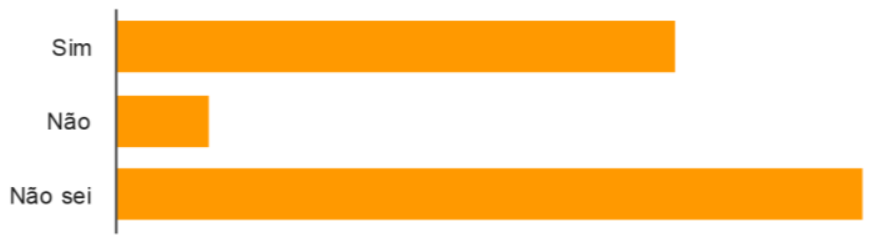

$\begin{array}{rrr}\text { Sim } & \mathbf{6} & 40 \% \\ \text { Não } & \mathbf{1} & 6.7 \% \\ \text { Não sei } & \mathbf{8} & 53.3 \%\end{array}$

Atores de outras unidades da empresa [Q1.3 - Os benefícios impactaram todos os envolvidos no projeto?] 


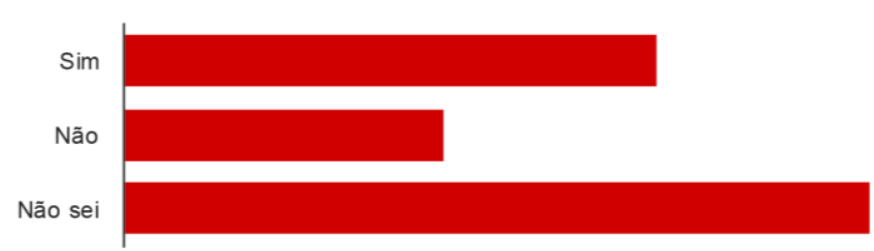

Não sei $746.7 \%$

Clientes [Q1.3 - Os benefícios impactaram todos os envolvidos no projeto?]

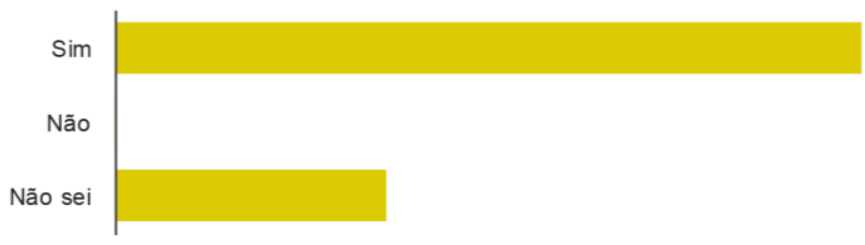

$\begin{array}{rrr}\text { Sim } & \mathbf{1 1} & 73.3 \% \\ \text { Não } & \mathbf{0} & 0 \% \\ \text { Não sei } & \mathbf{4} & 26.7 \%\end{array}$

Fornecedores [Q1.3 - Os benefícios impactaram todos os envolvidos no projeto?]

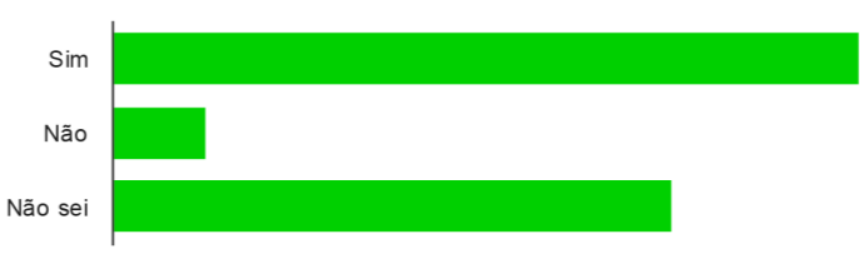

$\begin{array}{rrr}\text { Sim } & \mathbf{8} & 53.3 \% \\ \text { Não } & \mathbf{1} & 6.7 \% \\ \text { Não sei } & \mathbf{6} & 40 \%\end{array}$

Prestadores de serviço [Q1.3 - Os benefícios impactaram todos os envolvidos no projeto?]

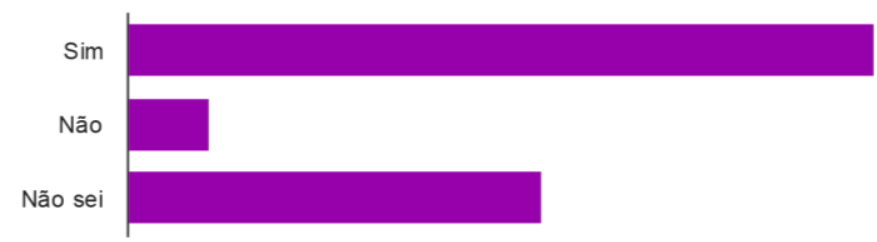




$\begin{array}{rrr}\text { Sim } & \mathbf{9} & 60 \% \\ \text { Não } & \mathbf{1} & 6.7 \% \\ \text { Não sei } & \mathbf{5} & 33.3 \%\end{array}$

Outros Parceiros [Q1.3 - Os benefícios impactaram todos os envolvidos no projeto?]

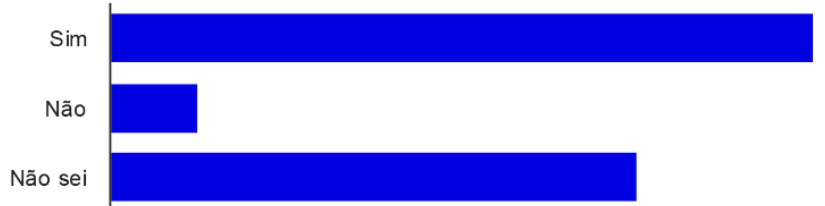

$\operatorname{Sim} 8 \quad 53.3 \%$

Não $16.7 \%$

Não sei $\quad 6 \quad 40 \%$

\section{Q2 - Limitações da aplicação da gestão ágil em redes de inovação}

Q2.1 - Foram identificadas limitações?

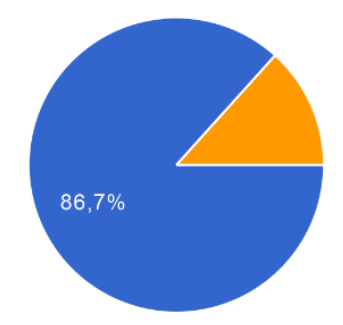

$\begin{array}{rrr}\text { Sim } & \mathbf{1 3} & 86.7 \% \\ \text { Não } & \mathbf{0} & 0 \% \\ \text { Não sei } & \mathbf{2} & 13.3 \%\end{array}$

Q2.2 - Quais as limitações identificadas?

Q2.3 - As limitações são passíveis de serem solucionadas com o modelo de gestão atual?

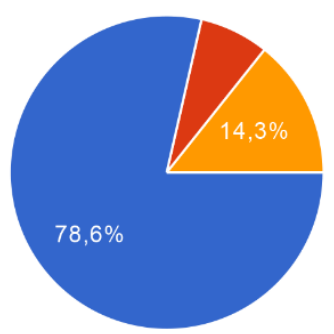

Não $17.1 \%$

Não sei $214.3 \%$ 


\section{Questionário 3 To-Be (Parte 2/3)}

Este questionário está relacionado a modelagem do estado futuro da unidade de análise e foi aplicado na Agência Reguladora. Para facilitar a leitura é apresentado em duas seções: uma para identificação do respondente e uma com as questões específicas da pesquisa. Esta abordagem visa checar variações na percepção da pesquisa, de acordo com o perfil afetado. Explicações fornecidas aos respondentes para cada questão:

O conjunto de perguntas da Questão 1 almeja verificar se os instrumentos utilizados são refletidos em benefícios (Questões 1.1); a extensão dos mesmos - a própria agência reguladora. prestadores de serviços, o Centro de pesquisas, concessionárias e outros parceiros - (Questão 1.2) e; quais as possíveis melhorias que podem ser aplicadas para limitações observadas (Questão 1.3). 


\section{1 resposta}

\section{Resumo}

\section{Identificação}

Função

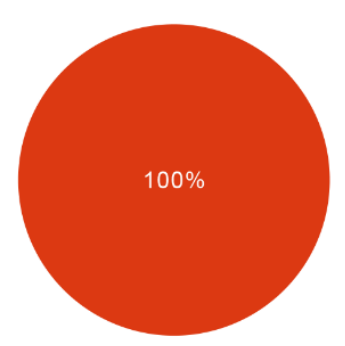

Técnico $\mathbf{0} \quad 0 \%$

Lider $1 \quad 100 \%$

Trabalha no projeto desde a fase inicial?

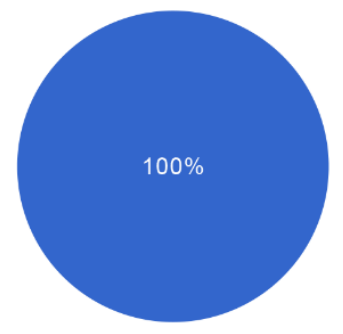

$\begin{array}{rrr}\text { Sim } & \mathbf{1} & 100 \% \\ \text { Não } & \mathbf{0} & 0 \% \\ \text { Não sei em que fase estava } & \mathbf{0} & 0 \%\end{array}$

Q1 - Benefícios obtidos com os instrumentos aplicados

Comunicação entre os envolvidos no projeto [Q1.1 - A utilização dos elementos refletiram-se em quais melhorias?] 


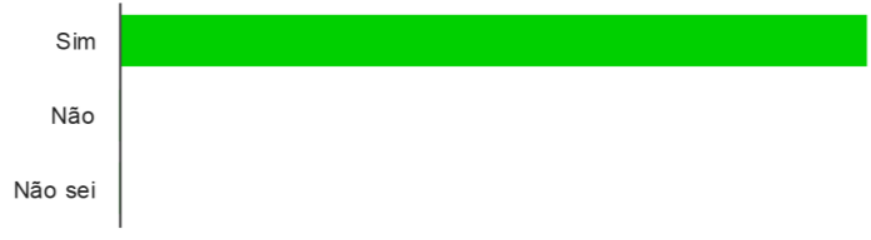

Não sei $\quad \mathbf{0} \quad 0 \%$

Confiança entre os envolvidos [Q1.1 - A utilização dos elementos refletiramse em quais melhorias?]

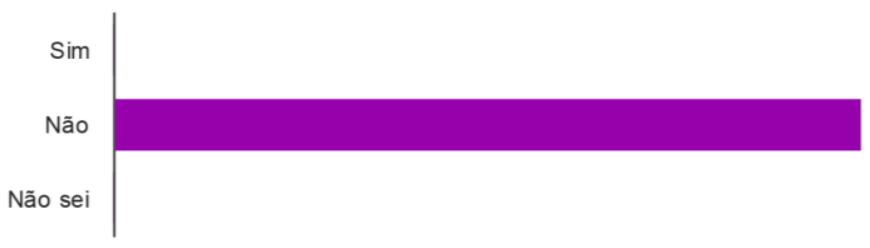

$\begin{array}{rrr}\text { Sim } & \mathbf{0} & 0 \% \\ \text { Não } & \mathbf{1} & 100 \% \\ \text { Não sei } & \mathbf{0} & 0 \%\end{array}$

Visibilidade de objetivos [Q1.1 - A utilização dos elementos refletiram-se em quais melhorias?]

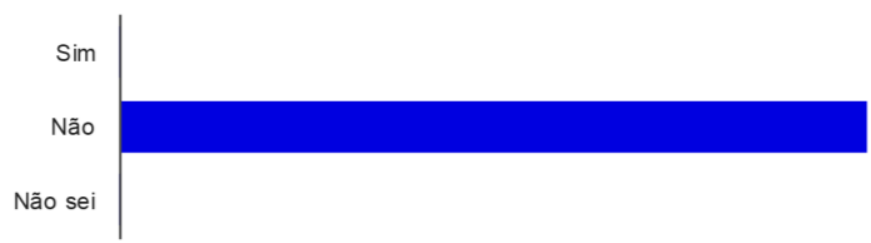

$\begin{array}{rrr}\text { Sim } & \mathbf{0} & 0 \% \\ \text { Não } & \mathbf{1} & 100 \% \\ \text { ão sei } & \mathbf{0} & 0 \%\end{array}$

Controle de ações necessárias [Q1.1 - A utilização dos elementos refletiramse em quais melhorias?]

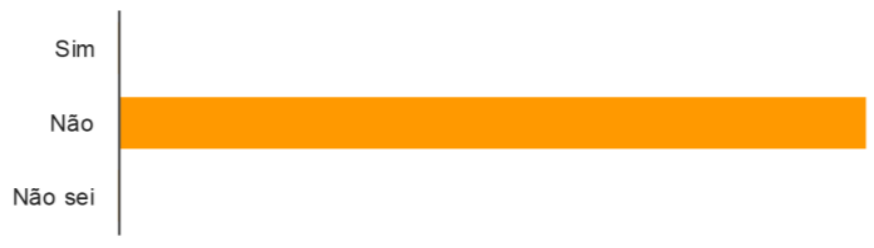




$\begin{array}{rrr}\text { Sim } & \mathbf{0} & 0 \% \\ \text { Não } & \mathbf{1} & 100 \% \\ \text { Não sei } & \mathbf{0} & 0 \%\end{array}$

Otimização de processos [Q1.1 - A utilização dos elementos refletiram-se em quais melhorias?]

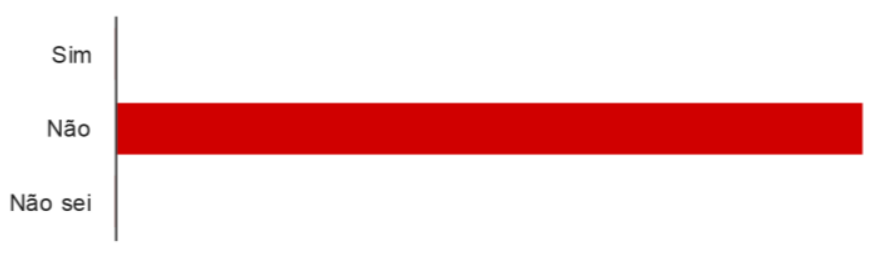

$\begin{array}{rrr}\text { Sim } & \mathbf{0} & 0 \% \\ \text { Não } & \mathbf{1} & 100 \% \\ \text { Não sei } & \mathbf{0} & 0 \%\end{array}$

Agilidade para solucionar problemas [Q1.1 - A utilização dos elementos refletiram-se em quais melhorias?]

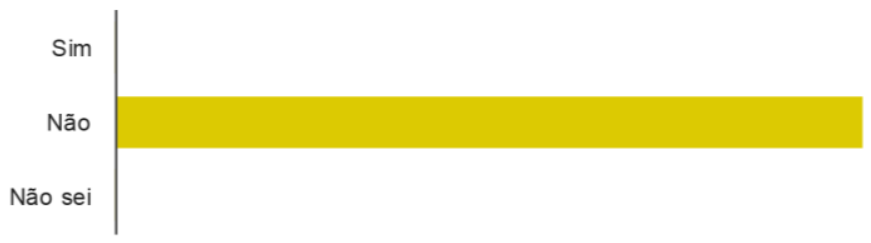

$\begin{array}{rrr}\text { Sim } & \mathbf{0} & 0 \% \\ \text { Não } & \mathbf{1} & 100 \% \\ \text { Não sei } & \mathbf{0} & 0 \%\end{array}$

Agilidade no cumprimento de prazos [Q1.1 - A utilização dos elementos refletiram-se em quais melhorias?]

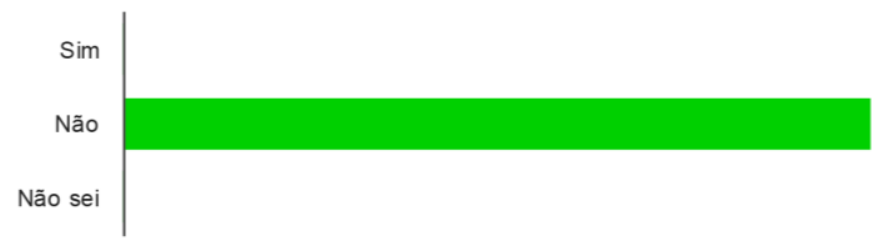




$\begin{array}{rrr}\text { Não } & \mathbf{1} & 100 \% \\ \text { Não sei } & \mathbf{0} & 0 \%\end{array}$

Agência reguladora [Q1.2 Os benefícios impactaram todos os envolvidos no projeto?]

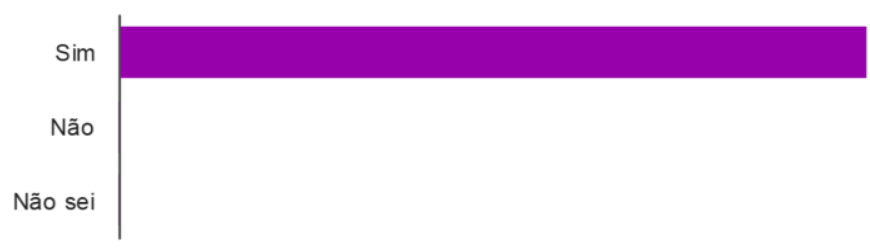

$\begin{array}{rrr}\text { Sim } & \mathbf{1} & 100 \% \\ \text { Não } & \mathbf{0} & 0 \% \\ \text { Não sei } & \mathbf{0} & 0 \%\end{array}$

Prestadora de serviço [Q1.2 Os benefícios impactaram todos os envolvidos no projeto?]

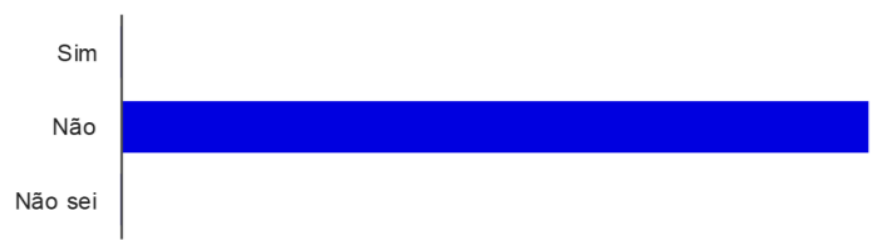

$\begin{array}{rrr}\text { Sim } & \mathbf{0} & 0 \% \\ \text { Não } & \mathbf{1} & 100 \% \\ \text { Não sei } & \mathbf{0} & 0 \%\end{array}$

Centro de pesquisas [Q1.2 Os benefícios impactaram todos os envolvidos no projeto?]

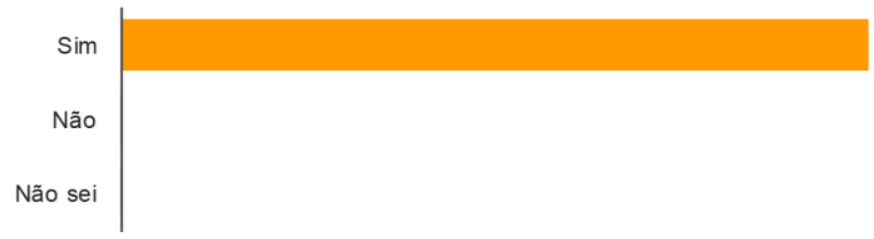

$\begin{array}{rrr}\text { Sim } & \mathbf{1} & 100 \% \\ \text { Não } & \mathbf{0} & 0 \% \\ \text { Não sei } & \mathbf{0} & 0 \%\end{array}$


Concessionárias de rodovias [Q1.2 Os benefícios impactaram todos os envolvidos no projeto?]

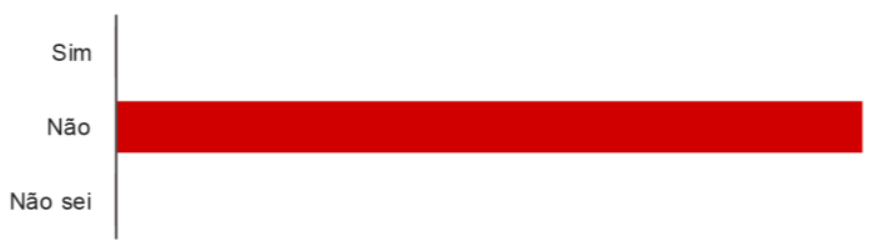

$\begin{array}{rrr}\text { Sim } & \mathbf{0} & 0 \% \\ \text { Não } & \mathbf{1} & 100 \% \\ \text { Não sei } & \mathbf{0} & 0 \%\end{array}$

Empresas que realizam requisições e recebem análises [Q1.2 Os benefícios impactaram todos os envolvidos no projeto?]

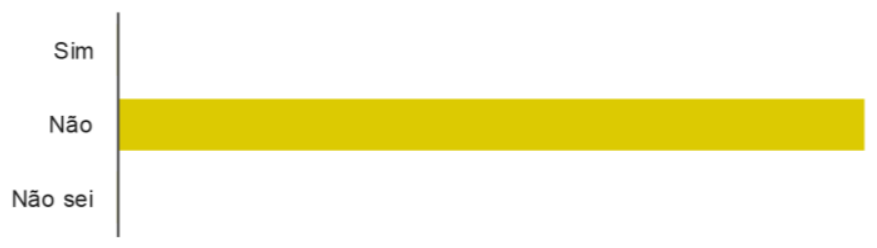

$\begin{array}{rrr}\text { Sim } & \mathbf{0} & 0 \% \\ \text { Não } & \mathbf{1} & 100 \% \\ \text { Não sei } & \mathbf{0} & 0 \%\end{array}$

\section{Q1.3 - Foram identificados pontos para melhorias?}

Necessitamos de reuniões regulares pelo menos 1 por mes, trabalhando mais próximos e isso gera afinidade e identificação de demandas de melhoria continua. 


\section{Questionário Modelagem To-Be (Parte 3/3)}

Este questionário visa verificar o nível de satisfação de um parceiro do tipo Concessionária de Rodovias com relação à algumas práticas implantadas e/ou otimizadas nos últimos meses - a modelagem do estado futuro aplicada. É apresentado em duas seções: uma para identificação do respondente e uma com as questões específicas da pesquisa. Explicações fornecidas aos respondentes para cada questão:

O conjunto de perguntas da Questão 1 almeja verificar se os instrumentos utilizados são refletidos em benefícios (Questões 1.1 e 1.2); a extensão do impacto causado pela mudança fornecedores, parceiros, agência reguladora, Centro de pesquisas - (Questão 1.3) e; possíveis melhorias aplicáveis ao projeto - ações que podem ser realizadas frente às limitações - (Questão $1.4)$. 


\section{2 respostas}

\section{Resumo}

Função

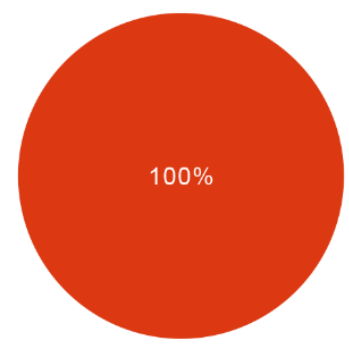

$\begin{array}{rrr}\text { Analista } & \mathbf{0} & 0 \% \\ \text { Lider Técnico } & \mathbf{2} & 100 \%\end{array}$

Trabalha no projeto desde a fase inicial?

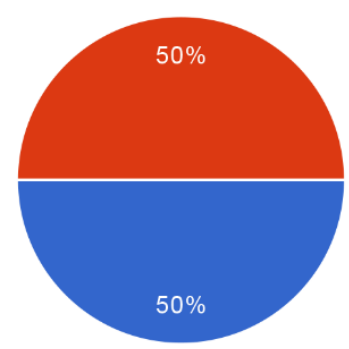

$\begin{array}{rrr}\text { Sim } & \mathbf{1} & 50 \% \\ \text { Não } & \mathbf{1} & 50 \% \\ \text { Não sei em que fase estava } & \mathbf{0} & 0 \%\end{array}$

\section{Q1 - Melhorias identificadas}

Controle de abertura de chamados para incidentes [Q1.1 - Foram identificadas melhorias nos seguintes elementos?] 


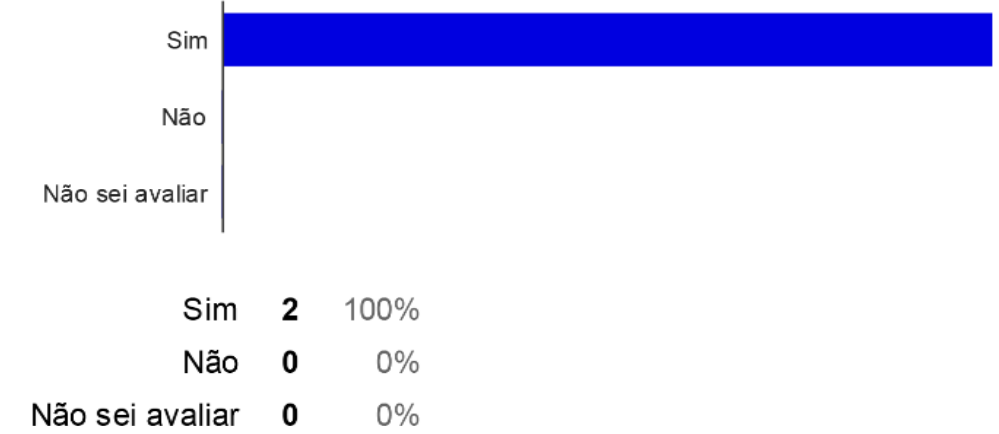

Informativos por e-mail para registro de ações (realizadas, necessárias, em andamento), envolvendo os interessados [Q1.1 - Foram identificadas melhorias nos seguintes elementos?]

Não sei avaliar

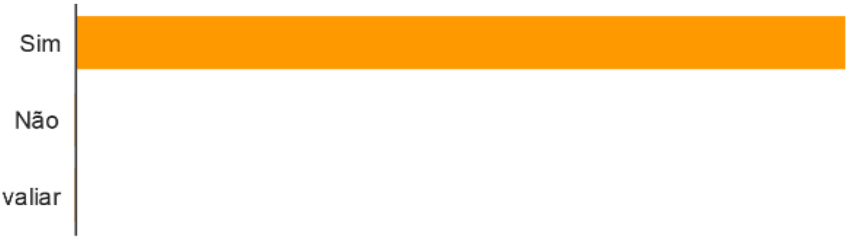

$\begin{array}{rrr}\text { Sim } & \mathbf{2} & 100 \% \\ \text { Não } & \mathbf{0} & 0 \% \\ \text { Não sei avaliar } & \mathbf{0} & 0 \%\end{array}$

Planilha de controle de ações [Q1.1 - Foram identificadas melhorias nos seguintes elementos?]

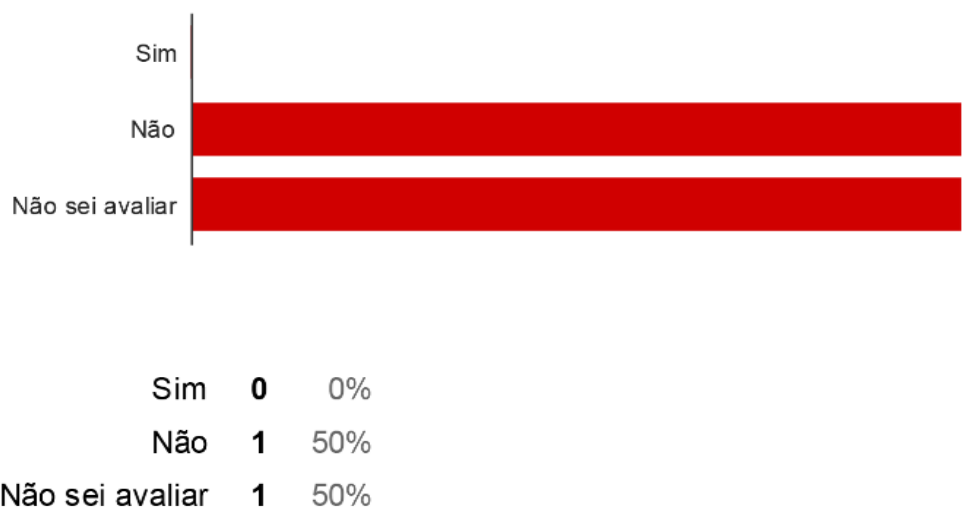

Comunicação entre os envolvidos no projeto [Q1.2 - A utilização destes elementos refletiram-se em quais melhorias?] 


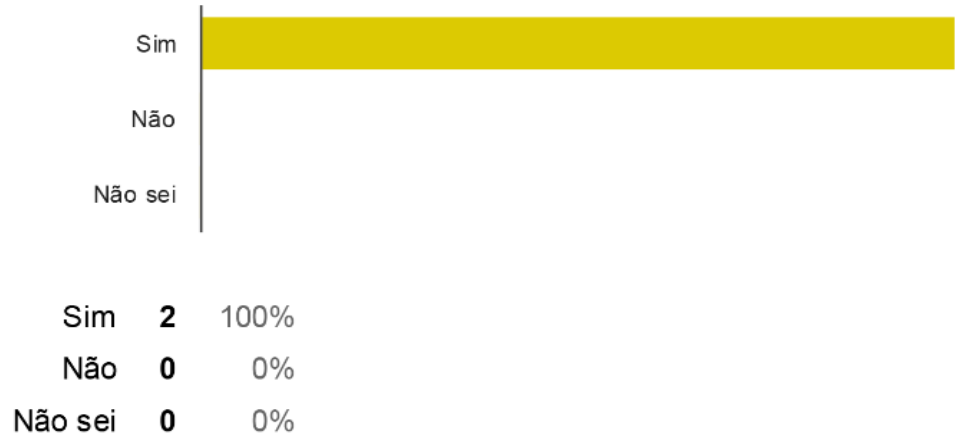

Confiança entre os envolvidos [Q1.2 - A utilização destes elementos refletiram-se em quais melhorias?]

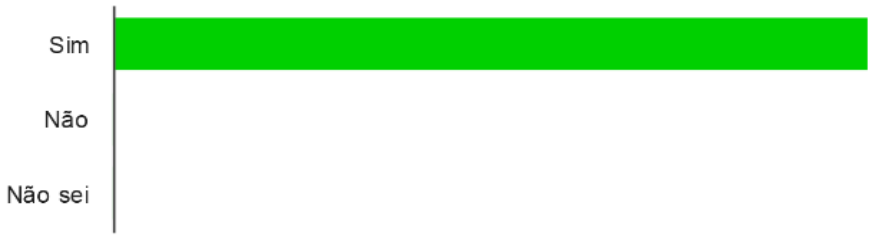

$\begin{array}{rrr}\text { Sim } & \mathbf{2} & 100 \% \\ \text { Não } & \mathbf{0} & 0 \% \\ \text { Não sei } & \mathbf{0} & 0 \%\end{array}$

Visibilidade de objetivos [Q1.2 - A utilização destes elementos refletiram-se em quais melhorias?]

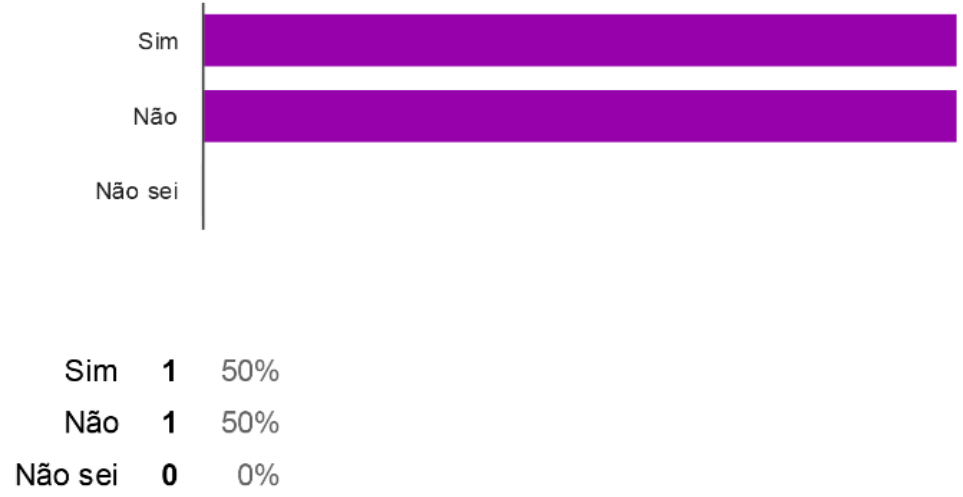

Controle de ações necessárias [Q1.2 - A utilização destes elementos refletiram-se em quais melhorias?] 


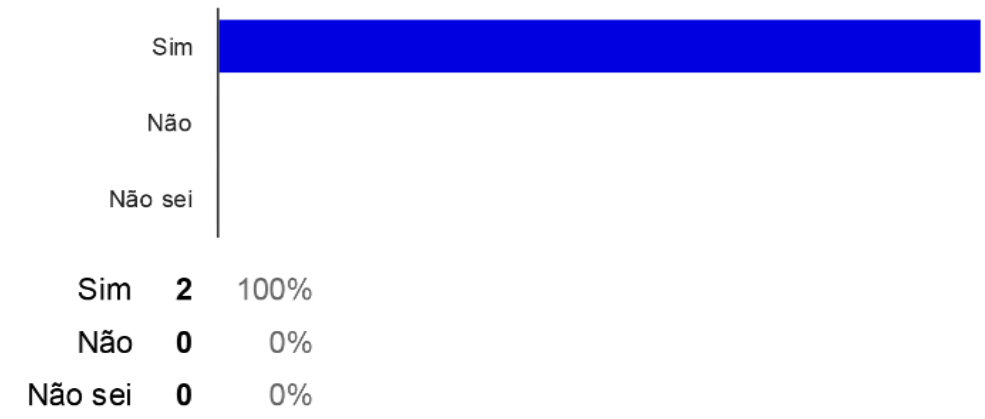

Agilidade para solucionar problemas [Q1.2 - A utilização destes elementos refletiram-se em quais melhorias?]

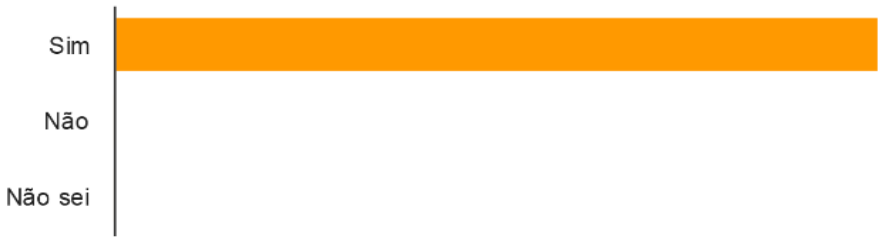

$\begin{array}{rrr}\text { Sim } & \mathbf{2} & 100 \% \\ \text { Não } & \mathbf{0} & 0 \% \\ \text { Não sei } & \mathbf{0} & 0 \%\end{array}$

Agilidade no cumprimento de prazos [Q1.2 - A utilização destes elementos refletiram-se em quais melhorias?]

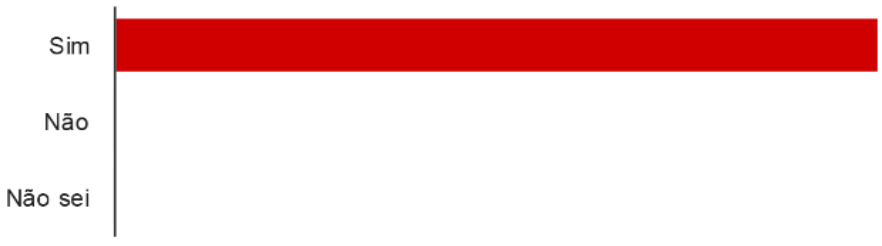

$\begin{array}{rrr}\text { Sim } & \mathbf{2} & 100 \% \\ \text { Não } & \mathbf{0} & 0 \% \\ \text { Não sei } & \mathbf{0} & 0 \%\end{array}$

Agência reguladora [Q1.3 Os benefícios impactaram todos os envolvidos no projeto?] 


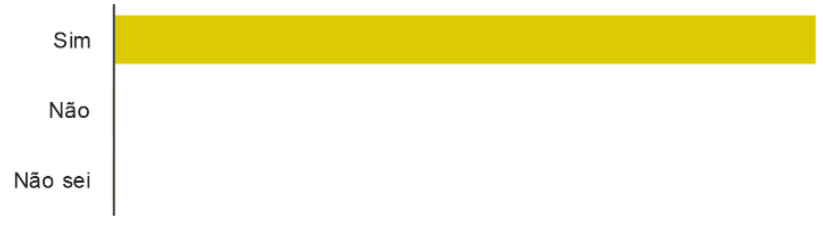

Concessionária de Rodovias respondente [Q1.3 Os benefícios impactaram todos os envolvidos no projeto?]

$\begin{array}{rrr}\text { Sim } & \mathbf{2} & 100 \% \\ \text { Não } & \mathbf{0} & 0 \% \\ \text { Não sei } & \mathbf{0} & 0 \%\end{array}$

Centro de pesquisas [Q1.3 Os benefícios impactaram todos os envolvidos no projeto?]

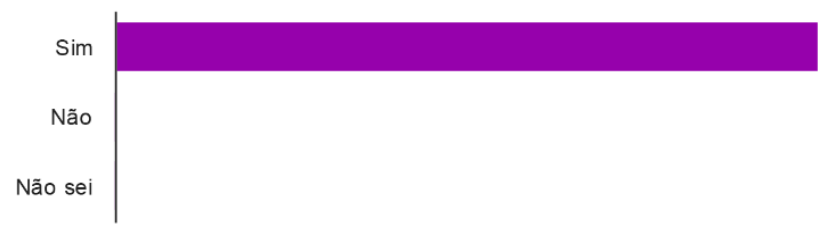

$\begin{array}{rrr}\text { Sim } & \mathbf{2} & 100 \% \\ \text { Não } & \mathbf{0} & 0 \% \\ \text { Não sei } & \mathbf{0} & 0 \%\end{array}$

Outras Concessionárias de rodovia [Q1.3 Os benefícios impactaram todos os envolvidos no projeto?]

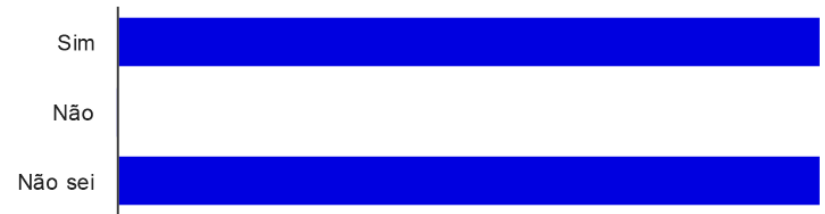




\author{
$\operatorname{Sim} 150 \%$ \\ Não $\quad 0 \quad 0 \%$ \\ Não sei $150 \%$
}

Outros parceiros - Empresas que realizam requisições e recebem análises [Q1.3 Os benefícios impactaram todos os envolvidos no projeto?]

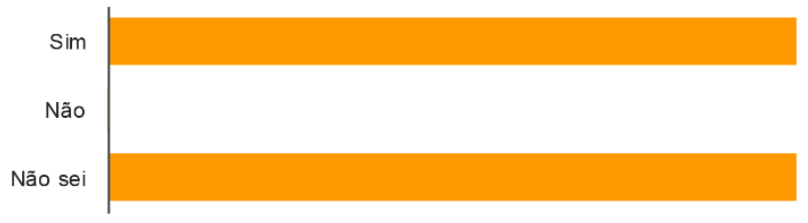

$\begin{array}{rrr}\text { Sim } & \mathbf{1} & 50 \% \\ \text { Não } & \mathbf{0} & 0 \% \\ \text { Não sei } & \mathbf{1} & 50 \%\end{array}$

Q1.4 - Foram identificados pontos para melhorias? 


\section{Questionário Validação da Modelagem de Empresas}

Este questionário está relacionado à validação da modelagem de empresas resultante das ações da pesquisa de campo na unidade de análise e foi aplicado no Centro de Pesquisas. Para facilitar a leitura e análise das respostas ele foi dividido em seções principais, de acordo com os tipos de modelos mapeados e; uma seção inicial para identificação do respondente. Explicações fornecidas aos respondentes para cada questão:

As perguntas da Questão 1 almejam verificar a percepção dos envolvidos sobre a validade do Modelo de Objetivos mapeado para a rede de modo geral (recorte macro) e para o projeto analisado (recorte micro), relacionado à gestão ágil aplicada (Questões 1.1 e 1.2). As perguntas da Questão 2 almejam verificar a percepção dos envolvidos sobre a validade do Modelo de Regras mapeado para a rede de modo geral (recorte macro) e para o projeto analisado (recorte micro), relacionado à gestão ágil aplicada (Questões 2.1 e 2.2). As perguntas da Questão 3 almejam verificar a percepção dos envolvidos sobre a validade do Modelo de Atores e Recursos mapeado para a rede de modo geral (recorte macro) e para o projeto analisado (recorte micro), relacionado à gestão ágil aplicada (Questões 3.1 e 3.2). As perguntas da Questão 4 almejam verificar a percepção dos envolvidos sobre a validade do Modelo de Processos mapeado para a rede de modo geral (recorte macro) e para o projeto analisado (recorte micro), relacionado à gestão ágil aplicada (Questões 4.1 a 4.11). As perguntas da Questão 5 almejam verificar a percepção dos envolvidos sobre a validade do Modelo de Componentes e Requisitos Técnicos (sistemas de informação) mapeado para a rede de modo geral (recorte macro) e para o projeto analisado (recorte micro), relacionado à gestão ágil aplicada. Por fim, as perguntas da Questão 6 almejam verificar a percepção dos envolvidos sobre o conjunto de modelos apresentado - modelagem de empresas - e sobre a possível aplicação do modelo em outros cenários, tanto em outros projetos da mesma empresa, quanto em outras unidades de análise com características similares. 


\section{4 respostas}

\section{Resumo}

\section{Identificação}

Função

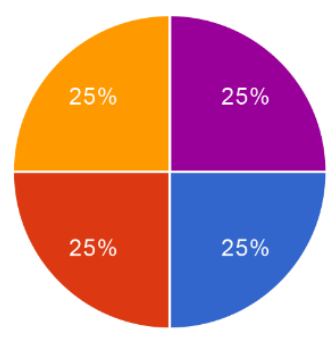

$\begin{array}{rrr}\text { Gerente de Sistemas } & \mathbf{1} & 25 \% \\ \text { Analista Sênior } & \mathbf{1} & 25 \% \\ \text { Analista Pleno } & \mathbf{1} & 25 \% \\ \text { Analista Junior } & \mathbf{0} & 0 \% \\ \text { Analista Trainee } & \mathbf{1} & 25 \%\end{array}$

\section{Q1 - Modelo de Objetivos}

(Objetivo 1) Gerar inovação no segmento de atuação [Q1.1 - Objetivos da visão Macro da Rede]

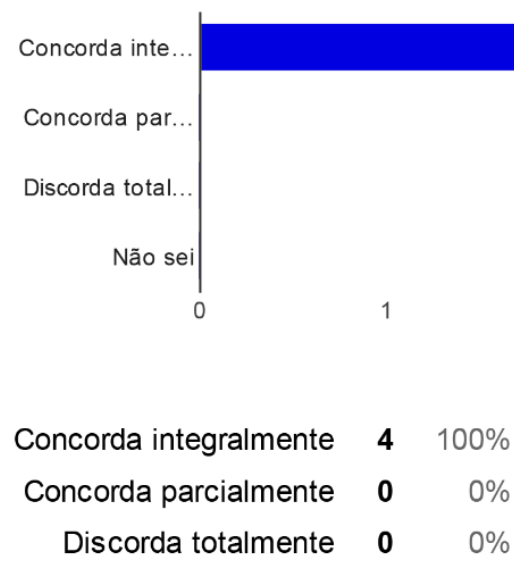


(Objetivo 2) Impulsionar aplicação de novas tecnologias no segmento [Q1.1 - Objetivos da visão Macro da Rede]

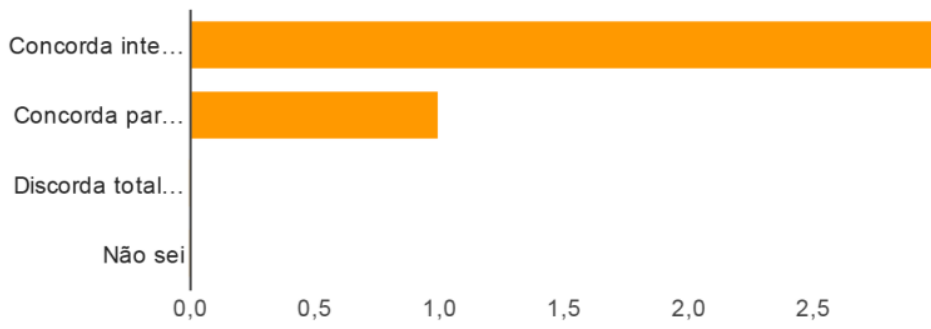

$\begin{array}{rrr}\text { Concorda integralmente } & \mathbf{3} & 75 \% \\ \text { Concorda parcialmente } & \mathbf{1} & 25 \% \\ \text { Discorda totalmente } & \mathbf{0} & 0 \% \\ \text { Não sei } & \mathbf{0} & 0 \%\end{array}$

(Objetivo 3) Gerar padrões para disseminar melhores práticas no segmento [Q1.1 - Objetivos da visão Macro da Rede]

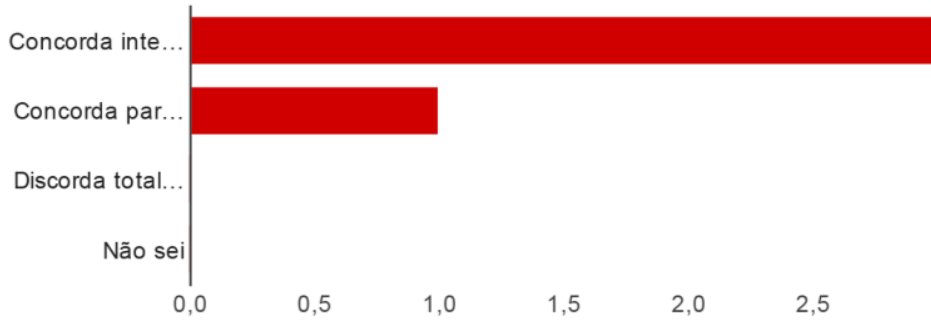

$$
\begin{array}{rrr}
\text { Concorda integralmente } & \mathbf{3} & 75 \% \\
\text { Concorda parcialmente } & \mathbf{1} & 25 \% \\
\text { Discorda totalmente } & \mathbf{0} & 0 \% \\
\text { Não sei } & \mathbf{0} & 0 \%
\end{array}
$$

(Objetivo 4) Melhorar visibilidade de objetivos e ações [Q1.2 - Objetivos da Visão Micro da rede] 


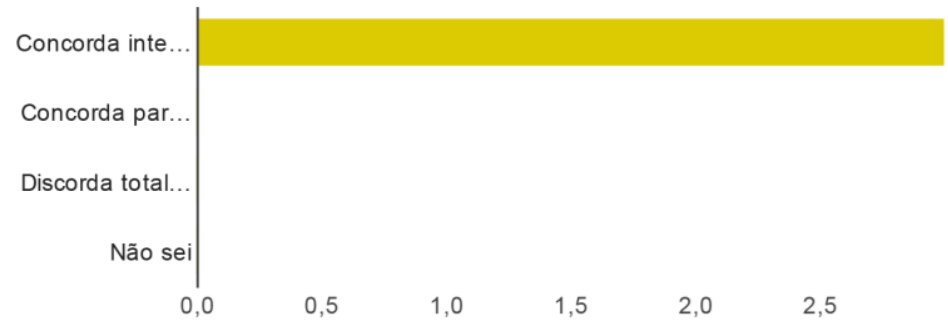

(Objetivo 5) Desenvolver soluções robustas [Q1.2 - Objetivos da Visão Micro da rede]

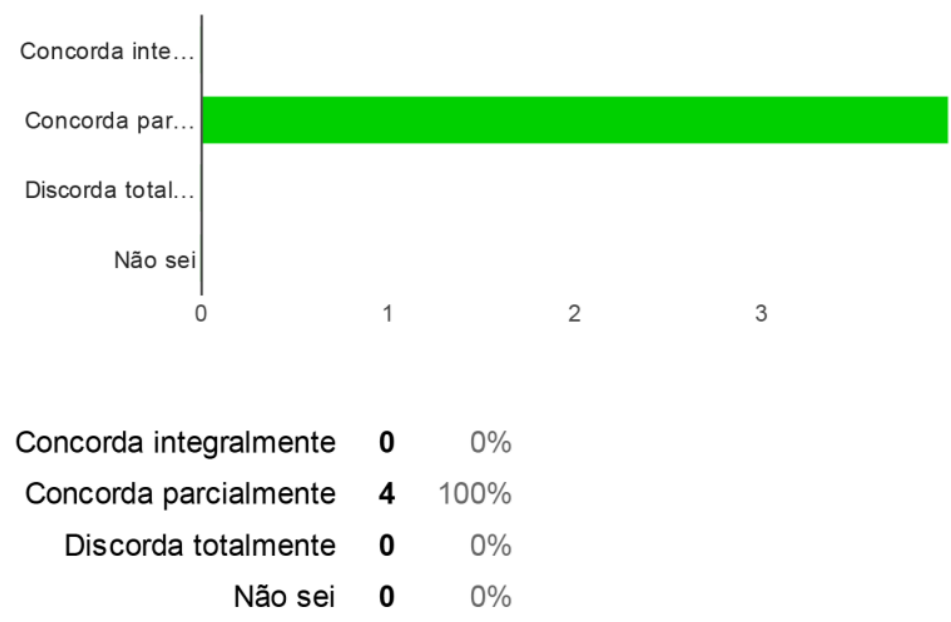

\section{Q2 - Modelo de Regras do Negócio}

(Regra 2) Garantir qualidade nas soluções desenvolvidas [Q2.1 - Regras da visão Macro da Rede]

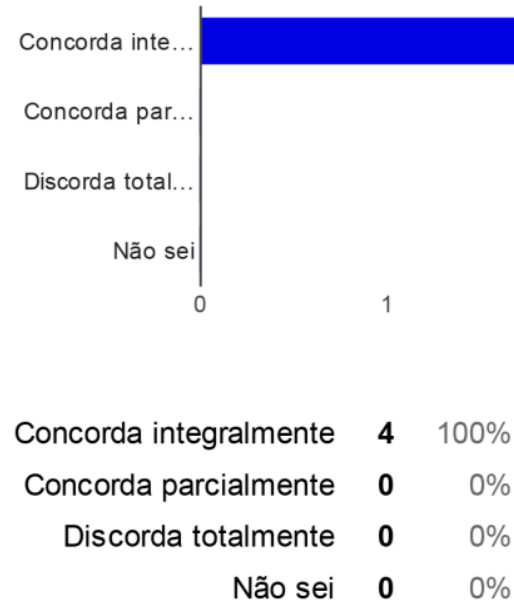

(Regra 3) Considerar requisitos e opiniões de todos os envolvidos [Q2.1 - 
Regras da visão Macro da Rede]

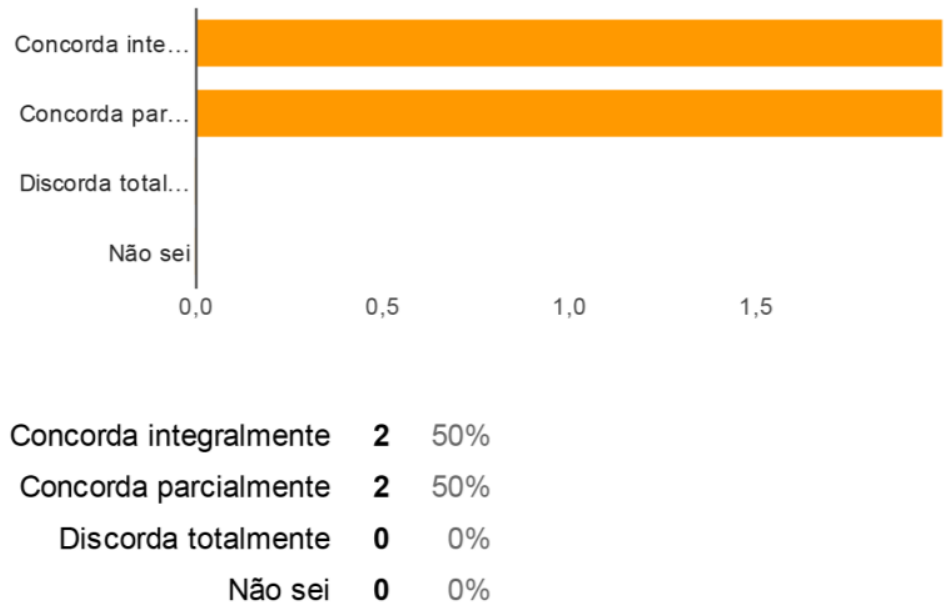

(Regra 1) Promover eventos de premiação para motivação [Q2.1 - Regras da visão Macro da Rede]

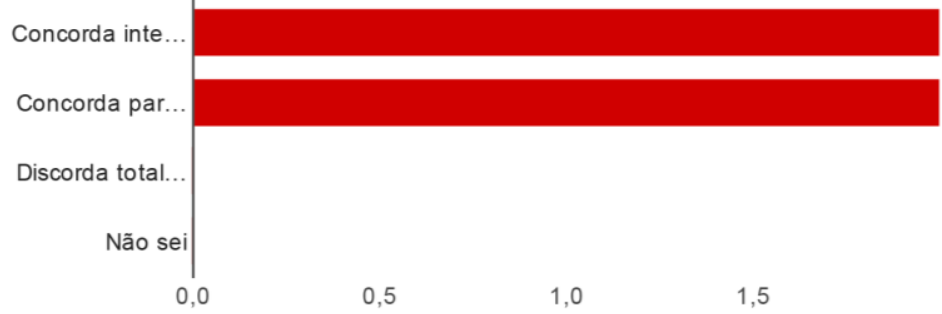

$\begin{array}{rrr}\text { Concorda integralmente } & \mathbf{2} & 50 \% \\ \text { Concorda parcialmente } & \mathbf{2} & 50 \% \\ \text { Discorda totalmente } & \mathbf{0} & 0 \% \\ \text { Não sei } & \mathbf{0} & 0 \%\end{array}$

(Regra 4) Estimular P\&D no segmento [Q2.1 - Regras da visão Macro da Rede]

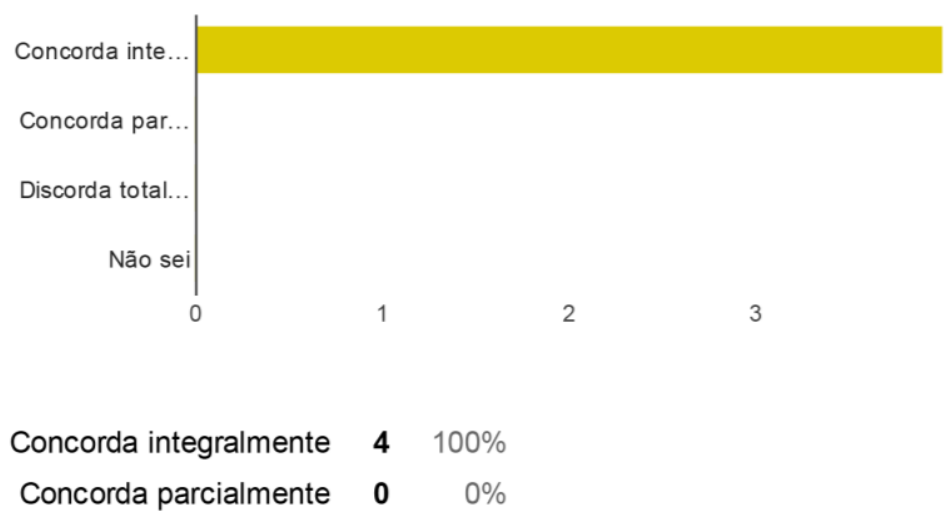




$\begin{array}{rll}\text { Discorda totalmente } & \mathbf{0} & 0 \% \\ \text { Não sei } & \mathbf{0} & 0 \%\end{array}$

(Regra 5) Balancear controle e flexibilidade [Q2.1 - Regras da visão Macro da Rede]

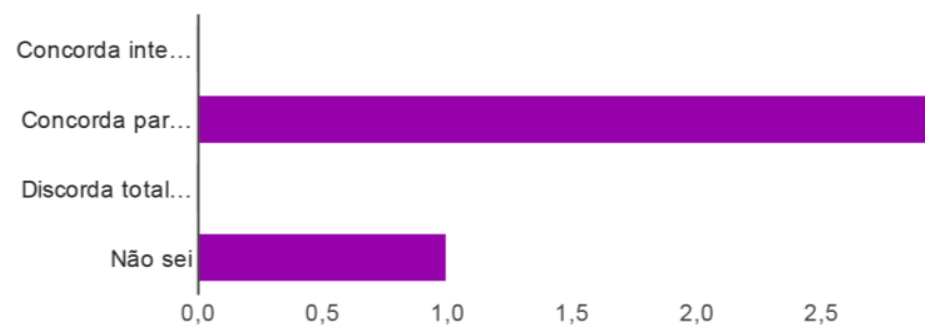

$\begin{array}{rrr}\text { Concorda integralmente } & \mathbf{0} & 0 \% \\ \text { Concorda parcialmente } & \mathbf{3} & 75 \% \\ \text { Discorda totalmente } & \mathbf{0} & 0 \% \\ \text { Não sei } & \mathbf{1} & 25 \%\end{array}$

(Regra 6) Alertar sobre problemas [Q2.2 - Regras da visão Micro da Rede]

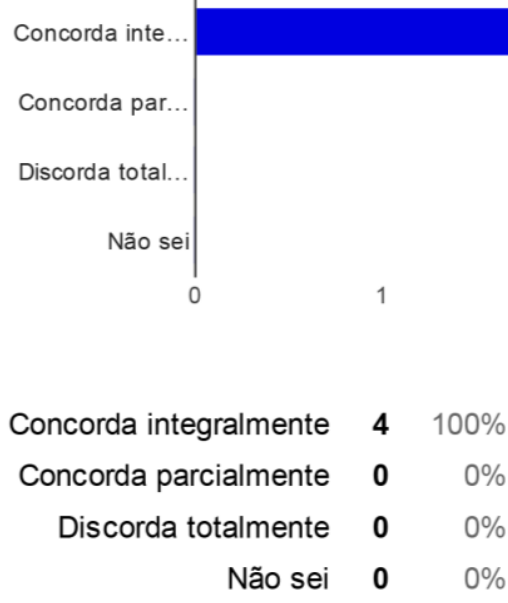

(Regra 7) Manter transparência nas ações [Q2.2 - Regras da visão Micro da Rede]

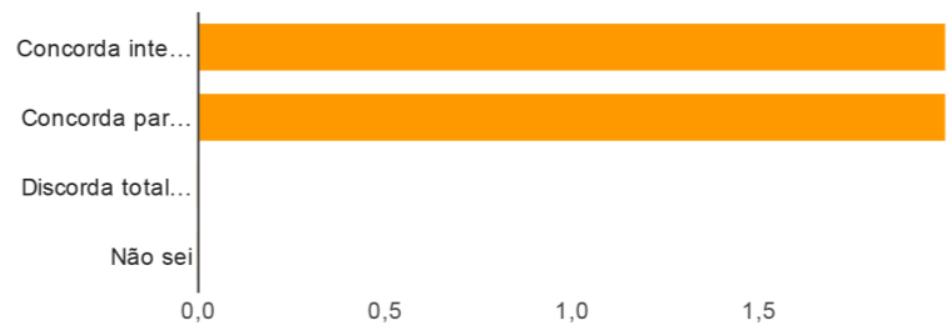




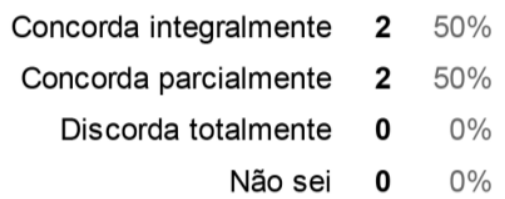

(Regra 8) Agir com imparcialidade nas definições [Q2.2 - Regras da visão Micro da Rede]

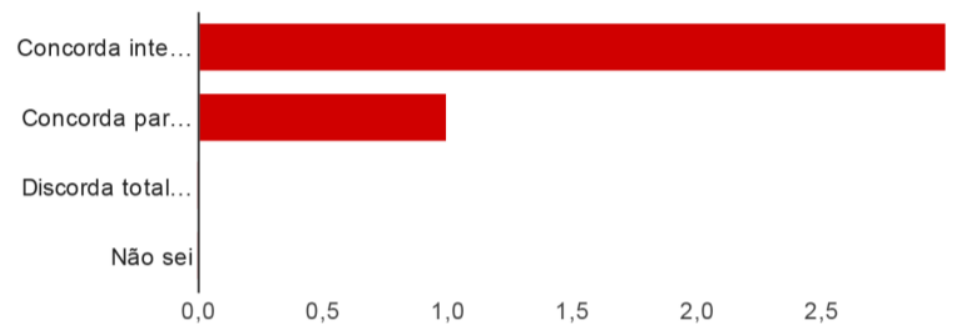

$\begin{array}{rrr}\text { Concorda integralmente } & \mathbf{3} & 75 \% \\ \text { Concorda parcialmente } & \mathbf{1} & 25 \% \\ \text { Discorda totalmente } & \mathbf{0} & 0 \% \\ \text { Não sei } & \mathbf{0} & 0 \%\end{array}$

(Regra 9) Responder requisitos dos envolvidos [Q2.2 - Regras da visão Micro da Rede]

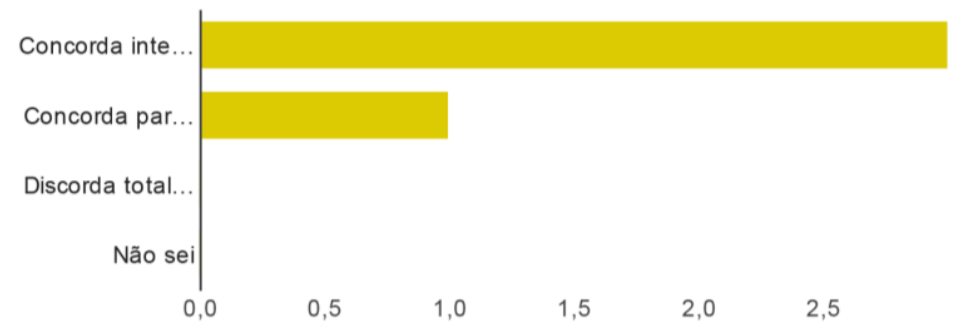

$\begin{array}{rrr}\text { Concorda integralmente } & \mathbf{3} & 75 \% \\ \text { Concorda parcialmente } & \mathbf{1} & 25 \% \\ \text { Discorda totalmente } & \mathbf{0} & 0 \% \\ \text { Não sei } & \mathbf{0} & 0 \%\end{array}$

(Regra 10) Garantir qualidade nas soluções desenvolvidas [Q2.2 - Regras da visão Micro da Rede] 


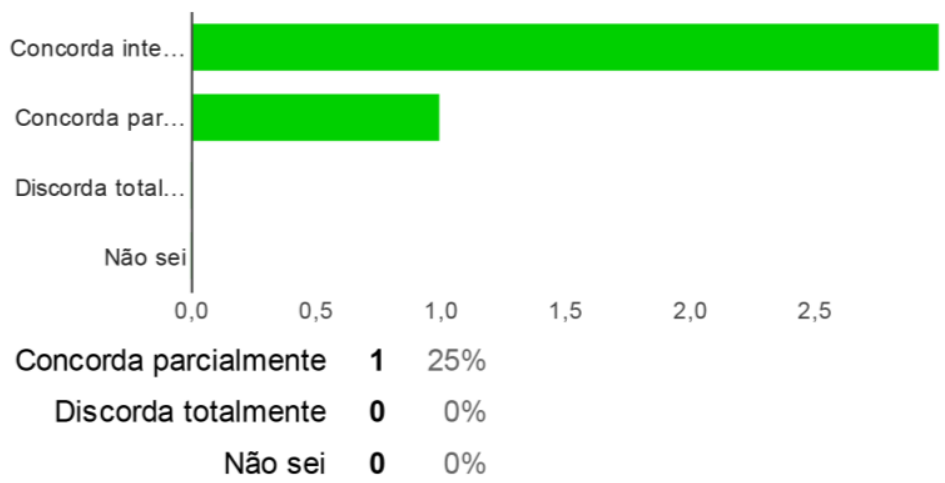

(Regra 11) Promover uso de softwares livres e tecnologias homologadas [Q2.2 - Regras da visão Micro da Rede]

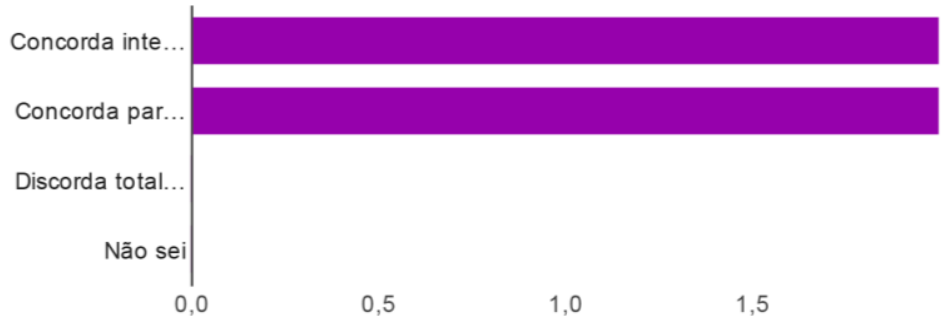

$\begin{array}{rlr}\text { Concorda integralmente } & \mathbf{2} & 50 \% \\ \text { Concorda parcialmente } & \mathbf{2} & 50 \% \\ \text { Discorda totalmente } & \mathbf{0} & 0 \% \\ \text { Não sei } & \mathbf{0} & 0 \%\end{array}$

(Regra 12) Utilizar meios de comunicação acordados [Q2.2 - Regras da visão Micro da Rede]

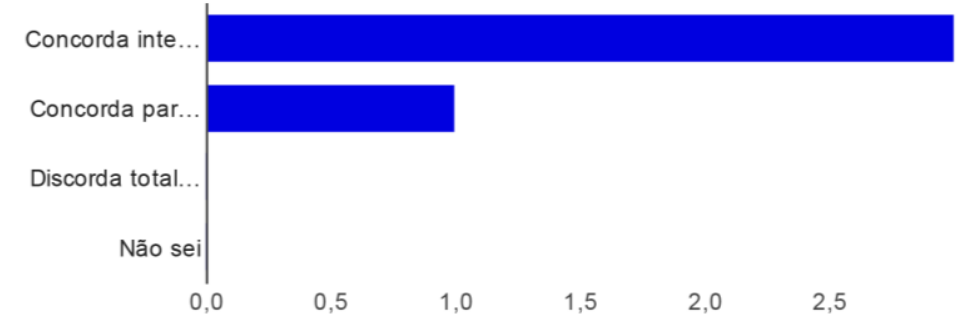

$$
\begin{array}{rrr}
\text { Concorda integralmente } & \mathbf{3} & 75 \% \\
\text { Concorda parcialmente } & \mathbf{1} & 25 \% \\
\text { Discorda totalmente } & \mathbf{0} & 0 \% \\
\text { Não sei } & \mathbf{0} & 0 \%
\end{array}
$$


(Regra 13) Promover a utilização das práticas do ágil [Q2.2 - Regras da vi: Micro da Rede]

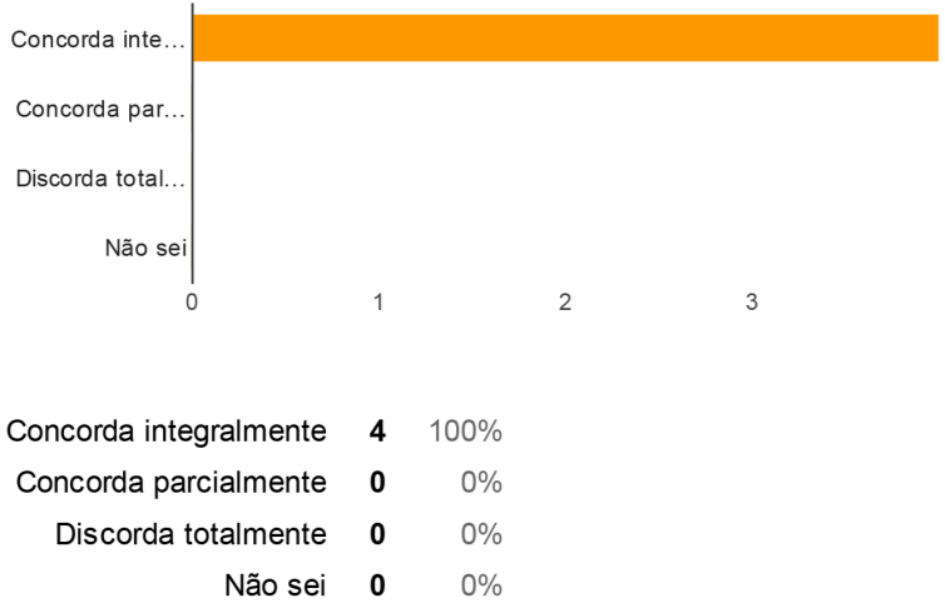

(Regra 14) Realizar treinamentos [Q2.2 - Regras da visão Micro da Rede]

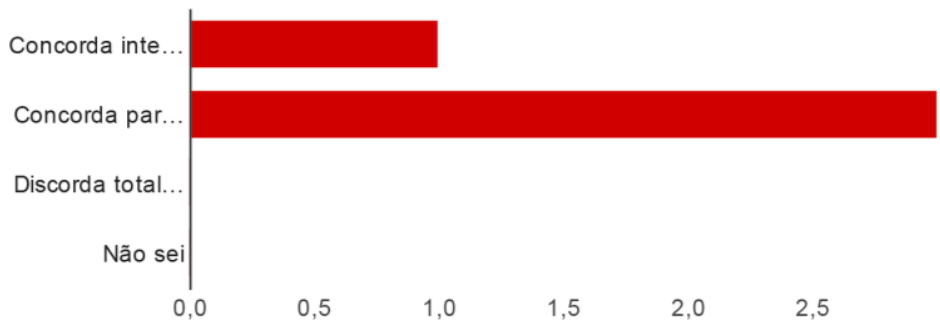

$\begin{array}{rrr}\text { Concorda integralmente } & \mathbf{1} & 25 \% \\ \text { Concorda parcialmente } & \mathbf{3} & 75 \% \\ \text { Discorda totalmente } & \mathbf{0} & 0 \% \\ \text { Não sei } & \mathbf{0} & 0 \%\end{array}$

Q3 - Modelo de Atores e Recursos

Q3.1 - Atores e Recursos da Visão Macro da Rede

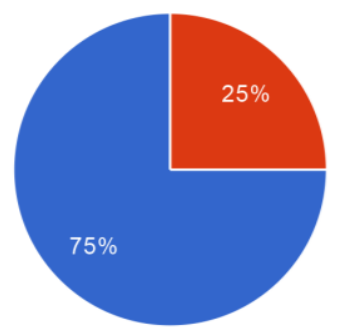




$\begin{array}{rrr}\text { Concorda integralmente } & \mathbf{3} & 75 \% \\ \text { Concorda parcialmente } & \mathbf{1} & 25 \% \\ \text { Discorda totalmente } & \mathbf{0} & 0 \% \\ \text { Não sei } & \mathbf{0} & 0 \%\end{array}$

Q3.2 - Atores e Recursos da Visão Micro da Rede

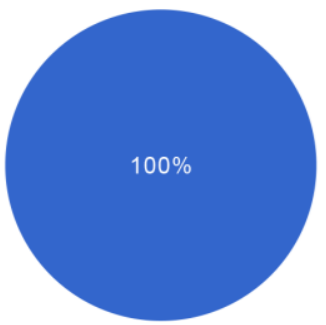

$\begin{array}{rrr}\text { Concorda integralmente } & \mathbf{4} & 100 \% \\ \text { Concorda parcialmente } & \mathbf{0} & 0 \% \\ \text { Discorda totalmente } & \mathbf{0} & 0 \% \\ \text { Não sei } & \mathbf{0} & 0 \%\end{array}$

\section{Q4 - Modelo de Processos}

Visão Micro da Rede [Q4.1 - Processo para transição do modelo de gestão]

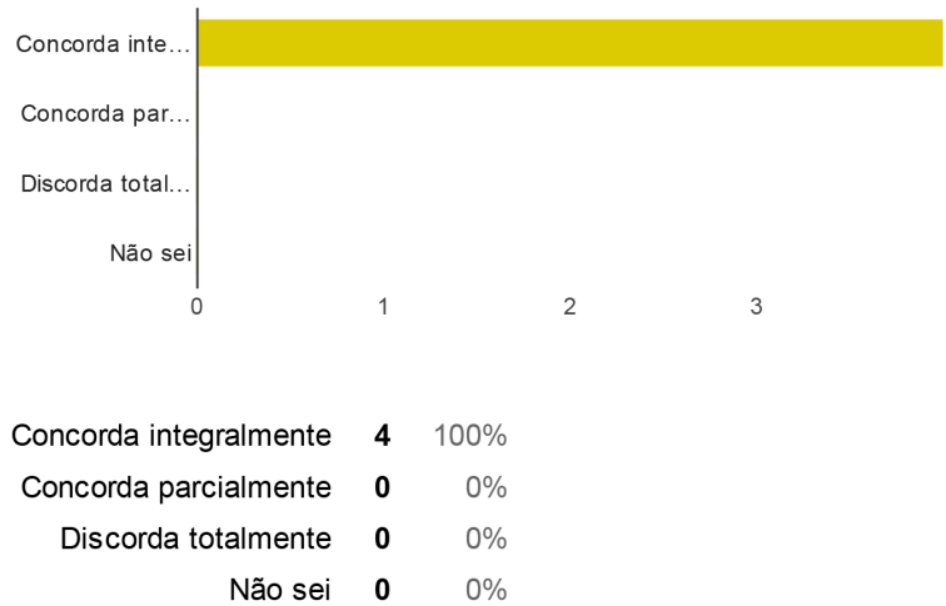

Visão Macro da Rede [Q4.2 - Processo para gerar demandas (partes 1 e 2)] 


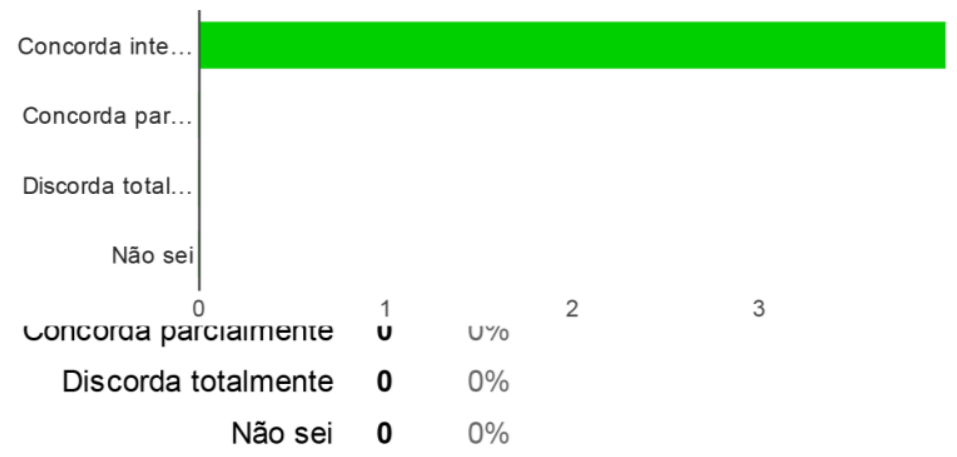

Visão Micro da Rede [Q4.2 - Processo para gerar demandas (partes 1 e 2)]

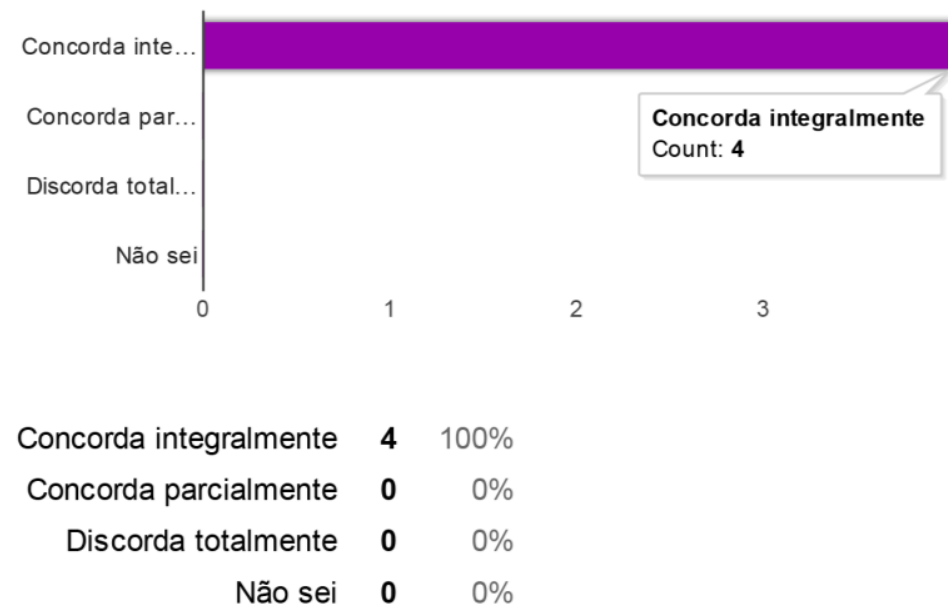

Visão Micro da Rede [Q4.3 - Processo para receber e tratar demandas (partes 1 e 2)]

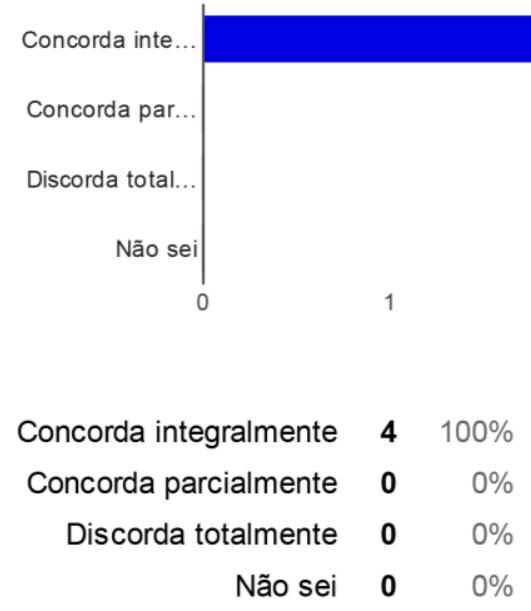

Visão Micro da Rede [Q4.4 - Processo para tratar demandas fixas (ágil 
+ ITIL)]

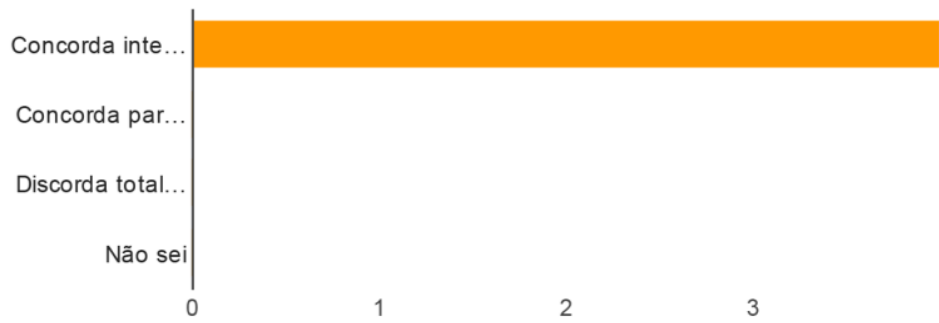

$\begin{array}{rlr}\text { Concorda integralmente } & \mathbf{4} & 100 \% \\ \text { Concorda parcialmente } & \mathbf{0} & 0 \% \\ \text { Discorda totalmente } & \mathbf{0} & 0 \% \\ \text { Não sei } & \mathbf{0} & 0 \%\end{array}$

Visão Macro da Rede [Q4.5 - Processo para acompanhar resultados e comunicar interessados (partes 1 e 2)]

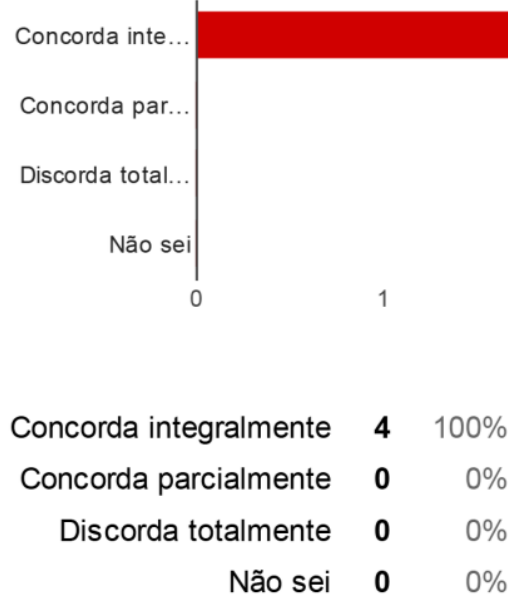

Visão Micro da Rede [Q4.5 - Processo para acompanhar resultados e comunicar interessados (partes 1 e 2)]

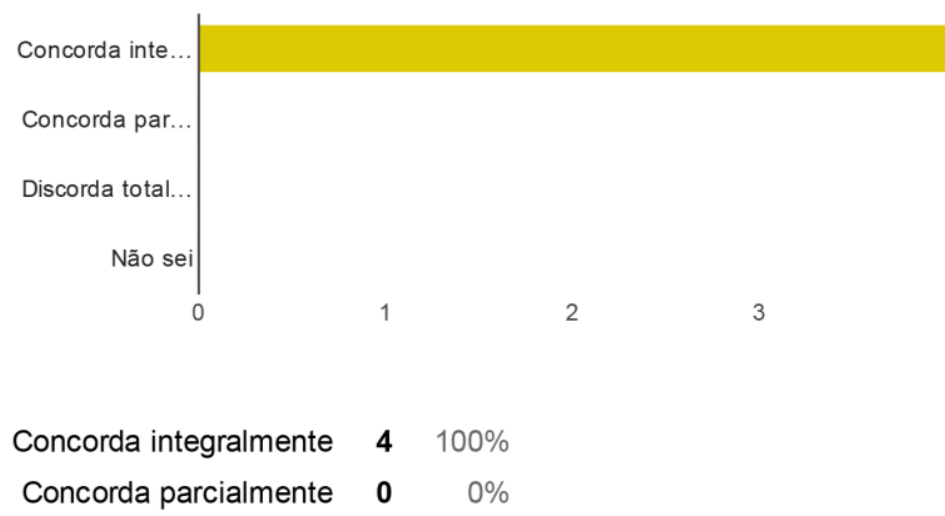




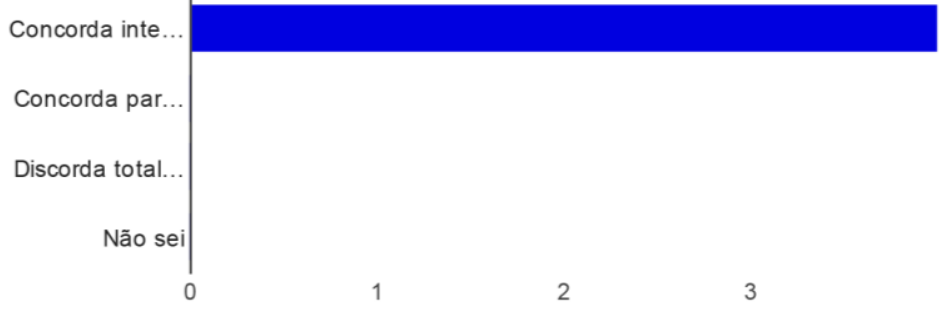

Visão Macro da Rede [Q4.8 - Processo para estimular inovação na rede]

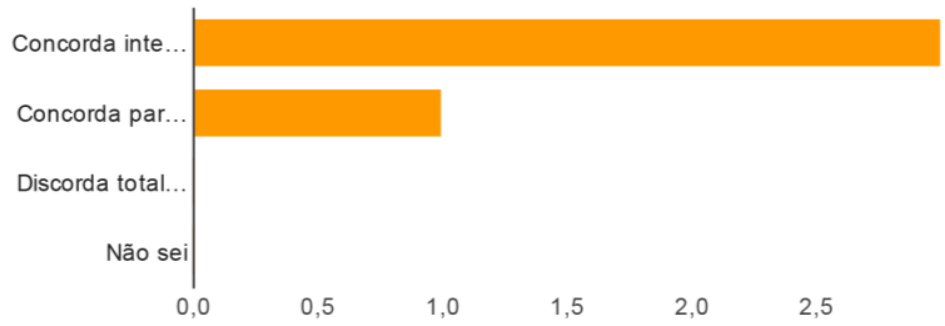

$\begin{array}{rrr}\text { Concorda integralmente } & \mathbf{3} & 75 \% \\ \text { Concorda parcialmente } & \mathbf{1} & 25 \% \\ \text { Discorda totalmente } & \mathbf{0} & 0 \% \\ \text { Não sei } & \mathbf{0} & 0 \%\end{array}$

Visão Micro da Rede [Q4.8 - Processo para estimular inovação na rede]

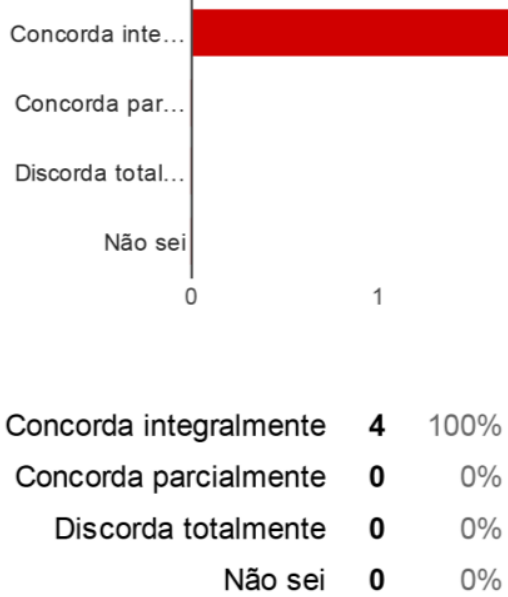

Visão Macro da Rede [Q4.9 - Processo para disseminar melhores práticas no segmento] 


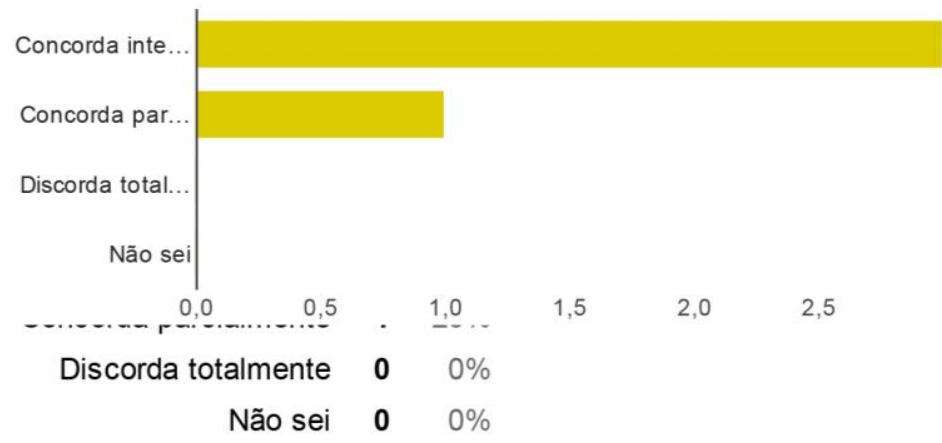

Visão Micro da Rede [Q4.9 - Processo para disseminar melhores práticas no segmento]

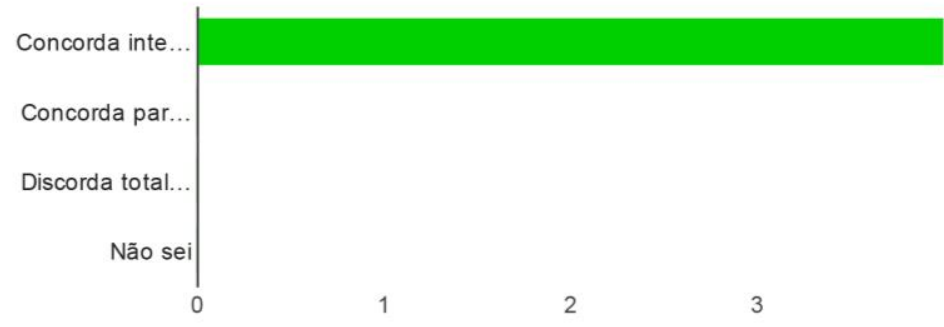

$\begin{array}{rlr}\text { Concorda integralmente } & \mathbf{4} & 100 \% \\ \text { Concorda parcialmente } & \mathbf{0} & 0 \% \\ \text { Discorda totalmente } & \mathbf{0} & 0 \% \\ \text { Não sei } & \mathbf{0} & 0 \%\end{array}$

Visão Macro da Rede [Q4.10 - Processo para realizar gestão de parcerias e RH (Partes 1 e 2)]

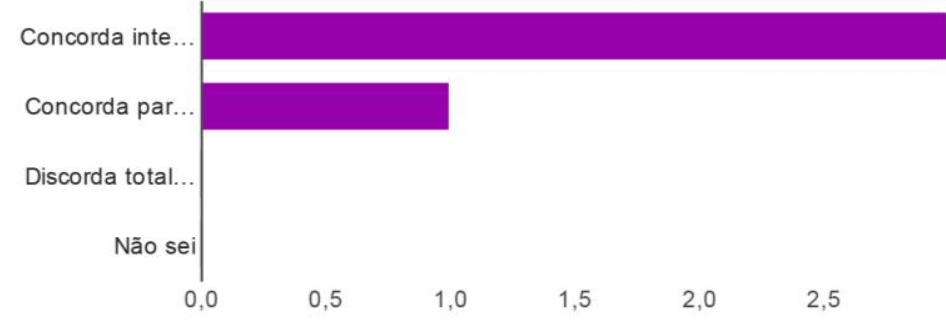

$\begin{array}{rrr}\text { Concorda integralmente } & \mathbf{3} & 75 \% \\ \text { Concorda parcialmente } & \mathbf{1} & 25 \% \\ \text { Discorda totalmente } & \mathbf{0} & 0 \% \\ \text { Não sei } & \mathbf{0} & 0 \%\end{array}$

Visão Micro da Rede [Q4.10 - Processo para gestão de recursos humanos 


\section{(Partes 1 e 2)]}

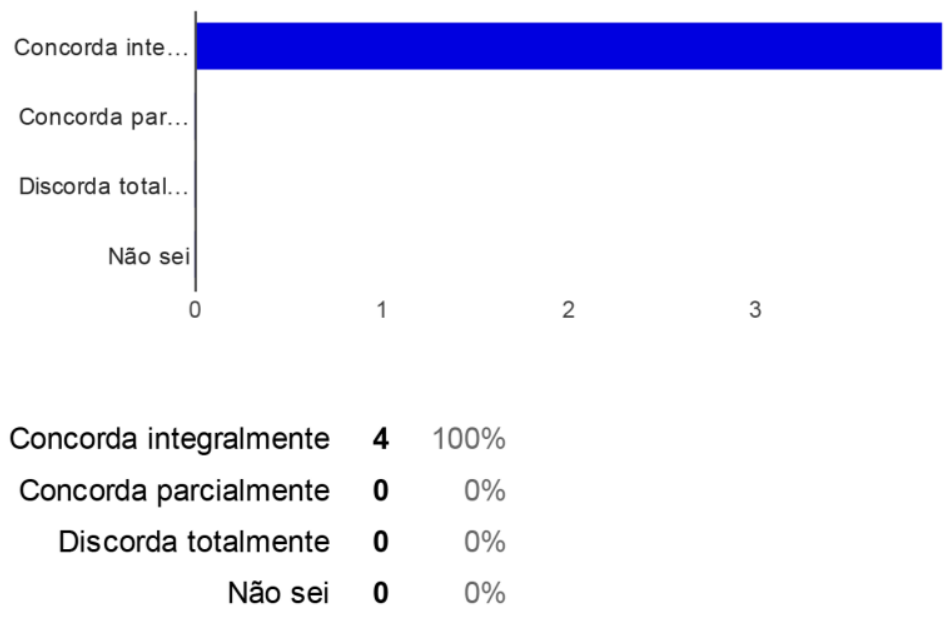

Visão Macro da Rede [Q4.11 - Processo de acompanhamento e liberação de recursos]

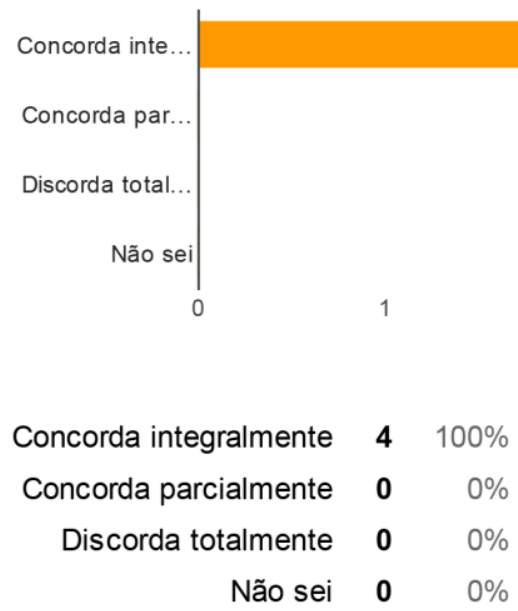

Visão Micro da Rede [Q4.11 - Processo de acompanhamento e liberação de recursos]

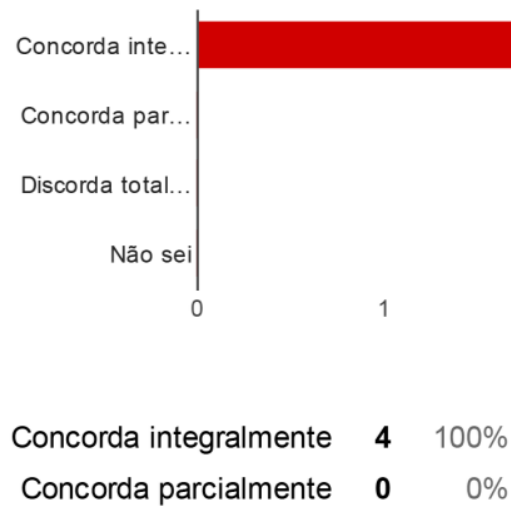




\section{Q5 - Modelo de Componentes e Requisitos Técnicos}

(Objetivo SI 1) Supervisionar processos operacionais [Q5.1 - Componentes e Requisitos Técnicos da Visão Macro e da Visão Micro da Rede]

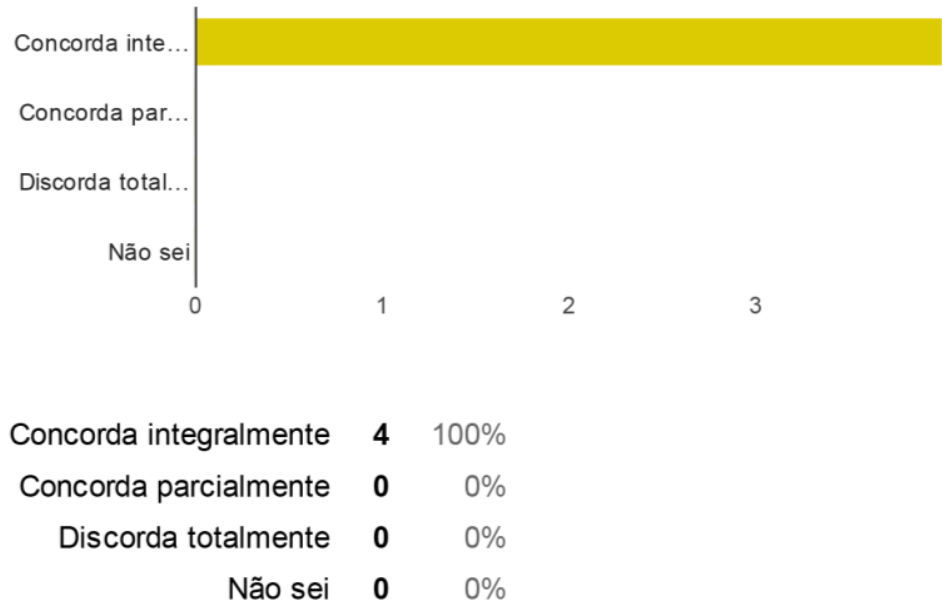

(Objetivo SI 2) Gerenciar demandas [Q5.1 - Componentes e Requisitos Técnicos da Visão Macro e da Visão Micro da Rede]

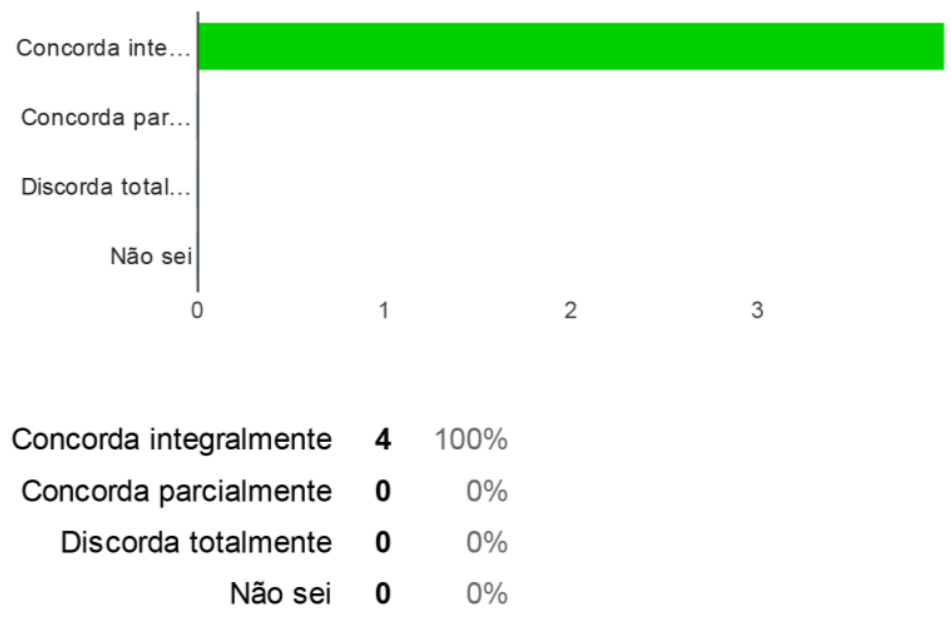

(Objetivo SI 3) Estimular comunicação dos atores [Q5.1 - Componentes e Requisitos Técnicos da Visão Macro e da Visão Micro da Rede] 


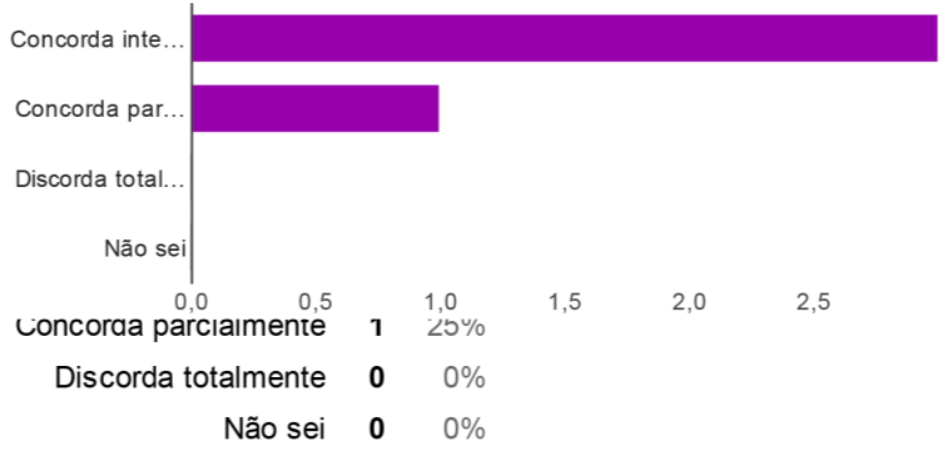

(Objetivo SI 4) Estimular gestão de conhecimento [Q5.1 - Componentes e Requisitos Técnicos da Visão Macro e da Visão Micro da Rede]

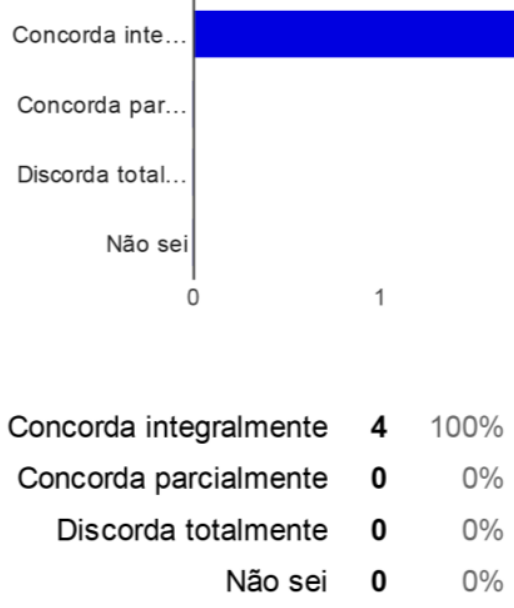

(Objetivo SI 5) Apoiar tomada de decisão [Q5.1 - Componentes e Requisitos Técnicos da Visão Macro e da Visão Micro da Rede]

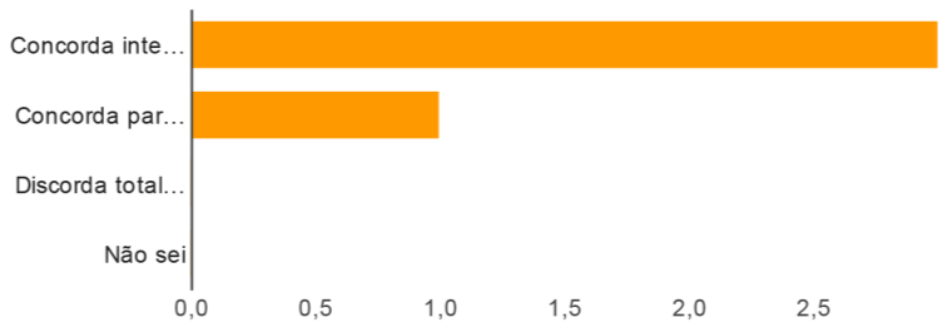

$$
\begin{array}{rrr}
\text { Concorda integralmente } & \mathbf{3} & 75 \% \\
\text { Concorda parcialmente } & \mathbf{1} & 25 \% \\
\text { Discorda totalmente } & \mathbf{0} & 0 \% \\
\text { Não sei } & \mathbf{0} & 0 \%
\end{array}
$$


(Objetivo SI 6) Divulgar evoluções [Q5.1 - Componentes e Requisitos Técnicos da Visão Macro e da Visão Micro da Rede]

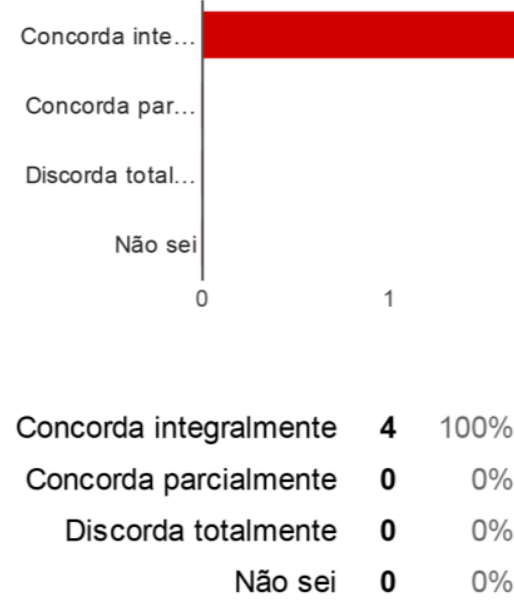

(Objetivo SI 7) Manter envolvidos alinhados [Q5.1 - Componentes e Requisitos Técnicos da Visão Macro e da Visão Micro da Rede]

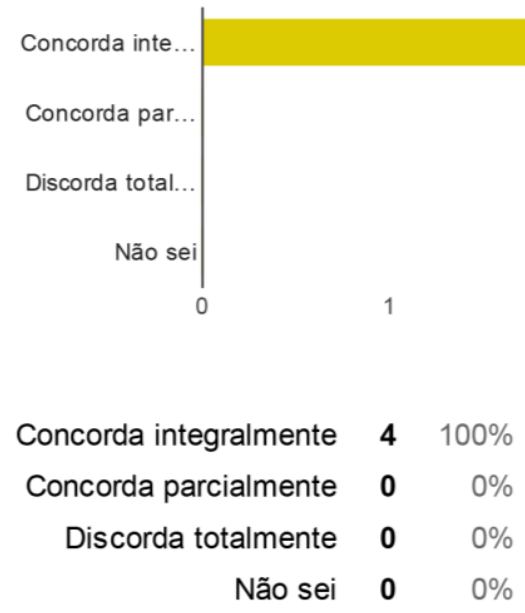

(Objetivo SI 8) Manter sistemas/ambientes operacionais [Q5.1 Componentes e Requisitos Técnicos da Visão Macro e da Visão Micro da Rede]

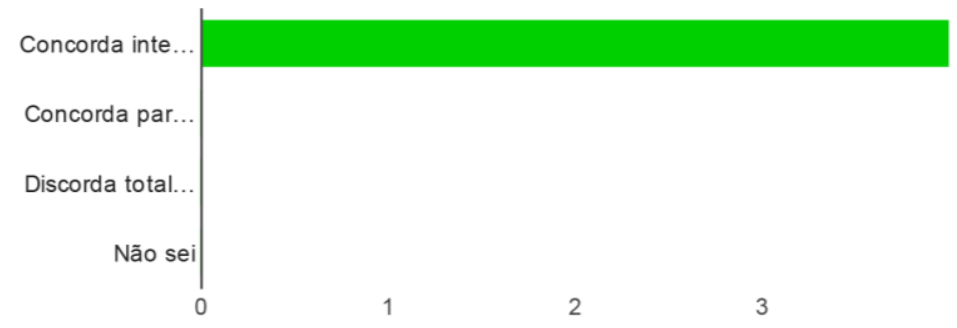


(Objetivo SI 6) Divulgar evoluções [Q5.1 - Componentes e Requisitos Técnicos da Visão Macro e da Visão Micro da Rede]

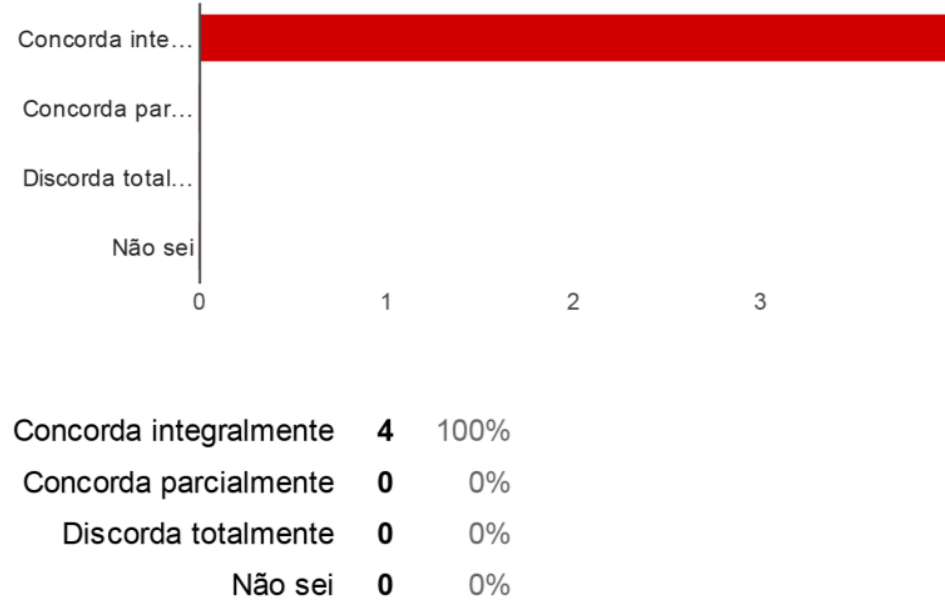

(Objetivo SI 7) Manter envolvidos alinhados [Q5.1 - Componentes e Requisitos Técnicos da Visão Macro e da Visão Micro da Rede]

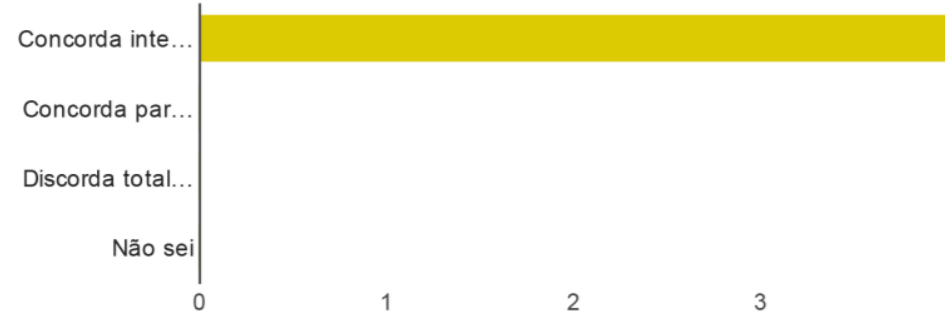

$\begin{array}{rlr}\text { Concorda integralmente } & \mathbf{4} & 100 \% \\ \text { Concorda parcialmente } & \mathbf{0} & 0 \% \\ \text { Discorda totalmente } & \mathbf{0} & 0 \% \\ \text { Não sei } & \mathbf{0} & 0 \%\end{array}$

(Objetivo SI 8) Manter sistemas/ambientes operacionais [Q5.1 Componentes e Requisitos Técnicos da Visão Macro e da Visão Micro da Rede]

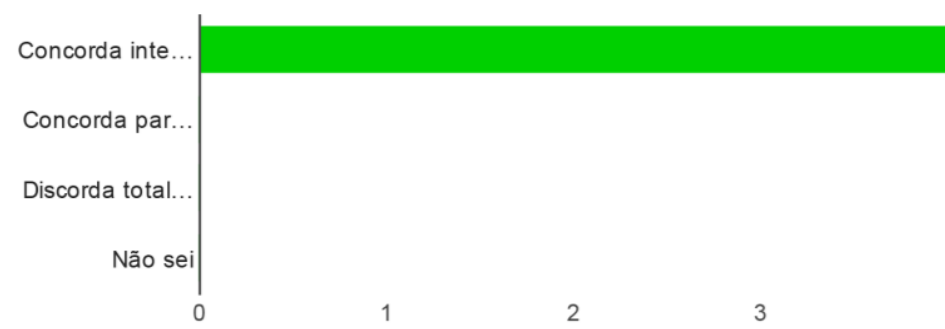




$\begin{array}{rrr}\text { Concorda integralmente } & \mathbf{4} & 100 \% \\ \text { Concorda parcialmente } & \mathbf{0} & 0 \% \\ \text { Discorda totalmente } & \mathbf{0} & 0 \% \\ \text { Não sei } & \mathbf{0} & 0 \%\end{array}$

\section{Q6 - Aplicabilidade como modelagem de empresas}

Q6.1 - O conjunto de modelos reflete a realidade da rede e do(s) projeto(s) analisados?

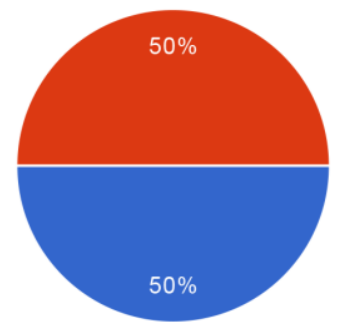

$\begin{array}{rlr}\text { Sim, totalmente } & \mathbf{2} & 50 \% \\ \text { Sim, parcialmente } & \mathbf{2} & 50 \% \\ \text { Não } & \mathbf{0} & 0 \% \\ \text { Não sei } & \mathbf{0} & 0 \%\end{array}$

Q6.2 - O conjunto de modelos facilita a visualização da estrutura da rede e de seus processos?

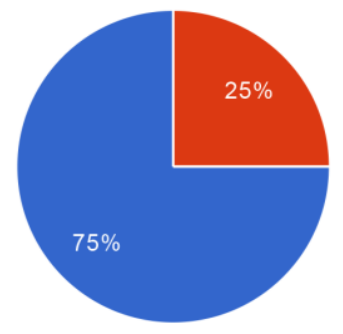

Sim, totalmente $375 \%$

Sim, parcialmente $125 \%$

Não $0 \quad 0 \%$

Não sei $\quad 0 \quad 0 \%$

Q6.3 - O conjunto de modelos pode ser adaptado para o contexto de gestão em outras redes e seus projetos? 


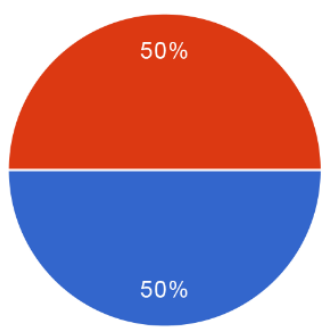

Sim, totalmente 2 50\%

Sim, parcialmente $2 \quad 50 \%$

Não $0 \quad 0 \%$

Não sei $\quad \mathbf{0} \%$ 


\section{APÊNDICE B - DETALHAMENTOS DE MODELOS EKD-CMM}

Visando facilitar a compreensão das ações realizadas, bem como possíveis replicações da pesquisa, este apêndice contém o detalhamento das modelagens de processos, desenvolvidas com o EKD-CMM, apresentadas nos estados atual (as-is) e futuro (to-be) - aplicada na unidade de análise - e ainda; uma parte extra (parte1/3) do modelo de componentes e requisitos apresentado na seção 3.1.2.5 (estado atual as-is).

\section{Modelo de processos $A s-I s$}

O modelo de nove processos citados de forma resumida na seção 3.1.2.4 deste material é detalhado como segue:

\subsection{Processo para gerar demandas}

Conforme a Figura 26 (página 238), as ações que requerem acompanhamento (Infoset 1) disparam processos de acompanhamento e atualização relacionados ao segmento de gestão de transportes e pedagiamento (Processos 1, 2 e 3), gerando uma lista de possíveis demandas (Infoset 2). Com essa lista, interessados são convocados para alinhamentos (Processo 4) com pauta (Infoset 3).

As reuniões são realizadas (Processo 5), resultando em uma seleção de demandas, por produtos, processos e/ou serviços (Infoset 4) que disparam a definição de um plano de ação (Processo 6) com ações, envolvidos e prazos (Infoset 5) e que demandam acompanhamento de resultados (Processo 7).

A partir do plano de ação (Infoset 5) inicia-se o processo de acompanhamento do Centro de pesquisas (Processo 8) que resulta em relatórios para acompanhamento (Infoset 6) da demanda (Processo 7). Similarmente, a definição do plano de ação (Processo 6) pode significar demandas por melhoria no projeto A (Infoset 7) que devem ser recebidas e tratadas pelo Centro de pesquisas (Processo 9), resultando em inovações no segmento (Infoset 8). 
Modelo de Processos: Processo para gerar demandas - Parte 1/2

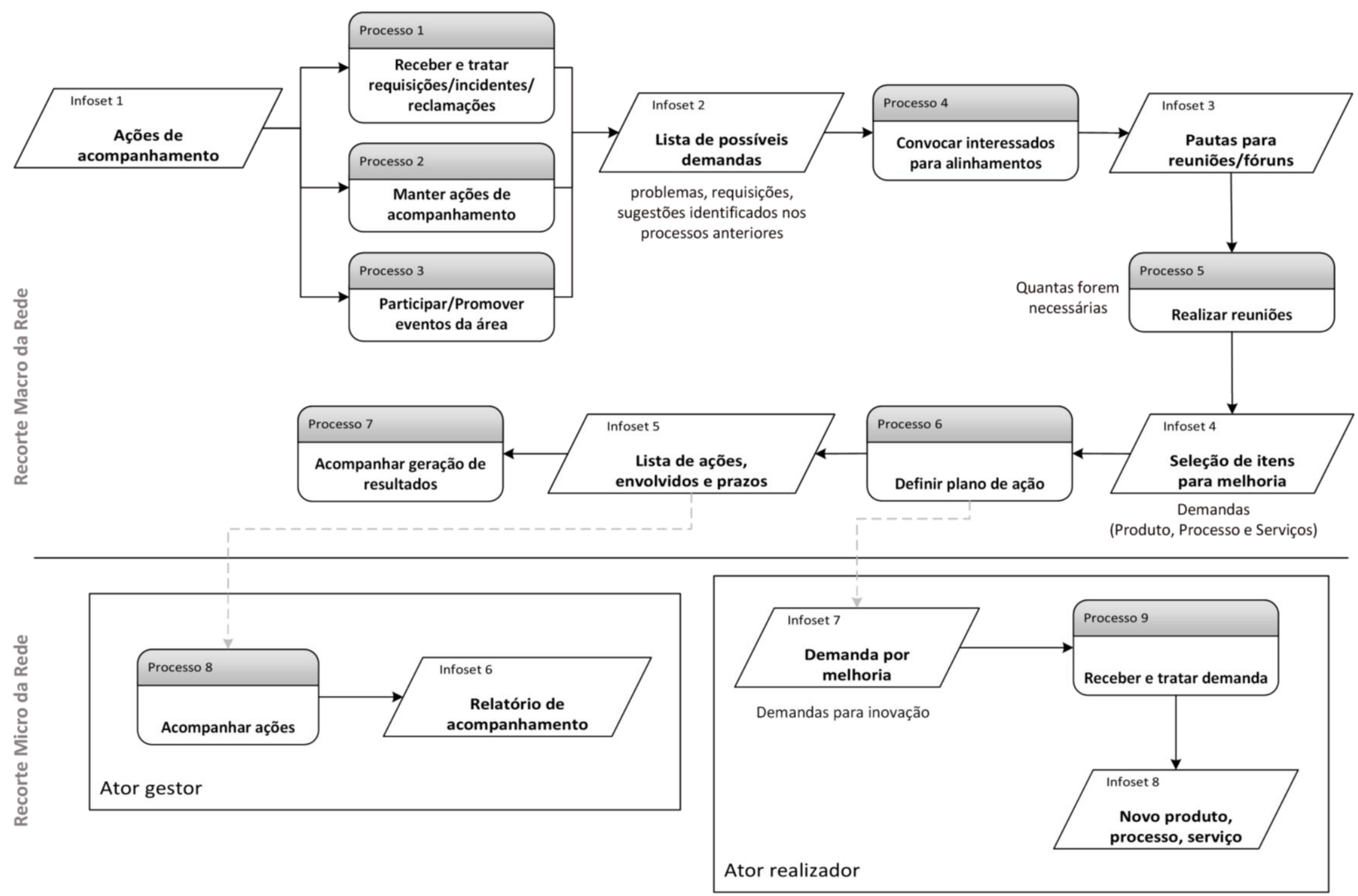

Figura 26 - Modelo de processos: gerar demandas - asis (parte 1/2) 
Conforme a Figura 27 (página 240), o plano de ação (Infoset 5) dispara o processo de acompanhamento no Centro de pesquisas (Processo 8), resultando em uma lista de itens para monitoramento do projeto (Infoset 9), recebida de diversos meios.

Essa lista dispara vários processos (Processos 8.1 a 8.6) que geram documentação das ações realizadas (Infoset 10) e, por sua vez, podem requerer estudos para solucionar problemas monitorados no segmento (Processo 8.7) que são reportados em relatórios (Infoset 11) para informar os envolvidos (Processo 8.8) e podem gerar novas demandas por inovação 


\section{Modelo de Processos: Processo para gerar demandas - Parte 2/2}

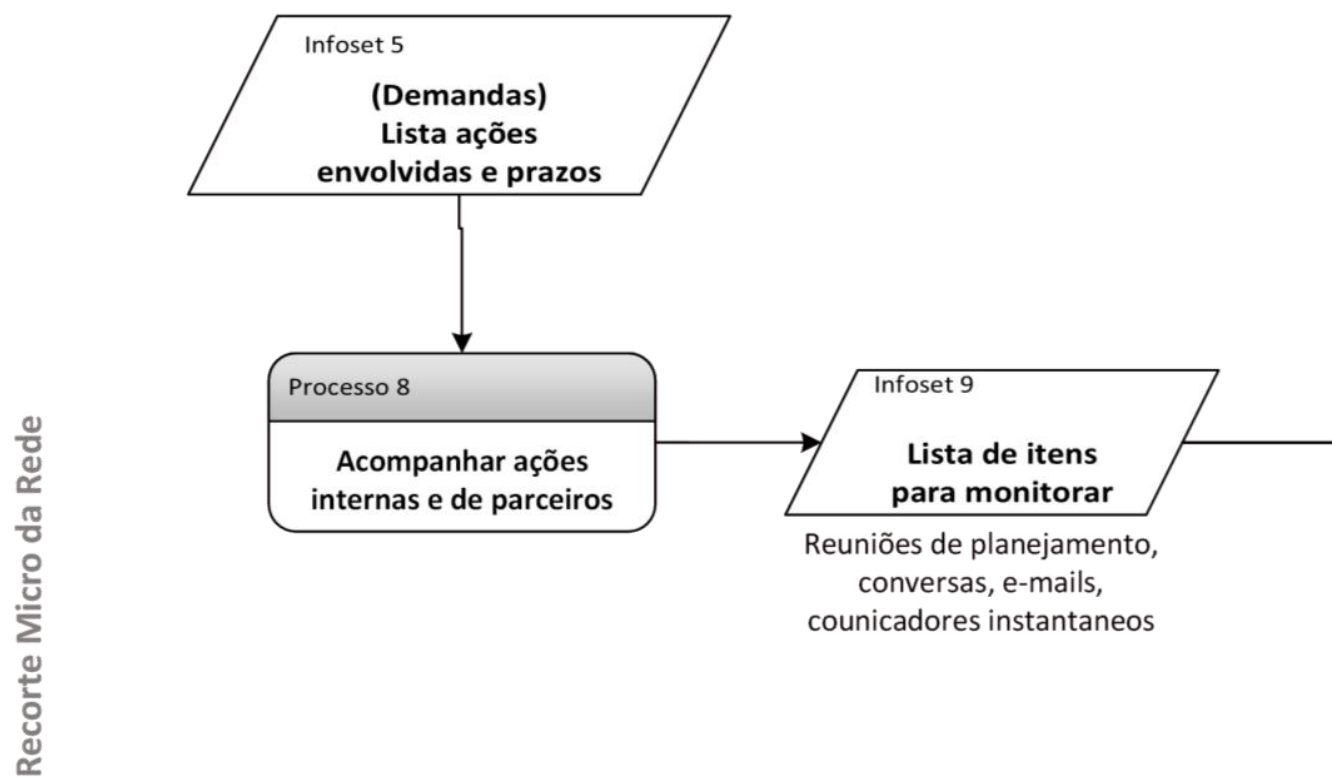

Lista de itens
para monitorar
Reuniões de planejamento,
conversas, e-mails,

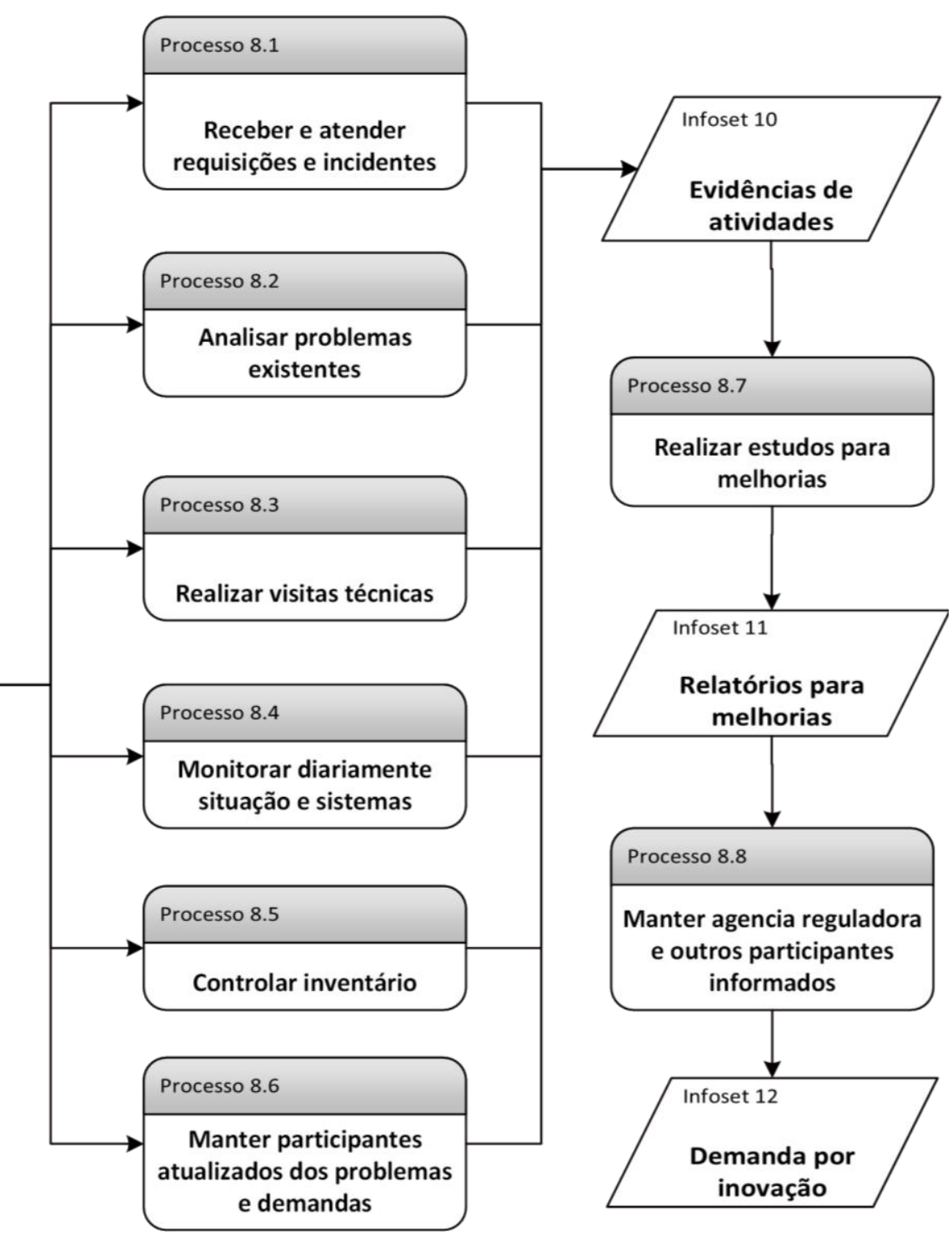

Figura 27 - Modelo de processos: gerar demandas - asis (parte 2/2) 


\subsection{Processo para receber e tratar demandas}

Conforme a Figura 28 (página 242), com o recebimento de demandas por melhorias (Infoset 1), vindas por diferentes meios, é necessário informar atores relevantes da equipe (Processo 1) usando o meio de comunicação adequado (Infoset 2).

Em seguida, as atividades devem ser definidas (Processo 2), através de um subprocesso que recebe a demanda (Infoset 1) e, se houver, o plano de ação previamente gerado no nível macro (Infoset 7). Diversos pontos relevantes são analisados (Processos 2.1 a 2.4), resultando em uma lista com objetivo, prazos e equipe alocada (Infoset 8). Essa lista é utilizada no planejamento das atividades para entregar a demanda (Processo 2.5).

O planejamento resulta em formas descentralizadas de documentação das atividades (Infoset 3), possibilitando a realização das atividades de desenvolvimento (Processo 3) e acompanhamento (Processo 4) da demanda, gerando artefatos de software, relatórios, hardware, entre outros (Infoset 4).

Os interessados são informados da evolução dos artefatos (Processo 5), através de reuniões e relatórios (Infoset 5) até que a demanda seja finalizada. Após a finalização, os resultados são entregues (Processo 6), através de repositórios de código, bancos, servidores, emails e relatórios (Infoset 6). 
Modelo de Processos: Processo para receber e tratar demandas

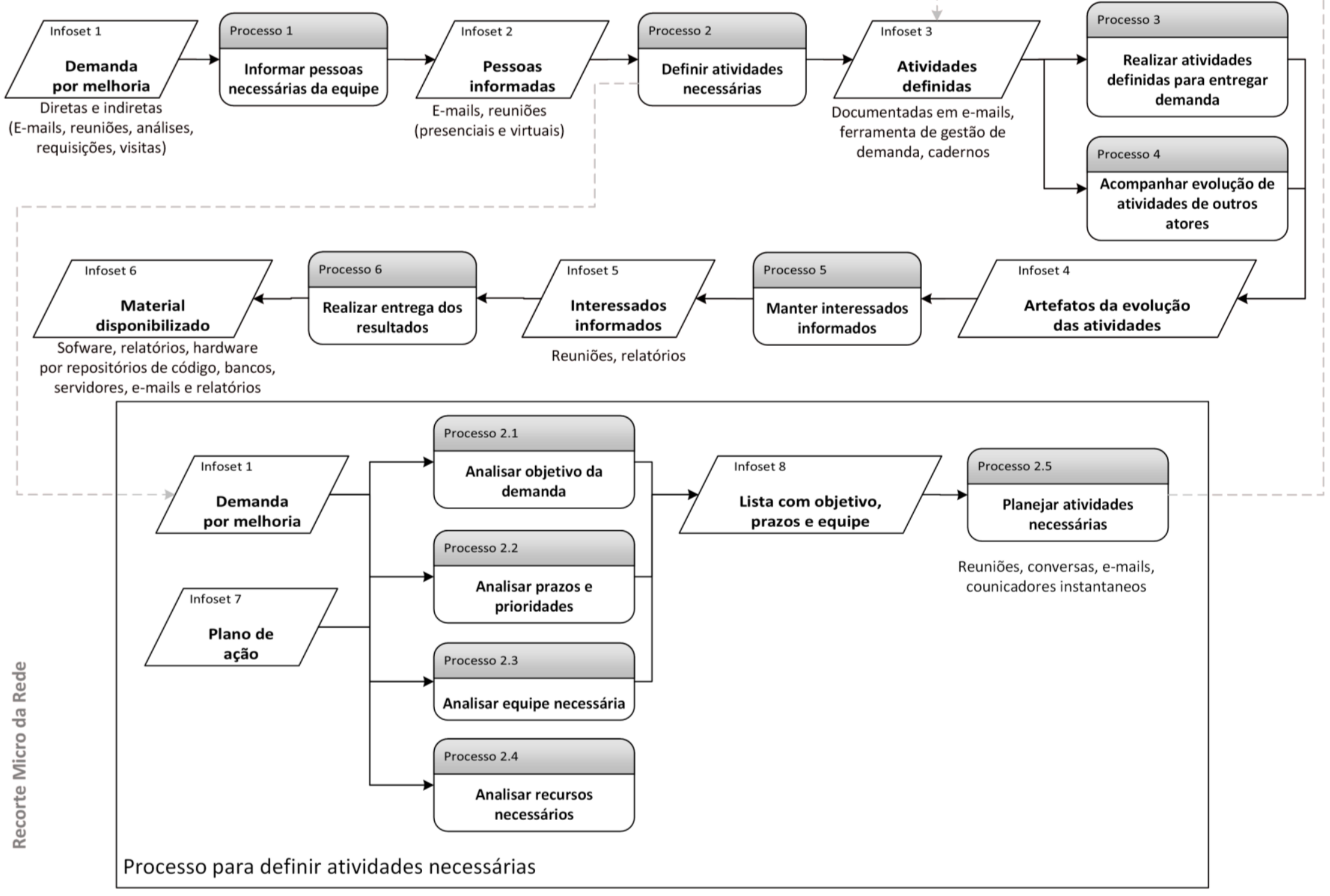

Figura 28 - Modelo de processos: receber e tratar demandas - asis 


\subsection{Processo para acompanhar resultados e comunicar interessados}

Conforme a Figura 29 (página 244), a ocorrência de demandas por melhorias (Infoset 1) junto as diretrizes de acompanhamento (Infoset 2) a serem seguidas, disparam três formas de acompanhamento dos resultados com etapas de comunicação aos interessados - relatórios, reuniões e visitas técnicas.

A primeira parte de uma solicitação por relatórios de acompanhamento (Processo 1) que resulta na obtenção do mesmo (Infoset 3). O relatório é analisado (Processo 2) e recebe um parecer com observações pertinentes à demanda (Infoset 4) que deve ser informado aos interessados (Processo 3).

A segunda parte de uma solicitação por reunião (Processo 4), através de um convite com a pauta (Infoset 5). A reunião é realizada presencial ou virtualmente, gerando uma lista de definições acordadas para a demanda (Infoset 6) que devem ser informadas aos demais interessados (Processo 6).

A terceira inicia-se com o devido planejamento das visitas (Processo 7), resultando em um plano (Infoset 7) que dispara as iterações de visitas técnicas necessárias, envolvendo: comunicar a visita (Processo 8) com um e-mail oficial (Infoset 8); realizar a visita ao local (Processo 9) para coletar dados (Infoset 9); gerar relatório (Processo 10) com informações da visita feita (Infoset 10) e; comunicar interessados (Processo 11). 
Modelo de Processos: Processo para acompanhar resultados e comunicar interessados - Parte 1/2

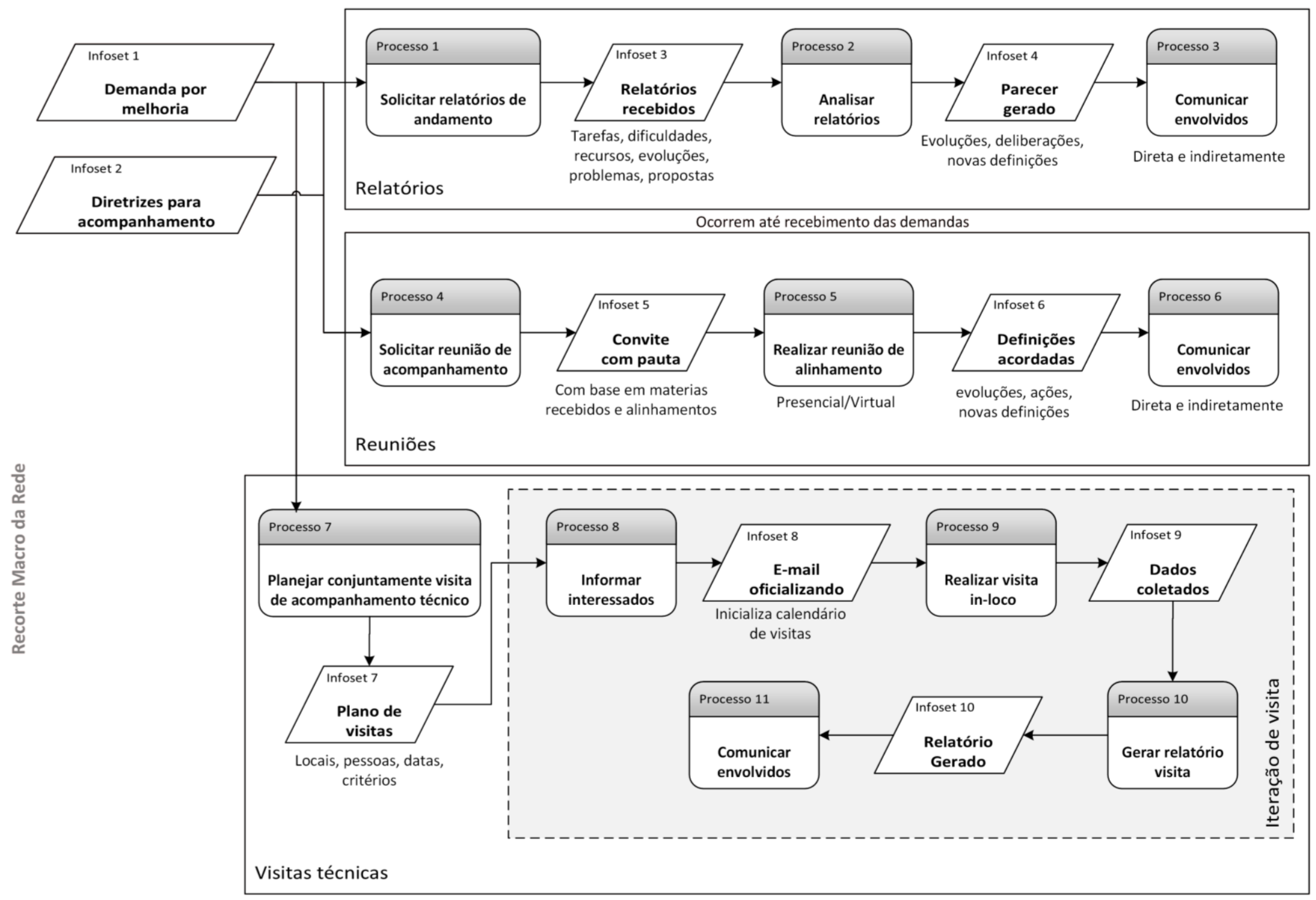

Figura 29 - Modelo de processos: acompanhar resultados e comunicar interessados - asis (parte 1/2) 
Conforme a Figura 30 (página 246), o ponto de partida também é a demanda por melhoria (Infoset 1) que dispara duas formas de acompanhamento dos resultados do projeto no Centro de pesquisas com etapas de comunicação - registro diário e reuniões.

A primeira parte de uma solicitação para preenchimento dos mesmos (Processo 12), enviada por e-mail à equipe do projeto (Infoset 2). Tal solicitação dispara, diariamente, de cada ator da equipe: a busca por sua respectiva planilha (Processo 12.1) no repositório (Infoset 4); atualização da mesma com evoluções pertinentes da demanda (Processo 12.2) e; disponibilização para a gerência (Infoset 5). As planilhas são acessadas para verificação do gerente (Processo 13) e pareceres são fornecidos (Infoset 3). Esses registros podem ser utilizados em reuniões gerais de acompanhamento da gerência.

A segunda parte de uma solicitação da gerência por reunião (Processo 15), através de um convite com a pauta (Infoset 6). A reunião é realizada presencialmente, gerando uma lista de definições acordadas para a demanda (Infoset 6) que, geralmente, é enviada por e-mail à equipe (Infoset 7) e podem ser informadas aos demais interessados (Processo 17) 
Modelo de Processos: Processo para acompanhar resultados e comunicar interessados - Parte 2/2

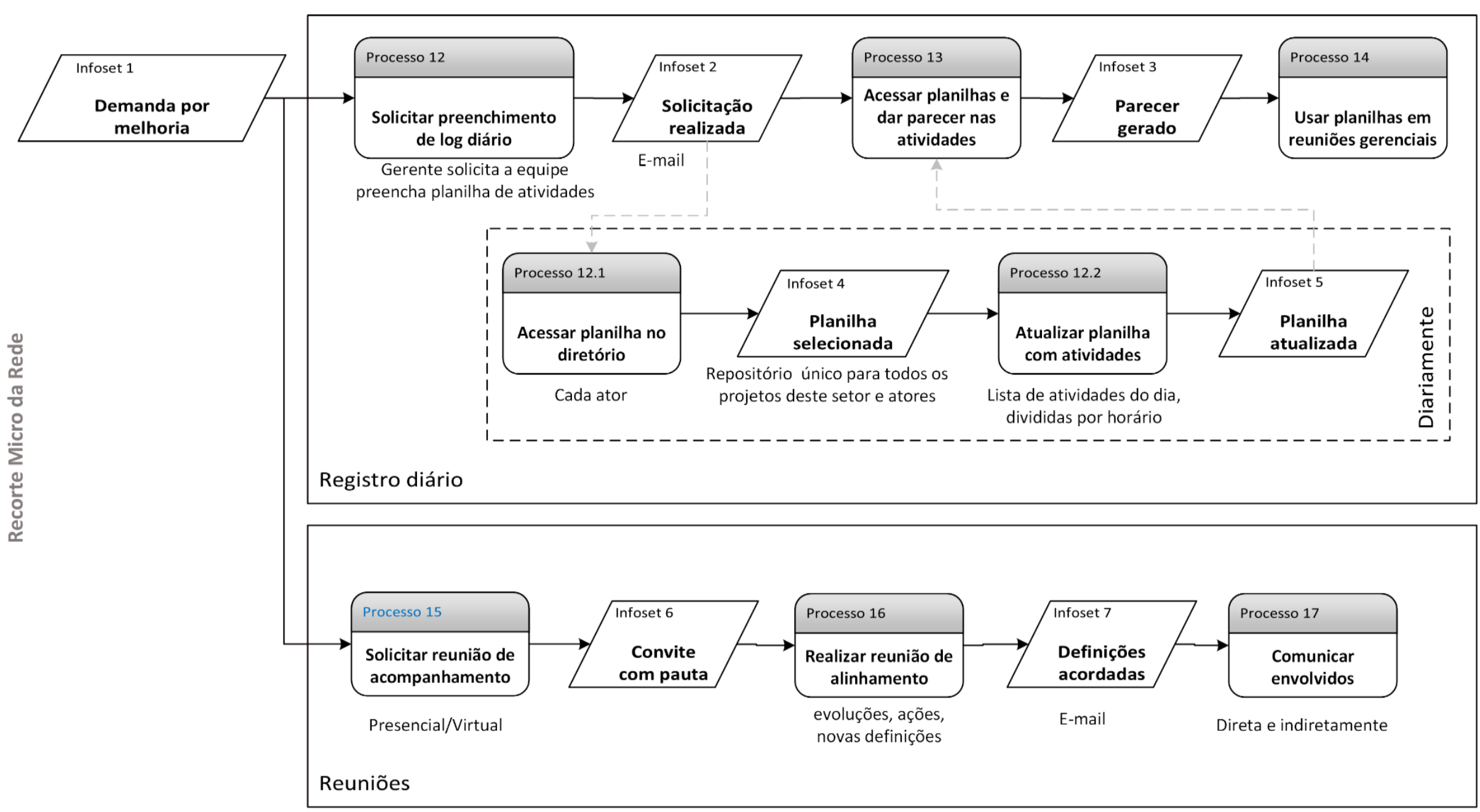

Figura 30 - Modelo de processos: acompanhar resultados e comunicar interessados - asis (parte 2/2) 


\subsection{Processo para entregar resultados e comunicar interessados}

Conforme a Figura 31 (página 248), para a demanda existente (Infoset 1), junto com as diretrizes de acompanhamento a serem seguidas (Infoset 2), é preciso definir a melhor forma de recebimento dos resultados (Processo 1), por exemplo, relatórios, ambientes de sistema, entre outros (Infoset 2). Com tal definição inicia-se o processo de acompanhamento da evolução da demanda (Processo 2), resultando em materiais de acompanhamento (Infoset 4), até que a demanda seja finalizada e recebida (Processo 3).

Com o novo artefato (Infoset 5), a Agência Reguladora confirma seu recebimento (Processo 4), através de um aceite formal (Infoset 6) e, se for aplicável, inicia as definições para oficialização do artefato (Processo 5), criando um material para divulgação (Infoset 7) que será utilizado para comunicar aos interessados (Processo 6).

Com o comunicado realizado (Infoset 8), é disponibilizado apoio técnico do Centro de pesquisas aos resposnáveis por colocar o artefato em operação ${ }^{49}$ (Processo 7), através de canais oficiais (Infoset 9). Por esses canais, são recebidas solicitações relativas ao artefato (Processo 8) que são compiladas em uma lista (Infoset 10) para análise de viabilidade (Processo 9). Essa análise pode gerar documentos oficiais de alterações e esclarecimentos (Infoset 11) que são divulgados (Processo 10) em canais oficiais (Infoset 12).

O ciclo ocorre até a estabilização e início da operação do piloto pelos envolvidos; geralmente, o apoio técnico é permanente. Se desejar, a Agência Reguladora atualiza seu portifólio com os resultados alcançados, visando eventos do segmento de gestão de transportes e pedagiamento (Processo 11).

\footnotetext{
${ }^{49}$ Por exemplo Concessionárias de rodovias e Operadoras de serviços.
} 
Modelo de Processos: Processo para entregar resultados e comunicar interessados

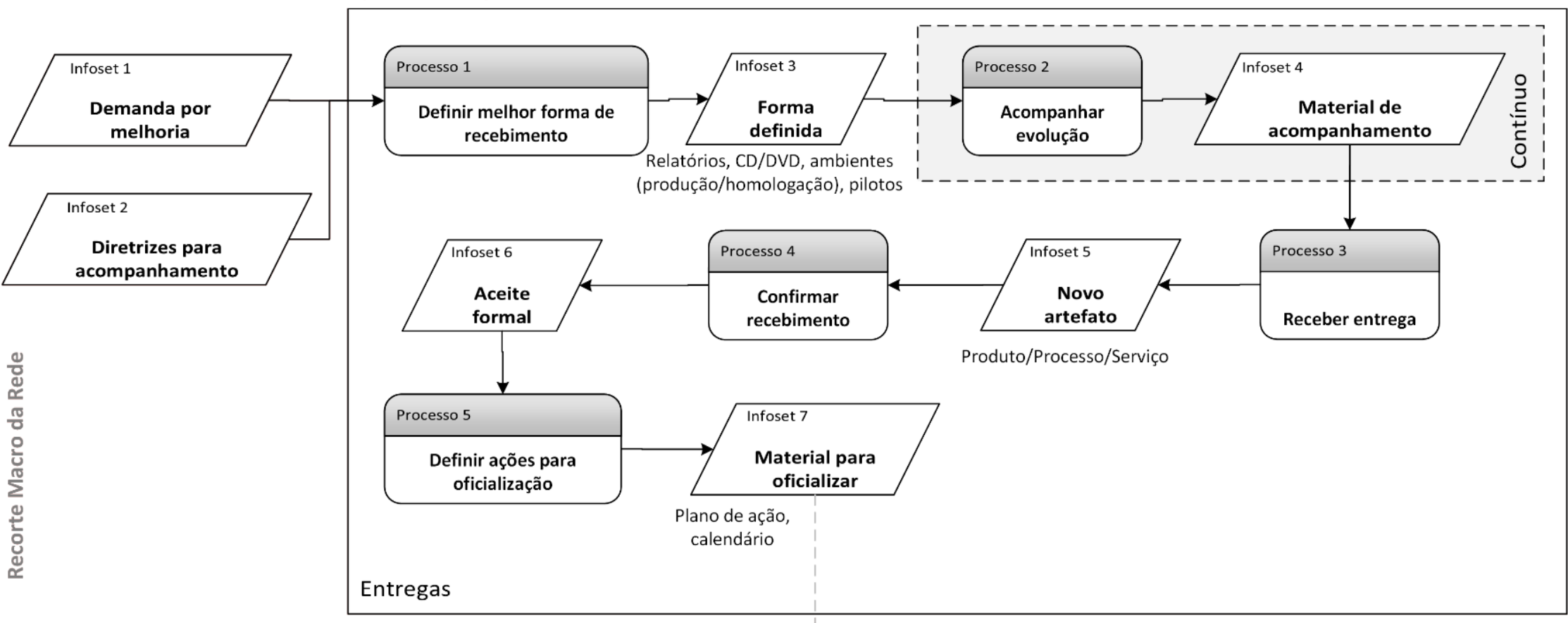

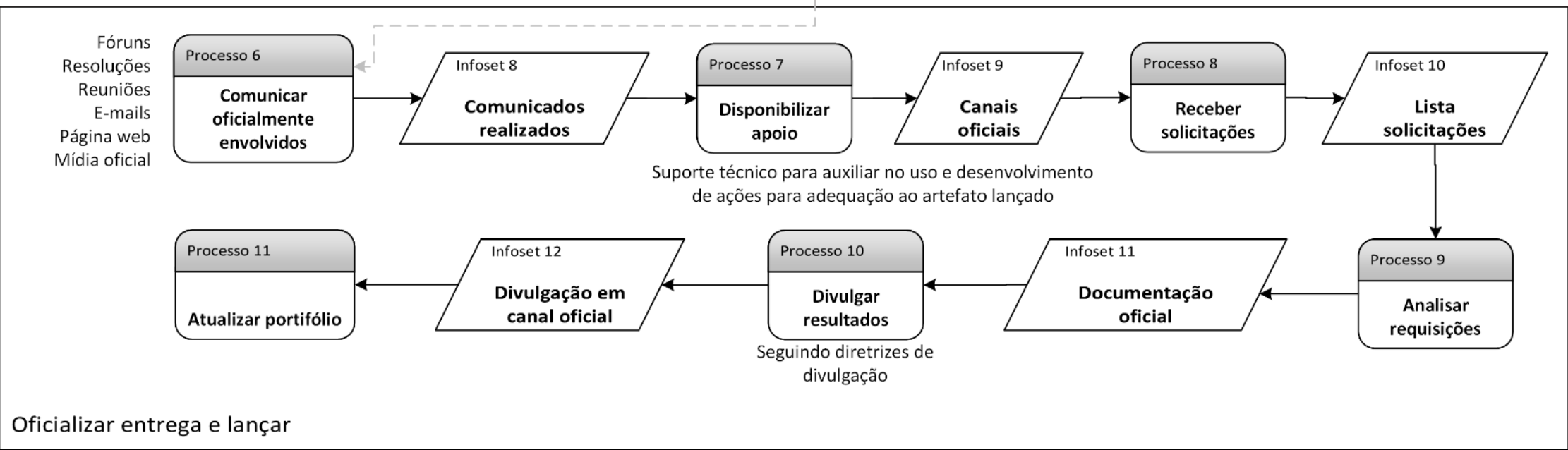

Figura 31 - Modelo de processos: entregar resultados e comunicar interessados - asis 


\subsection{Processo para transferência do conhecimento mensal}

Concorme a Figura 32 (página 250), partindo da lista de artefatos gerados no mês (Infoset 1), o gerente solicita à equipe do projeto o material comprobatório das atividades realizadas (Processo 1), por e-mail, comunicador instantâneo e pessoalmente (Infoset 2). A equipe é alocada para encontrar as evidências e organizá-las para entrega (Processos 2 e 3), gerando uma lista de evidências (Infoset 3) em e-mails, pendrive e outras mídias.

Com esse material o gerente redige o relatório mensal de acompanhamento (Processo 4), em repositório privado (Infoset 4), geralmente, sem auxilio de outros atores envolvidos. Afo finalizar disponibiliza-o para entrega à Agência Reguladora (Processo 5). Salienta-se que o setor Administrativo/Financeiro é encarregado do envio formal. 


\section{Modelo de Processos: Processo para transferência de conhecimento mensal}

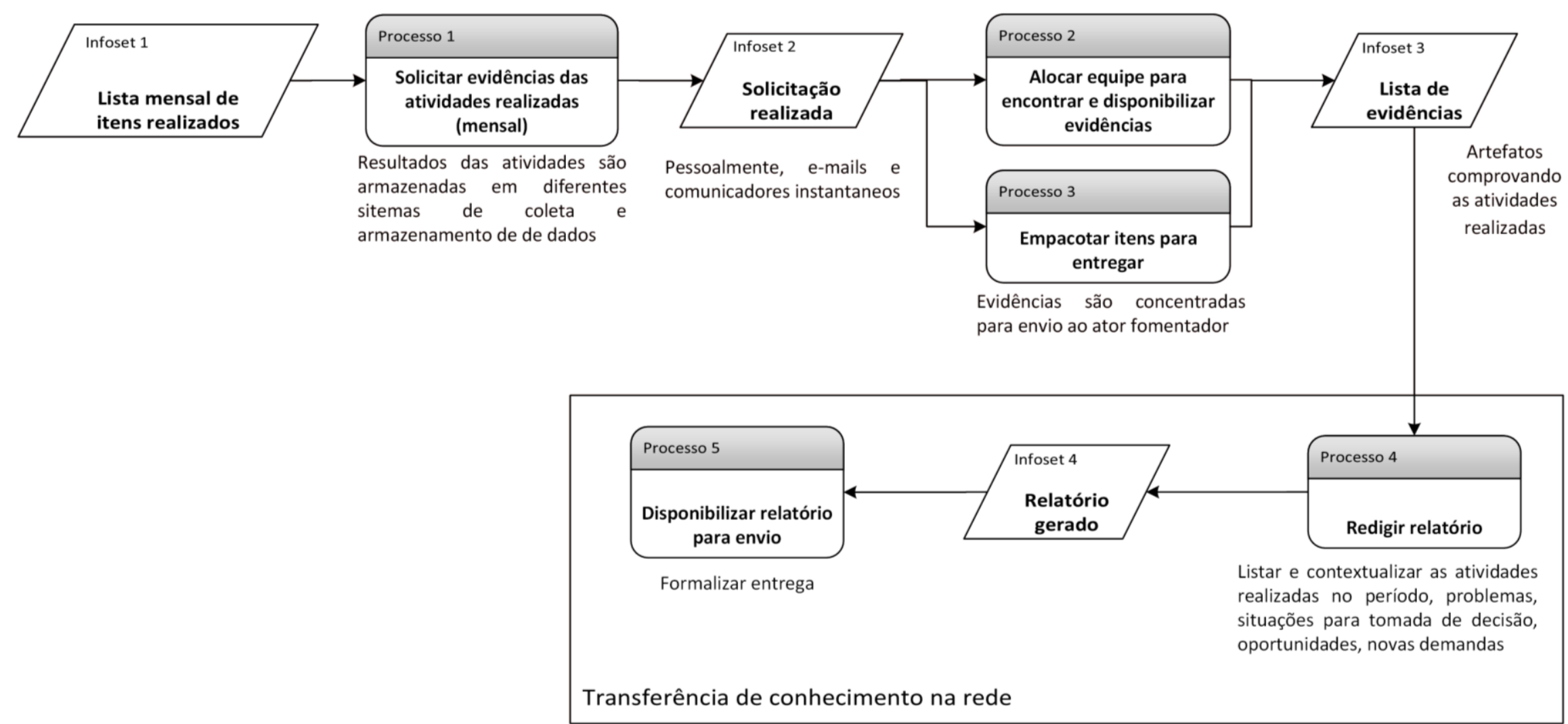

Figura 32 - Modelo de processos: transferência de conhecimento mensal - asis 


\subsection{Processo para estimular inovação na rede}

Conforme a Figura 33 (página 252), a lista de melhorias, bem como novos artefatos, gerados ao longo do ano (Infoset 1) disparam um processo de premiação (Processo 1) dos melhores parceiros da rede, envolvendo o convite aos demais atores estratégicos para o planejamento (Infoset 2).

As ações para planejamento envolvem: definir prazos, locais, meio de comunicação e o tipo de prêmio (Processo 2), gerando um plano de premiação (Infoset 3) e; levantar dados e critérios para premiar (Processos 3 e 4), gerando demanda para o Centro de pesquisas (Infoset 9) que a recebe e trata (Processo 9), liberando dados e critérios com base nas análises de desempenho e outras ações realizadas ao longo do ano (Infosets 4 e 5).

Com essas informações os dados são analisados (Processo 5), resultando em uma classificação das concessionárias (Infoset 6) que é refinada em alinhamentos (Processo 6) com a equipe participante, até a definição da lista final (Infoset 7). Com o resultado inicia-se a promoção do evento (Processo 7) com divulgação (Infoset 8) nos meios de comunicação adequados, seguido de sua realização (Processo 7).

Após o evento (Infoset 10), se desejar, a Agência Reguladora pode divulgar informações da premiação a outros interessados no segmento (Processo 10), mediante a atualização de um plano de marketing (Infoset 11) para expor os resultados alcançados. 
Modelo de Processos: Processo para estimular inovação na rede

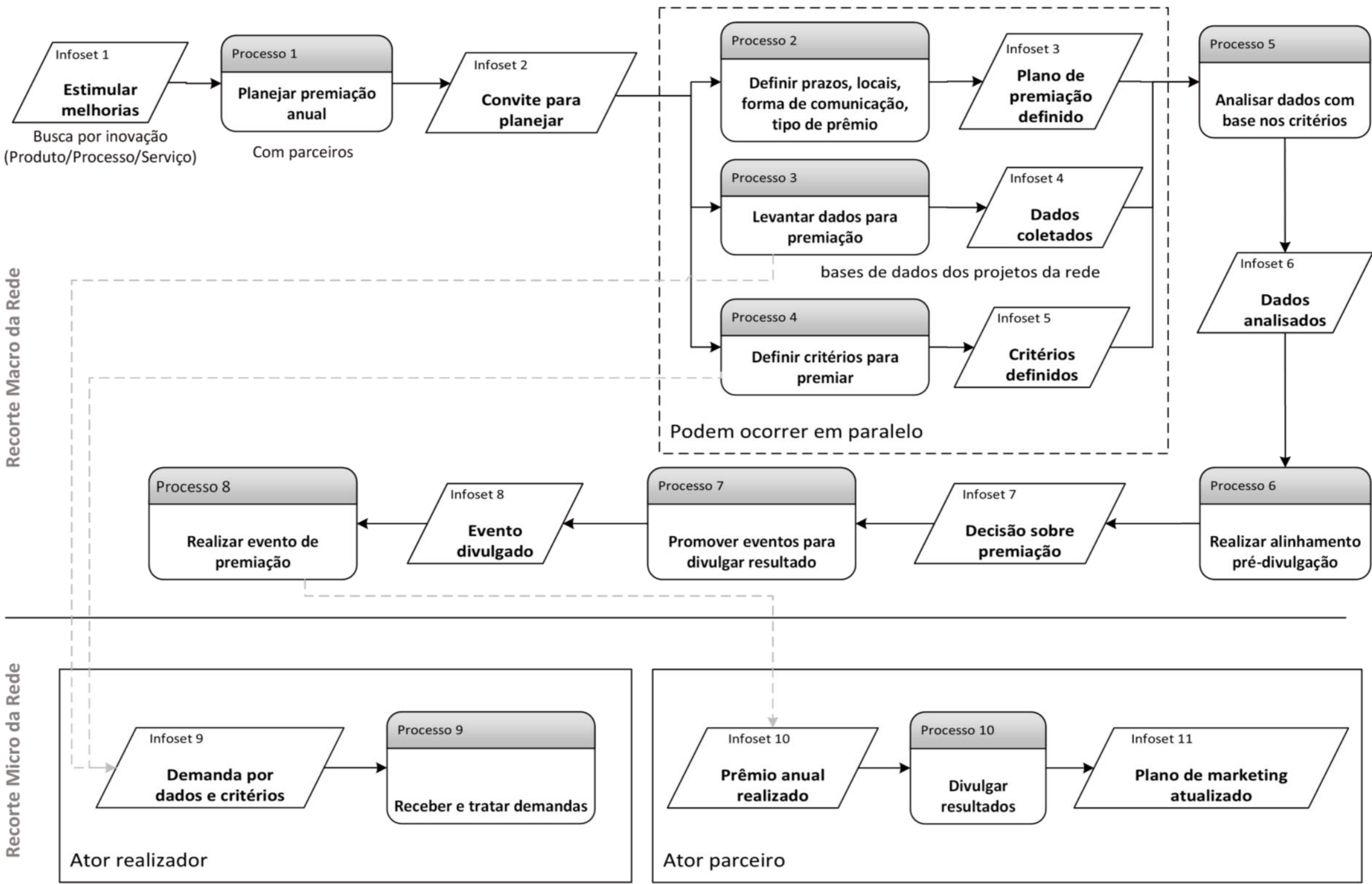

Figura 33 - Modelo de processos: estimular inovação na rede - asis 


\subsection{Processo para disseminar melhores práticas no segmento}

Conforme a Figura 34 (página 254), a visão de ser referência no segmento (Infoset 1) dispara o processo para a Agência Reguladora, entre outros atores, promover e/ou participar de ações com foco em inovação tecnológica (Processo 1) - congressos, workshops, estudos listando resultados sólidos que foram alcançados (Infoset 2).

Com a lista de resultados a divulgação é planejada (Processo 2), através de um plano de marketing atualizado (Infoset 3) e um material de divulgação (Processo 3) atualizado para a situação (Infoset 4). Com esse material, interessados são informados (Processo 4), em publicações e meios que destaquem os resultados alcançados na rede (Infoset 5) e cases são divuldados (Processo 5) em congressos e demais eventos da área (Infoset 6).

Dependendo do tipo de ação que será realizada para promoção, novas demandas podem ser direcionadas ao Centro de pesquisas (Infoset 7): para realização, através de seu processo de recebimento e tratamento de demandas (Processo 6) que resulta no artefato solicitado (Infoset 8) e/ou; para gestão, através de seu processo de acompanhamento (Processo 7) que resulta em relatórios. 
Modelo de Processos: Processo para disseminar melhores práticas no segmento

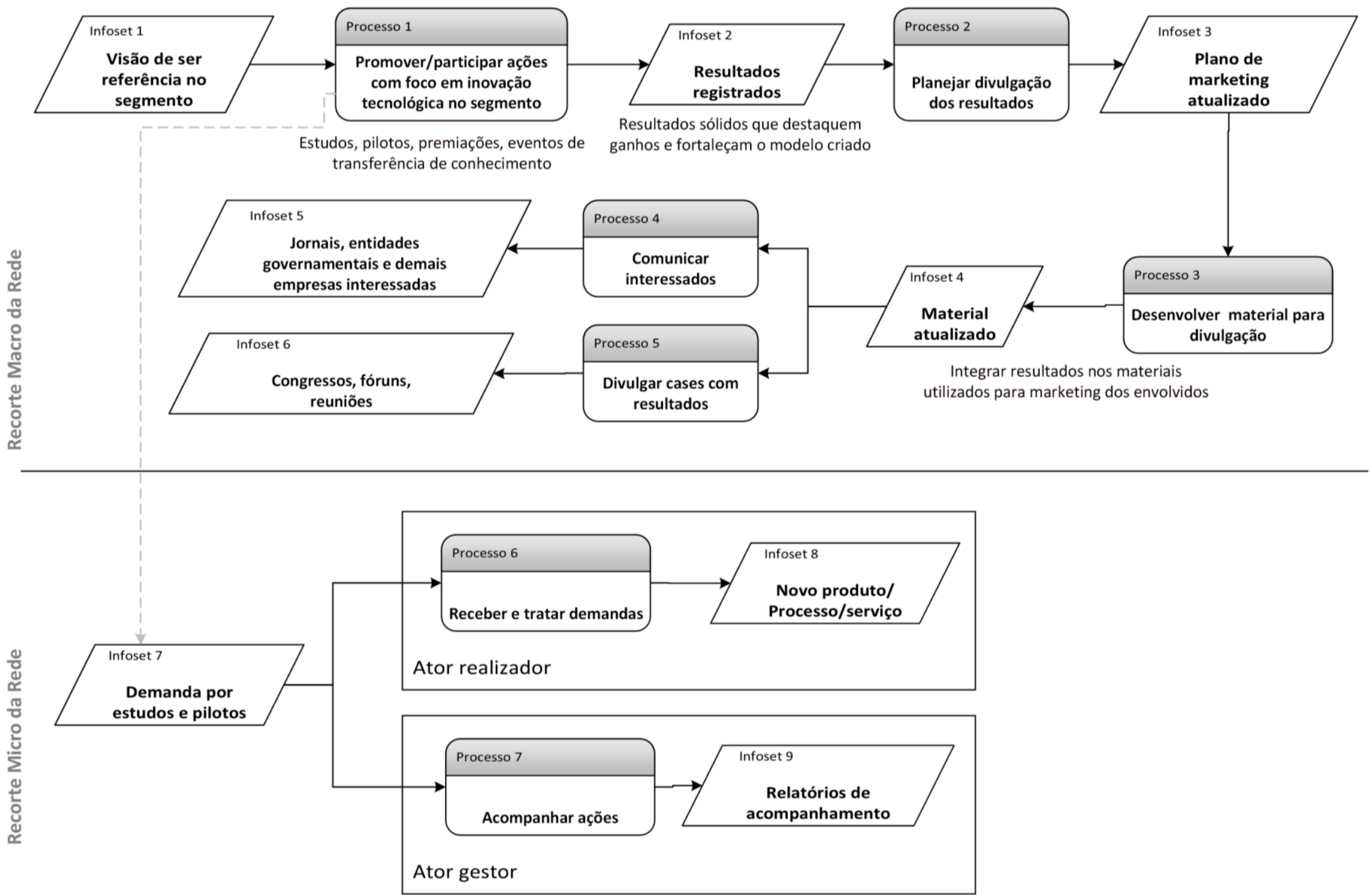

Figura 34 - Modelo de processos: disseminar melhores práticas no segmento - asis 


\subsection{Processo para gestão de parcerias e recursos humanos}

Conforme a Figura 35 (página 256), existem três formas de inserção de novos atores na rede - como Concessionária de rodovias ou Operadora de serviços; como Prestadora de Serviços e; como Parceiro tecnológico.

De acordo com a demanda necessária (Infosets 1, 4 e 7) são recebidas propostas de empresas interessadas para análise (Processos 1, 3 e 5), resultando em pareceres (Infoset 2, 5 e 8) que se positivos incidem em novas concessões e contratos (Processos 2, 4 e 6), formalizando a entrada de novos atores na rede (Infoset 3, 6 e 9). Esses atores possuem atividades, bem como solicitações que devem ser acompanhadas (Processo 7), através de diferentes artefatos (Infoset 10) que são utilizados para avaliar a permanência desses atores na rede (Processo 8).

A diferença dos subprocessos reside nos tipos de critérios utilizados para formar as parcerias, bem como nos tipos de contratos de oficialização que influenciam a gestão desses atores. Em especial no caso das parcerias tecnológicas ${ }^{50}$, as capacidades do possível parceiro são cruciais para a escolha - participação em outros projetos do segmento e desenvolvimento de técnologias inovadoras.

${ }^{50} \mathrm{O}$ Centro de pesquisas tem uma relação de parceria tecnológica com a Agência de Regulação de transportes. 


\section{Modelo de Processos: Processo para gestão parcerias e recursos humanos (atores) - Parte 1/2}

$\begin{gathered}\text { Demanda por } \\ \text { concessão }\end{gathered}$
$\begin{gathered}\text { Operação e manutenção dos } \\ \text { ambientes e auxiliar na } \\ \text { identificação de inovações }\end{gathered}$

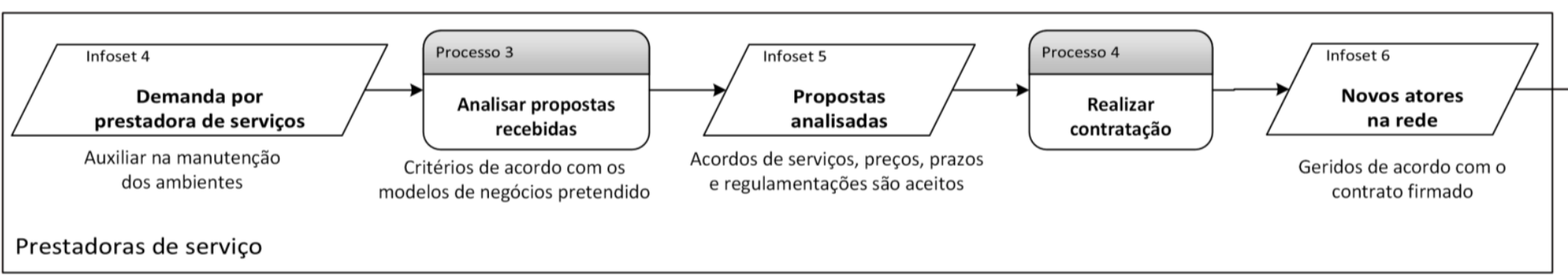

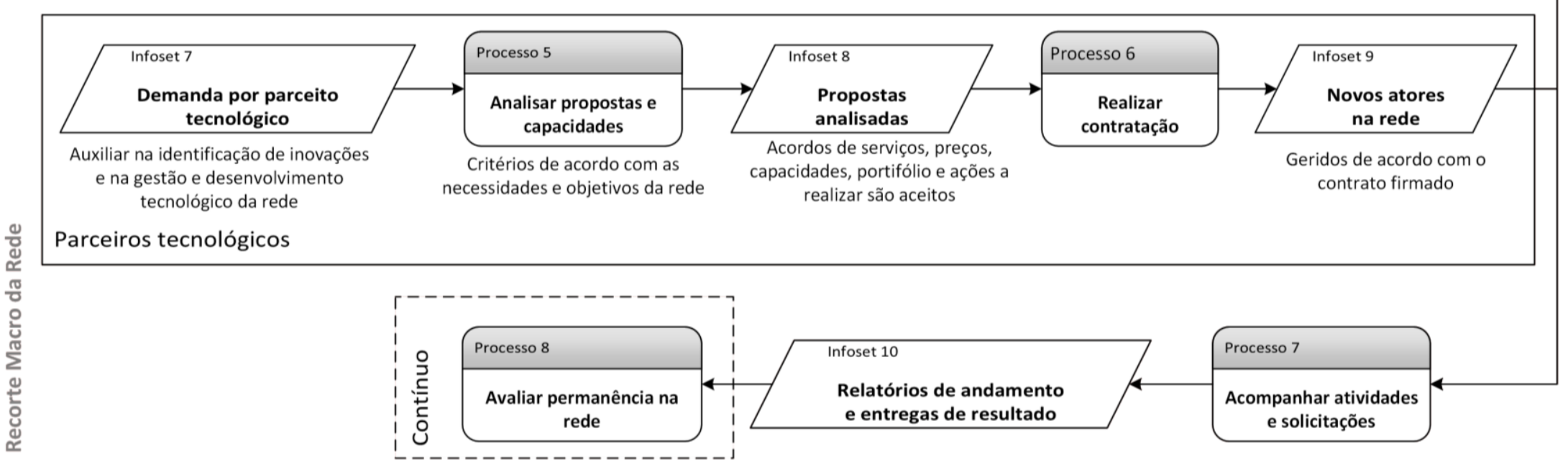

Figura 35 - Modelo de processos: gestão de parcerias e RH - ais (parte 1/2) 
No caso de recursos humanos, conforme a Figura 36 (página 258), a inserção de RH nos subprojetos da unidade de análise, inicia-se com demandas que necessitam de alocação (Infoset 1). O gerente analisa tal necessidade (Processo 1), confirmando-a (Infoset 2), antes de verificar a atual alocação da equipe (Processo 2) e listar as pessoas disponíveis (Infoset 3).

As pessoas da lista são informadas sobre a alocação (Processo 3), através do meio de comunicação viável (Infoset 4) e convocadas para um breve alinhamento das atividades (Processo 4) para transferência de conhecimento mínima (Infoset 5). A inserção do ator na equipe e seus resultados são acompanhados (Processo 5). 
Modelo de Processos: Processo para gestão de parcerias e recursos humanos (atores) - Parte 2/2

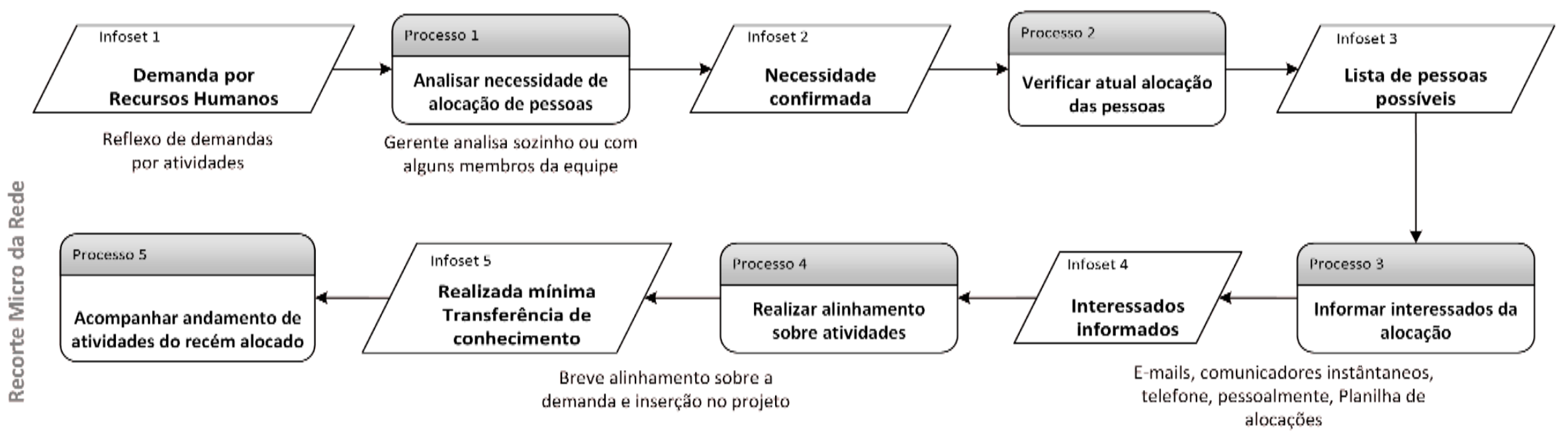

Figura 36 - Modelo de processos: gestão de parcerias e RH - asis (parte 2/2) 


\subsection{Processo de acompanhamento e liberação de recursos}

Conforme a Figura 37 (página 260), a junção das demandas por melhoria com as diretrizes de acompanhamento aplicadas na rede (Infosets 1 e 2), pode gerar demandas por recursos técnicos e financeiros que são recebidas pela Agência Reguladora e/ou Concessionária de rodovias (Processo 1), documentadas (Infoset 3) e analisadas (Processo 2). Com o restultado, os interessados são comunicados (Processo 3), a liberação autorizada (Infoset 5) e o responsável por efetivar a liberar do recurso acionado (Processos 4 e 5).

No recorte micro, as demandas por melhorias (Infoset 2), são recebidas (Processo 6) e/ou acompanhadas (Processo 7) e seu tratamento pode requisitar recursos (Infoset 6) que são solicitados aos interessados (Processo 8) formalmente (Infoset 7). Enquanto a liberação do recurso - ou negativa - não ocorre, é feito o acompanhamento da requisição (Processo 9) e quando liberado (Infoset 8) o processo de tratamento é retomado (Processo 10) até a entrega do resultado (Infoset 9). 


\section{Modelo de Processos: Processo para acompanhamento e liberação de recursos}

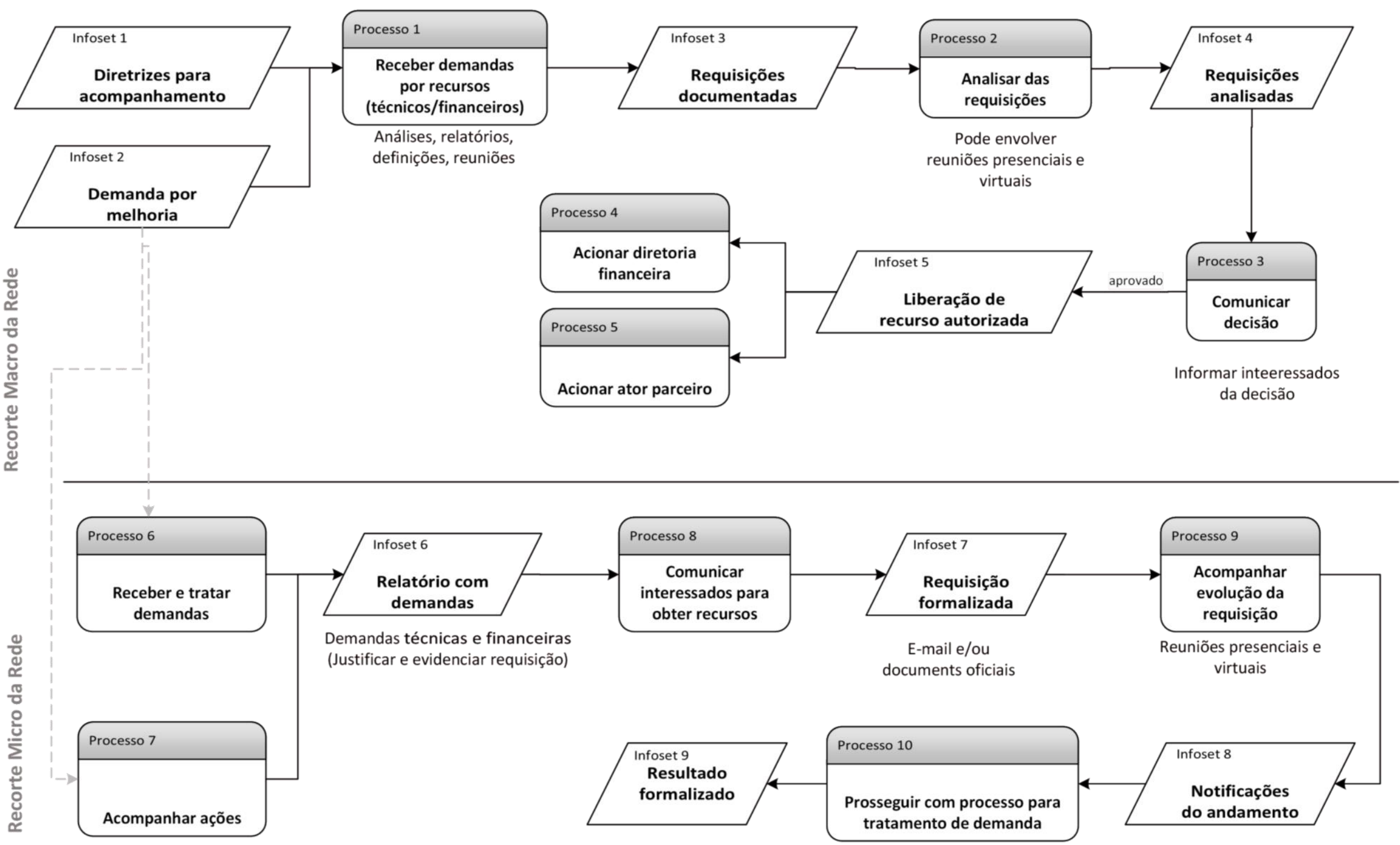

Figura 37 - Modelo de processos: acompanhamento e liberação de recursos - asis 


\section{Modelo de processo To-Be}

O modelo de onze processos citados de forma resumida na seção 4.1 .4 deste material é detalhados como segue:

\subsection{Processo para transição no modelo de gestão}

Conforme a Figura 38 (página 263), uma lista de motivadores identificados na pesquisaação (Infoset 1) motiva o planejamento da transição do modelo de gestão (Proceso 1), iniciandoa com a identificação dos principais desafios (Processo 1.1) que resulta nos desafios mapeados (Infoset 2) que disparam a identificação dos principais objetivos da mudança (Processo 1.2) que também são mapeados (Infoset 3). Esses objetivos são utilizados para mobilizar a equipe adequada para participar das ações de transição (Processo 1.3) que, uma vez identificada (infoset 4), auxilia no mapeamento das adaptações, bem como desenho de novos processos necessários para a mudança (Processo 1.4), resultando em um conjunto de processos que serão diretrizes do novo modelo de gestão (Infoset 5). Com os novos processos as ações necessárias para implementá-los são listadas (Processo 1.5) e documentadas (Infoset 6) para rodadas de validação junto à equipe (Processo 1.6). até que um novo modelo adequado à situação seja eleito (Infoset 7) e colocado em operação, envolvendo ações de acompanhamento e controle (Processo 1.7) para gerar evidências das ações (Infoset 8) e permitir ajustes. Treinamentos acerca das diretrizes do novo modelo - valores, príncipios e práticas - são realizados (Processo 1.8) para que a equipe esteja devidamente treinada.

A identificação dos principais objetivos da mudança (Processo 1.2) envolve o fortalecimento do conceito de visão, através: da identificação dos objetivos da rede e de seus subprojetos (Processo 1.2.1), dos atores, perfis e responsabilidades (Processo 1.2.2), da promoção desse conceito de visão entre os atores (Processo 1.2.3) e ainda, da definição do tipo de combinações de abordagem que são necessárias e válidas (Processo 1.2.4) para criar um modelo híbrido de gestão.

O mapeamento das adaptações necessárias e dos novos processos (Processo 1.4) envolve ações em prol de comunicação e gestão do conhecimento, através: da promoção de reuniões de planejamento, alinhamento, acompanhamento, retrospecção da iteração e revisão de entregas (Processos 1.4.1, 1.4.2, 1.4.3, 1.4.4, 1.4.5), bem como a intensificação do uso de comunicadores devidamente organizados para os subprojetos (Processo 1.4.6), conforme as práticas da gestão ágil. Ações relacionadas à liderança também são necessárias, por meio: da promoção do uso de ferramentas visuais e simples (Processo 1.4.7) como o quadro de tarefas, 
também organizadas por subprojetos; o fortalecimento do conceito de planejamento e trabalho por ciclos iterativos (Processo 1.4.8) e; promoção da auto-organização e autogestão na equipe (Processo 1.4.9).

Por fim, a organização e treinamento das equipes dos subprojetos (Processo 1.8) traduzse em ações para formar uma equipe ágil: treinar equipe com as novas diretrizes do modelo, em especial, acerca das iterações (Processo 1.8.1), expor os processos e ferramentas que serão utilizados (Processo 1.8.2), alertando para a adaptabilidade do modelo e promover a utilização de histórias, isto é, cartões de detalhamento de funcionalidade para documentar as ações da iteração (Processo 1.8.3). 
Modelo de Processos: Processo para transição no modelo de gestão
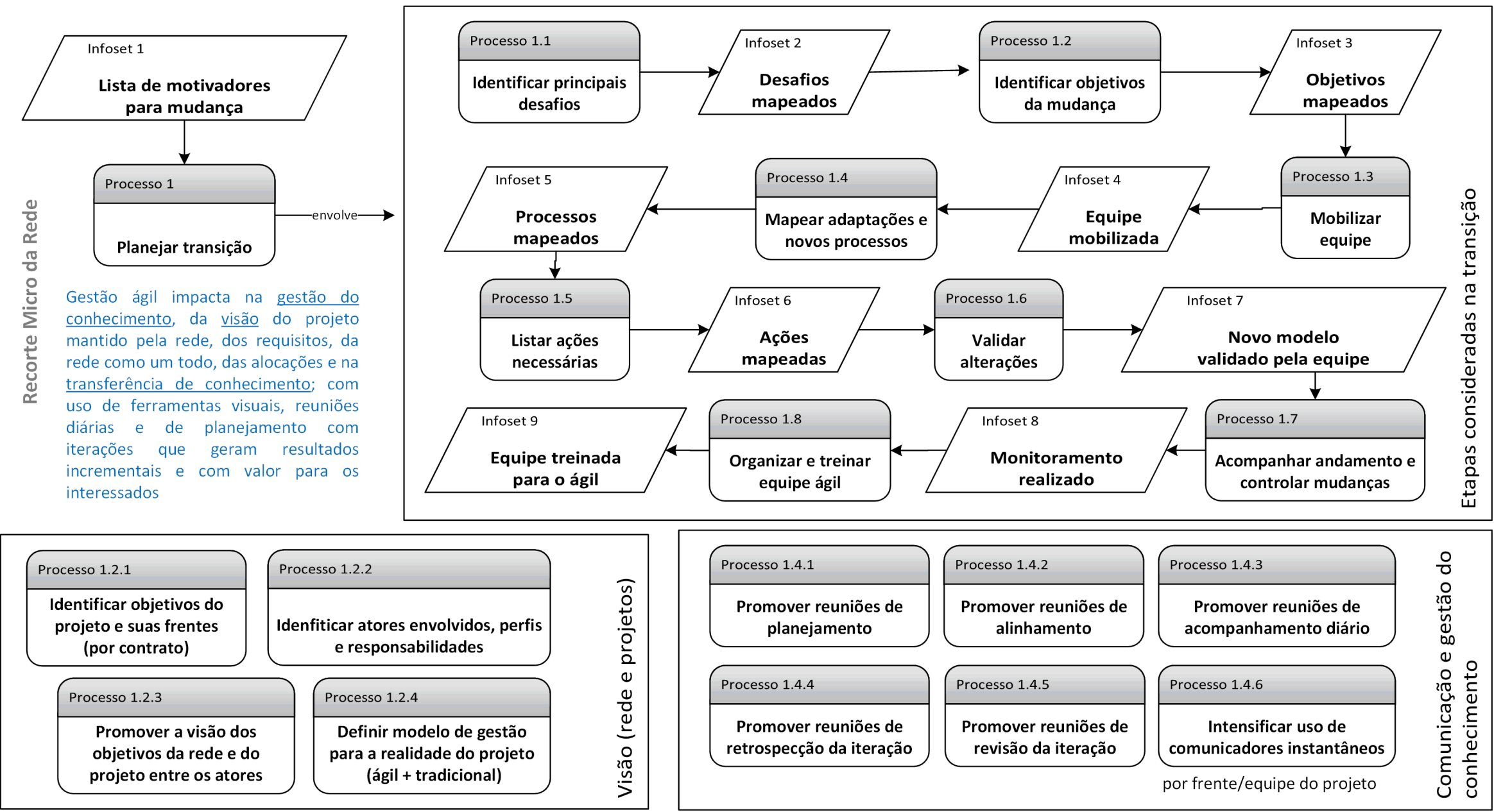

\begin{tabular}{|c|c|c|}
\hline Processo 1.8.1 & Processo 1.8 .2 & Processo 1.8.3 \\
\hline $\begin{array}{l}\text { Treinar equipe com o } \\
\text { modelopropostp e com o plano } \\
\text { de entregas (semanal e mensal) }\end{array}$ & $\begin{array}{l}\text { Expor os procedimentos } \\
\text { utilizados no ágil e ITIL e } \\
\text { o modelo adaptável }\end{array}$ & $\begin{array}{l}\text { Promover utilização de } \\
\text { histórias funcionais e } \\
\text { tarefas por iteração }\end{array}$ \\
\hline
\end{tabular}

\begin{tabular}{|c||c|c|}
\hline Processo 1.4.7 & Processo 1.4.8 & Processo 1.4.9 \\
\hline $\begin{array}{c}\text { Promover o uso das ferramentas } \\
\text { visuais selecionadas (repositórios, } \\
\text { quadros de tarefa) }\end{array}$ & $\begin{array}{c}\text { Fortalecer o conceito } \\
\text { de trabalho por } \\
\text { iterações }\end{array}$ & $\begin{array}{c}\text { Promover } \\
\text { auto-organização e } \\
\text { autogestão }\end{array}$ \\
\hline
\end{tabular}

Figura 38 - Modelo de processos: transição no modelo de gestão - tobe 


\subsection{Processo para gerar demanda}

Conforme a Figura 39 (página 265), esse modelo não sofreu alterações diretas no recorte macro, mas foi influenciado pelos resultados das mudanças no recorte micro (Processos 8 e 9), entre elas a agilidade no recebimento de informações que permitam a realização de ações de acompanhamento (Infoset 1), agregando celeridade aos processos utilizados para tal (Processos 1, 2 e 3), bem como na geração de listas de possíveis demandas (Infoset 2). A convocação de interessados para alinhamentos (Processo 4), quando repassada para o Centro de Pesquisas, recai nos fluxos utilizados com a gestão ágil, aumentando a gestão do conhecimento envolvido, por meio das iterações com entregas de resultados e comunicação constante. Similarmente, o processo de acompanhamento dos resultados (Processo 7) é influenciado pela transição do modelo, uma vez que resultados são entregues, por meio dos ciclos iterativos, isto é, semanalmente e consolidados mensalmente, com a devida formalização existente no contrato. 
Modelo de Processos: Processo para gerar demandas - Parte 1/2

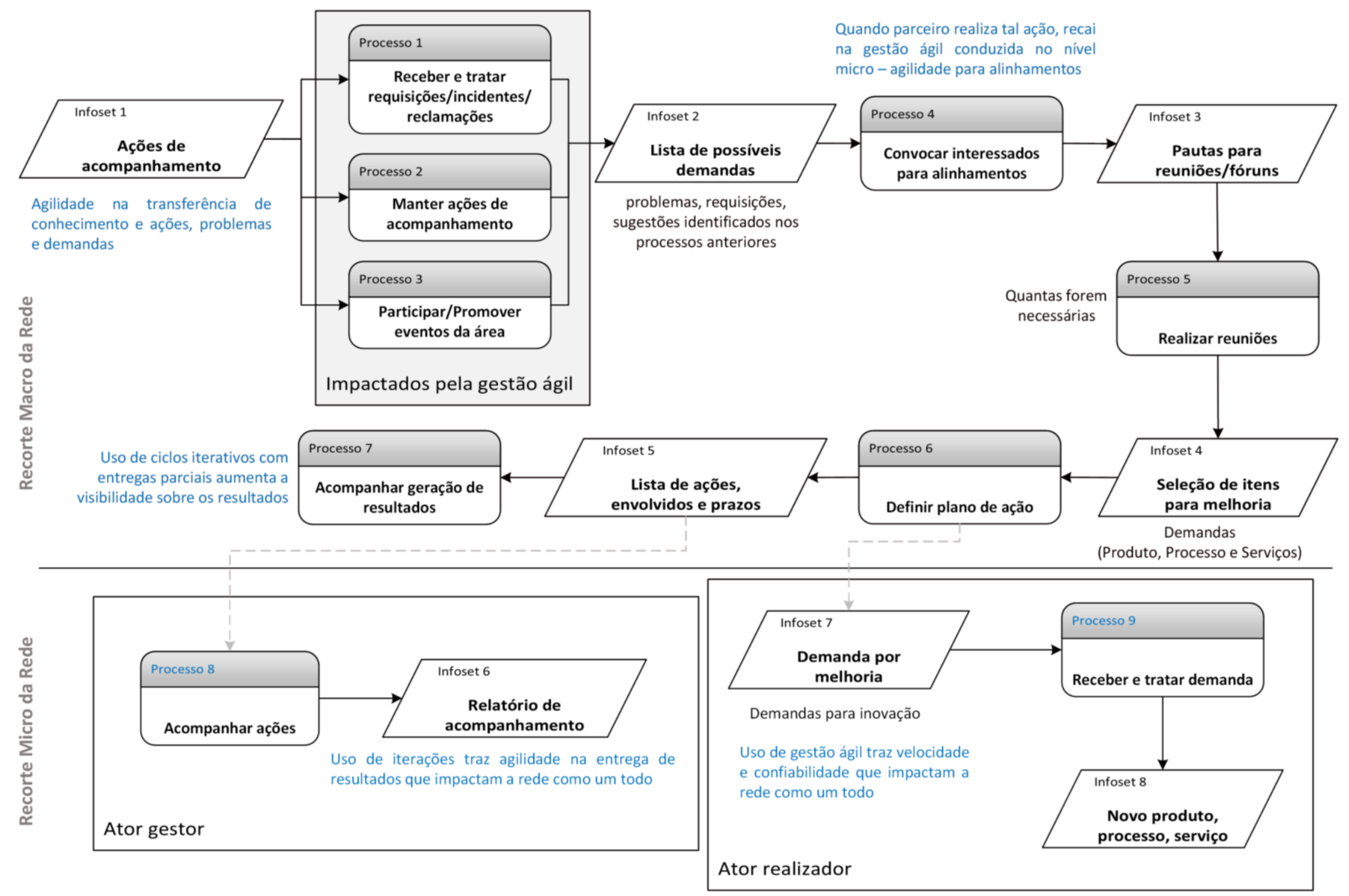

Figura 39 - Modelo de processos: gerar demandas - tobe (parte 1/2) 
Conforme a Figura 40 (página 267), o processo de acompanhamento no Centro de pesquisas (Processo 1) é alterado para contemplar o uso de ciclos de iteração, ferramentas visuais de acompanhamento, ferramentas para comunicação, controle de tarefas e gestão do conhecimento, recaindo na alteração da forma de trabalho da equipe (Processos 2 a 7) que por sua vez, otimiza a geração de evidências as ações realizadas (Infoset 3). Essas informações agregam confiabilidade e agilidade ao processo de realização de estudos para melhoria dos problemas identificados com as ações realizadas (Processo 8), bem como otimizam a gestão do conhecimento. O resultado das alterações influencia na comunicação com a Agência reguladora (Processo 9), conforme citado previamente, ampliando a interação com a mesma e entregando resultados mais frequentes, inclusive por meio de relatórios mais bem estruturados e com participação de toda equipe envolvida. (Infoset 5). 
Modelo de Processos:

Processo para gerar demandas - Parte 2/2

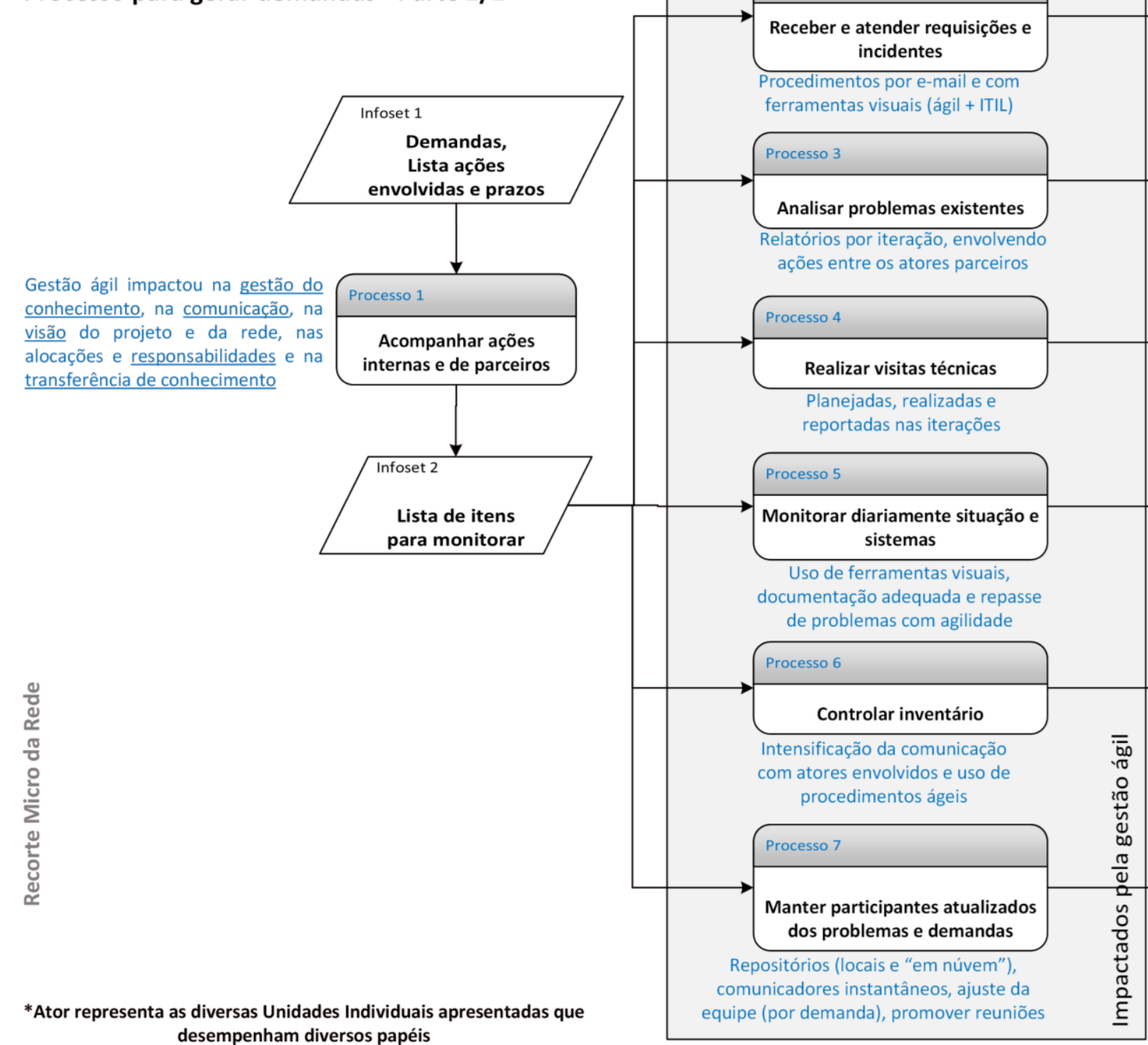

Gestão adequada do conhecimento (Uso

de repositórios locais e “em núvem”)

realização de entregas parciais

Infoset 3
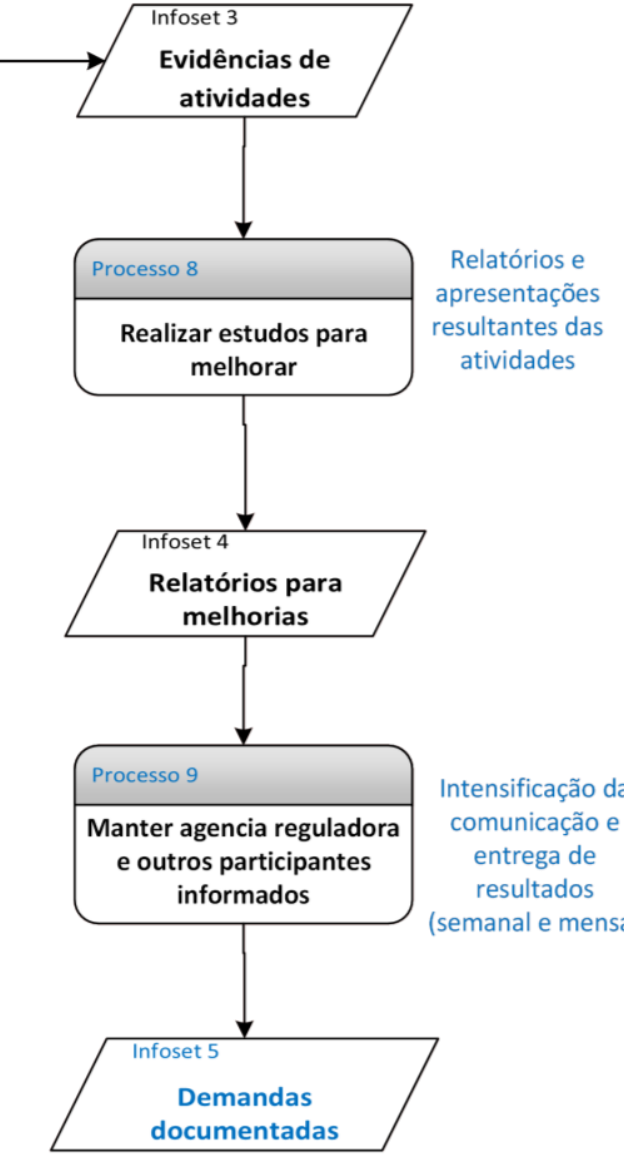

(Na Lista de demandas ou Quadros de tarefas do projeto ) Uso de iterações tra taridas do projeto ) Uso de iteracos traz que impactam a rede como um todo

Figura 40 - Modelo de processos: gerar demandas - tobe (parte 2/2) 


\subsection{Processo para receber e tratar demandas}

Conforme a Figura 41 (página 269), o recebimento de demandas requer que a mesma seja informada à toda a equipe (Processo 2), bem como que sejam inseridas na ferramenta de controle de requisições do subprojeto adequado (Processo 1) para documentação (Infoset 2), seguida de análise da prioridade da mesma, frente a iteração em andamento (Processo 3). Com a prioridade analisada (Infoset 4), dependendo do resultado, é realizada a inserção da demanda na iteração em andamento (Processo 4), através do quadro de tarefas (Infoset 5) ou seleção da mesma no planejamento da próxima iteração (Processo 5), selecionando-a na lista de requisições existentes (Infoset 6). Nos dois casos as atividades necessárias para entregar a demanda são planejadas (Processo 6) em uma reunião de planejamento com toda equipe, gerando os cartões com detalhamento das ações no quadro de tarefas virtual (Infoset 7). Um processo de aocmpanhamento da iteração (Processo 9) foi inserido para garantir que a equipe esteja alinhada à visão da demanda em andamento. O processo de entrega foi alterado (Processo 11) para que semanalmente evoluções sejam comunicadas/entregues e mensalmente o consolidado das mesmas é formalizado no relatório exigido pelo contrato. 
Modelo de Processos: Processo para receber e tratar demandas - Parte 1/2

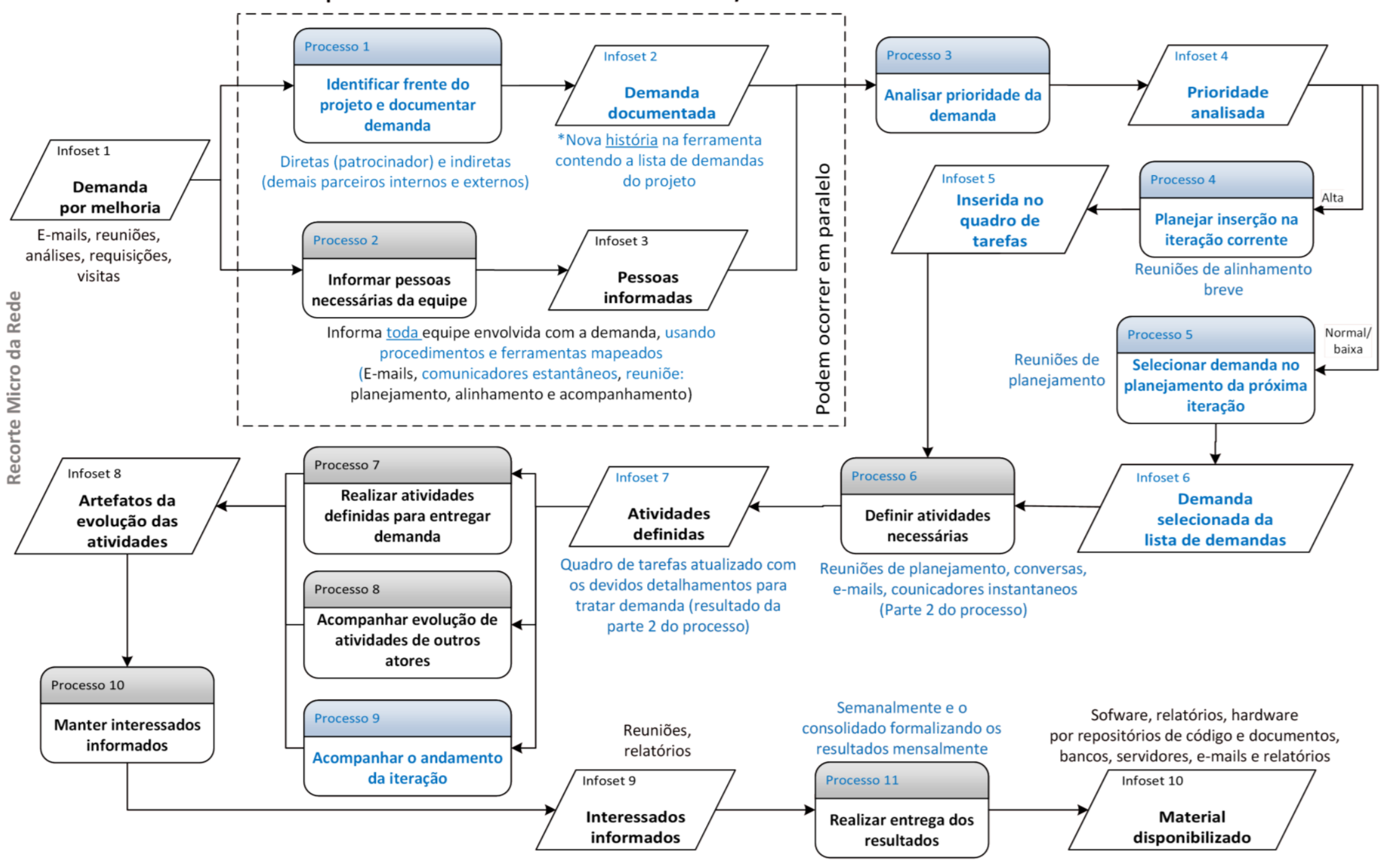

* Na gestão ágil, em especial em projetos de produto de software, o termo História é uma forma de nomear uma funcionalidade/requisito esperado, abrangendo ator interessado na mesma, ação desejada e funcionalidade que deve entregar com tal ação; geralmente é um cartão agregador de várias tarefas no quadro de tarefas da iteração

Figura 41 - Modelo de processos: receber e tratar demandas - tobe (parte 1/2) 
Conforme a Figura 42 (página 271), o planejamento da iteração para definição das atividades do período, considera as demandas documentadas nas ferramentas (Infoset 1) e planos de ação (Infoset 2) que podem ter sido inicializados no recorte macro, em termos de negócio e devem ser detalhados para entregas funcionalidades. O detalhamento é iniciado com uma retrospecção da iteração anterior (Processo 1) para que a equipe possa expor pontos de melhoria e atenção que gostaria de trabalhar com relação ao modelo de gestão (Infoset 3) e são realizadas ações para analisar a demanda, prazos, prioridades, alocação, recursos e atividades (Processos 2 a 6). Uma nova etapa foi inserida, em prol de realizar a gestão do conhecimento de forma eficiente, permitindo a equipe detalhar conjuntamente os cartões de atividades para as demandas selecionadas, usando o quadro de tarefas virtual (Processo 7) ao longo da reunião de planejamento, garantindo que as informações necessárias - funcionalidade desejada, quem precisa e os detalhes de funcionamento - não sejam perdidas ao longo da iteração (Infoset 5). 
Modelo de Processos: Processo para receber e tratar demandas - Parte 2/2

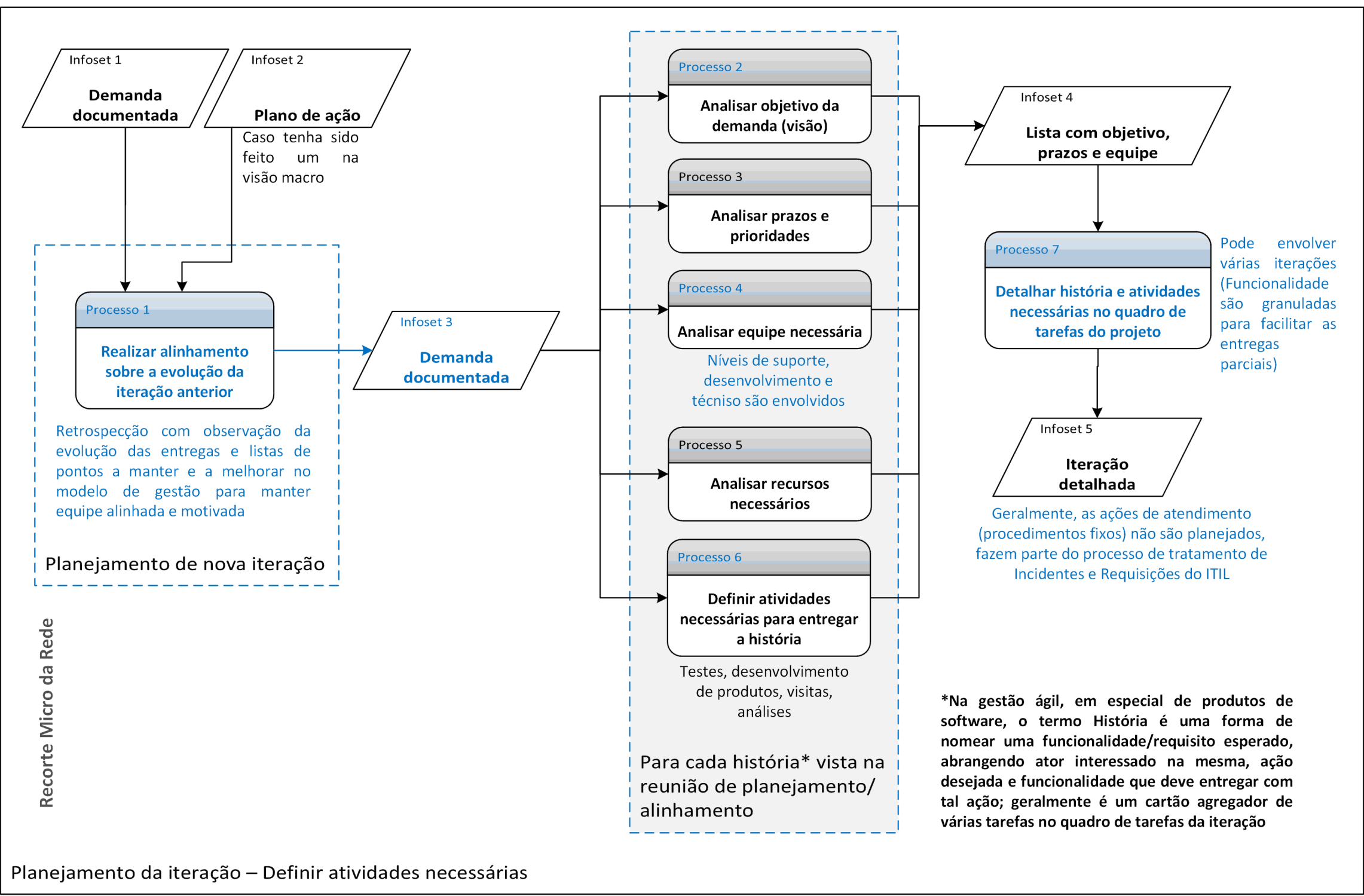

Figura 42 - Modelo de processos: receber e tratar demandas - tobe (parte 2/2) 


\subsection{Processo para tratar demandas fixas (Gestão híbrida)}

Conforme a Figura 43 (página 274), em casos de incidentes que envolvem tarefas padronizadas $^{51}$ (Infoset 1) o processo de gerenciamento de incidentes é disparado (Processo 1), envolvendo a ação do nível de suporte para documentá-lo (Infoset 2) na ferramenta de gestão de requisições, coletando informações da sua detecção e registro no canal de comunicação que o originou - comumente e-mail ou telefone utilizados por parceiros -, fornecendo o suporte inicial (Processo 1.2) com uso de roteiros e, se necessário, contactando áreas externas e internas (Processo 1.3) para encaminhar a requisição já formalizada no quadro de tarefas específico para tais demandas (Infoset 3).

O nível de desenvolvimento recebe a demanda e a trata como item na iteração corrente (Processo 6), isto é, trata a demanda como alta prioridade e documenta as ações realizadas para solucioná-la, utilizando o cartão de documentação recebido do nível de suporte, no quadro de tarefas virtual. Ambos os níveis envolvidos na demanda podem inserir e verificar informações (Infoset 3), mas o nível de suporte é responsável por retornar a demanda solucionada ao parceiro que a solicitou (Processo 1.3). O nível gerencial pode acessar as informações de incidentes tratados ao longo da semana (Infoset 5), visualizando detalhes da mesma no quadro de tarefas e reportando-os aos interessados (Processo 7).

O mesmo ocorre com demandas por configuração (infoset 1), isto é, solução de problemas relacionados à organização de ambientes, ferramentas, softwares, envolvendo ações padronizadas que disparam um processo para gestão de configuração (Processo 2), neste caso, por serem demandas com maior detalhe técnico, são diretamente associadas ao nível 2, através de registro nos quadros de tarefas dos subprojetos (Infoset 4).

A combinação de abordagens é realizada através da unificação de ferramentas utilizadas, bem como uso de diretrizes para ação - embasadas na visão de resolução de uma requisição e/ou problema de um parceiro da rede -, documentação e comunicação. Em especial, os processos de recebimento da demanda (Processo 6) e transferência do conhecimento (Processo 7) são realizados dentro da iteração semanal, isto é, registrados, solucionados e reportados dentro desse período, requerendo que as práticas da gestão ágil sejam utilizadas (Processos 8 a 15) para garantir que a equipe não necessite acessar informações em diversas ferramentas distintas, ou ainda, que haja falha de comunicação que prejudique o atendimento das requisições. Os roteiros utilizados pelo nível de suporte para padronização do tratamento

\footnotetext{
${ }^{51}$ Geralmente demandas que não recaem em reuniões de planejamento e detalhamento por serem solucionadas com procedimentos fixos e estruturados em roteiros, recaindo na gestão ágil combinada à tradicional e ao ITIL.
} 
inicial são fundamentados nas diretrizes do ITIL e a formalização dos resultados (Processo 7), realizada semanalmente, segue o modelo tradicional contratual que é envio de relatórios para Agência reguladora. Os processos demais processos do ITIL ilustrados na figura estão em processo de adequação para o modelo híbrido utilizado na unidade de análise. 
Modelo de Processos: Processo para tratar demandas fixas (Gestão Ágil combinada com ITIL)

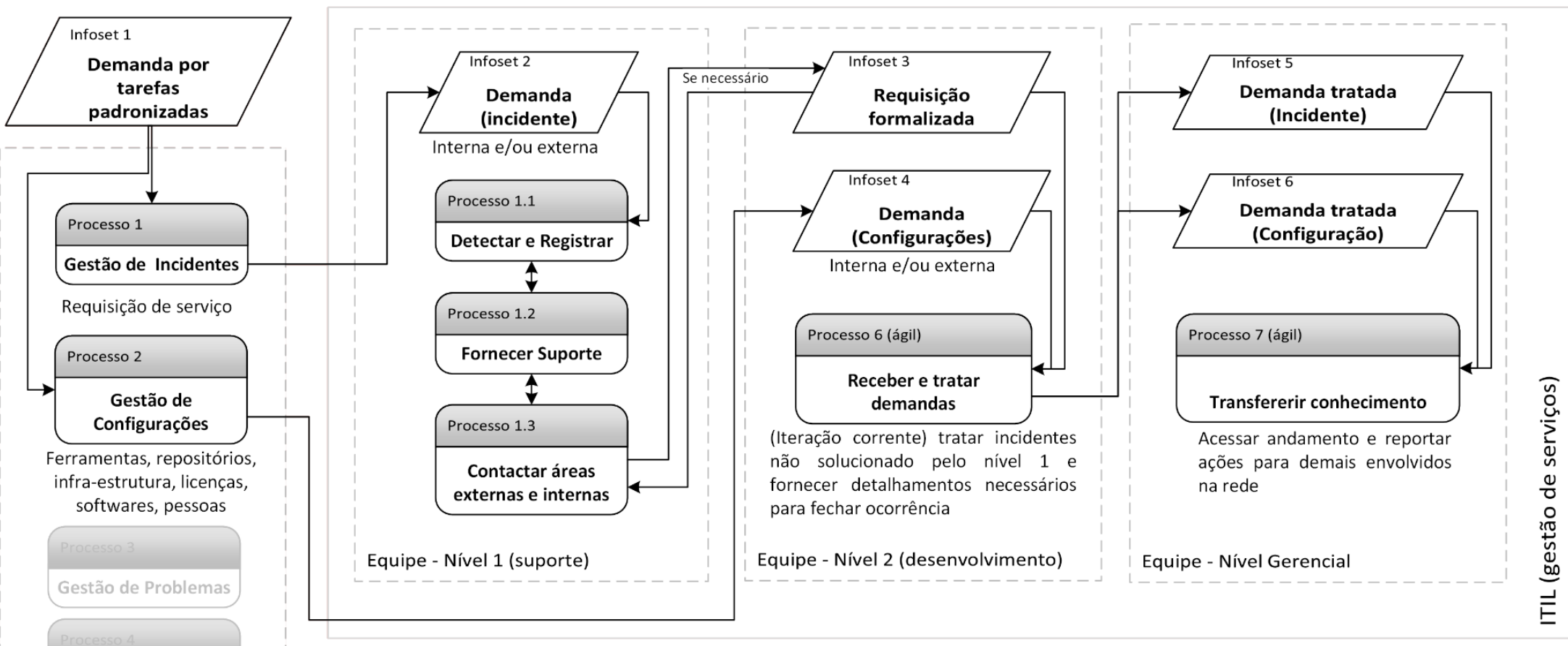

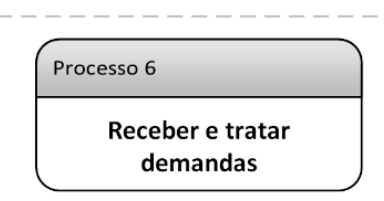

Processos do ITIL

Recorte Micro da Rede

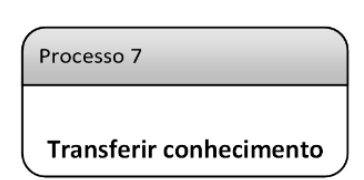

Iteração com equipe ágil (Níveis 1, 2 e Gerencial)
Número de protocolo (acompanhamento no itil) é o número da tarefa (no quadro de tarefas)

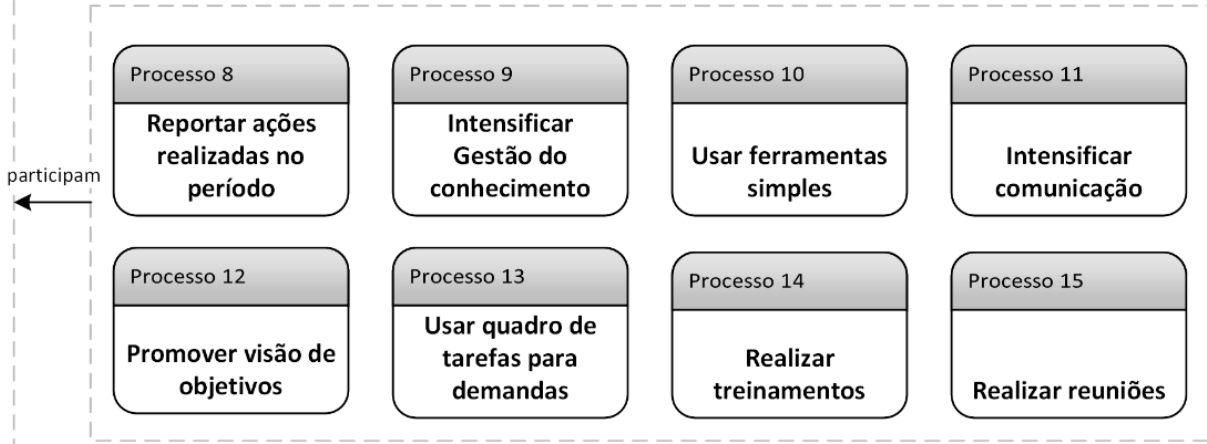

Figura 43 - Modelo de processos: tratar demandas fixas - tobe 


\subsection{Processo para acompanhar resultados e comunicar interessados}

Conforme a Figura 44 (página 276), esse processo não sofreu muitas alterações vindas da transição, mas é influenciado pelos resultados da mesma. Um novo processo para recebimento de relatórios semanais das ações realizadas foi instaurado (Processo 1). A solicitação de reuniões de acompanhamento (Processo 4), quando realizada pelo Centro de Pesquisas, envolve o levantamento de informações úteis com toda equipe, implicando em maior detalhamento de problemas, bem como maior agilidade, uma vez que demandas desse tipo são tratadas na iteração, não resultando em esquecimento que poderia prejudicar as atividades. $\mathrm{O}$ planejamento de visitas técnicas (Processo 7) também e realizado por iterações, isto é, a comunicação foi intensificada (Processo 8) e ao longo da iteração são planejadas, realizadas e reportadas um conjunto de visitas, aumentando a visibilidade de todos sobre a situação atual da rede. 
Modelo de Processos: Processo para acompanhar resultados e comunicar interessados

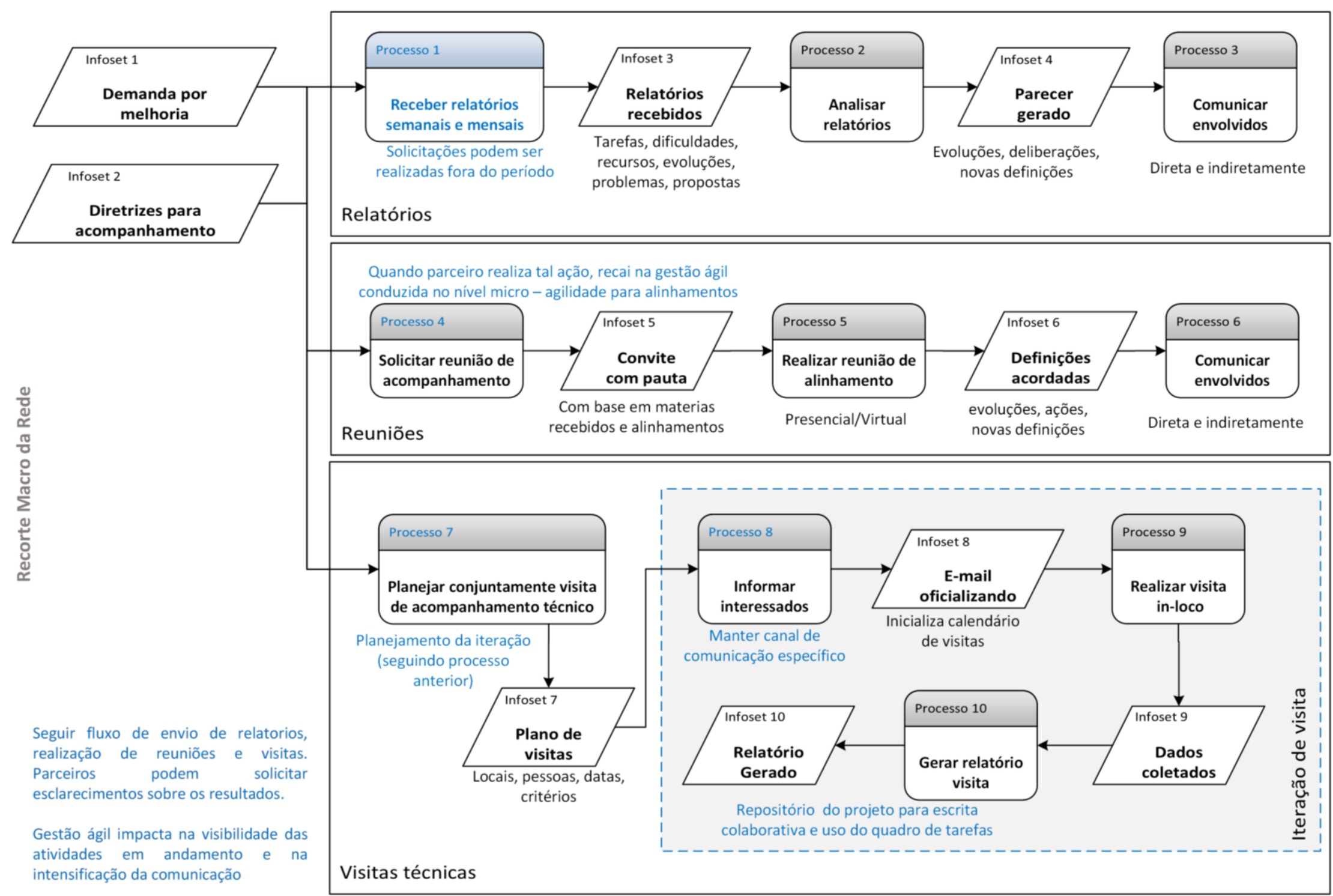

Figura 44 - Modelo de processos: acompanhar resultados e comunicar interessados - tobe 


\subsection{Processo para entregar resultados e comunicar interessados}

Conforme a Figura 45 (página 278), novamente o recorte macro sofreu influência das ações no recorte micro, em termos de acompanhamento de evolução de resultados por iteração (Processo 2) com entregas semanais e consolidadas mensais, bem como com outras entregas intermediárias, conforme necessário. Os processos utilizados no nível micro aumentam a qualidade dos resultados resultantes (Processo 3), por exemplo, relatórios mais direcionados para ação dos parceiros e necessidades da rede.

O processo de comunicação de formalizações na rede, resultantes de entregas (Processo 6) também é afetado pela gestão ágil, em termos de intensificação e agilidade para tratar esse tipo de demanda (Processos 8 e 9) que comumente recaem no nível micro da rede. 
Modelo de Processos: Processo para entregar resultados e comunicar interessados

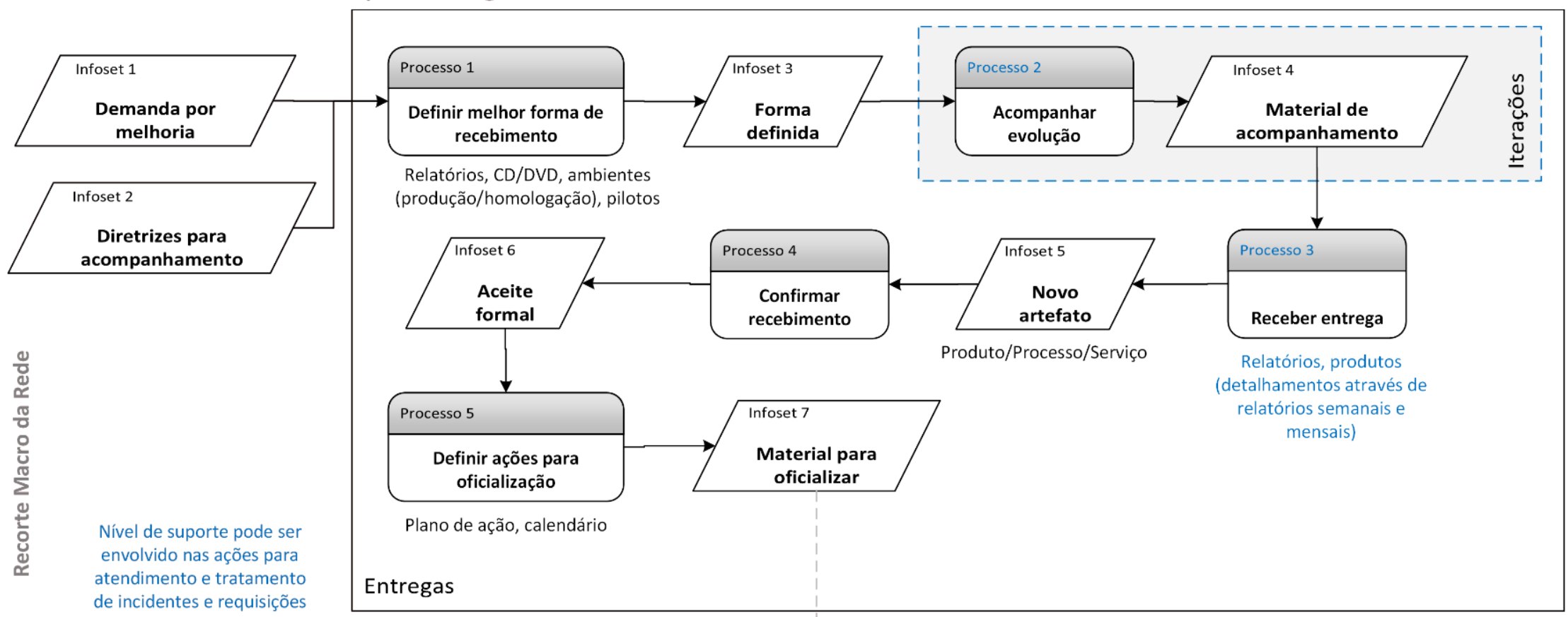

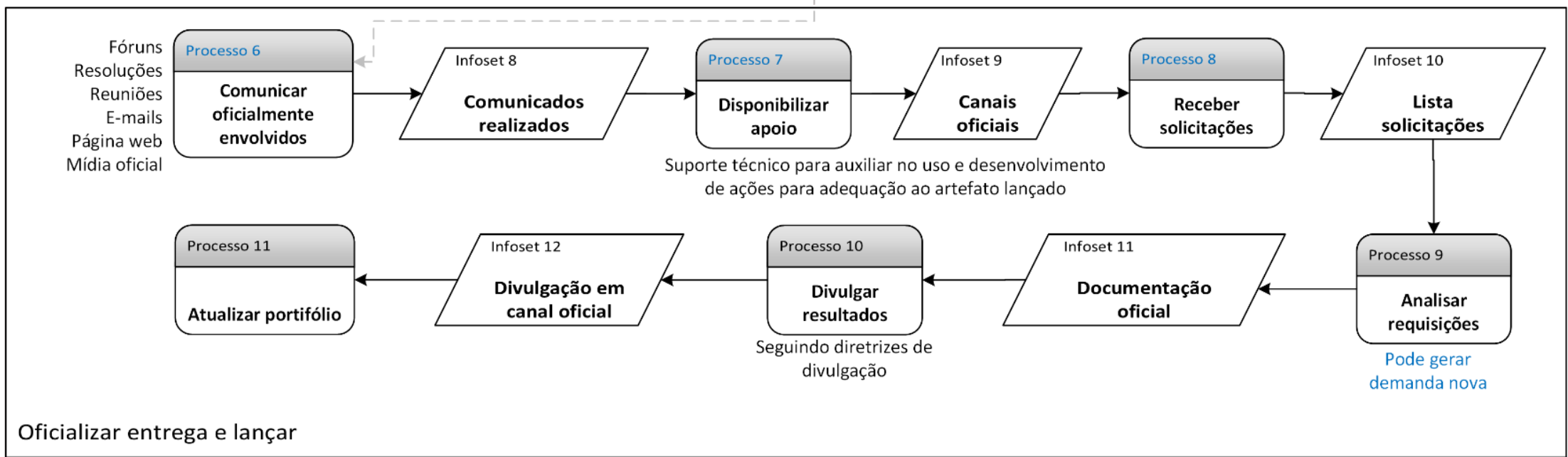

Figura 45 - Modelo de processos: entregar resultados e comunicar interessados - tobe 


\subsection{Processo para transferência do conhecimento ${ }^{52}$}

Conforme a Figura 46 (página 280) e já previamente citado, as iterações utilizadas para tratar demandas (Infoset 1) entregam resultados semanalmente. Os responsáveis por fazer tal comunicação, acessam o local onde relatórios semanais são mantidos (Processo 1), criam uma nova apresentação ${ }^{53}$ para reportar ações (Infoset 2), coletam dados de ações realizadas no período utilizando o quadro de tarefas (Processo 2), gerando uma lista de artefatos (Infoset 3 ) que é inserida pontualmente na apresentação (Processo 3) - pontos de atenção, tarefas realizadas, problemas, requisições - e ao finalizar (Infoset 4), disponibilizam para os demais membros da equipe revisarem (Processo 4), informando-os com comunicador instantâneo (Infoset 5). Toda equipe pode acessar a apresentação simultâneamente e realizar a revisão (Processo 5), finalizando a apresentação (infoset 6). Caso necessário, artefatos podem ser enviados anexos (Processo 6) - por exemplo, relatórios de desempenho de equipamentos, itens de formalização de entrega de software ou hardware, laudos de testes - formando um conjunto de todos os subprojetos (Infoset 7). O responsável pelo envio, novamente, notifica os demais que está formalizando o envio (Processo 7) e se todos estiverem de acordo, o e-mail é redigido (Processo 8) e a entrega semanal realizada (Infoset 9).

\footnotetext{
52 Apesar das várias etapas esse processo envolve ações automatizadas e seu tempo de geração foi reduzido de semanas para cerca de três dias, com aumento de qualidade e quantidade de resultados reportados.

${ }^{53}$ Optou-se por apresentação por ter apelo visual e ser de mais fácil leitura.
} 


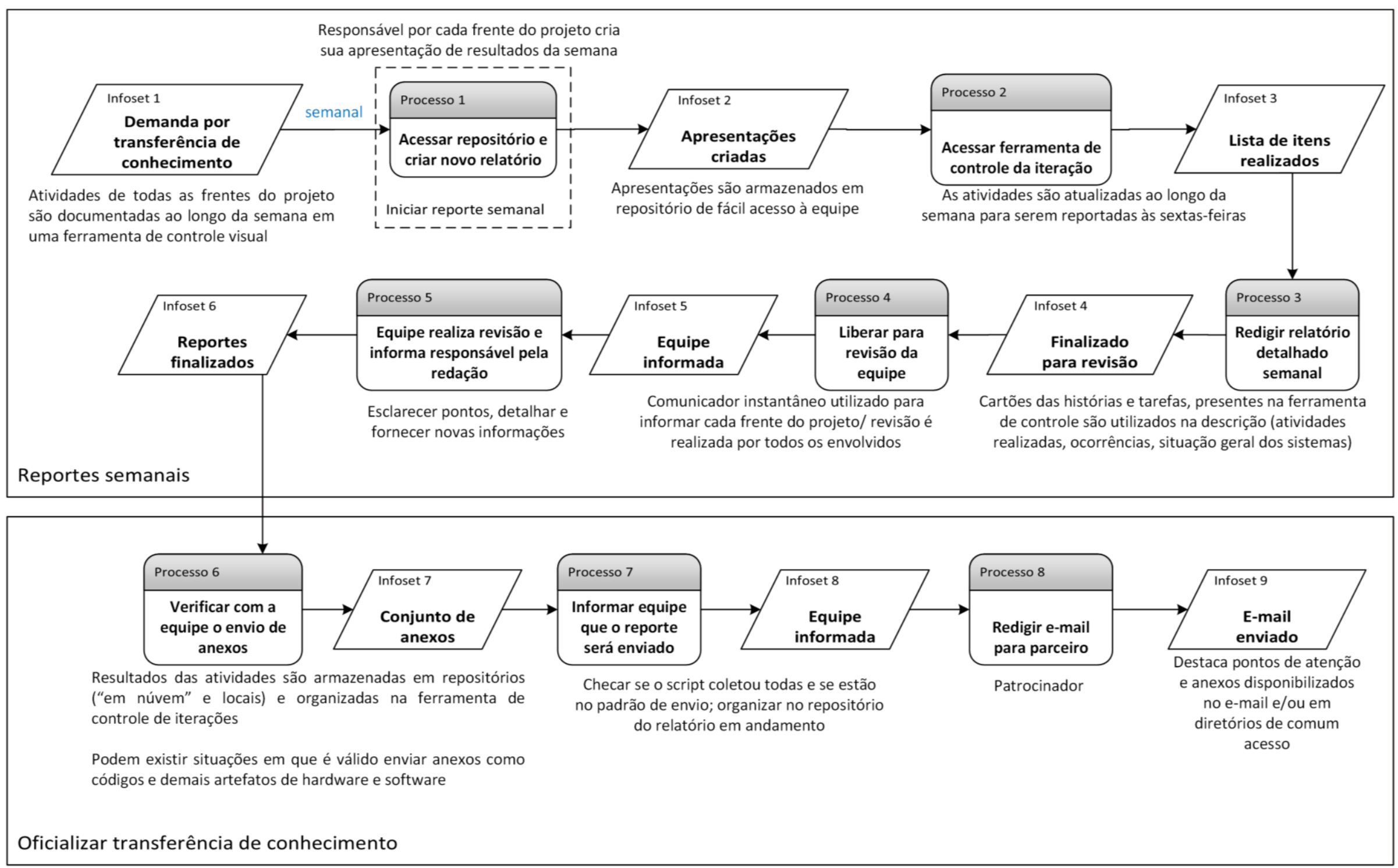

Figura 46 - Modelo de processos: transferência de conhecimento mensal - tobe (parte 1/2) 
Conforme a Figura 47 (página 282), a consolidação dos resultados gerados no mês (Infoset 1), inicia-se com o acesso ao repositório onde ficam centralizados tais relatórios (Processo 1) para criação de um novo (Infoset 2). O repositório onde ficam armazendas as apresentações enviadas semanalmente é acessado (Processo 2) para obter a lista de todas as ações realizadas (Infoset 3) e redigir o relatório com base nas informações já reportadas (Processo 3), se necessário o quadro de tarefas pode ser utilizado para coletar mais informações. Uma vez finalizado (Infoset 4) é liberado para revisão (Processo 4), mediante ferramenta de comunicação instantânea (Infoset 5) e após revisão (Processo 5), já finalizado (Infoset 6) as evidências das ações reportadas são coletadas na ferramenta de gestão de conhecimento (Processo 6) com uso de scripts automatizados que geram o conjunto de evidências do período (Infoset 7). As evidências são brevemente verificadas (Processo 7) e organizadas para envio (Infoset 8), se necessário outras são solicitadas à equipe (Processo 8) e também organizadas (Infoset 9). Com o relatório e evidências finalizados, a gerência é informada (Processo 9) por e-mail (Infoset 10), realiza a verificação final (Processo 10) e informa departamento Administrativo/Financeiro (Infoset 11) para envio (Processo 11) à Agência Reguladora. 
Modelo de Processos: Processo para transferência de conhecimento - Parte 2/2

Recorte Micro da Rede

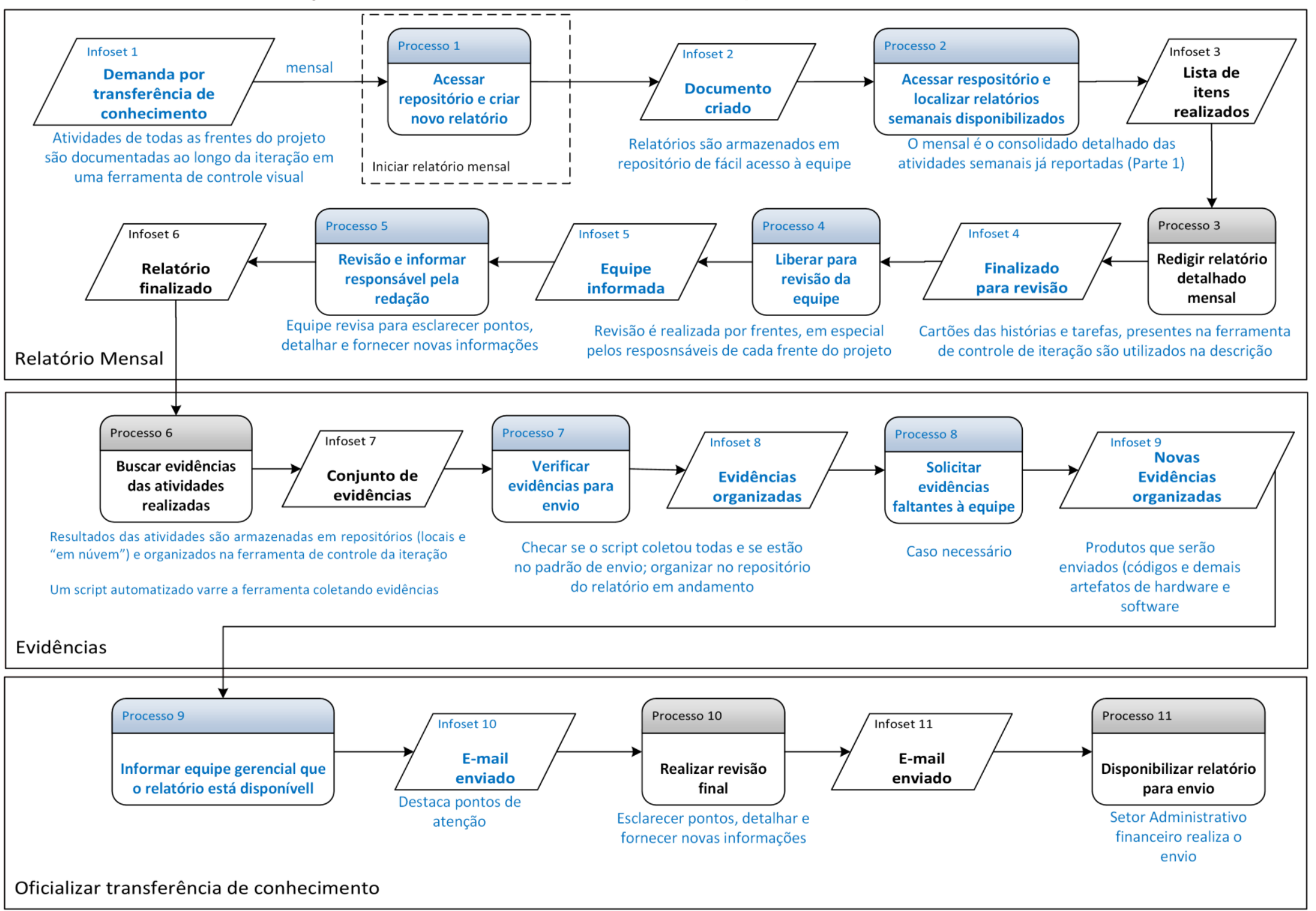

Figura 47 - Modelo de processos: transferência de conhecimento mensal - tobe (parte 2/2) 


\subsection{Processo para estimular inovação na rede}

Conforme a Figura 48 (página 284), novamente esse processo no recorte macro é influenciado pela agilidade no monitoramento, melhoria na gestão de conhecimento e intensificação da comunicação, vindas do recorte micro, em especial, nas ações que geram demandas para o Centro de Pesquisas (Processos 3 e 4) que disparam o processo de recebimento e tratamento de demandas (Processo 9). A celeridade na entrega dos resultados, bem como aumento da qualidade dos mesmos e alinhamento das equipes para a situação da rede, refletemse em otimizações no processo de planejamento de premiação. 
Modelo de Processos: Processo para estimular inovação na rede
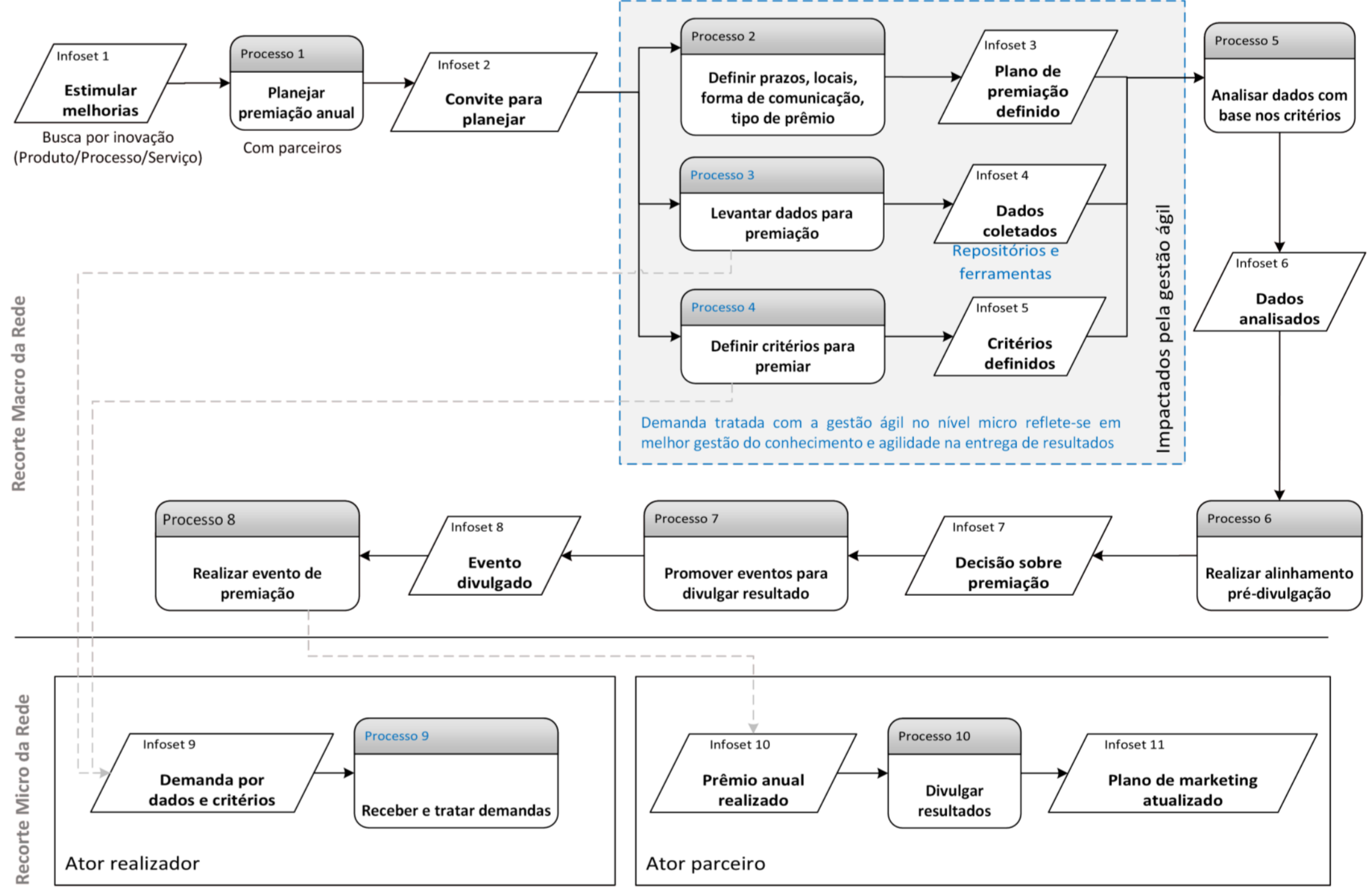

Figura 48 - Modelo de processos: estimular inovação na rede - tobe 


\subsection{Processo para disseminar melhores práticas no segmento}

Conforme a Figura 49 (página 286), similarmente ao processo anterior, aqui a celeridade na entrega de resultados é o principal destaque. Uma vez que demandas para participação em ações para divulgar inovações alcançadas (Processo 1), requerem materiais para divulgação (Processo 3) que são formulados, por exemplo, mediante as apresentações de resultados enviados que podem evoluir para cases mais bem detalhados (Processo 5). Tais ações disparam demandas no recorte micro que são recebidas e tratadas (Processo 6) ou ainda, quando envolvem outros parceiros, devidamente acompanhadas (Processo 7), por meio das diretrizes do modelo de gestã ágil aplicado. 
Modelo de Processos: Processo para disseminar melhores práticas no segmento

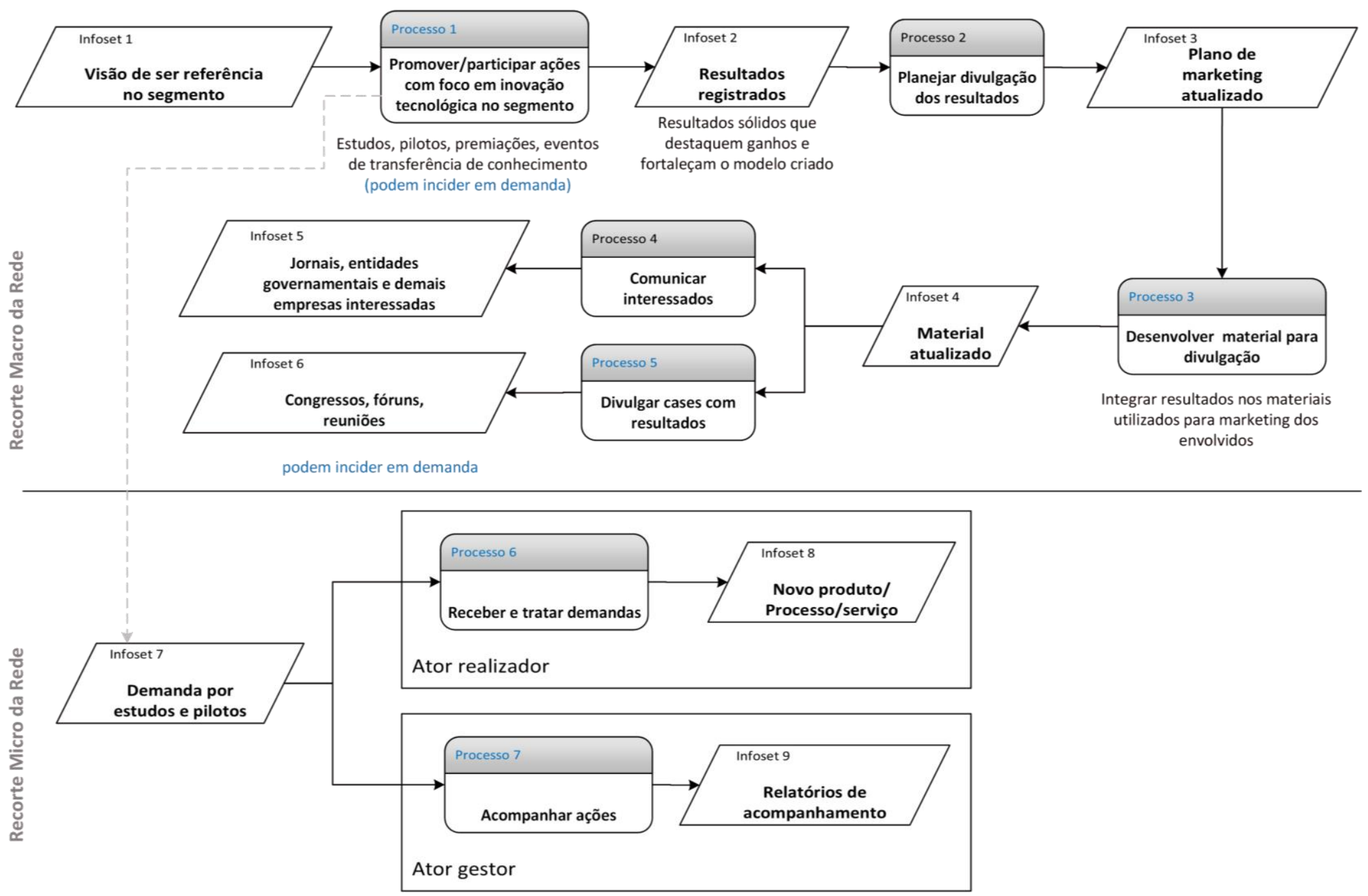

Figura 49 - Modelo de processos: disseminar melhores práticas no segmento - tobe 


\subsection{Processo para gestão de parcerias e recursos humanos}

Conforme a Figura 50 (página 288), devido as características da rede, o recorte macro desse processo não sofreu alterações diretas. O processo de contratação (Processo 6) de parceiros tecnológicos pode sofrer o reflexo das ações, uma vez que as capacidades são avaliadas e, no caso de renovações, os resultados gerados são argumentos para aprovação ou rejeição da mesma. Assim, aumento da qualidade de resultados e intensificação de ações colaborativas pesam positivamente. 
Modelo de Processos: Processo para gestão de parcerias e recursos humanos (atores) - Parte 1/2

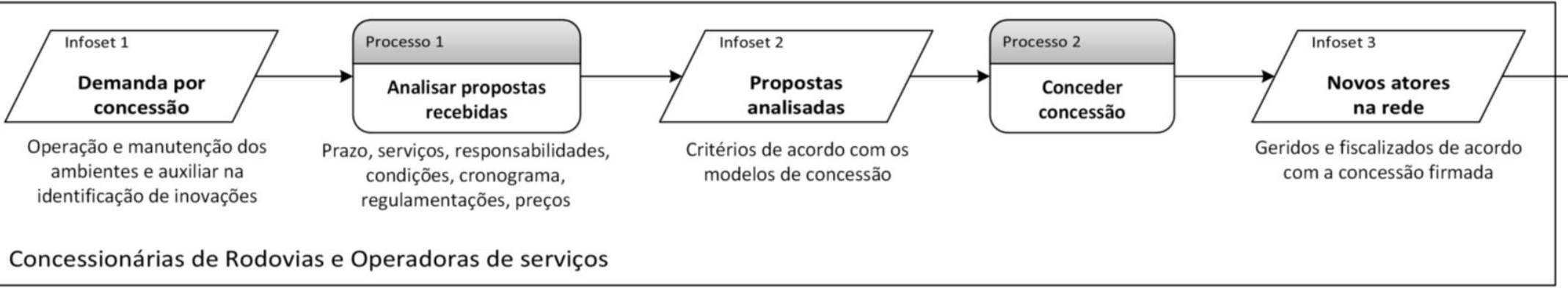

Prestadoras de serviço

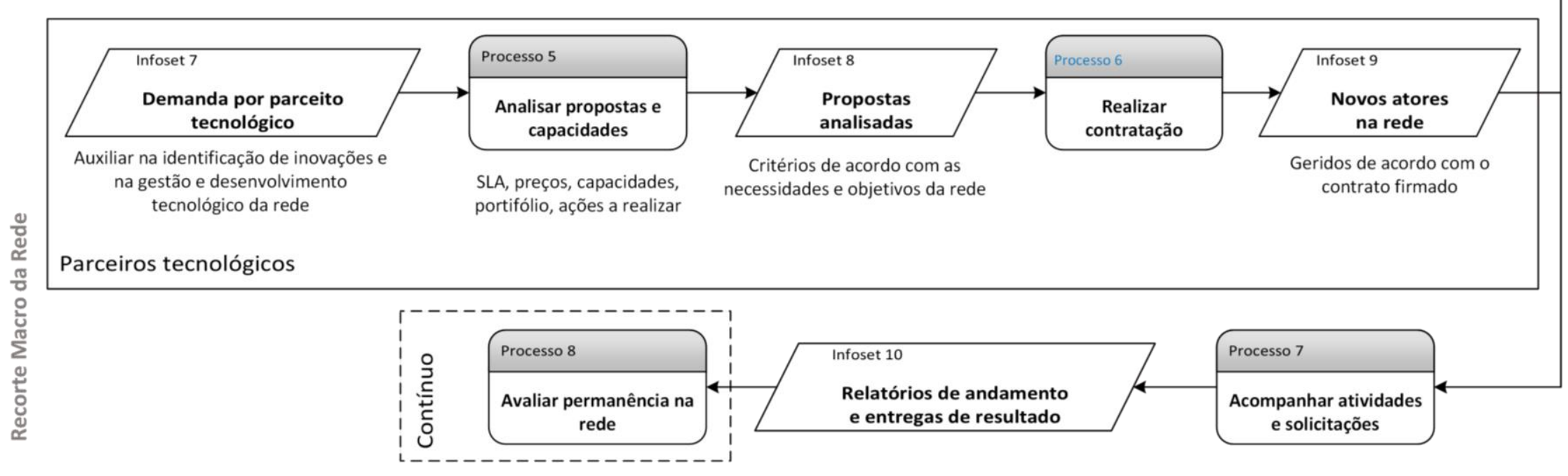

Figura 50 - Modelo de processos: gestão de parcerias e RH - tobe (parte 1/2) 
No caso de recursos humanos, conforme a Figura 51 (página 290), a inserção de RH nos subprojetos da unidade de análise, envolve mais pessoas da equipe, em prol analisar a prioridade da alocação (Processo 3) e com base nisso (Infoset 4) decidir por uma alocação de urgência mediante reunião de alinhamento (Processo 5) com o intuito de passar informações necessárias para atuação do novo alocado (Infoset 6) e ir fortalecendo a integração do mesmo à equipe ao longo das ações de acompanhamento (Processo 6) - ou alocação sem urgência - através da convocação para a reunião de planejamento de iteração (Processo 7) com um convite direcionado a toda equipe (Infoset 7). Na reunião são realizadas análises das demandas e ações da iteração anterior (Processo 8), fornecendo uma base inicial aos novos integrantes da equipe (Infoset 8) para facilitar a compreensão do mesmo, acerca dos alinhamentos e detalhamentos que serão tratados na reunião (Processo 9) e documentados no quadro de tarefas para gestão de conhecimento (Infoset 9). Novamente o recém alocado é acompanhado com as ações de acompanhamento que ocorrem na iteração (Processo 10), por exemplo reuniões diárias, para verificação da sua motivação, entendimento do projeto, bem como acompanhamento de atividades. 
Modelo de Processos: Processo para gestão de parcerias e recursos humanos (atores) - Parte 2/2
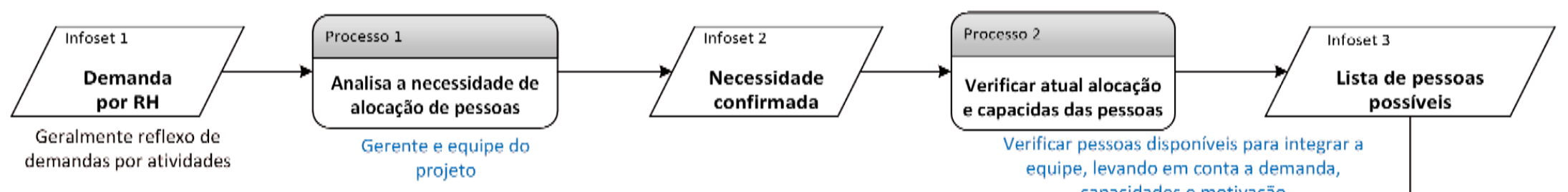

Verificar pessoas disponiveis para integrar a
equipe, levando em conta a demanda, capacidades e motivaçäo

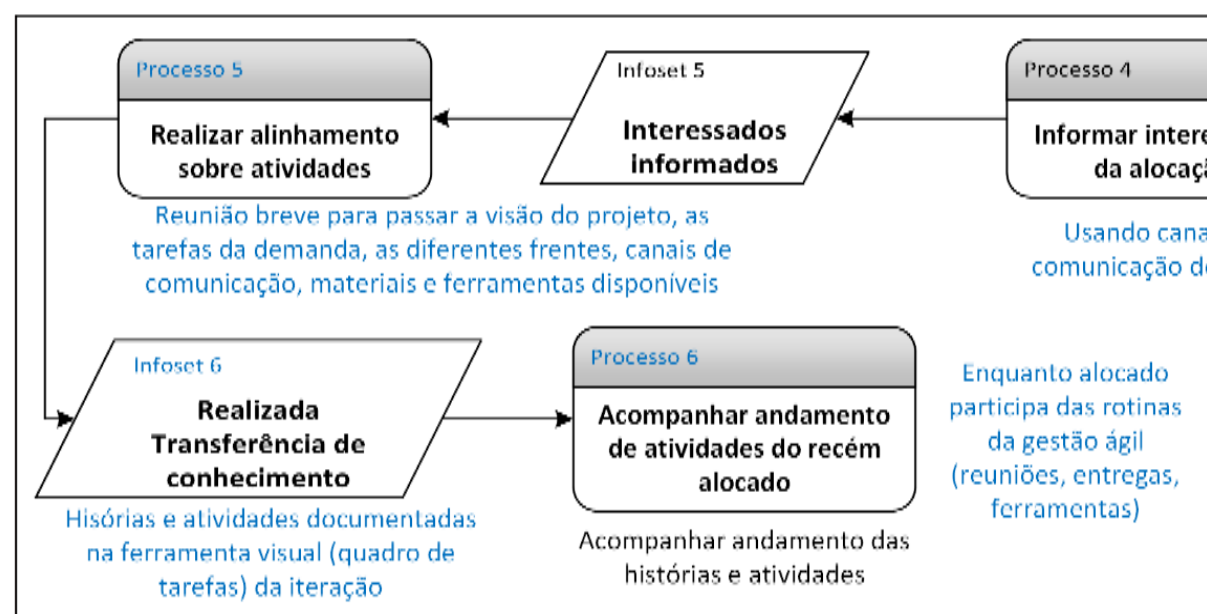

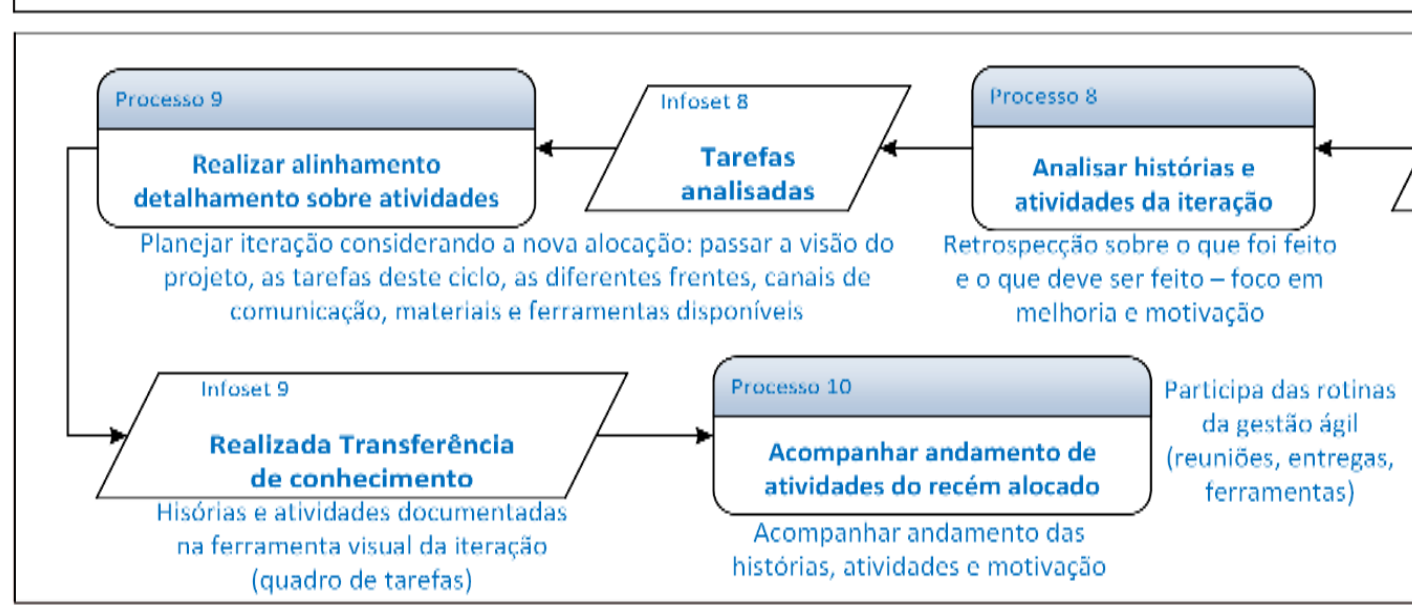




\subsection{Processo de acompanhamento e liberação de recursos}

Conforme a Figura 52 (página 292), a influência que a transição do modelo de gestão no recorte micro pode imprimir no recorte macro está associada ao nível de qualidade das requisições realizadas, isto é, o aumento do alinhamento da equipe, celeridade e frequência no envio de resultados, bem como intensificação da comunicação que resultam em aumento de qualidade na requisição formalizada (Processo 1), bem como maior alinhamento dos parceiros, acelerando o processo de liberação, em termos de entendimento da justificativa da requisição recebida e solicitação de liberação (Processos 4 e 5). No recorte micro, as ações de acompanhamento de requisições realizadas ao são acompanhadas (Processo 9), seguindo os fluxos de monitoramento do modelo de gestão ágil aplicado, isto é, semanalmente o estado dessas demandas é visitado e atualizações devidamente registradas e entregues aos interessados (Infoset 8), minimizando esquecimentos. 
Modelo de Processos: Processo para acompanhamento e liberação de recursos

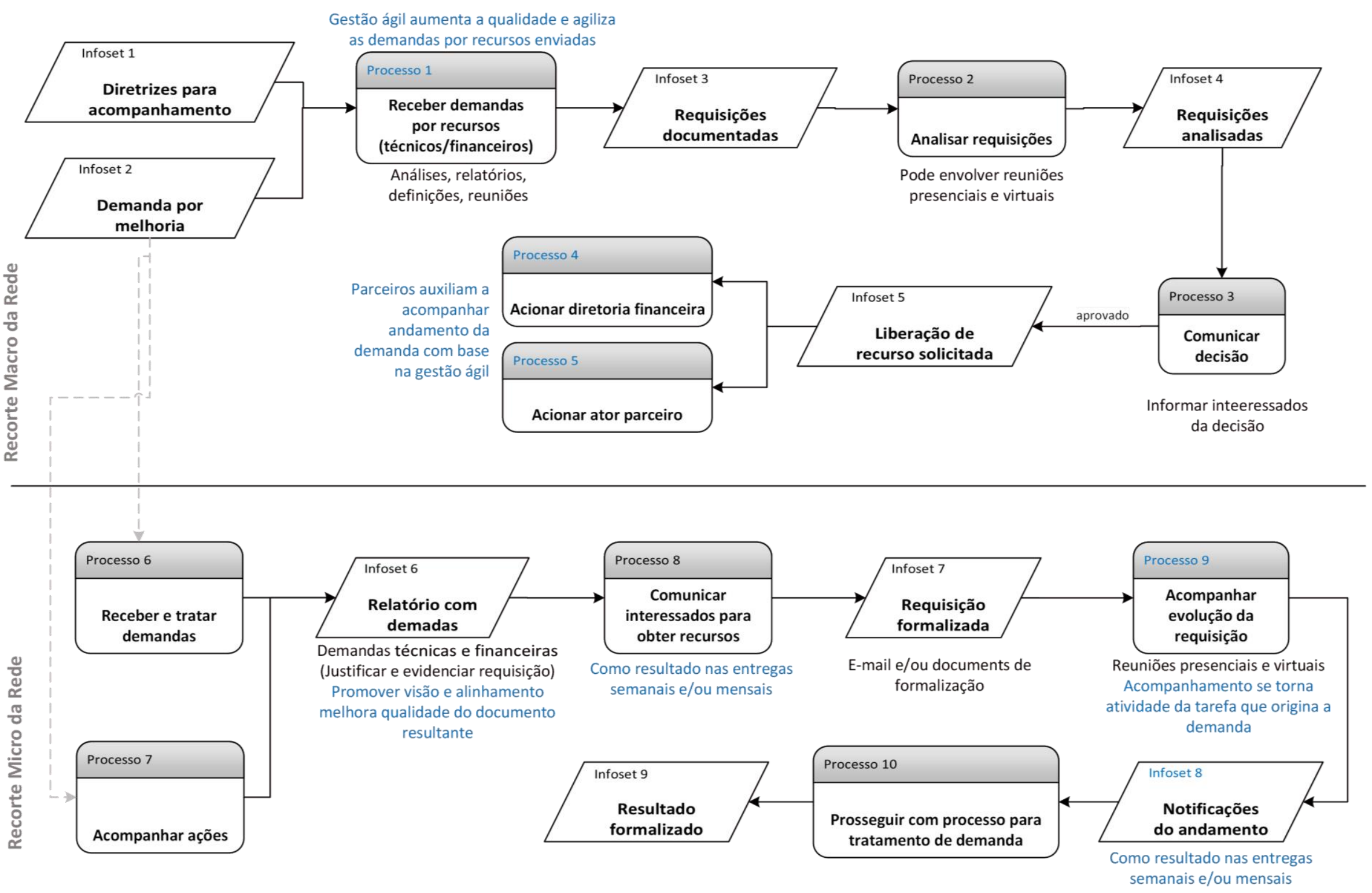

Figura 52 - Modelo de processos: acompanhamento e liberação de recursos - tobe 


\section{Modelo de Componentes e Requisitos Técnicos (Parte 1/3) As-Is}

Conforme a Figura 53 (página 294), o modelo de componentes desenvolvido é baseado nos objetivos identificados na rede e em seus subprojetos. Dessa forma, no recorte macro os objetivos de gerar inovação no segmento de atuação (Objetivo 1) e impulsionar a aplicação de novas tecnologias no segmento (Objetivo 2) motivam a criação de funcionalidades para supervisionar processos operacionais (Objetivo SI 1) e apoiar tomada de decisão (Objetivo SI 5). O objetivo de gerar padrões para disseminar melhores práticas no segmento (Objetivo 3) apoia a criação de funcionalidades para apoiar tomada de decisão (Objetivo SI 5) e motiva a criação de funcionalidades para divulgar evoluções (Objetivo SI 6). A supervisão de processos requer funcionalidades para gerenciar demandas (Objetivo SI 2), estimular comunicação (Objetivo SI 3) e a gestão do conhecimento (Objetivo SI 4).

No recorte macro, o objetivo de melhorar visibilidade (Objetivo 4) motiva a criação de funcionalidades para gerenciar demandas dos subprojetos (Objetivo SI 2), manter envolvidos alinhados (Objetivo SI 7) e apoiar a tomada de decisão nos subprojetos (Objetivo SI 5). O objetivo de desenolver soluções robustas motiva a criação de funcionalidades para gerenciar demandas (Objetivo SI 2) e apoia a criação de funcionalidade para manter operacionais os sistemas e ambientes dos subprojetos (Objetivo SI 8). Os quatro objetivos secundários de sistema de informação no recorte micro, são apoiados pelo objetivo principal de supervisionar processos operacionais (Objetivo SI 1) que é o mesmo do recorte macro. 


\section{Modelo de Componentes e Requisitos Técnicos - Parte 1/3}
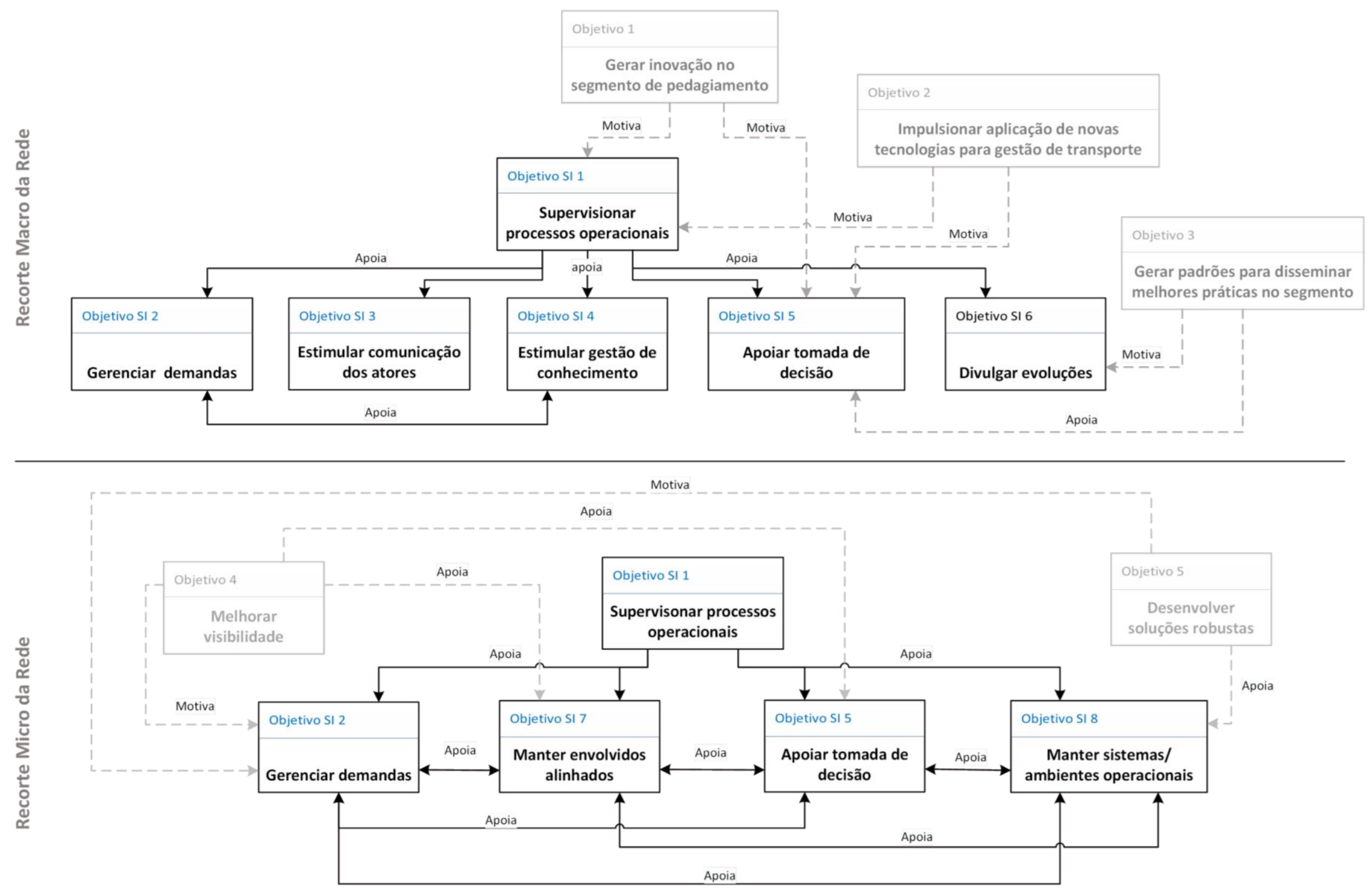

Figura 53 - Modelo de componentes e requisitos técnicos - asis (1/3) 


\section{APÊNDICE C - DETALHAMENTO DO PLANO DE AÇÃO}

Este apêndice contém detalhamentos sobre o plano de ação elaborado na pesquisa ação, no que tange a utilização da abordagem ágil de forma híbrida - conceitos úteis e exemplos de indicadores de desempenho -, visando facilitar a compreensão das ações realizadas, bem como possíveis replicações da pesquisa.

\section{Resumo de conceitos do ágil}

Os seguintes conceitos foram disponibilizados aos envolvidos, por meio de dispobilização do material e realização de treinamentos sobre o novo modelo de gestão.

Sprint (Iteração) - É o período de tempo, variando de 2 a quatro semanas (conforme andamento do time), em que desejamos completar um conjunto de histórias (funcionalidades) definidas e discutidas pelo time. As decisões para criar a sprint geralmente são feitas em uma reunião de planejamento (Planning) que, atualmente, ocorre no início do mês, pela manhã e envolve todos os interessados, sendo uma reunião para cada subprojeto;

História (Funcionalidade/Visão de objetivo) - É tratada como feature no Redmine (tracker no qual o ticket criado), sendo o que se deseja atingir (funcionalidade, otimização, solução de problema, requisito do cliente) e é composta, geralmente, por várias tarefas; uma história é considerada finalizada quando todas as tarefas mapeadas para ela forem finalizadas;

Tarefas - São tratadas como task/ticket no Redmine (rastreados pelo número do ticket criado), sendo as atividades necessárias para finalizar a história;

a tarefa deve ser atribuída a pessoa correta e seu andamento pode ser documentado usando os status apresentados no quadro de tarefas (new, in progress, on hold para quando a tarefa foi iniciada mas está parada por alguma razão, resolved para quando é uma tarefa que necessita de algum tipo de revisão, feedback quando a tarefa está parada aguardando informações/ações de um terceiro, closed quando foi finalizada e rejected para casos em que não será mais realizada);

Quadro de tarefas (taskboard) - É uma forma visual de organizar as tarefas, facilitando a visualização de tudo o que está ocorrendo em cada item do projeto;

Daily Meeting - Realizada, atualmente, com todos os envolvidos e deve ter duração entre 15 a 20min; todos informam rapidamente em que estão trabalhando e qual a situação; tem a intenção de melhorar a comunicação do time, sendo uma reunião de status e não de resolução e 
aprofundamento. Se identificada essa necessidade uma reunião em separado, somente com os interessados, pode ser realizada;

Product Backlog - Lista de todas as funcionalidades (histórias) desejadas, dela são retirados os itens que compõem uma sprint; é definido em conjunto com o cliente. Também utilizamos essa funcionalidade para armazenar requisitos que vão surgindo e são necessários, mas que ainda não estão em iteração de desenvolvimento. Dessa forma, não perdemos o controle das demandas do projeto.

Para cada subprojeto no Redmine, existe a sprint em andamento, na qual podemos visualizar e criar histórias e tarefas. A documentação adequada dessas tarefas, auxilia na organização do time, na visualização pelo gestor do projeto de tudo o que está ocorrendo e também, na geração de relatórios que podem ser enviados para clientes. Deste modo, é preciso empenho de todos para manter a ferramenta ativa e caminhando de forma organizada.

\section{Boas práticas:}

- Evitar remover tickets. Em vez disso, marcar como Rejected e adicionar o motivo. Se for o caso, marcar como duplicata de outro ticket

- Se tiver que parar de trabalhar em algum ticket por um período longo, lembre-se de mudar seu status de "In Progress" para "On Hold". Dessa forma podemos saber as atividades que encontram-se paradas, e, se necessário, realoca-las.

- Evitar usar o nome do ticket como descrição. O nome deve ser o mais enxuto possível, e a descrição é que deve explicar claramente a atividade

- Lembre-se que a pessoa que irá pegar o ticket pode não ter todo o contexto que levou a sua criação, portanto a descrição deve explicar de maneira objetiva a atividade e outras informações pertinentes para a mesma.

- Evite criar tickets com descrição vazia; tenha bom senso na criação de tickets, pequenas ações cotidianas não necessariamente precisam ser documentadas dessa forma no projeto;

- Sempre que um ticket tiver uma relação com outro, utilizar o campo adequado para relacionar os tickets;

- Caso veja algum ticket problemático (descrição ruim, ticket abandonado, duplicado...), corrigir e/ou notificar o dono, sugerindo uma correção

- Tarefas muito complexas devem ser quebradas em vários tickets. Nesse caso, crie um ticket macro, e então adicione sub-tarefas associadas a esse ticket. 
- Idealmente, um ticket deve ser possível de ser realizado em poucas horas.

- Categorizar corretamente os tickets por tipo no Redmine (Bug, feature, support...), considerando os tipos que deseja-se ter em uso no subprojeto.

\section{Dicas}

- No link 'My Page' (“Minha página”), é possível ter uma visão geral das atividades recentes. Lembre-se que essa página é personalizável, e pode mostrar um resumo dos tickets atribuídos à você (e/ou aos tickets em que você acompanha), além de uma lista de tickets recentemente abertos

- No link 'Activity' (Atividade) também é possível acompanhar a atualização das tarefas, por datas, facilitando a visão geral do andamento do projeto

- O Redmine disponibiliza uma Wiki (fórum) que pode ser utilizada para armazenar informações do projeto

- O Backlogs permite configurações para facilitar o uso, ver material de apoio para detalhes; em especial, é válido observar os tipos definidos para as tarefas (história/feature, tarefa/task, por exemplo)

\section{Google Drive}

A utilização do Google Drive centralizado do projeto, também facilita a organização, no caso de relatórios e demais ações que devem ser visualizaddas e trabalhadas/mantidas por todos nos subprojetos. Por exemplo, existe um diretório de Desenvolvimento para armazenar, eventualmente, pacotes de entrega e documentos que devem ser compartilhados e não seja viável fazer através do Repositório local e ainda, um diretório de Operação para controlar listas de equipamentos, bancos de dados, scripts de ação da Operação, documentos relevantes do projeto como Atas e Relatórios Mensais, sendo estes, também organizados por subprojetos. 


\section{Exemplos de indicadores}

Os indicadores foram mapeados durante a fase de ação da pesquisa-ação, considerando itens que a equipe julgou interessante mensurar quando processo de transição estivesse estável. Salienta-se que como as práticas do ITIL também estavam sendo utilizadas, elas também influienciaram nos indicadores listados.

- Quantidade total de incidentes

- Quanto tempo, em média, se leva para atender um chamado

- considerando o tipo de chamado e as frentes do projeto

- Tempo médio que se leva para restaurar um serviço desde o primeiro contato

- Quantidade de chamados resolvidos dentro do tempo esperado

- Quantas chamados são atendidos em média por período

- considerando o tipo de chamado e as frentes do projeto

- Quais os chamados mais recorrentes

- Quantidade de chamados reabertos

- Quantidade de chamados repassados incorretamente

- Quais os clientes com mais chamados

- Tipos de chamado por cliente (com base nas atribuições

- Quantidade de chamados resolvidos por período

- Quantidade de chamados considerando o status do chamado, por período

- Quantidade de chamados repassados ao nível de Desenvolvimento

- Quantidade de incidentes que resultaram em problemas

- Quantos incidentes por subprojeto

- Quantos incidentes por prioridade

- Quantidade de pessoas envolvidas na resolução de um incidente

- Quantidade de mudanças foram pedidas e realizadas

- Quantidade de incidentes reportados pela operação

- Quantidades de incidentes reportados pelo desenvolvimento 